\title{
Report of the \\ 64th National Conference \\ on \\ Weights and Measures \\ 1979
}

566

0

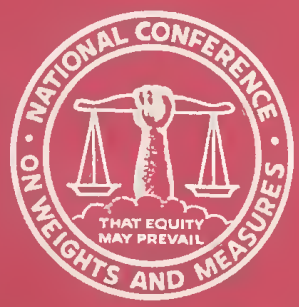


The National Bureau of Standards' was established by an act of Congress on March 3, $190 \mathrm{f}$ The Bureau's overall goal is to strengthen and advance the Nation's science and technology and facilitate their effective application for public benefit. To this end, the Bureau conducts research and provides: (1) a basis for the Nation's physical measurement system, (2) scientific and technological services for industry and government, (3) a technical basis for equity in trade, and (4) technical services to promote public safety. The Bureau's technical work is performed by the National Measurement Laboratory, the National Engineering Laboratory, and the Institute for Computer Sciences and Technology.

THE NATIONAL MEASUREMENT LABORATORY provides the national system of physical and chemical and materials measurement; coordinates the system with measurement systems of other nations and furnishes essential services leading to accurate and uniform physical and chemical measurement throughout the Nation's scientific community, industry, and commerce; conducts materials research leading to improved methods of measurement, standards, and data on the properties of materials needed by industry, commerce, educational institutions, and Government; provides advisory and research services to other Government agencies; develops, produces, and distributes Standard Reference Materials; and provides calibration services. The Laboratory consists of the following centers:

\section{Absolute Physical Quantities ${ }^{2}$ - Radiation Research — Thermodynamics and} Molecular Science - Analytical Chemistry - Materials Science.

THE NATIONAL ENGINEERING LABORATORY provides technology and technical services to the public and private sectors to address national needs and to solve national problems; conducts research in engineering and applied science in support of these efforts; builds and maintains competence in the necessary disciplines required to carry out this research and technical service; develops engineering data and measurement capabilities; provides engineering measurement traceability services; develops test methods and proposes engineering standards and code changes; develops and proposes new engineering practices; and develops and improves mechanisms to transfer results of its research to the ultimate user. The Laboratory consists of the following centers:

\section{Applied Mathematics - Electronics and Electrical Engineering ${ }^{2}$ - Mechanical \\ Engineering and Process Technology ${ }^{2}$ - Building Technology - Fire Research - \\ Consumer Product Technology - Field Methods.}

THE INSTITUTE FOR COMPUTER SCIENCES AND TECHNOLOGY conducts research and provides scientific and technical services to aid Federal agencies in the selection, acquisition, application, and use of computer technology to improve effectiveness and economy in Government operations in accordance with Public Law 89-306 (40 U.S.C. 759), relevant Executive Orders, and other directives; carries out this mission by managing the Federal Information Processing Standards Program, developing Federal ADP standards guidelines, and managing Federal participation in ADP voluntary standardization activities; provides scientific and technological advisory services and assistance to Federal agencies; and provides the technical foundation for computer-related policies of the Federal Government. The Institute consists of the following centers:

Programming Science and Technology - Computer Systems Engineering.

'Headquarters and Laboratories at Gaithersburg, MD, unless otherwise noted; mailing address Washington, DC 20234.

${ }^{2}$ Some divisions within the center are located at Boulder, $\mathrm{CO} 80303$. 


\section{4th National Conference on Weights and Measures 1979}

Sponsored by the National Bureau of Standards Attended by Officials from the Various

States, Counties, and Cities, and Representatives from U.S. Government, Industry, and Consumer Organizations Portland, Oregon, July 23-27, 1979

Report Editors: Harold F. Wollin Louis E. Barbrow Ann P. Heffernan

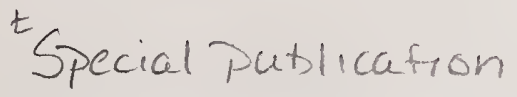

United States Department of Commerce Philip M. Klutznick, Secretary

1. SNational Bureau of Standards Ernest Ambler, Director 


\begin{abstract}
This is a report of the proceedings (edited) of the Sixty-fourth National Conference on Weights and Measures, sponsored by the National Bureau of Standards, held in Portland, Oregon, July 23-27, 1979, and attended by State, county, and city weights and measures officials, and representatives of the Federal Government, business, industry, and consumer organizations.

Major issues discussed at this conference included metric conversion in the United States, particularly the conversion of gasoline dispensers, problems relating to the quantity fill of packaged commodities, especially as affected by moisture loss, statistical approach to package checking, Federal grain inspection, and a legal metrology control system.

Key words: Consumer affairs; education; electronic devices; International Organization of Legal Metrology; legal metrology; measurement assurance; metrication; model laws and regulations; moisture loss; packaging and labeling; specifications and tolerances; weights and measures.
\end{abstract}

Library of Congress Catalog Card No. 26-27766 


\section{CONTENTS}

(Note: The reports of the standing and annual committees and the treasurer's report, which were presented on Thursday, have been arranged together beginning on page 156 for easier reference.)

Officers of the Conference .

Standing Committees -..-

Annual Committees ................. vii

Open Committee Hearings, Monday and Tuesday, July 23-24, 1979 ......... viii

MORNING SESSION-TUESDAY, July 24, 1979

Planning for the 1980 International Conference on Legal Metrology, by David E. Edgerly, National Bureau of Standards _........

Statistics Made Uncomplicated, by Edward E. Wolski, Colgate-Palmolive Company

Confidence in Package Checking Results, by Stephen Hasko, National Bureau of Standards

AFTERNOON SESSION-TUESDAY, July 24, 1979

Equity on the Move, by Kendrick J. Simila, Department of Agriculture, State of Oregon

Equity Beyond the Marketplace, by Donald R. Johnson, National Bureau of Standards

Committee Appointments .

Assisting the Conference in Meeting New Challenges in Measurement, by William T. Cavanaugh, American Society for Testing and Materials -......

National Conference of Standards Laboratories, Its Roles and Mission, by Ronald E. Kidd, Microwave Associates

Tradition in Transition, by Albert D. Tholen, National Bureau of Standards

\section{MORNING SESSION-WEDNESDAY, July 25, 1979}

A Legal Metrology Control System Applicable to the United States, by Kenneth F. Hammer, Fairbanks Weighing Division, Colt Industries ......-

Metric Update-USA, by Sydney D. Andrews, Department of Agriculture and Consumer Services, State of Florida

Metric Update_Canada, by John D. Buchanan, Department of Consumer and Corporate Affairs, Ottawa, Canada ...

Standards - Love Them or Leave Them, by Rodney E. Leonard, U.S Office of Consumer Affairs

Metric: Now or Later, by John A. Stitzell, Amoco Oil Company Association's Spot Reports:

American Petroleum Institute, by Richard Southers -

Northeastern Weights and Measures Association, by Sidney A.

Colbrook

Northwest Weights and Measures Association, by Alden M. Lemke -..National Scale Men's Association, by William V. Goodpaster .......... Scale Manufacturers Association, by Raymond J. Lloyd . Southern Weights and Measures Association, by John L. O'Neill .......Western Weights and Measures Association, by Joseph W. Jones ......- 
National Association of State Departments of Agriculture, by James A. Graham, North Carolina Department of Agriculture -................. Weighing Programs of the Federal Grain Inspection Service, by Richard R. Pforr, Federal Grain Inspection Service -......................... Net Weights, Part II, by Sydney J. Butler, U.S. Department of Agriculture Net Weight Labeling Regulations, by Taylor M. Quinn, Food and Drug Administration

National Net Weight or Federal "Rule of Thumb?", by Jerry Scribner, California Department of Food and Agriculture ............................ The Need for an Equitable and Practiced Net Weight System, Dr. Mahlon A. Burnette, Grocery Manufacturers of America -..................... Working of the Intergovernmental Affairs Office of U.S. Department of Agriculture, by Roger Sandman, U.S. Department of Agriculture

\section{REPORTS OF STANDING COMMITTEES}

List of State Voting Representatives

Report of the Committee on National Measurement Policy and Coordination, Presented by Kendrick J. Simila, Committee Chairman ..........

Report of the Committee on Laws and Regulations, Presented by Robert

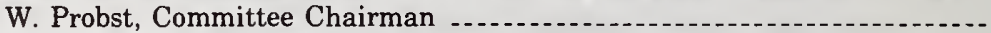

Report of the Committee on Specifications and Tolerances, Presented by

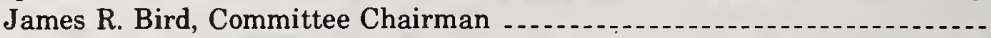
Report of the Committee on Education, Administration, and Consumer Affairs, Presented by Stephen A. Malone, Committee Chairman ............

Report of the Committee on Liaison, Presented by Charles H. Greene, Com-

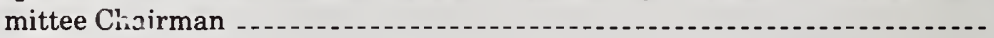

\section{REDORTS OF THE ANNUAL COMMITTEES}

Report f the Executive Committee, presented by Kendrick J. Simila, Conference Chairman ..............

Report of the Resolutions Committee, presented by Edward C. Heffron, Com-

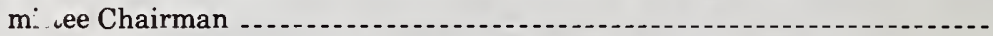

Report of the Nominations Committee, presented by James F. Lyles, Committee Chairman . .

List of Former NCWM Chairmen

Report of the Auditing Committee, presented by George S. Franks, Com-

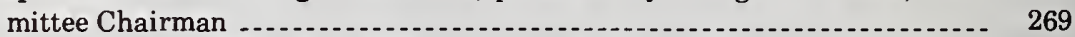

Report of the Treasurer, presented by James H. Akey, Treasurer _... _..._ $\quad 270$

Conference Registration List ......... 274

Weights and Measures Publications ........ 303

\section{OFFICERS OF THE CONFERENCE}

President: ERNEST AMBLER, Director, National Bureau of Standards

Executive Secretary: HAROLD F. Wollin, Assistant Chief, Office of Weights and Measures, National Bureau of Standards

Chairman: KendRICK J. Simila, Administrator, Weights and Measures, Oregon Department of Agriculture

Vice Chairmen:

ElviN R. LEEMAN, Standards/Measures Officer, State of Wyoming Department of Agriculture 
Norman M. Ross, Chief, Weights and Measures Division, Nebraska Public Safety Department

JoHn V. PUGH, Director, Metrology Division, South Carolina Department of Agriculture

Edward H. StadolniK, Assistant Director of Standards, Massachusetts Division of Standards

Treasurer: JAMES H. AKEY, Inspector, Weights and Measures, State of Wisconsin

Chaplain: JoHN H. LEwIS, Chief, Weights and Measures Section, Department of Agriculture, State of Washington

\section{EXECUTIVE COMMITTEE}

John T. BenNetT, Connecticut

Adin Helgeson, North Dakota

Francis W. DaniEls, Wayne County, Indiana

Gaylon M. Kennedy, Maine

JoHN C. MAYS, Dade County, Florida

W. R. Mossberg, Los Angeles County, California

Billy W. Sullivant, Arkansas

A. B. MooDY, Richmond, Virginia

JoHN O'NeILL, Kansas

Sam F. ValtrI, Philadelphia, Pennsylvania

(All officers of the Conference are, ex officio, members of the Executive Committee.)

\section{APPOINTED OFFICIALS}

\section{Sergeant at Arms:}

Max L. ClaRK, Supervisor, Packaged Products Programs, Oregon Weights and Measures

William C. Sullivan, Supervisor, City of Seattle Weights and Measurt 3

\section{Parliamentarian:}

David L. GRIFFITH, Director, Consumer Protection Division, West Virginia Department of Labor

\section{STANDING COMMITTEES}

The number of years each committee member has remaining to serve on the committee as of the 64th Conference is shown in parentheses. Also noted are the new appointees and newly designated committee chairmen.

\section{NATIONAL MEASUREMENT POLICY AND COORDINATION}

KENDRICK J. SimiLA, Chairman

JAMES R. BIRD, Chairman, S \& T Committee

RoBerT W. PRoBst, Chairman, L \& R Committee

Steven A. Malone, Chairman, Education Committee

Charles H. GReEne, Chairman, Liaison Committee

HAROLD F. Wollin, Executive Secretary, NCWM

JAMES F. LYLES, Representative, OIML-Virginia

SYDNEY D. ANDREWS, Representative, U.S. Metric Board-Florida

Ezio F. Delfino, Chairman, Task Force-California

(The members of this committee include the presiding chairmen of the other four standing committees and the Conference chairman who serves as the chairman of this committee. Mr. Vincent will serve as chairman next year.) 


\section{SPECIFICATIONS AND TOLERANCES}

JAMES R. BIRD, Chairman, New Jersey

Lacy H. DeGrange, Maryland (4)

Gary L. Delano, Montana (2)

DARREll A. Guensler, California (1)

Frank C. Nagele, Michigan (3)

OTTO K. WARnLOF, Staff Assistant, NBS

(Sidney A. Colbrook, State of Illinois, was appointed for a 5-year term to replace James R. Bird whose term expired. Mr. Guensler replaced Mr. Bird as chairman.)

\section{LAWS AND REGULATIONS}

ROBERT W. Probst, Chairman, Wisconsin (1)

JOHN T. BENNETT, Connecticut

Sam F. Hindsman, Arkansas (3)

DANIEL I. OFFnER, St. Louis, Missouri (2)

JoHN J. BARTFAI, New York (4)

JeFFrey V. ODOM, Staff Assistant, NBS

Eric A. VAdELund, Staff Assistant, NBS

(W. R. Mossberg, City of Los Angeles, was appointed for a 5-year term to replace Mr. Bennett whose term expired. Mr. Offner replaced Mr. Probst as chairman.)

\section{EDUCATION, ADMINISTRATION AND CONSUMER AFFAIRS}

Steven A. Malone, Chairman, Nebraska (2)

ANTHONY J. LADD, Akron, Ohio (1)

ROBERT W. WALKER, Indiana (3)

JOSEPH L. SWANSON, Alaska (5)

StAN J. DARSEY, Florida (4)

RICHARD N. Smith, Staff Assistant, NBS

(J. Swanson, State of Alaska, was appinted for a 5-year term to replace Mr. Helmick, whose term expired. Mr. Darsey, State of Florida, was appinted for a 4-year term to replace Mr. Junkins who has found it necessary to resign from the committee. Mr. Ladd replaced Mr. Malone as chairman.)

\section{LIAISON}

Charles H. Greene, Chairman, New Mexico (1)

JANE S.WILSON, Federal-State Reports, Inc.

MERrill S. Thompson,Chadwell, Kayser, Ruggles, McGee \& Hastings, Ltd. (3)

TERRY A. HocIN, Chicago, Illinois (4)

Charles E. Forester, Texas (2)

Sam F. Hindsman, National Task Force Coordinator-Arkansas

STEPHEN Hasko, Staff Assistant, NBS

(Charles R. Cavagnaro, U.S. Office of Consumer Affairs, was appointed for a 5-year term to replace Ms. Wilson, whose term expired.) 


\section{ANNUAL COMMITTEES}

\section{Nominations}

JAMES F. LyLES, Chairman, Virginia

RichaRd L. THOMPSON, Maryland

SYDNEY D. ANDREWS, Florida

JoHN H. LEwIS, Washington

GEORGE L. JoHnSON, Kentucky

KENNETH R. ADCOCK, Ohio

ELVIN R. LEEMAN, Wyoming

\section{Resolutions}

EdWARd C. HeFFron, Chairman, Michigan

PATRICIA M. Fullinwider, Arizona

SidNEY A. COLBROOK, Illinois

Maria A. Maldonado Garcia, Puerto Rico

JosePh L. Swanson, Alaska

ROBERT M. REEVES, Tennessee

TOM W. SCOTT, North Carolina

\section{Auditing}

George S. Franks, Chairman, Cumberland Co., New Jersey

Eugene KeELEy, Delaware

Fred A. Gerk, New Mexico

\section{Credentials}

John M. Chohamin, Chairman, Middlesex County, New Jersey

JAMES C. BlaCkWOoD, Dallas, Texas

LYMAN D. HOLLOWAY, Idaho

\section{Associate Membership}

ERIC Allen, Chairman, The Measuregraph Company

WALTER F. GERDOM, Tokheim Corporation

RalPH W. Miller, JR., Jewel Companies, Inc.

William N. SHANNON, III, Berkel Incorporated

RICHARD SOUTHERS, American Petroleum Institute

RAYMond R. Wells, Seraphin Test Measure Company

EDWARD E. WOLSKI, Colgate-Palmolive Company

THOMAS M. STABLER, Toledo Scale Company

ALFRED E. JOHANSON, CPC North America

AUSTIN RHOADS, Milk Industry Foundation/International

Association of Ice Cream Manufacturers 


\title{
LADIES' ARRANGEMENTS
}

\author{
VIRGINIA WOLLIN \\ MARGARET THOLEN \\ IRENE WARNLOF
}

\section{METROLOGY WORKSHOPS}

There were three metrologist's workshops scheduled during Conference week. The purpose of these workshops was primarily to train State and local metrologists in laboratory calibration procedures and techniques.

\section{MANUFACTURERS' EQUIPMENT AND PRODUCT DISPLAY}

An informal display of new equipment and products by manufacturers and suppliers was held on Monday evening from 5:00 to 7:00 p.m. for the education of the conference delegates.

A film, Electronic Weighing Comes of Age, was shown at 8:00 p.m. on Monday by Transducers, Inc.

MONDAY, JULY 23, 1979

and

TUESDAY, JULY 24, 1979

\section{OPEN COMMITTEE HEARINGS}

Monday and Tuesday were set aside for hearings of the five Conference standing committees. Notices of these hearings were carried in the Conference Announcement booklet, in all pre-Conference publicity, and in the printed Conference program. Many delegates participated in the committee hearings and presentations were given by representatives of weights and measures, industry, government, and consumer groups. The discussions which took place played an important role in guiding the committees in their deliberations and preparations of their final reports. The final reports of the committees will follow later in this publication and will reflect the discussions that took place and the actions taken by the Conference at the time the final reports were presented to the delegates. 


\section{PLANNING FOR THE 1980 INTERNATIONAL CONFERENCE OF LEGAL METROLOGY}

\section{Presented by David E. Edgerly, Chief, Office of Domestic and International Standards, National Bureau of Standards}

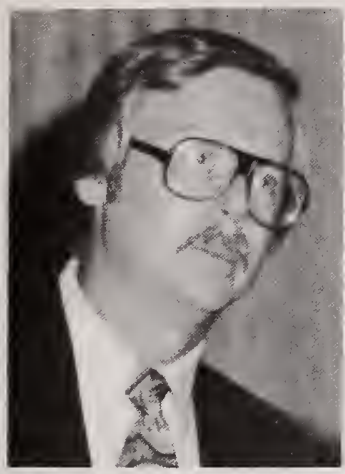

The United States will host the Sixth International Conference of Legal Metrology in Washington, D.C. on June 14-20, 1980. On behalf of Mr. Bernard Athane, the Director of the International Bureau of Legal Metrology, and Dr. Arthur McCoubrey, the U.S. Representative to the International Committee of Legal Metrology, I am pleased to invite each of you to participate as observers in the plenary sessions of this Conference. Generally speaking, the International Conference is the policy-making body of the International Organization of Legal Metrology (OIML). Its purpose is to sanction International Recommendations after they have been approved by the OIML technical network, which is directed by the International Committee of Legal Metrology (CIML) and which consists of some 200 technical committees called Pilot and Reporting Secretariats.

Presently, OIML consists of 44 member Nations, which include virtually all of the U.S.'s major trading partners. These nations represent almost all of the geographical regions in the world, with the exception of South America, whose only member is Venezuela. However, it is hoped that Brazil and Peru eventually will join the list of OIML members. By 1980, OIML expects its membership to increase to 47 nations.

It is anticipated that some 150 delegates will assemble for the Conference in Washington, D.C. Although most will be official representatives of the OIML Member Nations, others will be representing OIML Corresponding Member Nations, of which there are 17. A typical delegation consists of from two to five government officials, and the leader of each is usually the Director or Deputy Director of each national metrology laboratory. The U.S. delegation will be composed of representatives from NBS, NCWM and private industry.

Other participants will include representatives of the 15 international institutions in liaison with OIML, such as the International Organization for Standardization, the International Electrotechnical Commission, IMEKO, BIPM, UNESCO, and UNIDO. The representatives of these organizations will be invited to participate in the Conference as observers.

The Conference meetings will.take place in downtown Washington at the Department of State which has excellent facilities in terms of meeting rooms, documentation capabilities, and translation services. 
The official language of OIML is French and therefore much of the Conference will be conducted in that language. However, the State Department will provide interpreters for simultaneous translation into English, Russian and French throughout the Conference.

The International Conference and the NCWM were planned in sequence to encourage interaction between U.S. weights and measures officials and those of other countries. Accordingly, Bud Wollin and I are discussing the possibility of joint social functions as well as several OIML guest speakers during the NCWM. These addresses would be given by selected foreign delegates and would deal with specific technical issues or informative subjects such as the differences between U.S. and foreign weights and measures enforcement and the question of training of officials. Furthermore, the Shoreham Hotel will serve as the headquarters hotel for both Conferences. It is hoped that you will plan to arrive early and participate in the OIML plenary sessions and by the same token that the OIML delegates will remain in Washington the following week to participate in the NCWM.

The two conferences differ in several respects. First, the International Conference devotes considerable time to the approval of the OIML four-year budget, in this case 1980-1984. Second, one of the major functions of the International Conference is to sanction International Recommendations which have been developed during the previous four years by the various OIML Pilot and Reporting Secretariats. Approximately 15-20 of these technical documents will be voted upon at the upcoming International Conference. Third, the International Conference adopts overall OIML policy. For instance, some of the policy issues under consideration will be an OIML International Certification Program, a change in the OIML Convention to resolve problems associated with voting procedures, and assistance to developing countries. Finally, whereas the National Conference deliberates on specific technical issues during its annual Conference, no technical discussions are permitted during the International Conference. Basically, there are two reasons for this. Technical issues upon which a vote will be taken have undergone approval at several levels within the OIML working structure. By the time these documents reach the International Conference level, the technical experts from the various Nations have agreed on their content and the only remaining step is to attain the final approval of the official national delegations to the Conference. Moreover, the technical experts are rarely members of the Conference delegations. For these reasons, this Conference in general is more formal than the National Conference and proceeds at a slower pace.

In any case, I hope that all of you will take advantage of this timely opportunity to participate in this Conference and to meet the legal metrologists of other nations. There is a lot to be gained from this experience such as increased communication and cooperation and I assure you that you will find it quite interesting. 


\section{STATISTICS MADE UNCOMPLICATED}

\section{Presented by EdWARD E. WolskI, Manager, Quality Control,}

Colgate-Palmolive Company

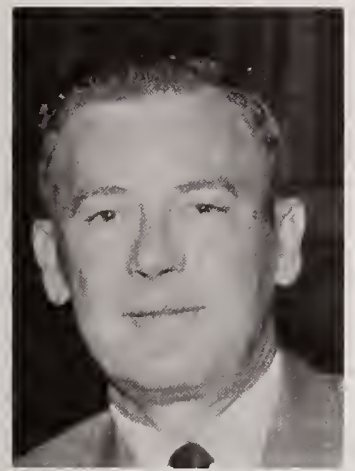

Let's look at what it's all about. In order to evaluate the performance of a packager, or to determine if a meat case is in compliance, for example, we need more than a small sampling and its average. We would know whether the average of that sample is over or short, but we haven't learned anything about the seller's intent, his performance, or how reliable his control system is.

Let me tell you a little story. Once upon a time, a shipwrecked sailor was washed ashore on a desert island. There was no vegetation, no water, and no animal life there. There was a supply of water in the lifeboat, a shotgun with two shells, and enough food to keep him alive for 28 days. But he knew he would surely starve because the next ship scheduled to pass was not due for 29 days, too late to save him. But miraculously, with his time running out, on the afternoon of the 28th day, a duck flew over his island. In his excitement, the starving man fired both barrels of the shotgun. One charge passed two feet in front of the duck, while the other passed two feet behind the duck. He was overjoyed because he was surely saved; on the average he had brought the duck down twice. But the duck didn't know how much faith people have in averages, and it flew away.

That's what Statistics is about. It is a tool which permits us to evaluate the dispersion, or "scatter", of the sample values about their average and to reach valid conclusions about the larger quantity from which the sample was drawn. We can do this with comparatively small samplings and can know how reliable our conclusions and assumptions are likely to be. This is because Statistics is based upon the Mathematical Theory of Probability. But, as it is applied to Weights and Measures evaluations it is not at all complicated. Ordinary arithmetic will do the job for everything we study. 
Now, let's look at some basics. Two fundamental facts must be recognized and accepted, and they must be clearly understood. The first of these is that no two things are exactly alike. If we look closely enough, the differences are always there. For example, two automobiles of the same make and model will differ in their performance. Measure and inspect two peas from the same pod closely enough and you'll find they aren't alike at all!

The second of these facts is that this variation takes a predictable pattern. The scatter may be great or it may be small, but the pattern is predictable from previous data. In fact, if the pattern differs significantly from the predictable pattern, you can be certain that outside factors are involved.

Let's look now at how this tool of Statistics is used. First, there are some terms which need to be understood. Like every other system, Statistics has its language, but the vocabulary isn't extensive.

Population: The "Population" is the entire group, and it may be large or small. It can be all of a given size and brand of a product in a retail store, or all of that size and brand in a warehouse. It can be all of the random weight packages in a retail meatcase.

Sample: The "Sample" is that part of the Population which is collected and examined to obtain the statistical facts such as length, weight, or volume. It is obvious that it is not usually practical to examine every individual unit. It is of utmost importance that sampling be done randomly. "Random" means that each individual sample is drawn without any set pattern, and in such a way that any unit has the same chance as any other of being drawn. If the samples are not random, the conclusions reached from the data may not be valid.

Subgroup: A "Subgroup" is a small group of a sample. The total sample would be made up of a number of such subgroups. For example, if our sampling plan called for 100 random packages to be drawn from a large warehouse lot, the first five would be a subgroup of five; the second five would comprise another subgroup of five, and so on. The total sampling of 100 would consist of 20 such subgroups of five units each. You will see later how this subgroup technique can be very useful to you.

$\mathrm{X}$ : The letter " $\mathrm{X}$ " is used to designate the value measured for each item examined. For example, if the first sample checked was found to weigh $16^{1 / 2}$ oz, then $X_{1}$ is $16^{1 / 2}$ oz. If the second package weighs $16^{1 / 4} \mathrm{oz}$, then $\mathrm{X}_{2}$ is $16^{1 / 4} \mathrm{oz}$. The letter " $\mathrm{X}$ " simply denotes an individual item fact. Numbering them $X_{1}, X_{2}, X_{3}, X_{4}, X_{5}$ simply identifies which item in the subgroup provided that fact. 
n: The letter " $n$ " is used to designate the number of items or subgroups in a sample. If you have ten items, then " $n$ " is ten; if you have 30 , then " $n$ " is 30 , and so on. We use " $n$ " as convenient shorthand for "how many".

$\overline{\mathbf{X}}$ : The average of the items in the subgroup is called $\bar{X}$ (X-Bar). This is just the average as we have always known it. You add the values and divide by how many. Let's look at that in the Statistics shorthand we've learned so far:

$$
\bar{X}=\frac{X_{1}+X_{2}+X_{3}+\ldots X_{n}}{n}
$$

$\overline{\bar{X}}$ : The overage of all the items which were measured is called "XDouble Bar", and written as: $\overline{\mathrm{X}}$. It can be determined by taking the average of the $\bar{X}$ values for the subgroups, or by taking the average of all the individual items. Either method gives the same result.

Range: The difference between the largest and smallest value in a subgroup is the "Range". Our shorthand designation for Range is the letter " $R$ ". If, in a subgroup of five packages, the lightest weighed $15 \frac{1}{2} \mathrm{oz}$ and the heaviest weighed $16 \mathrm{oz}$, the range for that subgroup would be $1 / 2 \mathrm{oz}$. If another subgroup had $161 / 4 \mathrm{oz}$ as the lightest weight and $16 \frac{1}{2} \mathrm{oz}$ as the heaviest weight, the range for that subgroup would be $1 / 4 \mathrm{oz}$. The Range is just the spread between the largest and the smallest value in the subgroup. Later you will see how valuable this Range information is in determining if a seller has control and is giving fair measure.

Average Range: The "Average Range" is just the average of all the subgroup Ranges. If, for example, our sampling plan called for 30 units to be drawn and measured, we would have six subgroups of five, and six Range values. We simply average these six Range values. We use the term " $\mathrm{R}-\mathrm{Bar}$ " to denote the Average Range, and write it as $\overline{\mathrm{R}}$.

Frequency: The letter " $f$ " is our shorthand for Frequency. The number of times any one value is observed out of all the observations made is the "Frequency". For example, if we make 100 weighings and find fifteen at $16 \mathrm{oz}$ and twenty at $16^{1 / 4} \mathrm{oz}$, their Frequencies are $15 / 100$ (or $15 \%$ ) for $16 \mathrm{oz}$ and $20 / 100$ (or $20 \%$ ) for $16 \frac{1 / 4}{\mathrm{oz}}$.

Frequency Distribution: A "Frequency Distribution" is simply a tally of the number of times each value occurs, and illustrates the 
pattern of variation. If we make 100 weighings and record them, the tabulation really doesn't tell us very much. All we have is a mass of numbers.

For standard pack items, Weights and Measures inspections usually consist of ten packages drawn from the lot at random, and the item weights are usually recorded as plus or minus, to the nearest $1 / 16 \mathrm{oz}$. If we took the values from ten inspections of a manufacturer's product and tabulated them, they would look like this:

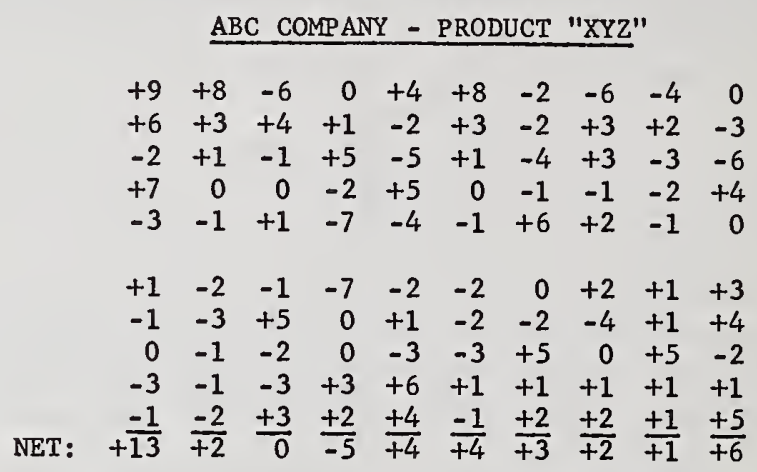

A tabulation of this sort lists all the facts, but not in a very useful form. If we make a tally of these same facts, we can see a picture of the pattern that looks like this:

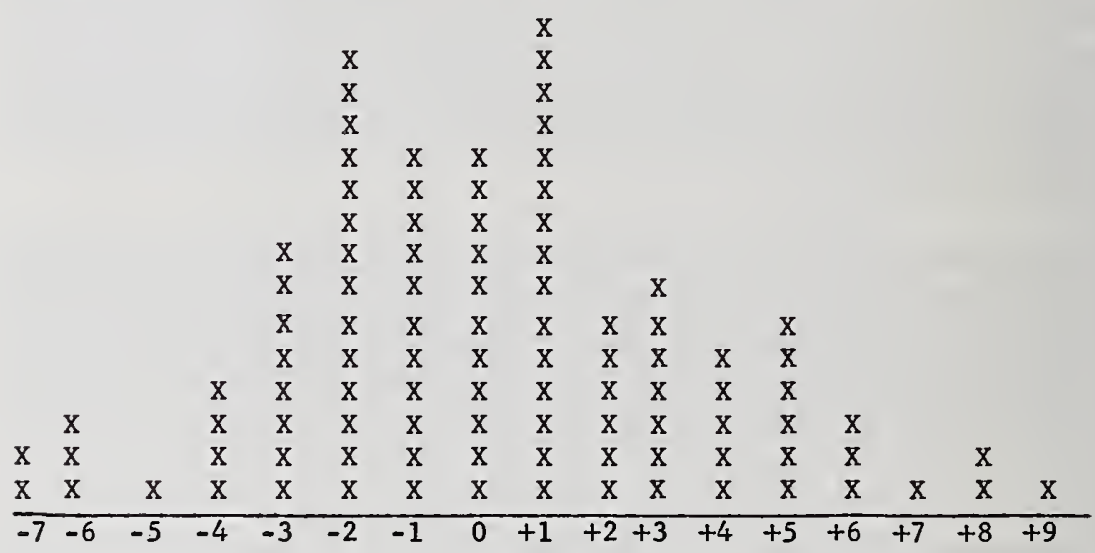

ABC COMPANY - PRODUCT "XYZ": FREQUENCY

DISTRIBUTION FROM TEN RETAIL STORE SAMPLINGS

This is easy enough. We've all made a tally at one time or another. This lets us quickly see if the packages center at or above the stated 
quantity, and whether the variation tends to be biased either toward the heavy side or the light side.

Frequency Curve: If the Frequency Distribution included enough items, it would show in a smooth pattern just what the packager is doing. If we were to connect the tops of the tallies with a smooth line, we would have a "Frequency Curve". The Frequency Curve is a picture of the packager's pattern of variation. The spread reflects the overall result of variation in his product, machine variation, whatever effect operators might introduce, and all other variables which are part of his operation and can affect the uniformity of his measure. For example in the case of bottle filling, the variation in size of the bottles themselves will be one of the variables influencing the overall spread.

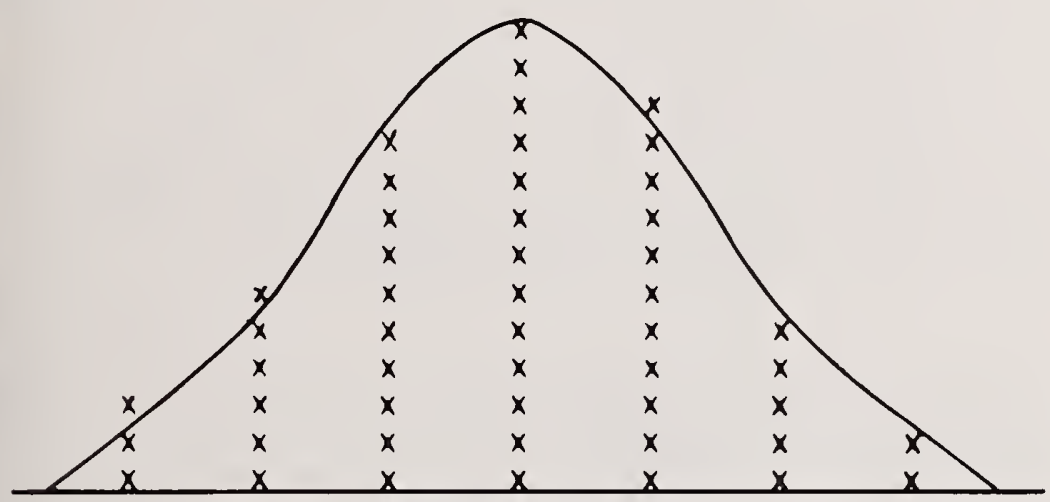

FREQUENCY CURVE

To reduce this spread the packager must change either his equipment, his product, or his process to reduce the causes of variation. Unless he makes a significant change, the amount of scatter and the pattern it takes will remain the same. For example, raising the target fill by one unit will only shift the whole population up one unit, with the same pattern and scatter. The frequency curve is the fingerprint of the packager's overall performance.

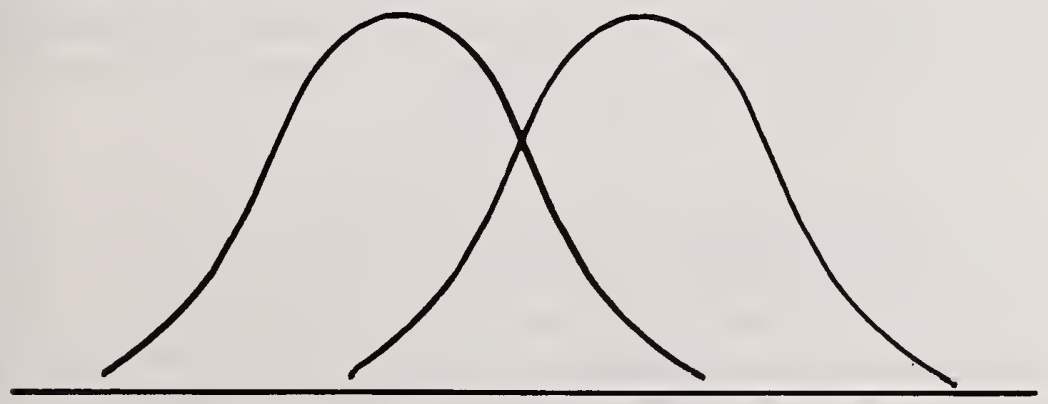

MOVING THE TARGET WILL NOT CHANGE THE SCATTER! 
Normal Curve: The frequency curve which most often occurs in nature is symmetrical and bell-shaped. For example, the frequency curve for the heights of several hundred random U. S. men would take the symmetrical, bell-shape shown below, and would be centered at about five feet, ten inches. This would be true unless your sample included midgets from a visiting circus or the players from the basketball tournament.

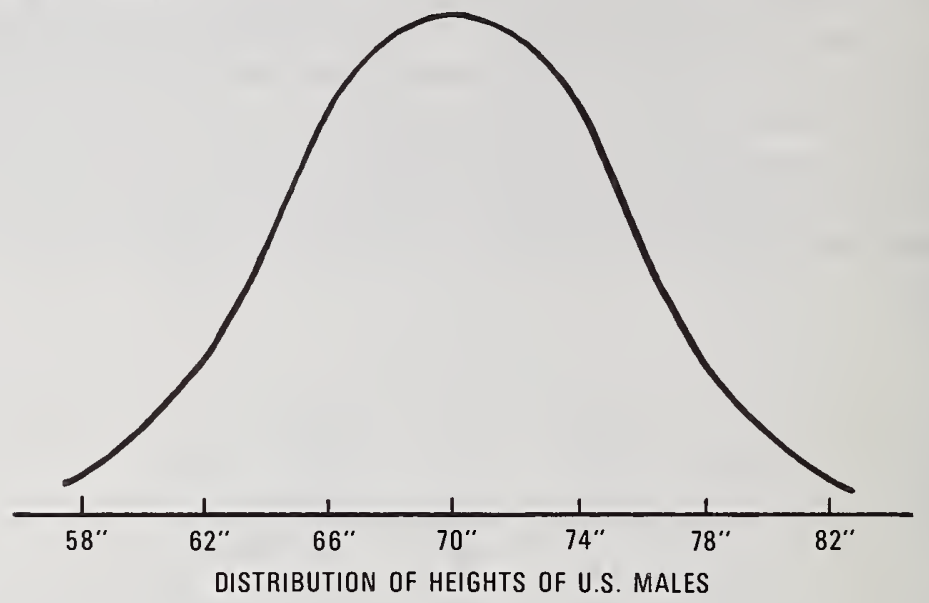

There are some relationships about the spread and the pattern which are very useful, since most processes approximate the normal distribution closely enough for us to be able to make that assumption without too much risk of major error. The better controlled the operation, the more closely the frequency distribution approaches the normal distribution of values. We will discuss the normal curve in more detail later on.

Standard Deviation: The "Standard Deviation" is designated by the Greek letter "sigma", in our shorthand, written like this: $\sigma$. The Standard Deviation is just a relationship between the overall average of all the values in the sampling (which we called "X-Double Bar"), and how the individual values vary, or scatter, from that average. It is a sort of average difference among the items, or put another way, a measure of the scatter. It is one of the most useful of all statistical facts obtained by sampling. It permits us to measure a packager's capability, and to determine his intent.

There are mathematical formulas for calculating the Standard Deviation which look complicated, but aren't. But it is made even easier because the Statisticians have developed shortcuts which give very nearly the same answer, and adequate for most evaluations. One of these shortcuts takes advantage of the relationship between the Average Range $\bar{R}$ for subgroups, and the Standard Deviation. All you 
have to do is determine the Average Range for the subgroups in your sample, apply a factor the Statisticians have developed for subgroup sizes, and you have a good value for Sigma. There is one factor for subgroups of four, another for subgroups of five, and so on. Most weights and measures store inspections are of ten packages, so each store inspection of a product could be considered to be two subgroups of five. Ten such store inspections could be combined into one large sampling of twenty subgroups. The factor for calculating Sigma from subgroups of five is 0.43 . You just multiply the Average Range by 0.43 .

Now, what will all this do? You will recall that the Frequency Distribution is the fingerprint of a packager's performance, that most distributions approximate the "normal" distribution, and that the better a packager's control is, the more nearly normal the distribution will be.

Now, the "normal" distribution curve has some properties which are very valuable in projecting the findings from sampling and in making valid assumptions about the overall population, based on the sampling. These properties are the same whether the production yields product which tends to be quite variable, or whether it is quite uniform. If the production is relatively uniform, the curve will be narrower, and quite high, because the sample values are tightly grouped, like this:

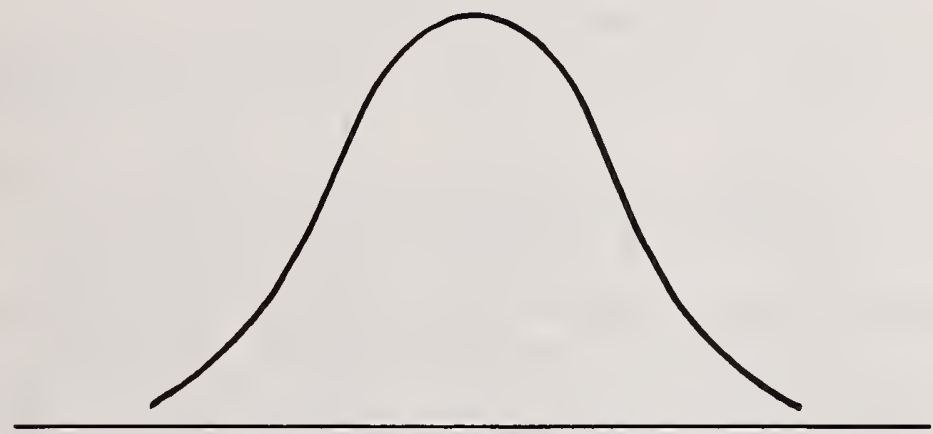

NORMAL CURVE-NARROW SCATTER

If the production is more variable, the curve will be flatter and wide because of the scatter, but bell-shaped, like this:

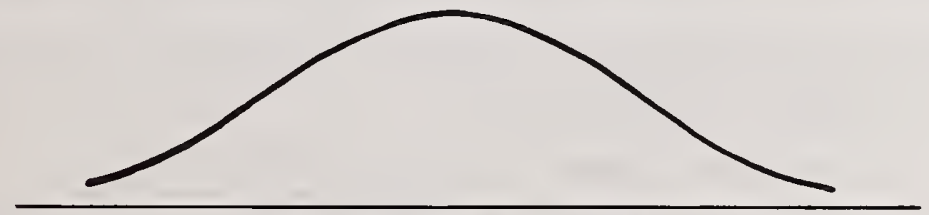

NORMAL CURVE-WIDE SCATTER 
Both of these examples are what you would expect, when you think it out. If the product is more variable, the curve will spread out more because of the scatter. If it is more uniform, it will have a narrower pattern, and will group more toward the center.

Now, let's talk about the normal curve and its properties. The first of its characteristic properties is that the individual values will most frequently be near the average. Another characteristic is that there will be approximately the same number of results above the average as there are below the average, and they will be over and under by about the same amount. Another important property is how they tend to scatter and that is where the standard deviation comes in.

If we calculate the standard deviation, and step off the scatter in terms of the standard deviation, practically all of the normal curve falls within plus or minus three sigma. About $95 \%$ will be between plus or minus two sigma, and about two-thirds will be between plus and minus one sigma. This is illustrated below:

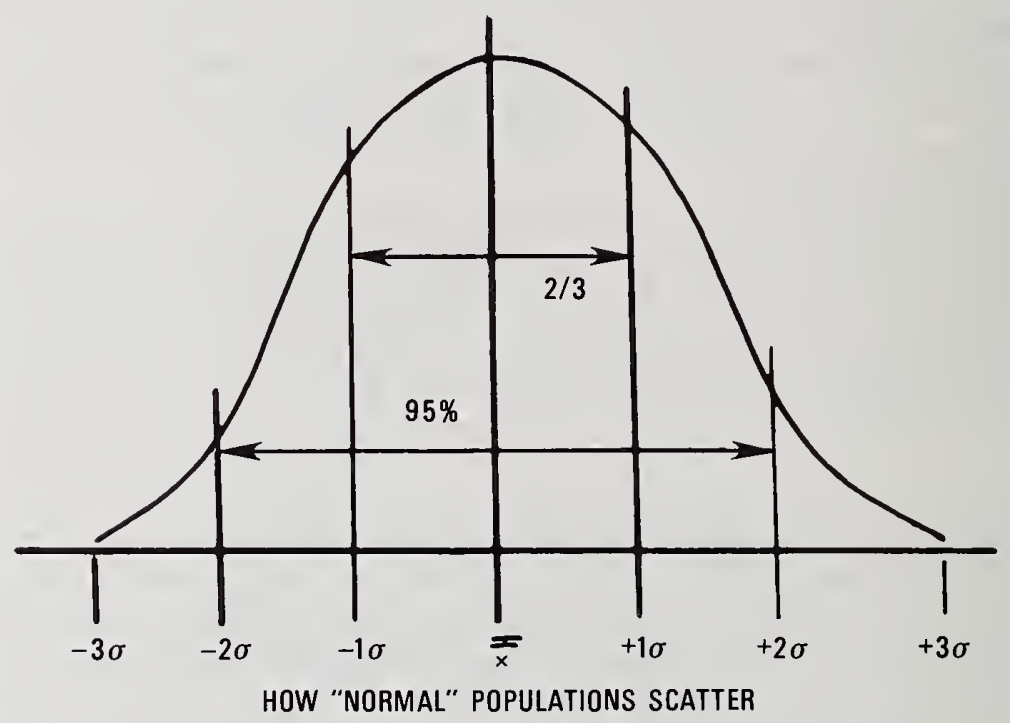

Now, let's see what we do with this. First, we'll look at standard pack goods, then later at random pack.

Weights and Measures Officials are concerned by two questions:

1) Which are the packagers who give fair measure, and who reliably control their operations?

2) Which packagers require enforcement action?

With the Statistical "Tool Kit", it is easy to determine which packagers have consistent, reliable control and which do not. If your in- 
spection findings give you reason to suspect that enforcement action is indicated, plot the sample data as a Frequency Distribution. If your suspicions are based on fewer than ten store samplings, additional store inspections should be made to obtain sufficient data. The data can then be readily evaluated as follows:

1) Consider each store sampling of ten packages as two subgroups of five. Determine the two range values for each, using the first five packages as one subgroup, and the second five as the second subgroup.

2) Determine the overall average of all ten packages. This is $X-$ Double Bar.

3) Determine the average of the 20 range values. This is the average range, or " $R-B$ ar".

4) Calculate sigma: This is $\mathrm{R}-\mathrm{Bar}$ multiplied by the factor of 0.43 for subgroups of five:

$$
\text { sigma }=\overline{\mathrm{R}} \times 0.43
$$

(Remember! All ranges must be from subgroups of five.

You cannot mix subgroups of different sizes.)

5) Step off plus and minus 1-sigma, 2-sigma, and 3-sigma on the Frequency Distribution.

6) Evaluate:

A Is the overall average at or above the marked quantity? If so, the packager gives fair measure.

B) Are about two-thirds of the values between plus and minus two-sigma? If the answer is yes, he has control.

C) Are only a few outside plus or minus 3-sigma? If more than a scattered few are outside the 3-sigma limits, his operation goes out of control, or his reject system is not effective.

7) What is his intent?

A) If he averages the marked quantity or more, he obviously has the intention of giving fair measure. If this is so, and he has control as shown by the Frequency Distribution, he is no problem to you unless he produces an excess of Unreasonable Minus Errors. In that case, he must raise his average to control them.

B) If he averages the marked quantity or more, has control, 
and limits the Unreasonable Minus Errors, he is no problem to you.

C) If he averages the marked quantity or more, but does not have control, his intentions are good, but he needs assistance.

D) If he averages less than the marked quantity, and does not have control, he is a problem to you. He either does not know the law, does not control, or cannot control. Action is indicated.

E) If he averages less than the marked quantity, but has control, he is the fellow you are really after. He knows what he is doing, and knows how to do it, and is giving short measure. He merits a lot of your attention. A good place to start would be a major warehouse or distribution point, so that the sampling would represent a large segment of his goods. The Office of Weights and Measures of the U.S. Bureau of Standards is publishing a Handbook which will include the sampling plan information you need to obtain evidence which will support prosecution of such violators.

The value of this statistical know-how is that it gives you the ability to identify the packager who deserves your attention, and then obtain statistically sound sampling data for prosecution. As you become familiar with it, you will find it to be one of your most valuable tools. Of course, it can't be really learned by reading through it once, or by listening to it once. It needs to be studied out a little. It's worth the small amount of time and effort. Anything worthwhile usually requires a little effort to master.

We've discussed standard packs, but what about random packs, such as a typical meat case? Random packs are really easier, because they are packaged at the store, and the whole population is right there on the spot.

First, let's discuss the Sampling Plans being provided by the Office of Weights and Measures. There are two: Plan " $A$ ", and Plan "B". Plan " $B$ " is really a survey plan. It is a $50 \%$ Risk Plan, which means that if a lot is in control, and averages the stated quantity, it will pass $50 \%$ of the time and will fail $50 \%$ of the time. The value of such a plan is that it does not require a large sample, and the consistent failures are readily identified. Where a product consistently passes, you simply maintain this small-sample routine auditing. For those in the "gray area", or which consistently fail, you apply Plan "A".

Plan " $A$ " is a larger sample, and consequently gives a more reliable result. It's as simple as that. The more facts you have, the more certain you are of what they are telling you. All the Statistics have 
been worked out for you, and Plan " $\mathrm{A}$ " is a 95\% Plan. The sample is of such size that you will be $95 \%$ sure of your result. You should use Plan "A" if you intend to prosecute, since 95\% certainty, based upon statistically sound sampling, certainly resolves the question of "reasonable doubt".

Now, let's look at a typical example. Plan "A" calls for 30 items to be drawn if the population consists of more than 30 and up to 800 items. The typical meat case falls in that bracket. You draw a random sample of 30 from all varieties, and all sizes, across the whole meat case display. You must be sure to remember the importance that the sampling be random, with no set pattern, so that every package in the display has the same chance as any other of being drawn for the sample.

First, the average tare is determined. Then all 30 are weighed net, and the net weights tabulated, plus or minus, from the stated quantity. Any errors exceeding the Maximum Allowable Variation (MAV) listed in the OWM Plan "A" should be circled.

Statistically, a sample of 30 packages drawn from between 31 and 800 packages will have no more than one package outside the MAV if the store's weighing system is properly maintained and is operated to give correct weight. If more than one result is circled, you are $95 \%$ certain that there is a violation. No further testing is necessary.

If fewer than two packages are found outside the MAV, determine the average error for the sample. If it is plus, the meat case passes.

If it is minus, the sample data must be evaluated to determine if the result is within the statistical probability that it could reasonably occur with the lot actually in compliance. All you do is mark off the individual data into subgroups of five. You then determine the range for each of these six subgroups (there are 30 packages in the total sample). You then determine the average range $(\overline{\mathrm{R}})$ from these six values.

If you multiply $\bar{R}$ by 0.157 the answer will be the minus error which could be observed in sampling even though it is in compliance, and if your sample were only a very small fraction of the total packages in the case. The factor 0.157 has been worked out by statisticians; the sample average can vary that much about the true average for the population.

Let's digress just a bit. If you think it out, it is obvious that as you examine more and more of the total packages, the more reliable the sample results will be. If there had been only 30 packages, and you had weighed them all, your results would be reliable, and no question about it. With more and more packages in the population, the risk of sampling variation becomes greater. The OWM sampling procedure includes provision for this, and permits a Statistical adjustment to the calculated allowable error to compensate for this. This is necessary to protect the validity of the findings as evidence for prosecution. 
These factors are included in a table. All you do is determine what percentage of the total packages in the meat case you actually weighed, and obtain the factor for that percentage from the table.

Now, all you do is multiply your value for $\bar{R}$ by 0.157 , then multiply the result by the factor from the table. If the average error is smaller than that final result, the meat case passes. If it is larger, it is shortweight, and action should be taken against those responsible.

We started by saying that Statistics is not complicated. Taken bit by bit, it really isn't. You will find that if you go over this a few times, it all falls together and truly is uncomplicated. The real value is that your samplings will be statistically sound, and truly meaningful when it is necessary to institute action against violators. You have an extremely valuable new tool, which will permit you to make an even greater contribution in maintaining equity in the marketplace. 


\section{ABC COMPANY - PRODUCT "XYZ"}

$\begin{array}{llllllllll}+9 & +8 & -6 & 0 & +4 & +8 & -2 & -6 & -4 & 0\end{array}$

$+6+3+4+1 \quad-2+3 \quad-2 \quad+3 \quad+2 \quad-3$

$\begin{array}{llllllllll}-2 & +1 & -1 & +5 & -5 & +1 & -4 & +3 & -3 & -6\end{array}$

$\begin{array}{llllllllll}+7 & 0 & 0 & -2 & +5 & 0 & -1 & -1 & -2 & +4\end{array}$

$\begin{array}{llllllllll}-3 & -1 & +1 & -7 & -4 & -1 & +6 & +2 & -1 & 0\end{array}$

$\begin{array}{llllllllll}+1 & -2 & -1 & -7 & -2 & -2 & 0 & +2 & +1 & +3\end{array}$

$\begin{array}{llllllllll}-1 & -3 & +5 & 0 & +1 & -2 & -2 & -4 & +1 & +4\end{array}$

$\begin{array}{llllllllll}0 & -1 & -2 & 0 & -3 & -3 & +5 & 0 & +5 & -2\end{array}$

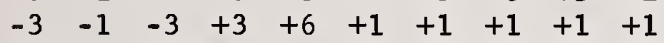

$\mathrm{NET}: \quad+\frac{-1}{13} \quad \frac{-2}{+2} \quad \frac{+3}{0} \quad \frac{+2}{-5} \quad \frac{+4}{+4} \quad \frac{-1}{+4} \quad \frac{+2}{+3} \quad \frac{+2}{+2} \quad \frac{+1}{+1} \quad \frac{+5}{+6}$

$\begin{array}{lllllllllll}\text { RANGES: } & 12 & 9 & 10 & 12 & 10 & 9 & 10 & 9 & 6 & 10\end{array}$

$\begin{array}{llllllllll}4 & 2 & 8 & 10 & 9 & 4 & 7 & 6 & 4 & 7\end{array}$

AVERAGE RANGE = SUM OF RANGES + N: $158+20=7.9$

PIGMA $=\vec{R} \times 0.43: 7.9 \times 0.43=3.397$ (or 3.4)

CHEN: 1 Sigma $=3.4$ (say, 3)

2 Sigma $=6.8($ say, 7$)$

3 Sigma $=10.2$ ( say, 10)

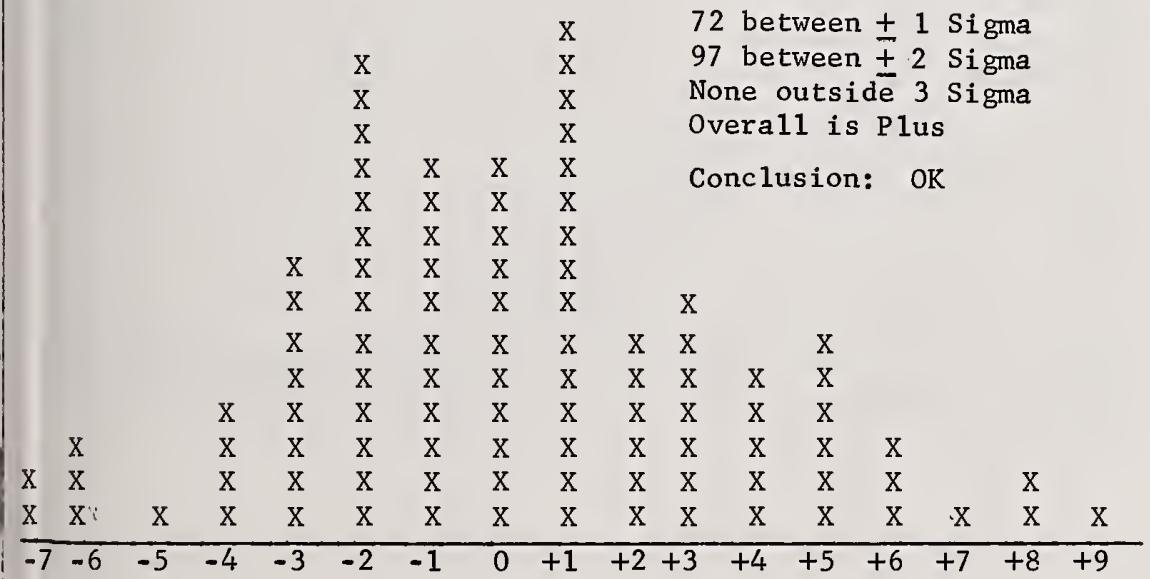




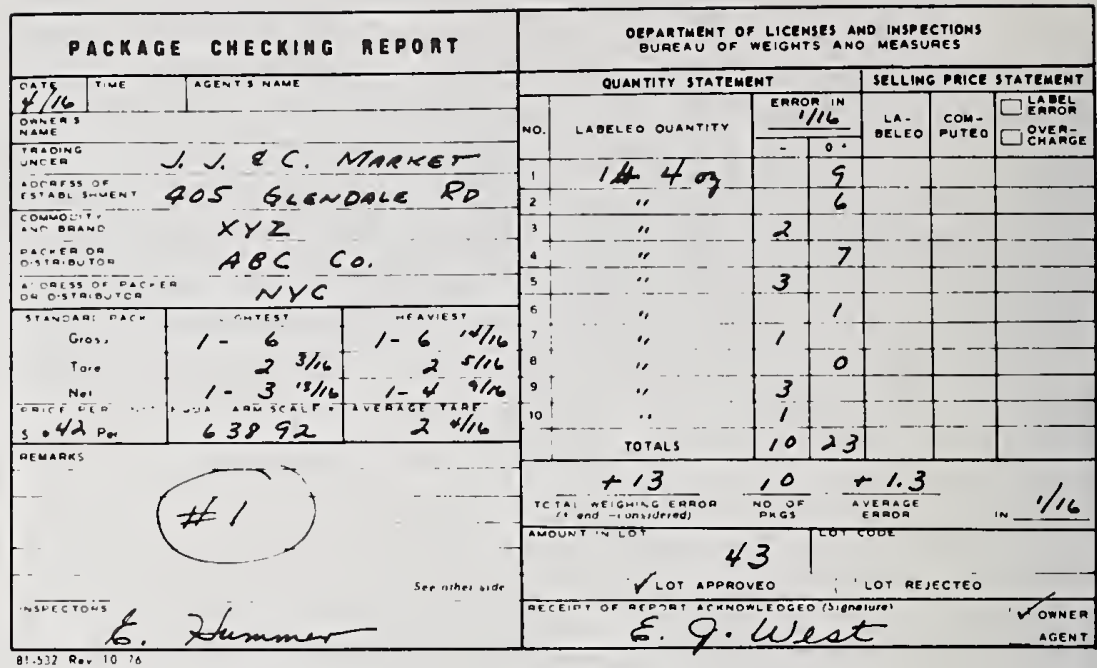

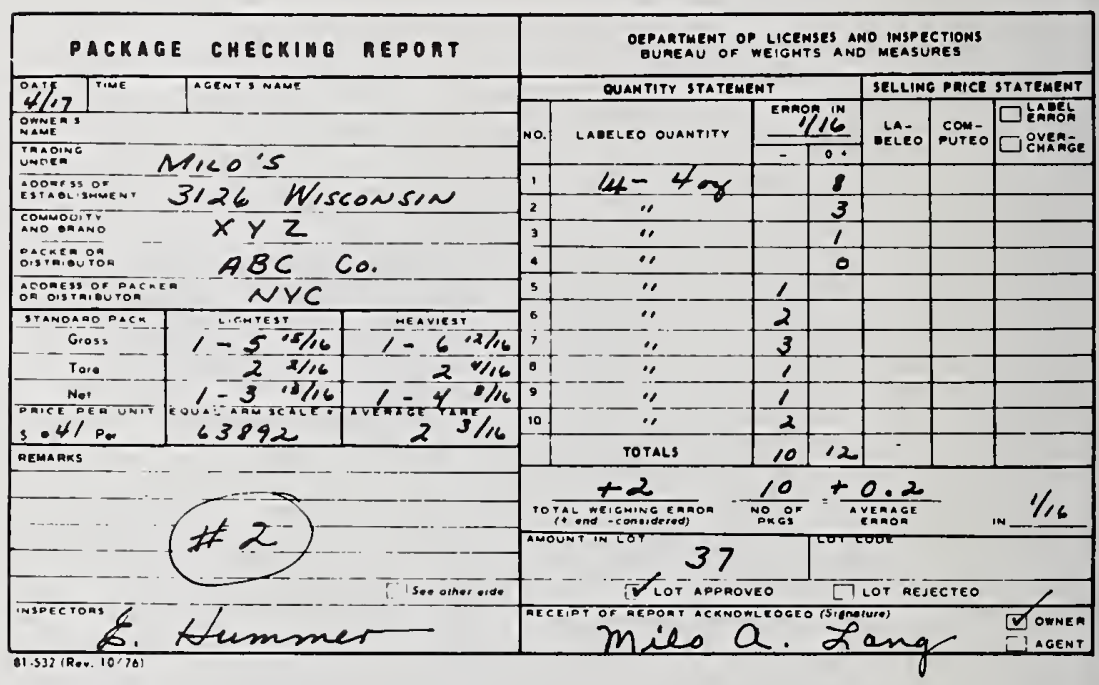




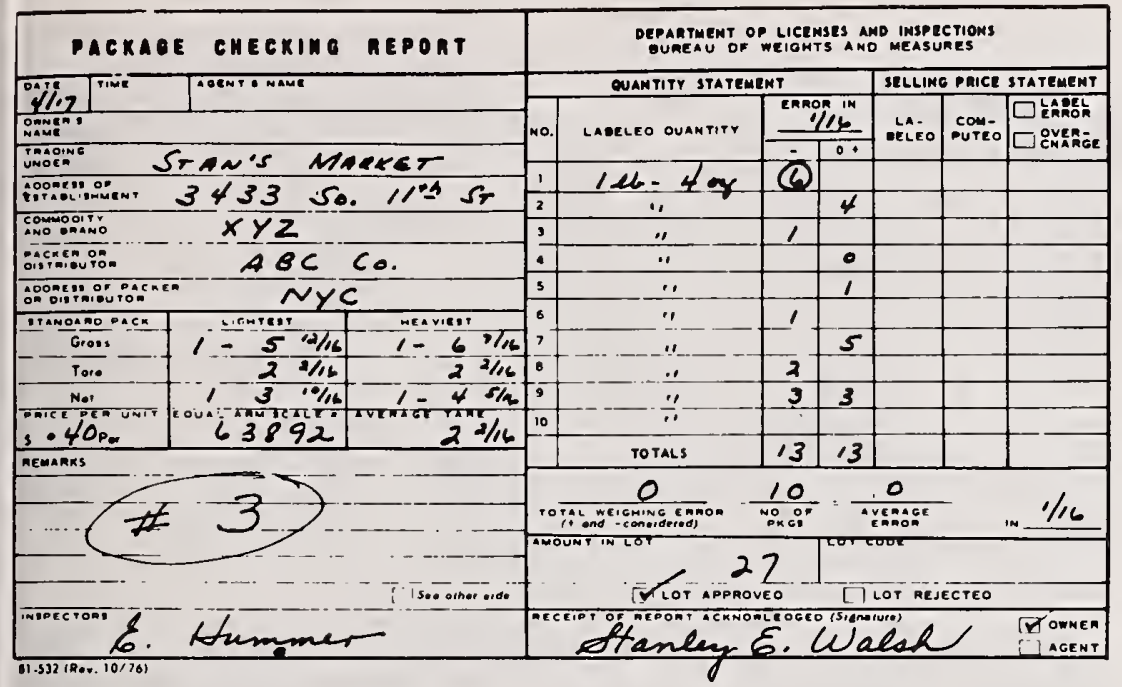

\begin{tabular}{|c|c|c|c|c|c|c|c|}
\hline PACKAOE CHECXIMG REPORT & \multicolumn{7}{|c|}{$\begin{array}{l}\text { OEPARTMENT OP LLCEMSES ANO INSPRECTIONS } \\
\text { BUREAU OF WEIGWTS A ND MEASURES }\end{array}$} \\
\hline $8 \geqslant$ & \multicolumn{4}{|c|}{ OUAMTITY STATEMENT } & \multicolumn{3}{|c|}{ SELLING PRICE STA TEMENT } \\
\hline 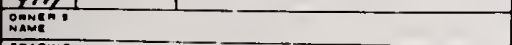 & \multirow[t]{2}{*}{ мо. } & \multirow[t]{2}{*}{ LAEELEO OUANTITY } & \multicolumn{2}{|c|}{ Ennon $1 / 6$} & \multirow{2}{*}{ GELËO } & \multirow{2}{*}{ COTEO } & \multirow{2}{*}{ 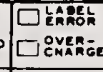 } \\
\hline CHASE'S & & & -1 & $0+$ & & & \\
\hline A4t Alocemarce $5 T$. & i & 1440 & & 0 & & & \\
\hline$x y z$ & $\frac{2}{3}$ & $\ddot{\prime \prime}$ & & 1 & & & \\
\hline$A B C$ &. & $\ddot{\prime}$ & 2 & 5 & & & \\
\hline 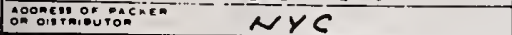 & 5 & $\because$ & (7) & & & & \\
\hline 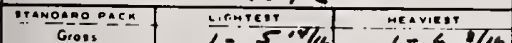 & 6 & $\because$ & (5) & & & & \\
\hline $1-\frac{5}{2} 5 / 16$ & $?$ & $\ldots$ & & 0 & & & \\
\hline 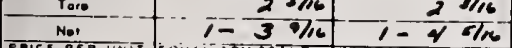 & 9 & $\because$ & & 0 & & & \\
\hline $\begin{array}{l}547 / \mathrm{Pox}^{2} \\
5421\end{array}$ & 10 & $\because$. & & 2 & & & \\
\hline nemanks & & TOTALS & 16 & 11 & & & \\
\hline & & 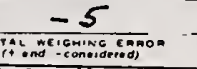 & $\frac{10}{10}$ & & $\frac{0.5}{0.5}$ & & $1 / 16$ \\
\hline 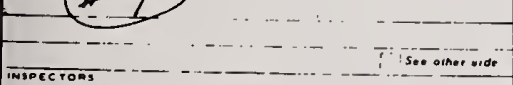 & & FUN 3 & & [4] & Lot Res & JECTEO & \\
\hline $25.25 \operatorname{cec}$ & & 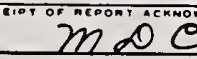 & & thiente & & & [Y OWNER \\
\hline
\end{tabular}




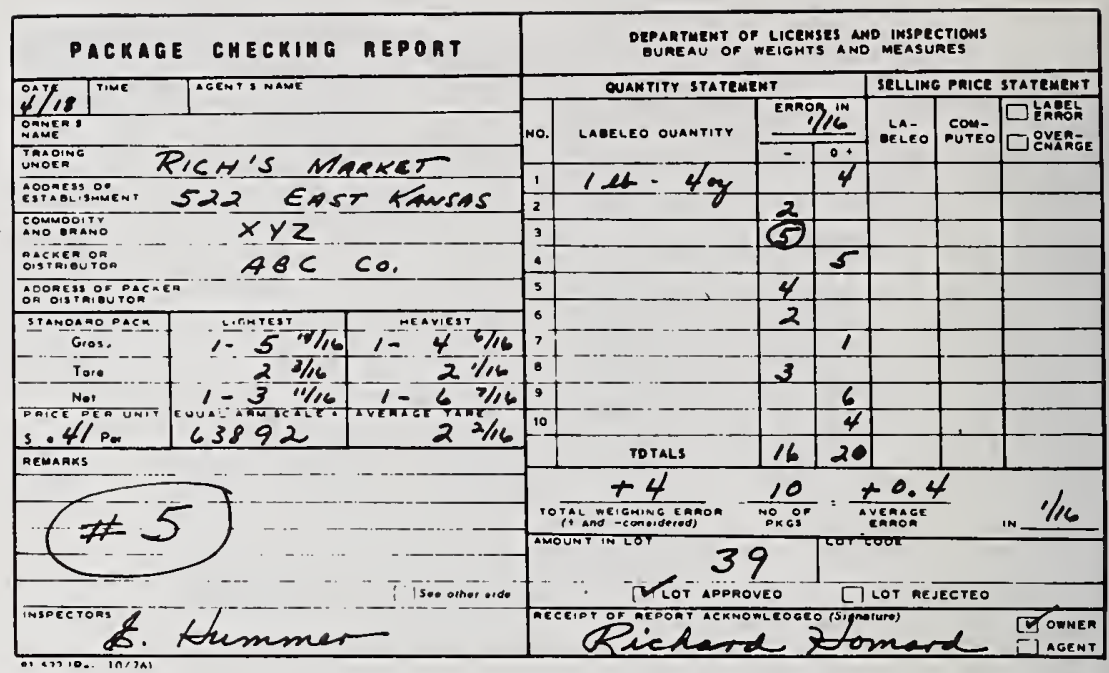

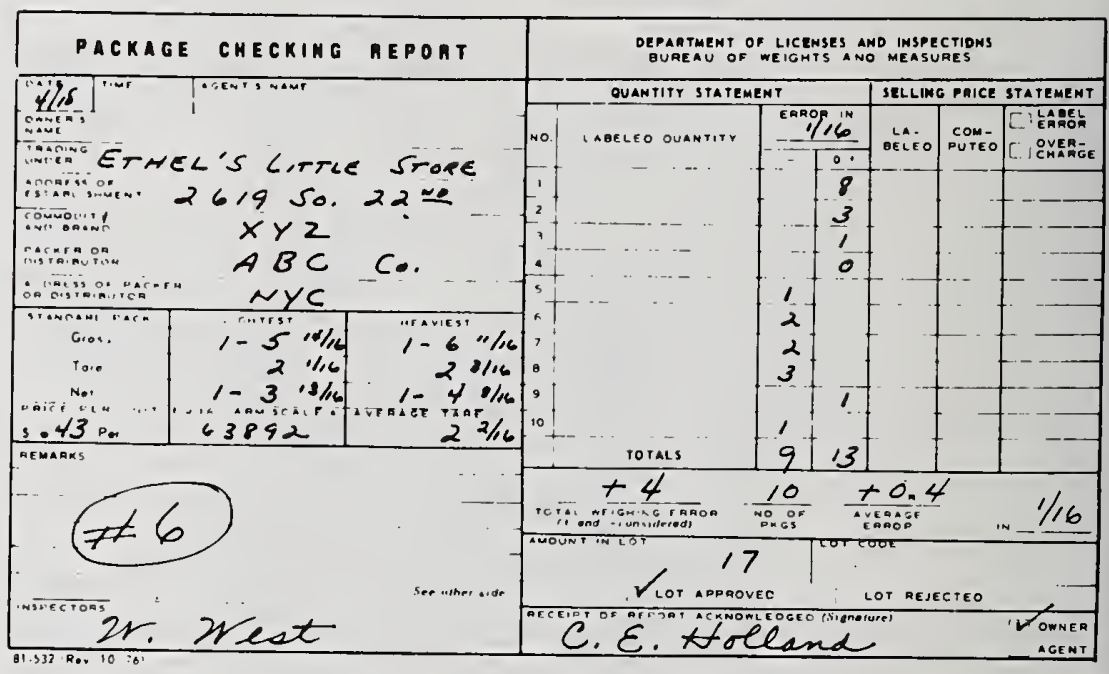




\section{CONFIDENCE IN PACKAGE CHECKING RESULTS}

\section{Presented by STEPHEN HASKo, Engineer, Office of Weights and Measures, National Bureau of Standards}

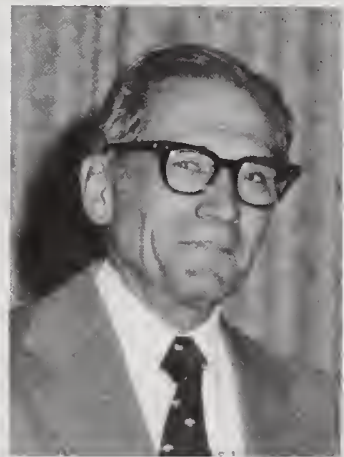

In many conversations with weights and measures officials on the subject of package inspection the question has been asked "Why do we need a new handbook for the determination of package net contents?" A simple reply to that question is that, when (in a matter of time) there is considerably more information available on the subject outside of a handbook than there is in a handbook, it is time to prepare a new handbook.

Let us go back in retail history a bit. Here we have an illustration of an old-fashioned food store. Judging by the fixtures and products, and my own recollection as a child, I would say it is representative of the "Roaring Twenties," give or take a decade. Most products were sold from bulk, and weighed, measured, or counted at the time of sale. If you wanted to purchase a pound of navy beans, the retailer would weigh out a pound of beans on his scale. There were a few packaged items, but not many. All meats were cut and weighed at the time of sale. Milk was sold in bottles-a measure container. Even motor oil at the gasoline stations was measured and sold in lubricating oil bottles.

Then along came the self-service stores with prepackaged products and even prepackaged meats. That is when weights and measures became interested in package checking. The interest was primarily centered on the prepackaged meat and dairy counters with their random packed meats and cheeses and prepackaged milk products. This was the basis for the development of Handbook 67, published in 1959. Many other products were also put up in package form; the handbook, however, was primarily directed toward the prepackaged meat and produce counter and conventional standard-pack products labeled by weight and volume.

Meanwhile, the packaging of products has expanded in all directions. In hardware-it is difficult to buy nails or screws in bulk anymore. In the pharmacy the prescription scales and measures are rapidly becoming collector's items. We have had the stone age, the bronze age, the iron age, and now we are well into the packaging age. We have seen the Universal Product Code on so many items, who knows where it will appear next?

Handbook 67 was a good start in checking the products of automated packaging, in the same manner as the Model T Ford was a good start in the mass production of automobiles. Just how many of 
you would be content with a Model T Ford today? Would you prefer a car you start by cranking with a hand crank, ventilate and aircondition by dropping the celluloid windows, heat with a bucket of hot coals, and climb a hill by backing up-compared to what you have today? Incidentally, they say that at times the Model $\mathrm{T}$ almost appeared human-especially when it would pin you up against the garage wall while you were starting it.

The new handbook, like the new car, includes considerably more and does considerably more for you. It is important to understand that the basic principles of Handbook 67 are still an integral part of the new package inspection handbook just as the basic principles of the Model T are still a part of the modern automobile. The "heart" of the automobile is still the basic fuel-driven internal combustion engine.

The "heart" of package checking, whether it is Handbook 67 or the new package checking handbook, is contained in the fundamental principles set forth in Section 12.1.1. of the Model State Packaging and Labeling Regulation which states that:

"variations should not be permitted to such an extent that the average of the quantities in the packages of a particular commodity, or a lot of the commodity that is kept, offered, or exposed for sale, or sold, is below the quantity stated and no unreasonable shortage in any package shall be permitted."

The first part is the "average concept" which in plain everyday language states that the average quantity of a lot, shipment, or delivery must equal or exceed the labeled weight. The second part is the basis for maximum allowable variations (MAV), also referred to as "unreasonable errors."

You know that there is nothing more frustrating than finding yourself in a strange building that has directions for everything except that room which is of vital interest to you. In the preparation of the new handbook we have tried to anticipate all the needs and vital interests in package testing of the prospective users. We feel that once you become fully acquainted with the handbook you will find it an indispensable tool and reference. The new handbook provides two sampling plans identified as category A and category B.

It has been traditional in package checking in the U.S. to use sampling plans like category B. Such plans have a 50-50 risk of acceptance-failure for lots that average at label weight (and when individual packages fit well within their allowed limits). It splits the risk between the packer and consumer. There is some evidence that category B sampling plans are viewed as risky; some of the jurisdictions that have used them in the past added a safety factor in the form of either a tolerance or loosely designed auditing inspection parameters. The category B sampling plans would make excellent auditing procedures. 
The category A sampling plans are designed for situations where the possible consequences for the packager are of relatively great severity $: 3$, for example, legal action. These plans actually have a confidence limit greater than $95 \%$-closer to $97 \%$. A $97 \%$ confidence limit means that you are $97 \%$ confident that the test results are correct. Because of the high confidence level the category A sampling plans eliminate the need for a safety factor such as has been used with category B sampling plans.

The one thing about the category A procedure that seems to scare a lot of people is the use of the term "standard deviation." I must confess that at one time it had me worried, too. However, the standard deviation calculation using the range method is really quite simple. It is simpler than completing a liquefied-petroleum gas meter report form, or developing tolerance limit tables for taximeter measured courses, or for that matter determining the applicable tolerances in the scale code. I have always had problems with the scale code. The reason why I have problems with it is that I do not work with it. Once you get well acquainted with something that "bugs" you it really becomes quite simple. Do not underestimate your abilities.

While the new handbook will not materially affect the current random pack procedures in use at the meat case, it does provide methods of expediting such procedures so more time can be spent in other areas of packaging.

The new handbook provides tables of maximum allowable variations (MAV) in inch-pound and metric units for packages labeled by weight, volume, length or area, and count. It provides 14 pages of comprehensive information pertaining to test equipment, including specifications, such as:

1. Package checking scales in 5- and 20-pound capacities as well as similar designs in metric;

2. Test weight kits in inch-pound ( $31 \mathrm{lb})$ and metric units $(15 \mathrm{~kg})$, as well as smaller weight kits, and larger test weights (i.e., 25 and $50 \mathrm{lb}$ and 10 and $20 \mathrm{~kg}$ );

3. Volumetric flasks and graduates in inch-pound and metric units; measures range from a $2-\mathrm{fl}$ oz [50-mL] graduate to 1 -gal [5-liter] fläsks;

4. Density cups for volume measurement of viscous products such as caulking compounds;

5. Plastic discs for volume measurement of glassware and disposable cups and containers; 
6. Dead weight dial micrometers for measuring the thickness of polyethylene sheeting;

7. Measuring boards for paper plates and sanitary paper products; and

8. Test equipment for aerosol packaged products.

The new handbook provides many procedures for checking standard pack packages labeled by weight and includes:

1. Conventional packages such as detergents, canned goods, cheese and meat;

2. Frozen foods such as fruits, vegetables, and dinners;

3. Aerosol packaged products such as hair spray, shaving creams and paints;

4. Packages labeled by drained weight such as olives and mushrooms;

5. Separate drained weight procedures for frozen foods, and another procedure for glazed raw seafood and fish; and

6. A detailed substitution weighing procedure for products exceeding the capacity of package checking scales.

A section is also devoted to random pack packages labeled by weight. The meat and dairy counters are the principal sources of random packages.

There are procedures for standard pack products labeled by volume:

1. Products such as milk, cooking oils, juices, and beverages;

2. Paint, varnish, and lacquer products (These procedures also have their own auditing procedures.);

3. Viscous products such as caulking compounds, pastes, glues, etc.;

4. Particulate materials sold by dry measure, as well as peat moss and containers labeled by volume.

Included also are procedures for:

1. Variable tare: Packages where the variation in tare weight may be greater than "normal", such as aerosol packaged products or products packed in glass; 
2. Packages labeled by count such as disposable cups and plates, plastic bags, and stationery;

3. Packages labeled by linear or area measure such as waxed paper, gift wrap, roofing shingles, and floor tile; and

4. Polyethylene sheeting packaged in rolls or cut sizes.

Other features incorporated into the handbook include:

1. A new report form and work sheet that have been developed to lead you through the test procedure.

2. Decision charts that outline a procedure in a flow-diagram style.

3. A complete listing of all references cited in the handbook for those desiring more background information.

Finally, there is also an appendix containing:

1. Definitions-no handbook is complete without definitions for terminology employed. There are over 60 definitions.

2. Package Net Contents Regulations-This section includes the NCWM model and Federal agency regulations.

3. Random Sample Selection Discussions-Several methods are proposed.

4. Random Number Tables-These tables are provided to expedite random sample selection. They are not, however, the only approach to random number generation.

5. Average Range Calculation-This section is devoted to a simple approach to standard deviation calculation.

6. Certain Equipment Tolerances-This section is devoted to tolerances for field standard weights and measures.

We are also planning to develop training materials and to hold regional training seminars geared to explain the use of the new package inspection procedures. Any of you who have participated in any of our regional seminars know that the subject will be thoroughly covered.

Abraham Lincoln is quoted as saying that "The legitimate object of government is to do for a community of people whatever they need 
to have done, but cannot do at all, or cannot do for themselves, in their separate and individual capacities."

A noted engineer and administrator, Vannevar Bush, once said "If men are to accomplish together anything useful, they must above all, be able to understand one another. That is the basic reason for a National Bureau of Standards."

The National Bureau of Standards through the Office of Weights and Measures is seeking to promote such an understanding through handbooks and publications such as the new package inspection handbook. These are standards to which all concerned can repair. 


\section{"EQUITY ON THE MOVE"}

Address by KENDRICK J. Simila, Administrator, Weights and Measures Division, Department of Agriculture, State of Oregon

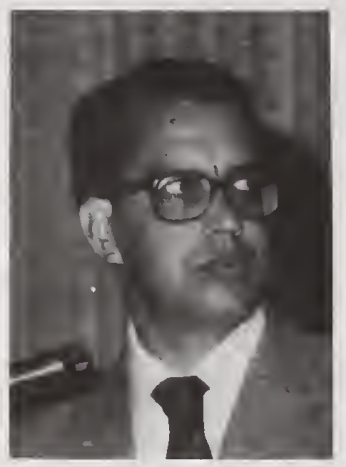

Conference Members, Associates, Advisory Members, Distinguished Visitors and Guests.

Truly the past 12 months have witnessed many changes. In July, 1978, few Americans ever heard or thought about Iran, gas lines, DC-10's or thermostat settings. We were conscious, perhaps, of the California tax revolt and of paying $62.9 \notin$ per gallon for regular gasoline. Events since that time have demonstrated how dynamic the cultural, economic and political fabric of our society can be. Our perceptions have changed. Our collective consciousness has been raised in many areas. Movement has taken place on many fronts, including the economic sector where quantity measurements occur millions of times daily.

As described in the announcement booklet for this conference, our theme "Equity on the Move", was chosen to reflect the dynamic conditions that prevail in our nation's weights and measures system. Changes affecting measurement accuracy and fairness in the marketplace are resulting from actions taken by the Federal, State, and local government and by industries and businesses which serve the public. Weights and Measures officials are facing serious challenges to increase protection of buyers and sellers from inequities in commercial transactions; to expand into new areas of measurement activity; to improve the efficiency of their operation; and to maintain a high quality of service even though their budgets are being trimmed and resources are limited.

Nevertheless, we are collectively finding it possible to move equity forward, when, through the National Conference, actions are taken such as:

1) Adopting (1957) a Handbook 44 Scale Code user requirement (UR.4.4.) that bans multiple draft or axle weighing of motor vehicles for commercial purposes;

2) Adopting (1973) a Handbook 44 General Code provision (in GUR.4.1.) that enables an inspector to reject devices found within tolerance but predominantly in a direction favorable to the device owner or operator; 
3) Adopting (1977) a Model State Method of Sale of Commodities Regulation Section (1.11) that provides minimum standards for identifying to the purchaser what they are receiving when buying meat by carcass, side or primal cut;

4) Adopting (1979) criteria against which our own state and local weights and measures agencies and programs can be objectively evaluated, as a basis for improving and upgrading them.

These are just a few examples of how our actions during the week of the National Conference assist equity to be on the move.

It is not sufficient, however, for us as state and local weights and measures officials who comprise the ACTIVE MEMBERSHIP of the National Conference, to assist the process of moving equity forward just one week each year during this annual meeting. More important to the overall success of our efforts is what we do for equity during the 51 weeks each year when the NCWM is not in session. Let me illustrate this point by mentioning three areas where we can observe wide ranges of behavior in the ACTIVE MEMBERSHIP, after the annual NCWM meeting adjourns each July.

AREA ONE is the behavior of ACTIVE MEMBERS with respect to Legally Adopting in their jurisdiction the "Products" (that can be given such official sanction) of the NCWM. Recall now, these NCWM products are in four categories:

1. Model state laws and regulations

2. Device technical requirements (Handbook 44) and test procedures Handbook 112, and Handbook 67

3. Educational and administrative programs to assist weights and measures officials

4. Liaison efforts with other groups (Federal agencies, OIML, etc.)

Certainly the Model State Weights \& Measures Law, the Model Regulations, and Handbook 44 can be given such official sanction. Some of the other products of NBS-OWM programs that are NCWM endorsed may not be appropriate for legislative or executive sanction (such as the "EPO's", Lab Auditing Program, Handbook 67, or the "Home Study Program") but may be adopted in the context of a Division policy or other appropriate recognizing mechanism.

Successful "behavior" by ACTIVE MEMBERS in this area ("legal adoption") is not easy. It involves many variables often beyond our direct control. Getting a state legislature to modify the state's weights 
and measures law each year or every other year is difficult ... sometimes next to impossible. In most cases it means a massive selling job first . . . in our parent agency (often through 3 or 4 levels of review) even before it gets to the legislature. Legislative and executive agency philosophies on who should initiate such law changes and how frequently vary widely, both around the U.S. and even from session to session in one state.

The updating or adoption of the NCWM Model State Regulations (Packaging and Labeling, Method of Sale, Registration of Servicemen, and/or Unit Pricing, etc.) and Device Technical Requirements (Handbook 44) likewise is not easy. In many cases, however, this can be done through agency rule-making without involving a legislative body. In a limited number of jurisdictions where automatic adoption of technical requirements by reference (with a "latest edition" or an "including additions or supplements thereto" clause) is possible, at least the problem of legally recognizing Handbook 44 changes does not exist. To change regulations in accordance with a state's Administrative Procedures Act, hold public hearings, etc. does require sustained, determined efforts.

AREA TWO is the behavior of ACTIVE MEMBERS with respect to implementing the NCWM model state laws, regulations and Handbook requirements to the extent a jurisdiction has succeeded in adopting them. Behavior that is successful in terms of adopting NCWM "products" can be partially or completely nullified if subsequent follow-througi and enforcement are neglected or ignored. A number of factors can coniribute to poor results by active members in implementation, incluaing:

1) An inadequate Weights \& Measures staff training and updating program (need to communicate new requirements and educate staff)

2) Lack of supervision, ("old dogs" reject new tricks)

3) Provincialism (selectively enforcing or applying requirements)

4) Politics (being forced to deviate from adopted requirements)

5) Insufficient resources (manpower, equipment, etc.)

Some of the above we can combat and overcome, some we must endure and some we have to outlast.

Again, the results of "behavior" in this area by ACTIVE MEMBERS of the Conference, although less measurable, are still observable. Our actions in implementing the model laws, regulations and requirements as we have adopted them speak louder (especially to 
industry) than our professed intentions to "be like" (or to do things like) the NCWM recommends.

The THIRD AREA of observable behavior of the ACTIVE MEMBERSHIP of the Conference THROUGHOUT the year is the area of accountability-accountability not only to the management of our parent state or local agency if we are part of one, but also to our constituents. Being accountable to "Constituents" or those who pay for our services means being accountable not only to the public or consumers, but to businesses as well, since they too pay state or local income, sales, and property taxes (and in some cases license fces) which support our budgets. Our observable behavior is less than accountable if we do not (or feel no need to) provide an uiderstandable answer to anyone with a legitimate request or question about our programs such as:

1) What is this particular scale inspection requirement or policy based on?

2) What is the level of funding for packaged products inspections and what degree of compliance is being achieved?, or

3) Where are bulk petroleum meter examinations least effective?

Behavior that isolates us from being accountable may prc $r i d e$ short range relief from unpleasant or difficult situations, but at the $c_{i}$ st of much needed program support in the long run, . . . support that is very difficult to regain.

How, then, has the behavior of the active membership in the three areas of: 1 Legal adoption of NCWM products, 2) Implementation and enforcement, and 3) Accountability to constituents, assisted or defeated the mutual goals and purposes of the Conference to move equity forward?

Let me cite some examples.

Example 1-A SUCCESS-Our mutual goals of developing a consensus, promoting uniform requirements and fostering cooperation (among Weights and Measures, business and consumers) were achieved in package quantity work with respect to:

1. "the average of the lot concept" and

2. "reasonable variations."

That is for the most part active members have through their behavior caused these concepts to be 
A. legally adopted

B. implemented and enforced

C. accounted for (explained and defended)

Example 2-A STANDOFF OR DRAW-Our mutual goals were partially realized and partially defeated in the late 1960 's when Congress enacted the "Fair Packaging and Labeling Act". Some of the problems (e.g., preemption; vague Federal standards) we have faced and are currently facing in package quantity control directly relate to wording or powers granted in this act. Suffice it to say, a failure of a sufficient number of active members to have adopted the existing NCWM Model Packaging \& Labeling Requirements in existence by 1966 , was behavior that has partially defeated our mutual goals.

Example 3-A MODERATE FAILURE-Not in legal adoption of an NCWM "product" ... that has been done ... but in implementation and enforcement. The drafting into the recent Grain Standards Act regulations by FGIS, of certain specifications (minimum divisions), tolerances ( $1 / 2$ Handbook 44$)$ and testing procedures (Hopper Scale Corner testing) inconsistent with the NCWM's Handbook 44 requirements for grain weighing equipment (including truck scales) is directly attributable to actual implementation and enforcement practices (behavior) in many jurisdictions by active members being different than what was legally adopted in those jurisdictions.

The above are just three examples of how the behavior of the active membership during the 51 weeks between National Conferences has had a direct cumulative effect not only on the member's own jurisdiction, but on moving equity forward for the weights \& measures active membership as a whole.

I could cite other examples . . . one coming down the road for which it is too early to predict the outcome is national device type approval. If the active membership cannot reach a consensus, and formulate and implement a workable system, Congress in its 535-member wisdom will provide one for us eventually. The need is clearly there.

Let me shift gears and conclude my remarks by indicating that I stand before you today harboring two different emotional states, both enjoyable. As Administrator of the Weights and Measures Division, Oregon Department of Agriculture, I am pleased that we are able to be your hosts this week. As Chairman of this 64th Conference, I am 
honored that the Membership elected me to represent them the past year. Both sets of responsibilities I have not taken lightly.

Counting this Conference I will have attended 10 meetings, hearings, seminars, or conferences in my role as NCWM Chairman. These ten events total 33 days away from my home and office. I am grateful to my family and the Oregon Department of Agriculture for their tolerant understanding of these absences from Salem. Certainly this year I have not experienced the slow passage of time that our 5 year old son, Mark, encountered on our recent ten-day vacation trip to Canada by car. The first 2 days went pretty well. By the 3 rd day, however, my wife Pat and I were continually responding to Mark's inquiries of "Are we almost there?" or, "How much longer is it?" We thought we had this problem solved when we forbad the asking of those two nagging questions. For a long time after that Mark was silent. He finally could stand it no longer, but avoiding the forbidden language he quietly inquired, "Will I be alive when we get there?"

Equity is on the move. Will we be alive when it gets there? That I don't know. I do know that for the rest of this week, in July, in Portland you have the opportunity to guide it in the responsible the progressive ... direction. 


\section{EQUITY BEYOND THE MARKETPLACE}

Presented by Donald R. Johnson, Deputy Director for Programs, National Measurement Laboratory, National Bureau of Standards

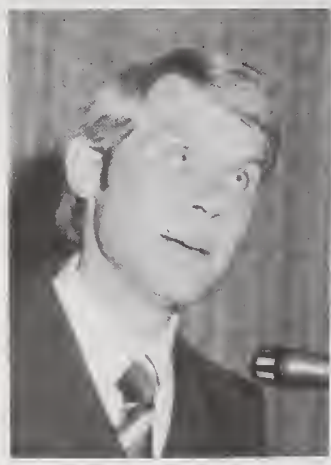

It is a pleasure for me to represent $\mathrm{Dr}$. Ambler, your Conference President, on the program here today. Dr. Ambler is involved in a planning meeting at NBS and regrets that he is not able to be here in Portland with you. He sends his greetings and best wishes for a successful meeting. I appreciate very much the opportunity to meet many of you for the first time and to set this Conference in action.

As we all know success always seems to generate new demands. Therefore this Conference should not be surprised that it faces a wide variety of new challenges. Equity in the marketplace has been a very successful experience in this country. That success is a tribute to you and to all those who have participated in this Conference for the past 74 years. It is because of your efforts that the American public can make millions of transactions in a very complex retail marketplace with confidence. Nevertheless, as Ken Simila has indicated, it is a challenge to keep equity on the move. And indeed equity is moving. It is moving beyond today's retail marketplace and presenting new measurement challenges. This afternoon I will describe one of the mechanisms that we at NBS have found to be particularly effective in meeting these challenges.

Let me begin by focusing on the marketplace itself. First, let me suggest a definition of a marketplace as a point of contact between two parties where a decision is made. Of course, traditionally we think of this in terms of the retail market where buyer and seller meet. Here a decision results in money changing hands. But, decisions which affect equity in the market are actually made in a much larger arena beyond the retail marketplace.

What do I mean by equity beyond today's retail marketplace? Let me try to explain. Step back if you will from the sales arena to the point where products are being made-to the point where the quality of the product is being determined-where precise amounts of ingredients are blended-where parts are accurately welded together or assembled. At this point, quality control of the product is of importance. Equity here, as anywhere, means fairness; it is the assurance to both the producer and consumer that the future performance of the product will match expectations. This assurance can only be based on accurate and reliable measurements. 
The role of measurement in quality assurance is well illustrated with a local example. The ESCO Corporation here in Portland is a producer of high alloy specialty steels. These special steels require precise amounts of certain metals such as chromium and nickel in order to achieve their desired properties. Steels are of course produced in discrete batches. Toward the end of each batch process a sample of the molten metal is dipped out and sent to a quality control laboratory for analysis. In this laboratory, measurements must be performed very rapidly while the bulk of the metal is held in a molten state. Adjustments to the composition of the steel can then be made to meet the desired specifications before the metal is allowed to cool and harden.

The key to equity in this example is, of course, the reliable determination of the chemical composition of the sample in the laboratory. In the steel industry this determination is made via a direct comparison of the composition of the unknown steel sample with the composition of a standardized reference sample following an agreed upon test procedure. For specialty steels it is clear why direct analysis of composition is required. But, special alloys represent only a small component of the steel market and quality control is equally important for the large volume, low alloy steels used for auto bodies, girders and pipelines. NBS has worked on problems of quality control with the steel industry for over 75 years and we have found that standard reference materials are an effective way to transfer our measurement technology to the industry. We now offer over 100 different steel reference materials covering a wide variety of important compositions.

As I indicated earlier it must be remembered that these standard reference materials by themselves do not make a complete measurement system. They must be used with a standardized measurement procedure which spells out how the comparison of the unknown sample with the reference sample should be carried out. In the case of steel, these procedures reflect industry consensus and are developed by voluntary standards organizations such as the American Society for Testing and Materials. Industry consensus is also important here for another reason since comparative tests like these are used by purchasers of steel for acceptance testing. Acceptance testing of course leads to a second decision point in the steel industry where equity issues are raised. Penalties are sometimes written into contracts for small deviations from the specified quality and acceptance tests are the agreed upon means of assessing these deviations.

Measurements impact the quality of products in much more subtle ways in other segments of our economy. Take the agricultural food industry, for example, where questions have recently been raised about contamination of fruits and vegetables grown near sources of urban pollution. Leafy vegetables, such as lettuce and spinach, grown 
near industrial plants or highways are reported to acquire potentially harmful surface contaminations which are difficult to remove by washing. Toxic contaminates such as heavy metals are also found in the soil and may eventually be absorbed into the plant tissue itself. The quantitative determination of the extent of this contamination requires accurate data on the trace element composition of fruits and vegetables grown at various locations in both clean and polluted environments. The problem is further complicated by the fact that certain substances, such as chromium, are known to be toxic at one level but are essential nutrients at lower levels. Thus accurate analysis of the plant or food product is critical. In response to this and other related measurement challenges NBS has developed a series of biological reference materials. One particular material offered as part of this series consists of dried and pulverized spinach which has been carefully analyzed for trace elements. The spinach samples are used to calibrate analytical instruments that are in turn used for studying the effects of the environment on the food products mentioned above.

Let me now turn your attention to a different marketplace where personal services are bought and sold; in particular I would like to focus on the health care industry where medical decisions are made based on the results of clinical laboratory tests. Nearly 4 billion individual measurements are made annually in conjunction with these tests in hospitals and clinical laboratories throughout the country. The estimated cost to the consumer is $\$ 8$ billion. The accuracy of such measurements is of course of paramount importance to both the physicians and their patients since the analytical results form the basis for an evaluation of the patient's health. NBS offers over 30 different Standard Reference Materials to clinical chemists to help calibrate their instruments and thus improve the accuracy of these critical measurements. These same Standard Reference Materials along with companion reference methods help provide the basis for regulation by the Food and Drug Administration (FDA), as well as for proficiency testing of clinical laboratories.

Perhaps a very specific example will help to bring the importance of proper measurement into perspective. There are approximately 2 million victims of epilepsy in the U.S. at the present time. In most cases the epilepsy can be fairly well controlled with drugs. However, in the past the accuracy of laboratory tests for drug dosage control was extremely poor and many doctors chose to simply rely on patient reaction to determine the appropriate drug level. In the fall of 1978 NBS issued a new anti-epilepsy drug SRM which consists of a set of 4 vials of freeze-dried human serum. Three of the vials contain 4 important anti-epilepsy drugs at different concentration levels: toxic, therapeutic, and sub-therapeutic. The 4 th vial is a serum blank. With this set of reference materials a clinical laboratory is able to analyze a sample of a patient's blood with assured accuracy and thus assist 
the physician in establishing the exact dose required for proper therapy. Thus the health care received by the patient can be optimized with minimal side effects.

There is still another decision point well beyond the marketplace where the question of equity is raised. That is the point where regulatory decisions are made. A host of new laws have been enacted in the past decade that affect environmental regulation. By far the most significant Federal laws are the Clean Air Act of 1969, the Federal Water Pollution Control Act of 1972 and the Occupational Health and Safety Act. The economic impact of these laws is enormous. The Council on Environmental Quality estimates that the nation will spend $\$ 486$ billion in the period between 1975 and 1981 just to reach the environmental objectives alone. An additional $\$ 25$ to $\$ 30$ billion in capital costs will be associated with occupational health and safety for the same period. As you well know, the regulatory measurement system associated with these laws is also very large. It not only includes Federal agencies and U.S. industry, but State and local governments as well. Standard Reference Materials can play a key role here in helping to achieve equity between the regulators and those who are being regulated. Over 80 NBS SRM's are currently being used to assure the accuracy and compatibility of environmental measurements.

In the area of automobile pollution monitoring and mileage testing alone 36 NBS gas SRM's are required to place the measurements on a firm basis. In emission testing laboratories all over the country exhaust gases are collected and analyzed to determine the amount of each pollutant gas emitted per vehicle mile. The results of these tests are tremendously important. First, they are used to determine whether the vehicle meets the pollution emission standards required by the Clean Air Act. But that is not the only application. They are also used in an EPA formula to calculate the fuel economy value-or the gas mileage-for a particular make of automobile. These are the fuel economy estimates you see posted on all new car windows. They are required by law so that the consumer has an accurate basis for comparative shopping. There is a further fuel economy regulation included in the Energy Policy and Conservation Act of 1975. It requires that each car manufacturer achieve a certain weighted, average fuel economy for his total product line in a given model year. If the manufacturer's average is short of the standard, the law prescribes a penalty of $\$ 5.00$ for each 0.1 mile per gallon his average falls below the standard times the total number of cars produced in that model year. For a company like Ford that is a potential penalty of about $\$ 15$ million for each tenth of a mile per gallon. From this example alone, you can begin to appreciate the fact that accurate and reliable measurements are essential to equitable regulatory decisions. NBS SRM's are the primary calibration standards for these exhaust gas measurements. 
Regulatory decisions are, of course, still being made and significant measurement problems remain. For example, urban dust is known to be a harmful pollutant but it has not been characterized well enough to establish a sound scientific basis for control. Over a twoyear period NBS collected 50 pounds of dust from the air over Saint Louis, Missouri. After careful blending to insure homogeneous samples, the composition of the material was analyzed and the levels of certain critical heavy metals in the dust such as lead, iron, uranium, cadmium, chromium, copper and zinc were established. The resulting urban dust SRM is now being used as a research tool to develop new analytical techniques in anticipation of regulations on respirable dust. In fact, lead is already being regulated and the urban dust SRM is providing the measurement assurance for equitable compliance.

New measurement challenges are facing us even in areas much closer to the marketplace. Waste disposal for large urban centers is rapidly becoming a serious problem, a problem where measurement technology will play a significant role. The City of San Francisco serves as an excellent example. Sanitary landfill sites within close proximity to the city have been impossible to locate. The nearly 2000 tons of solid waste generated each day must be loaded on long-haul vehicles and transported to a landfill located in the city of Mountainview, approximately 30 miles to the south of San Francisco. Transportation costs are rapidly rising and the Mountainview Site has limited capacity. The next suitable land fall site will require even longer hauls.

Possibly of more importance in the long term is the fact that we are wasting precious resources with our present disposal techniques. Approximately $70 \%$ of municipal solid waste is usable as a fuel. In addition other precious resources, such as ferrous metals and aluminum, are present in the waste stream in substantial quantities. The technology for recovery of these materials is now available, but serious market barriers exist. Large scale resource recovery facilities are exceedingly expensive. Thus before investments in recovery facilities can be expected, markets for the recovered materials must be assured. In order to assure these markets technical specifications must be developed to classify the recovered products as to quality, uniformity, and use. NBS is already heavily involved in developing reliable measurement techniques to characterize such things as heat and ash content of refuse-derived fuels. Again we expect Standard Reference Materials to play a key role in assuring equity in many aspects of this unique marketplace.

So you see equity appears in many places. Fairness must be achieved at many points of contact where decisions are made. I recognize that many things are needed to achieve equity but certainly an approach based on measurements is a vital component. One measurement mechanism we have found to be successful is built around 
Standard Reference Materials-materials produced in quantity with one or more chemical or physical properties measured and certified by NBS. More than 1000 different SRM's are now available from NBS. The 1979 sales of these materials is expected to reach a total volume of 38,000 units. These will be purchased by 10,000 different laboratories, $25 \%$ of which are to foreign countries. Our highest volume of sales in a single category has traditionally been in industrial quality control. Our fastest growing categories in sales are in the clinical and environmental areas. As you heard, in each of these categories measurement plays a key role in the large arena beyond the marketplace.

Standard Reference Materials are just one of the measurement services that NBS offers to help you develop accurate and reliable measurement capabilities to meet the challenges of the future.

\section{COMMITTEE APPOINTMENTS BY DR. JOHNSON}

In accordance with the Organization and Procedures of the National Conference on Weights and Measures, the Director of the National Bureau of Standards, in his capacity as ex officio President of the Conference, has responsibility for announcing appointments to the four standing committees. It is my privilege in behalf of Dr. Ambler, Director of the National Bureau of Standards, to announce these committee appointments at this time.

We all know how important the work of the various committees is to the orderly and successful accomplishments of the National Conference on Weights and Measures. To the outgoing committee members we give thanks for your valuable contributions to weights and measures technology and administration in the United States. To those new committee members who are taking on this vital responsibility, we offer our best wishes for an enjoyable and rewarding experience.

The appointments to committees are as follows:

\section{Committee on Specifications and Tolerances}

Mr. Sidney A. Colbrook, Program Supervisor of Weights and Measures, Illinois Department of Agriculture, is appointed for a 5-year Term to replace Mr. James R. Bird whose term is expiring.

\section{Committee on Laws and Regulations}

Mr. Wes R. Mossberg, Director of Weights and Measures, Los Angeles County, California, is appointed for a 5-year term to Replace Mr. John T. Bennett whose term is expiring. 
Committee on Education, Administration, and Consumer Affairs

Mr. Joseph L. Swanson, Chief, Weights and Measures Section, Alaska Department of Commerce, is appointed for a 5-year term to replace Mr. Raymond $\mathrm{H}$. Helmick who is no longer employed by the State of Arizona and whose term expired.

Mr. Stan J. Darsey, Chief, Bureau of Weights and Measures, Florida Department of Agriculture and Consumer Services, is appointed for a 4-year term to replace Mr. Walter F. Junkins who is no longer employed by the State of Pennsylvania.

(Note: Both Mr. Swanson and Mr. Darsey were appointed to serve during the 64th Conference by the Chairman to fill the vacancies created during the year by the resignations of Mr. Helmick and Mr. Junkins.)

\section{Committee on Liaison}

Mr. Charles R. Cavagnaro, Deputy Director, United States Office of Consumer Affairs, is appointed for a 5-year term to replace Mrs. Jane S. Wilson whose term is expiring.

\section{Committee on National Measurement Policy and Coordination}

There are no appointments to this committee as the Membership is comprised of the Chairman of each of the four standing committees and the Conference chairman.

Again, Thank you and good luck! 


\section{ASSISTING THE CONFERENCE IN MEETING NEW CHALLENGES IN MEASUREMENT}

\section{Presented by William T. Cavanaugh, Managing Director, American Society for Testing and Materials}

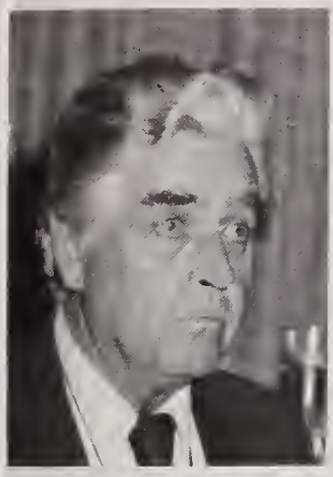

As ASTM continues its task of standards development and maintenance to keep pace with the needs of our nation's marketplace, the evolution of new technology coupled with new public- and private-sector demands have dramatically changed the climate in which standards-writing committees operate. A major factor affecting this change has been the explosion of federal regulatory activity, which has an impact to some degree or another on virtually all areas of technical concern to ASTM committees. Actions taken by an estimated 80 government agencies, which carry a price tag of well over 100 billion dollars, have increased the Code of Federal Regulations to about 70,000 pages. But the significance to ASTM is that the regulatory structure has become an integral part of the marketplace in which ASTM standards are used. ${ }^{1}$

As you are probably aware, the Federal Government is now considering the adoption of a policy on federal participation in and the development and use of voluntary standards which sets forth two basic principles: (1) Federal participation in standards related activities of voluntary bodies provides added incentives and opportunities to establish standards that serve national needs; and, (2) Federal use of voluntary standards, whenever practicable and appropriate, reduces the cost of developing and using standards for procurement and regulatory purposes and thereby serves the public interest. When and if such a federal policy is finally adopted it will move the government and the private sector standards bodies into a closer partnership in the massive and important task of generating needed standards. There are also happenings and new initiatives on the international scene that will impact this Conference and I will mention these a little later. One important aspect of standardization is assuring accurate and reliable measurement. Thus, your Conference theme "equity on the move" is indeed a timely subject.

I raise this concept of a closer partnership between government and private standards bodies in meeting national regulatory and procurement needs because I am convinced that the same needs exist at the state and local levels and I am concerned that major efforts are

\footnotetext{
${ }^{1}$ Paragraph quoted from Editor's comments, page 7, ASTM Standardization News, March 1979.
} 
not underway to promote and accept the same principles of cooperative undertaking to produce needed standards at the state level. In the years that I have come to know the National Conference on Weights and Measures, I have developed a profound respect for your mission and I have followed with great interest the spirit of openness and cooperative give and take through which you arrive at the various outputs of this Conference. ASTM's business is also conducted in an atmosphere of "cooperative give and take" which, I think, is a compliment. Healthy controversy is a sign of vitality and commitment, and to quote an unknown source: "It is better to debate a question without settling it, than to settle it without debate."

Over the years ASTM has provided assistance to the measurement community in many respects and I will cover just a few of these areas with you. In the early 1960's the Federal Trade Commission-an organization whose name we seem to encounter frequently-informed the peat moss industry associations that it intended to formulate industry guidelines for peat moss classification and marketing language. The FTC's problem was with the large variety of weights and volumes of peat moss commonly sold in local stores. The complaints directed to the FTC were also directed to state officials, who expressed their concern in your National Conference. The Conference asked the National Bureau of Standards to develop a model commodity regulation for state use.

These problems were then brought into focus by the peat moss trade associations with a request to ASTM to form a standards-writing committee to straighten things out. These issues were aired at an ASTM meeting and a committee was recommended. This committee was formed with the FTC as one of the 40 participating groups and has produced eight test methods, a sampling plan, and a series of pertinent definitions. Not only have all interests, including yours, been served, but the FTC was satisfied and has not pursued its original plan to issue peat moss guidelines.

Here's another example. Recently octane numbers have appeared on gasoline pumps across the nation, courtesy of the FTC. For the first time, owners of new cars requiring lead-free gasoline found out why their new car performance was lower than that of their former car which used the less expensive leaded gasoline-the octane ratings for the new higher priced lead-free "regular" gasoline are poorer than the octane numbers for the lower priced leaded "regular"!

\section{What are octane numbers? Where do they come from?}

The octane number is a measure of the actual performance of gasoline in a test engine. These engines developed in accordance with ASTM standards are used by the entire petroleum industry to obtain uniform data on gasoline quality. Every gallon of gasoline sold in the 
United States must have as its pedigree a proven relationship to an acceptable octane number measured by the ASTM tests.

How do we know that the pedigree claims are valid?

There is within the ASTM Committee on Petroleum Products, a long-established group called the "National Exchange Group." This group is open to anyone running octane tests. Members include all gasoline suppliers, interested commercial laboratories and state laboratories that have the ASTM test engines. The program is conducted by the U.S. Department of Energy, and before that department came into existence, by the U.S. Bureau of Mines. The program manager circulates a gasoline sample every six months to participants, assembles their test data, and issues evaluated results. Each individual laboratory then has an evaluation of how well that laboratory stands in relation to the others. This voluntary self-checking program assures the public-and the FTC - that the values shown at the pump are indeed correct.

There is, of course, strong economic incentive for the gasoline producer to maintain good laboratory practices. Should his octane number be too high, he would be giving away value not reimbursed at the pump. On the other hand, should his octane number be too low, he could expect one of your state inspectors to impound his product.

Without this kind of program there could be endless debate as to which of the contending parties had in fact been correct.

Naturally the effort required to develop an ASTM standard test and its associated measurements is very large. But so are the benefits. To review them again, the benefits are increased knowledge of the technology, increased understanding of the issues, and increased validity of the results. The importance of this validity arises whenever the results are used in the courts.

There is yet another perception here that is important to you. That is international activities in the standards field and particularly, standards relating to measuring instruments and measurement methods. You have undoubtedly heard of ISO, the Geneva-based voluntary International Organization for Standardization, and IEC-the International Electrotechnical Commission, which is ISO's electrical counterpart. These two organizations are the principal international voluntary standards bodies and have produced more than 4,000 international standards. ISO alone hopes to reach an annual output of 700 to 800 new or revised standards per year by the end of this year. ASTM committees maintain an active interest in ISO and IEC and in the case of 36 ISO committees, the U.S. consensus vote on standards being developed within the working groups are developed within ASTM. The success of the U.S. effort may be measured by the large number of ASTM standards that have formed the basis of ISO stand- 
ards. This has been particularly true in such activities as steel, plastics, petroleum, coal, rubber, and water quality. In just a minute I will explain why our international standards connections are becoming even more important.

There is another international organization concerned with measurements whose influence is growing. This is the Paris-based International Organization of Legal Metrology with which you are familiar because of its activities in developing model laws and regulations for measuring instruments that impact upon Handbook-44 and other outputs of this National Conference. OIML's mission as an intergovernmental organization is very similar to your own-to achieve uniformity of mandatory requirements for measuring instruments and methods among its 44 member nations. Recently, ASTM has been working with Art McCoubrey and Dave Edgerly from NBS, who manage the U.S. program in OIML, to outline specific technical activities within OIML and ASTM where there are common interests. There is little question in my mind that the ASTM technical committee can be as effective for the development of U.S. inputs to OIML as they have been in ISO, which is a matter that will eventually be of some importance to you.

Now you may be wondering why so much emphasis on the international arena and further, how international standards impact upon what is going on in this Conference or what you are doing in your state or city. Well, international standards are needed to support the world's economy and this country must ensure that standards that are adopted internationally do not inhibit export opportunities. You have probably heard of or recently read about the package of nine international agreements under the General Agreement on Tariffs and Trade (GATT) that were signed in Geneva in April by the United States and 22 of our major trading partners. These agreements which are now before the Congress for approval are intended primarily to ensure that the international trading system is both fair and open.

Among the nine agreements is a code for the prevention of technical barriers to trade, more commonly referred to as the GATT Standards Code. The bill (HR4537) to implement the standards code is now before the Congress. Basically, it specifies that no federal agency may engage in a standards-related activity that creates unnecessary obstacles to the foreign commerce of the United States. Further, federal agencies, in developing standards of their own, shall take into consideration international standards and shall, if appropriate, base their standards on international standards. The bill also says, for example, that as with federal agencies it is the desire of the Congress that no state agency and no private person should engage in standards-related activities that create unnecessary obstacles to U.S. foreign commerce and that states and private organizations (ASTM) should use international standards as the basis for the standards we 
develop. The bill covers the activities of ASTM and, as I see it, the activities of this Conference as regards Handbook-44 and, perhaps, other Conference model codes and test methods. What this new legislation will mean is that we will have to be sure that the standards ASTM develops and that this Conference develops do not inhibit U.S. products from competing in foreign markets. I am sure that you will be hearing more about this legislation as time goes on. The point I want to make is that insofar as the outputs of this Conference affect intrastate and interstate commerce you must now also consider the effect of your actions on foreign commerce.

Now, finally, I should point out that your measurement concerns are not entirely new to ASTM Committees. On the ASTM Books are standard methods for testing laboratory balances, specifications for laboratory precision mass standards, specifications for volumetric flasks, specifications for a variety of thermometers, and calibration procedures for various thermocouples. Additionally, numerous specifications for analytical equipment have been published. Many of these have been developed in the ASTM "service" committees. This is a feature of ASTM worth another moment here.

Within the ASTM system there are quite a number of specialty "service" committees, which lend their expertise to our product and materials standard-writing committees. These service committees include experts on statistical problems, on setting up interlaboratory test programs, on using specific kinds of instruments for chemical, physical, and electrical tests, even experts on computerized laboratory systems. All function as consultants to other ASTM committees, and all contribute to the integrity of the ASTM system.

The consensus process used by ASTM has great value and has enhanced the field of measurement technology by producing standards which enjoy general acceptability. Such standards extend into almost every segment of the U.S. economy. My review has tried to show that the ASTM forum when applied to matters as earthy as peat moss or as volatile as gasoline can achieve results credible enough to resolve government concerns without the need of costly regulation. It has been shown that the influence of the concerned citizen working in ASTM can extend far beyond the borders of the United States. But most important, it shows that equity is a common goal shared and sought by both your Conference and ASTM.

Unquestionably, ASTM can do more to assist the weights and measures community and I will take a few minutes to mention some of the possibilities in this regard. Your Conference works very effectively to produce technical specifications and tolerances for commercial weighing and measuring instruments which you incorporate into Handbook-44 and adopt as regulations within the states. Indeed, the requirements laid down in Handbook-44 are the principal means for achieving uniformity of regulations covering commercial measuring 
devices among the 50 states. In enforcing the requirements of Handbook-44 it is essential to have available standard test methods and procedures for determining compliance with Handbook-44. ASTM has worked successfully with many groups over the years to produce test methods for a wide variety of materials and products. You might consider how ASTM could be of service to the National Conference in this connection.

The scientific and measurement instrument industry is undergoing a vast electronics revolution brought about by microprocessors and solid state memory units. Measurements of greater accuracy are obtained with greater speed than formerly, and exceptional events are easily noted, remembered, and displayed on command. Department of Commerce industry predictions are that microprocessors and the resulting so-called "smart" generation of instruments will continue to penetrate the measuring device industry for at least 6 or 7 more years. The result is a much more sophisticated family of measuring devices. The weights and measures community and the National Conference will need to keep pace with these new technologies through appropriate revisions of Handbook-44 and, perhaps, of other Conference model laws and regulations. It seems to me that ASTM might be of service by providing the forum through which specialized measurement committees could be established to provide information and data on which the Conference might base recommended answers to specific measurement problems.

In conclusion, ASTM is prepared to assist the Conference in meeting new challenges in measurement. All you have to do is ask. 


\section{NATIONAL CONFERENCE OF STANDARDS LABORATORIES IT'S ROLES AND MISSION}

\section{Presented by Ronald E. KIDD, Microwave Associates, Standards and Calibration Laboratories}

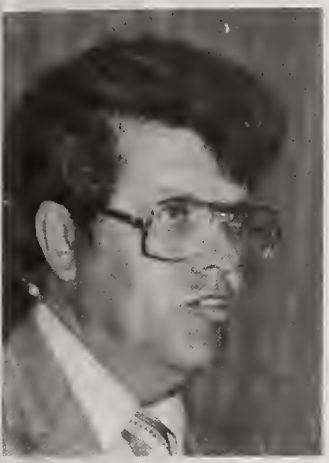

As President of the National Conference of Standards Laboratories, I appreciate the invitation to speak at this 64 th Annual National Conference on Weights and Measures. I welcome this opportunity to very briefly describe to you the NCSL. I am hopeful that some of you-if not all of you-will choose to participate in some manner in NCSL's activities.

The National Conference of Standards Laboratories is a non-profit management organization of some 400 standards laboratories, calibration laboratories, organizations that maintain such laboratories, or other organizations having related interests in metrology, the science of accurate measurement.

Membership in NCSL includes representatives from every sector of the measurement community. It includes laboratories from academic, scientific, industrial, commercial, and governmental organizations.

Member organizations vary widely in size; measurement laboratories consisting of a couple of persons to a couple of hundred persons. They have one common interest, metrology.

The genesis of the National Corference of Standards Laboratories was in a suggestion by Harvey Lance, a National Bureau of Standards employee, to the effect that some sort of association of standards laboratories could help in solving their common problems. He made that suggestion while presenting a paper at a conference on standards of electromagnetic measurement at the NBS Boulder laboratories in June 1960. It was an idea whose time had come. During the discussion that followed his paper, several attendees suggested a meeting to explore the formation of such an organization. The next morning 132 people showed up for an impromptu meeting on the proposal. They chose from their number a steering committee; and the following year, on September 15, 1961, the National Conference of Standards Laboratories was chartered-essentially in its present form.

The National Conference of Standards Laboratories has only one sponsor: The National Bureau of Standards of the United States. The Director of the NBS designated one person to represent the bureau in the NCSL organization. That person is called the Sponsors Delegate; and he has traditionally been someone from the upper echelon 
of Bureau management who effectively acts as liaison agent between the nation's principal standards laboratory and the working laboratories of commerce, industry, academia, the Department of Defense, and other governmental organizations.

The current Sponsor's Delegate is Dr. Bascom W. Birmingham, Director of the NBS Laboratories in Boulder, Colorado. NCSL members are a major constituency of users of NBS services and can significantly influence those services NBS will be offering a few years hence. Dr. Birmingham has been doing an outstanding job of providing effective opportunities to effectuate said influence. One method is a direct annual meeting of NCSL officers with Dr. Ernest Ambler, Director of NBS. This year's meeting, held in April, covered several topics which I will cover very briefly. The major topics were education and training, Measurement Assurance Programs (the technique of providing calibration laboratory management with methods for evaluating and/or improving the quality of measurements performed by their laboratories); and the rapid growth of Automatic Test Equipment and the Computer industry. It is said that if the automobile industry had experienced the same rate of technological change as the computer industry, a Rolls Royce now would cost fifty cents and get sixteen million miles per gallon. A meeting with NBS staff in Gaithersburg, Maryland led to a meeting with Albert Tholen and the invitation to speak about NCSL at this conference.

A distinctive provision of NCSL bylaws provides that NCSL members are laboratories, organizations, or companies-not individuals. Each member laboratory, organization or company then selects someone from within its organization to represent it as a member of NCSL. This person is called a "Member Delegate."

Member Delegates, in turn, elect from their ranks a Board of Directors to manage the National Conference of Standards Laboratories. The Board of Directors comprises the officers of NCSL-namely, the President, Executive Vice-President, Secretary, Treasurer, Immediate Past President, four Vice-Presidents, five Directors, and the Sponsor Delegate.

The high point of the National Conference of Standards Laboratories operation is its annual meeting, held alternately at the NBS laboratories in Boulder, Colorado, and Gaithersburg, Maryland. This meeting is traditionally held in the fall of the year, usually October. This year's conference will be held in Boulder, Colorado on October 15,16 , and 17, 1979. The technical sessions of that meeting are often workshops, and they are open not only to people from member laboratories but also to anyone else who is interested in furthering the art and science of metrology. Though the annual meeting is the highlight of the NCSL organization, it is far from being the only function of the organization. It may not even be the most important function. 
The grass-roots strength of NCSL is in its regional organizations. There are eight regions within the United States plus an international region. Each region has a coordinator appointed by the Board of Directors. Member delegates within the regions are encouraged to meet at least twice each year-more often if they wish. These meetings can be particularly effective not only in solving common problems of a regional nature, but in identifying the larger needs of the entire membership. I know that several of the attendees at this conference have participated at our regional meetings near their companies' location. I invite you all to attend one of these meetings.

On the national scale, much of the important work of the NCSL is done by standing and ad hoc committees. These committees, appointed by the Board of Directors, concentrate on finding solutions to problems confronting member laboratories. Committees currently operating in NCSL are: National Measurement Requirements, Laboratory Evaluating, Biomedical and Pharmaceutical Metrology, Calibration Systems Management, Measurement Assurance, Product Design and Specifications, Educational and Training, and Recommended Practices.

Other standing committees of NCSL take care of continuing housekeeping and communications responsibilities. These committees currently handle Meetings and Programs, Honors and Awards, Newsletter and Information Directory.

NCSL coordinates its activities with those of other organizations through liaison with those groups. Organizations that currently have liaison delegates are: Government-Industry Data Exchange Program Metrology Committee, the Measurement Science Conference, the International Organization of Legal Metrology, the Precision Measurement Association, the American Society of Quality Control, the Instrument Society of America, the American Association for Laboratory Accreditation, and the American Society for Testing and Materials. In fact, I serve on two ASTM committees (E-36 Criteria Evaluation of Test and/or inspection Agencies, and E-46 Quality Systems). I was voted by the NCSL Board of Directors at the last meeting to be that liaison delegate to ASTM. I welcome this opportunity to personally meet Mr. Cavanaugh, Managing Director of ASTM, at this conference.

When asked, "What are the advantages of membership in NCSL?" members most often identify the NCSL Newsletter. It is a valuable compilation of articles, reports, and comment that reflect the thinking and that highlight the interests of the entire measurement community.

Recommended practices found in the NCSL members' "Information Manual" are also mentioned. Currently recommended practices cover: "Evaluation of Measurement Control Systems and Calibration Lab- 
oratories", "Established and Adjustment of Calibration Intervals", "Preparation of Calibration Procedures", and "Calibration Systems Specification."

The NCSL Directory of Standards Laboratories is also a popular publication with both members and non-members. The directory lists more than 110 standards laboratories, indicates their calibration capabilities, and gives a mailing address and telephone number. There is even a listing by zip code so you can quickly locate those laboratories in your vicinity.

Another membership advantage often cited is the NCSL Training Aids Library. This is a collection of video tapes, audio tapes, and 35 $\mathrm{mm}$ slides that is available to members at no charge. Less easily identified are the less tangible advantages in NCSL: the good ideas you got from the fellow member at the last Regional Meeting, the opportunity to compare and contrast your laboratory's operation with others-both small and large. Or perhaps it is just the satisfaction of knowing that you are contributing to the overall effectiveness of the National Measurement System. Or maybe it is the camaraderie that is found among people who understand and appreciate the satisfaction of precision measurement. Maybe it isn't easy to identify the most important reason for joining NCSL; but taken altogether, NCSL membership is not only a bargain in today's world-it is also one of the most cost-effective investments any organization can make if accurate measurements are important in achieving the goals of the organization.

It is easy to join NCSL. I have brought two hundred green covered NCSL brochures which have descriptions of the organization and applications on the back. They are available on the rear tables and describe the process. Please take one with you.

I hope that this brief review of the National Conference of Standards Laboratories Roles and Mission has been of interest to the members of this Conference on Weights and Measures; hopefully, if you express an interest, NCSL can provide the needed services. 


\section{TRADITION IN TRANSITION}

Presented by Albert D. Tholen, Chief, Office of Weights and Measures, National Bureau of Standards

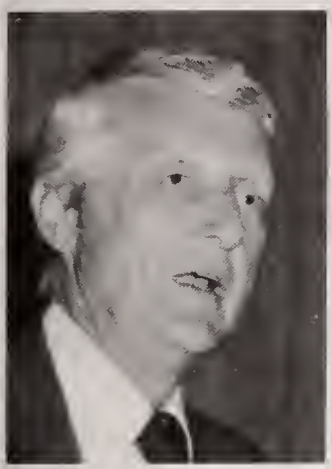

I believe that the title of my message "Tradition in Transition" and the theme of this 64th Annual Conference on Weights and Measures "Equity on the Move" are a perfect example of counterpoint.

I make this counterpoint to assure you that I am in tune with you and in the hope that you will find what I have to say to be harmonious with your theme song.

It is entirely appropriate that this conference is here in the West. We in the East are often told that breaks with tradition originate out here and are rapidly adopted in the East.

The most recent proof of that is the current gasoline shortage. The gasoline lines showed up first in California (breaking with the tradition of plentiful, cheap fuel) and rapidly spread eastward.

Then, odd/even days were adopted out here-breaking with the tradition that any American has the right to buy anything, anytime, as long as he or she can pay for it (or charge it). Now, folks in the East are sorted out as odd or even. I happen to have a license plate which is all letters-OWM NBS, which is my way of telling the world I am proud to be with the Office of Weights and Measures of the National Bureau of Standards (ergo OWM NBS).

I find that many people do not know about us-which, by the way is one of the crosses you folks share with me. You do such a good job of providing equity and uniformity that the public takes their protection for granted. (In fact, they often do not even know we exist.)

But, back to odd/even. Since my plate contains all letters, the State regulation defines me as even. I find, however, that when I am in line for gas on even days, a lot of the even folks in line are very odd.

I also read that Oregon, in its earlier days, was populated for the most part by traders and missionaries. That seems to say a lot about traders, doesn't it? I meant to ask Ken Simila whether there are more or fewer missionaries in Oregon now that the traders have been replaced with environmentalists. Yes, the great Northwest is trying to preserve its tradition of unspoiled nature.

Exploring the origin of our traditions can be fun-often rewarding with the insights that knowledge gives us. We all want to know how it all began. We are anxious to understand why we do things as we do, and why we possess the feelings, the convictions, we do; and why we do things in certain prescribed ways. 
The story of our traditions is not always easy to trace. Perhaps we. take our traditions on faith. In the musical of the 1960's "Fiddler on the Roof" tradition was the thread of continuity woven through every facet of the lives of those who lived in the village of Anatevka. The lead role, played by Zero Mostel, was the milkman Tevye. Tevye was the Fiddler on the roof. As he sits precariously on the steeply pitched roof of his house, he says:

"Tradition. Without our traditions, our lives would be as shaky as-as a fiddler on the roof."

Those of you who saw the show or know the story will share with me the soul searching dilemma. The villagers were faced with transition all around them-a transition threatening their very existence-an existence based on very strong tradition. In this case, the outside transition was met by further retreat into tradition, untiltheir entire world flew apart.

Today, in 1979, in Portland, Oregon, the assembled representatives of weights and measures programs of device manufacturers, of processors, of packagers, of service companies, of standards groups, of consumers, meet as they have met on 63 occasions in the past, as they have traditionally met since 1905 . But, thank goodness, we are not like Tevye, sitting precariously on a roof, fiddling away our future. No! We are here assembled traditionally, but prepared to shape our tradition to serve American society in transition, in a transition which is challenging many of the traditions of our community:

A tradition based on mechanical measuring and weighing devices.

A tradition based on using inches and pounds.

A tradition using intuition and experience rather than statistical procedures.

A tradition of patronage-based staffing.

Oh, but you say, tradition has served us well in the past. Therefore, it will serve us well in the future.

Yes, I am convinced that the weights and measures system in this country has been a tremendous success. Our shoppers by the millions shop every day and make tens of millions of purchases based on weight, measure, and count. They shop in the well-placed belief that they will not be cheated. You make confidence in the honesty of the market $a$ fact. Your predecessors built the heritage which makes the slogan "Equity-in-the-marketplace" a proud and real tradition, a tradition in which every one of us should be proud.

The challenge today is not of defending our tradition against transition like Tevye, but to build on our tradition-to shape it, to embellish it, to automate it, to mechanize it.

Again, in Fiddler on the Roof, ${ }^{2}$ with chaos all around them, the

\footnotetext{
1 "Fiddler on the Roof" Prologue

2"Fiddler on the Roof" Scene 4, Tradition, Reprise
} 
villagers sang a song declaring their defense of tradition. Let me read the words, paraphrased for us today:

"They gave each other a pledge

unheard of, absurd.

You gave each other a pledge?

Unthinkable.

Where do you think you are?

(In New York?) (In Hawaii?)

Where do you think you are?

(Portland?)

What do you think you are doing?

(You device maker. You inspector.)

Who do you think you are?

King Solomon?

This isn't the way it is done,

Not Here! Not now!

Some things I will not, I cannot, allow.

Tradition"

This week in dealing with tradition you are facing transition. You are going to make some decisions based on your collective perceptions of the proper balance of tradition in transition.

Let's not fiddle around.

Let's get the job done.

Between 1909 and 1911, inspectors from the Bureau visited every State of the Union, testing over 30,000 scales, weights, and dry and liquid measures in 3,220 different shops and stores. They were not surprised to find that almost half the scales tested were badly inaccurate, that 20 percent of the weights, half the dry measures, and a quarter of the liquid measures were in error, or that with remarkable consistency these scales and measures favored the storekeeper. The Bureau estimated that in the case of pre-packaged butter alone the annual loss to the consumer, through rigged or faulty weighing devices, amounted to more than $\$ 8,250,000$. From the start, journalists and reporters followed the track of the Bureau inspectors, and with the first disclosures of what the journalists termed "the knavish distortion of weights and measures," the crusade began. New York State's superintendent of weights and measures, Dr. Fritz Reichmann, and Mayor Gaynor of New York City soon launched investigations of their own and other States followed. Over the next two years almost a hundred articles in the periodical press reported the weights and measures campaign across the country. 
As a result of the widespread demand for better laws and better inspection of trade weights and measures in the wake of the survey, first New Jersey and then other States enacted the model law proposed by the Bureau, and State after State exhumed and submitted for verification to the Bureau the standards that had been furnished them some fifty years earlier or purchased new equipment for their State sealers. Answering urgent appeals, the Bureau drafted a model weights and measures ordinance for municipalities, and detailed its experts to first one and then another of the States which requested aid in setting up their inspection departments.

This kind of experience has been and can be repeated as individual weights and measures programs pass through cycles of high and low fundings. There is high payoff in terms of accuracy-in terms of equity-in terms of honesty. Weights and measures programs are strong when they are strong in management, inspection, and enforcement.

What is urgently needed is a reference document-a world almanac of weights and measures facts. We need to know how many scales were tested, how many meters were examined, how many packages were checked. We need to know what compliance levels are, what the trends in compliance are. We need to do the analysis which will support your programs and justify your budget requests.

We intend to work in this direction. We expect to get a better handle on this challenge through use of the "National-Regional-State Telecommunication Exchange Network" operated by the FDA. This system provides two-way communications between the Federal Government and all fifty States plus Puerto Rico for facsimile transmission as well as teletype. They (the FDA), as many of you know, collect activity data from the States; this, together with reports you send OWM, plus results expected from the program review plan being developed by your Education Committee will serve as the basis for assembly of weights and measures program justification for defense of local budgets.

A railroad problem came to the Bureau early in this century when the Interstate Commerce Commission, aroused by mounting complaints, requested that a study be made of railroad, elevator, grainhopper, and other large-capacity scales used in determining freight charges in interstate shipments. Few States inspected scales, the Bureau found, and many railroads maintained such scanty supervision over their freight scales that some were little more than "guessing machines." As a result, railroad freight scales, upon which more than $\$ 2$ billion annually in revenues were determined, had long been a source of bitter complaint and litigation.

In 1913 , with an appropriation from Congress of $\$ 25,000$ for the investigation, the Bureau had a special railway scale test car built, hitched it to a series of slow freights headed north, and began testing railroad scales in the States of New Jersey, New York, Connecticut, 
and Vermont. The results matched the earlier experience with market weights and measures. Allowing a fair tolerance for such scales, between 75 and 80 percent of the track scales tested were candidates for outright rejection, some weighing short by as much as 3.9 percent $(1,349$ pounds with a load of 35,000 pounds) and 3.5 percent $(2,459$ pounds with loads of 70,000 pounds). Acquiring another test car, the Bureau extended its investigation of scales into the Midwest and the South.

As the railroads, as well as manufacturing concerns and State agencies, set up inspection procedures under Bureau direction the large capacity scales began to register more nearly true (i.e., with a tolerable error of 200 pounds in 100,000 pounds gross weight). The Bureau test cars with their master scales still continued their rounds, adjusting track scales and calibrating the scale cars that were acquired by the railroads.

If you will excuse my pun, we at NBS have been asking if we are "on the right track" regarding the railroad track scale calibration activities. A program begun in 1913 as a research effort is still going on in 1979-66 years later. Certainly 66 years alone should not condemn an activity. What is a fact is that this is an operation based on the fruits of research. It should be in the hands of a regulatory organization, not a research laboratory.

Here, an activity had become a tradition-period. We propose a transition of this tradition. A transition in which the FGIS will operate the test cars and the metrology laboratory of the State of Illinois will calibrate the test weights and provide traceability to the National Standards through their State standards. All involved parties have agreed in principle with this plan to be effective by October 1 , of this year.

How about metrication? Here we are face to face with tradition; face to face with resistance to transition.

Now I'm no Don Quixote. I have no intention of tilting with windmills. Although "The Impossible Dream" is an invigorating ballad, I don't subscribe to all the lyrics, especially becoming "scorned and covered with scars." The fact is, use of the metric system is growing voluntarily and it is not necessary to charge out in front like Don Quixote. It is necessary, however, to be prepared to protect and promote uniformity and equity. In the change to the metric system, we must be ready to protect the traditions of uniformity and equity-inthe-marketplace by being tuned into the transition of metricationand away from the tradition of inch-pounds. Let me review our role in this situation-a good example of "tradition in transition."

Weights and measures officials have a key role to play in the conversion process. NBS, through its Office of Weights and Measures (OWM), is in a unique position to coordinate this activity. NBS organized the National Conference on Weights and Measures in 1905 
to achieve uniformity in weights and measures operations (tradition.) The Conference has been so effective in this mission that PL 94-168 called on the NCWM to be active in metric conversion.

NBS itself has also been a key agency within the Federal Government with regard to metrication. The U.S. Metric Study was conducted by NBS from 1968 to 1971. Following the study, NBS maintained a Metric Information Office until after the passage of PL 94-168 which created the U.S. Metric Board. The National Conference, recognizing its need to respond to the metric situation in the country, formed a Metric Planning Committee in 1974.

The Metric Act does not add new responsibilities to NBS or OWM. Rather, it simply calls upon them to continue to provide leadership during one of the most important periods of weights and measures in the U.S. To date NBS/OWM working with the NCWM has:

- Provided technical guidance for introduction of metric terminology and SI units into the Model State Packaging and Labeling Regulation.

- Initiated work for introduction of metric terminology in: (1) Model State Regulations for unit pricing, open dating, and method of sale of commodities; and (2) Handbook 44 "Specifications, Tolerances, and Other Technical Requirements for Commercial Weighing and Measuring Devices."

- Responded to the current issue of gasoline sales as the price moves to over $\$ 1$ per gallon by working towards a coordinated approach to metric as each State selected that solution.

- Kept weights and measures officials up-to-date on metric activity by informal newsletters and memorandum as well as reports at national and regional meetings.

Even if the metric act had not mentioned NCWM and (indirectly) NBS, OWM would have needed to be involved in this activity due to its traditional and ongoing role in working with the Nation's weights and measures officials. This activity is clearly compatible with the NBS Organic Act (tradition) and reinforces long-running NBS programs.

We are proud professionals. We know that our roots-our weights and measures roots-go back to earliest history. We know that God told the people in Israel in Leviticus, Chapter 19, Verse 36 that "Just balances, just weights . . shall ye have."

We also know that our Constitution speaks to weights and measures. Our lineage is long. Our lineage is respectable. But a long, respectable lineage is no guarantee of a successful future. The future 
depends on our planning_planning which: First, keeps each one of us up to date, keeps our skills in a transition of growth. We know that technology is in transition. You cannot and I cannot handle the new technology with traditional skills alone.

Second, we must bring new professionals into weights and measures who already have the basic educational skills needed tomorrow and next year. We must get measurement training into transition:

- Training of inspectors using audio-visual technology

- Two year associate programs at junior colleges, and

- Introduction of measurement science into undergraduate and graduate programs at selected universities.

Regarding the first item, OWM is procuring audio-visual equipment and had arranged for assistance from our media experts to begin production of training sessions on audio-visual casettes. Our first product will be developed late this fall-and if successful-will be reproduced and sent to each major jurisdiction.

In the second area-we want to work with Yuba College and Alfred Tech to develop more formal associations.

In the third area-our goal is more challenging:

To develop formal undergraduate and graduate programs in measurement science at a leading university;

To establish a measurement science curriculum as:

A minor in undergraduate degree programs;

A separate masters program; and,

A Ph.D. program

To accomplish this we must have support of:

- State and local weights and measures officials (and their parent organizations);

- Industry and business decision makers;

- The National Bureau of Standards;

- The educational community-the universities. 
The program will probably be under the direction of a School of Engineering and will be a cooperative activity of the university, industry, and government providing education, research, and service programs related to measurement.

Measurement science is based on tradition but it is in a very challenging state of transition. We must recalibrate ourselves and our organizations with new skills.

Your Conference Education Committee is working diligently along these lines.

I'd like to call your attention to a few facts:

- First, you had the printed proceedings of last year's conference in your hands for use before coming to this conference-

- Second, you have the report of the temperature compensation seminar in hand-printed-

- Third, you have a draft of HB 44 in the format recommended by your committee-

- Fourth, you have a draft of a new handbook (HB 130), a compendium of weights and measures laws and regulations complete with adoption history and information on promulgation-

- Fifth, you have a draft prospectus designed to aid in broadening the participation in the NCWM as a professional society.

These documents are tangible evidence of hard work by your committees, of hard work by the staff in the Office of Weights and Measures, and are tangible evidence of the use of new management techniques and word processing technology.

What are your committees looking for in the future? What is the OWM looking for in the future?

We want to put more technical and administrative resources in your hands, and do it in a more timely fashion. Prior to the interim meetings, we want to get the proceedings out, we want to get the updated Handbook 44, and we want to get the revised Model Laws and Regulations out.

Why? For two reasons: First, so that you can get the necessary information to your legislatures. Second, so that weights and measures officials, industry, consumers, and other government agencies will be better prepared for the interim meetings in January.

We had to break with tradition in putting these documents together. We are making the transition. Now, there is another goal, another potential payoff of this new procedure if you support a recommendation of your committees. 
That goal, in addition to getting documents, handbooks, reports to you sooner, is to get the proceedings into the hands of not 500 weights and measures officials only-although that is extremely important. The goal is to get the proceedings into the hands of every inspector, manager, serviceman, official, businessman, and tradesman who is involved in weights and measures anywhere and everywhere. Not 500 but 5,000 , then 6,000 , possibly even 15,000 and to do the same with Handbook 44, and with Handbook 130 , and with any other professional weights and measures reference.

This is possible, this is essential, if we are going to grow professionally in State programs, service companies, device marketing, device manufacturing, and consumer understanding.

Our tradition has limited our potential. Let's make a transition to bring all of our associates into the NCWM-a NCWM known and accepted as a professional society-and without harming the marvelous, effective, mechanism for change-for uniformity-for equity, which it has been-and is.

Let's make it even more effective. Let's make it even more respected.

This is a busy week. Your committees have labored long and hard in the weights and measures vineyards. They have wrestled with bringing new ideas forward. Trying to sort out cumbersome tradition. Mixing some solid transition.

Now, we ask for your contribution-a contribution based on a willingness to be a part of "Tradition in Transition." For if we choose right we shall all benefit, all who are here, all who deal in the marketplace, every resident in this country.

Let me leave you with this promise, a quote from Lord Byron written in 1817:

"To do good for mankind is the chivalrous plan, and is always nobly requited,

then battle for (progress) wherever you can, and, if not shot or hangedyou'll ket knighted"

Let's continue our good work for mankind, let's battle for progress-built on the best of our tradition-progress harnessing transition.

Then, I'm confident that none of us will be shot or hanged, but rather that all of us will be candidates for knighthood. 


\section{A LEGAL METROLOGY CONTROL SYSTEM APPLICABLE TO THE UNITED STATES}

Presented by Kenneth F. Hammer, President, Fairbanks Weighing Division, Colt Industries

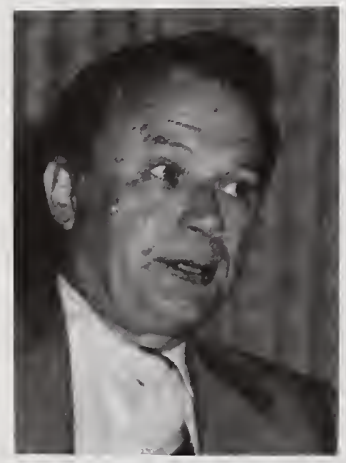

The Scale Manufacturers Association is what its name implies. Additionally, its members are exclusively U.S. manufacturers. The Association was founded in 1945 .

We are proud of the long history since that time of legitimate reconciliation of our differences as competitors and constructive contributions to the deliberations of the National Conference on Weights and Measures.

I am privileged today to represent the Scale Manufacturers. Since 1974, we have had the benefit of professional association management leadership of our administrative and technical activities. That leadership has allowed us to define issues, to identify motives, and to quickly reach positions of constructive agreement or recognizable situations of irreconcilable disagreement.

Most of our deliberations are addressed to issues affecting H-44. Our principal contact with the National Conference has been through its $\mathrm{S} \& \mathrm{~T}$ Committee.

But of recent years the activity level has increased and the issues have broadened. We hope the view we express today will be of interest and significance to all of you. We ask that you consider it in the intervening months between now and your next regional meetings. We suggest that the subject of this address be given formal consideration by an appropriate committee at the 65th National Conference.

The world of commercial legal measurement has recently been and will probably remain for another ten years, subject to dynamic change. Using industries and measurement equipment manufacturers are introducing new technologies. Consumers and trade associations demand the consideration of ever-changing interests. Regulatory agencies and sealers strive for ever-higher plateaus of cost effectiveness and certainty regarding measurement assurance. At the same time, underlying and fundamental concepts are changing which influence the whole fabric of $\mathrm{H}-44$ as in the case of the consideration of metrication of U.S. measurement and under the influence of European ideas as fostered by the O.I.M.L. technocracy.

The resulting flood of change proposals to $\mathrm{H}-44$ threatened to inundate the SMA. We increased our capacity through substantial 
member contribution of technical time and talent as well as the addition of permanent staffing which the Board of Directors again increased yesterday. But we found that consistent consideration of the multiplicity of change proposals coming from sources of differing motivations required a preconceived and common underlying philosophy.

That philosophy is expressed in a document adopted as a unanimous SMA member position on November 14, 1978. It has been in use within the Association since that time. We find it useful in determining whether we support the motivation of a proposed change. We find it useful in determining whether the proposed change will produce the desired effect. And we find it useful in reconciling the positions we take at different points in time. We present to you an SMA recommendation for "A legal Metrology Control System Applicable to the U.S." I hope that you all at this point in time have copies available to you for your perusal during the balance of this presentation. [The recommendation appears as an appendix to this report]

The parties to a commercial transaction at the time of the transaction need confidence in the measurement upon which that transaction is based. We agree that the object of commercial legal metrology is to "achieve a specified accuracy with a specified degree of assurance at the places of the commercial transaction." That a gasoline pump, a scale, or a length-measuring device used in the transaction was accurate at some time past is not sufficient. But we also recognize that individual measurement by impartial referees is not economically possible nor politically tolerable.

So we begin with the examination of the entire process of measurement. Essentially this involves the creation at some point in our economy of a new measurement capability. Somewhere back in a Fairbanks laboratory is a new microprocessor-based measurement device of which you have no knowledge. Ultimately that device will be made available to the market and provided by sale to a particular measurement location. The provision will include installation. The measurement capability will then be used by its new owner in commercial transactions with others. At some point in time, it will require maintenance and will be returned to use.

Cost effective control of the quality of legal commercial measurement in the U.S. involves understanding that process and asserting control at some points in it.

Exhibits I, II, and III of the paper you hold define that process. Effectively they are a map of the process. I will not attempt to detail it here, but hope only to facilitate your ability to examine the admittedly complex diagrammatic form on the appendices A4, A6, and A8. Both dimensions represent time. Events to the right of the page occur later than events at the left. Events at the bottom occur later than those at the top. 
In that fashion at the top of this Figure if we were to consider submissions by manufacturers of new devices to a type approval office, submissions by manufacturers one after the other appear from left to right as rendered.
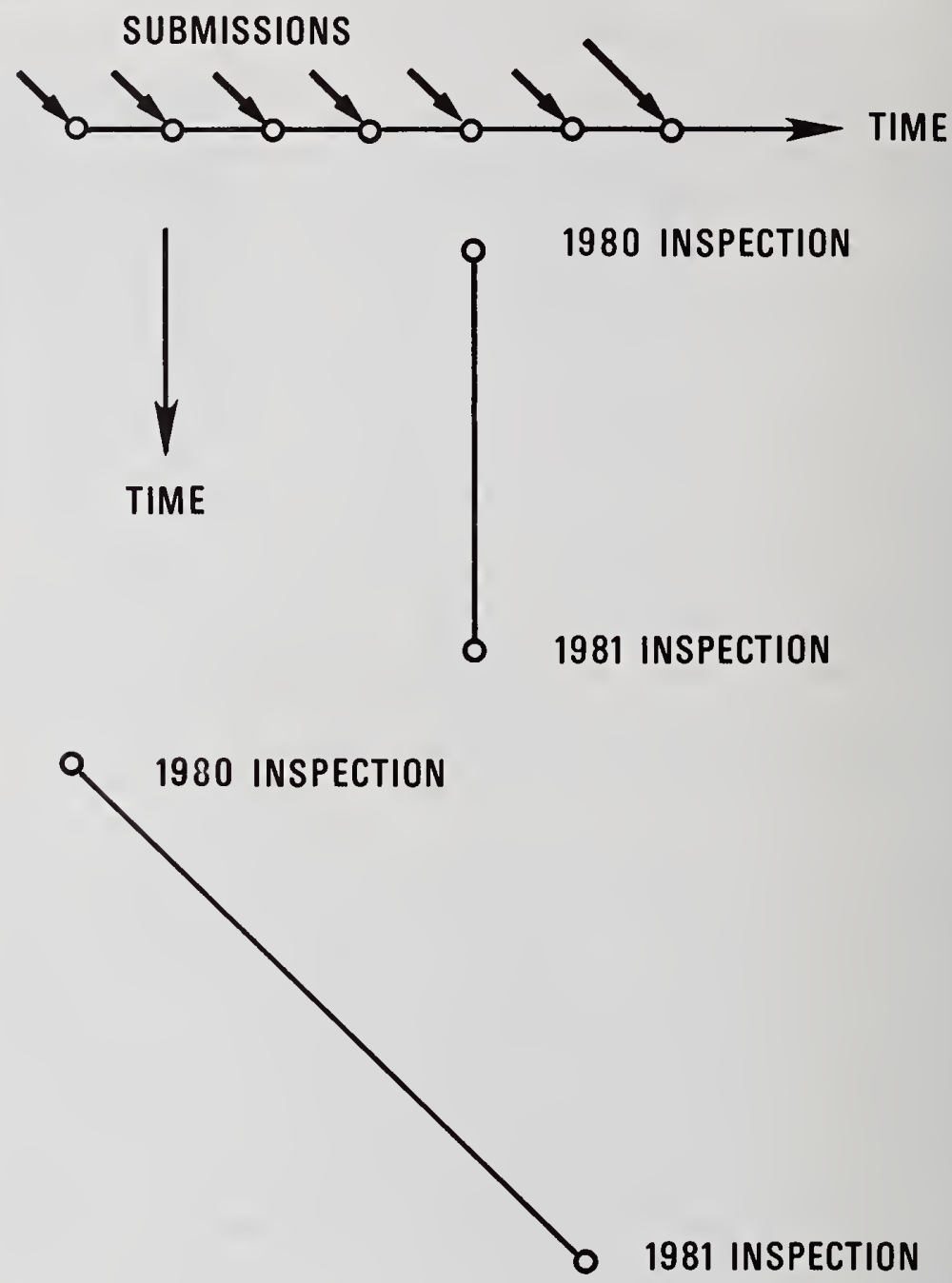

In the middle of the Figure, we illustrate a 1980 Field inspection of a particular installed device occurring again in 1981 lower on the page.

At the bottom of the Figure, we show that 1981 inspection lower and to the right as they actually appear in your Exhibits I, II, and III. 
The three Exhibits depict the phases of the process. Component supply is the creation of the availability to the market of a piece of measurement equipment. The second phase is component application, the sale and installation of a measuring unit at a particular location of intended use. And the third phase, of course, is the actual commercial use and maintenance of the measurement capability.

As the steps in the process are the subjects of Exhibits I, II, and III, the hazards to measurement confidence during that process are depicted on appendices A10, A12, and A14 in Exhibits IV, V, and VI.

We in the SMA have found these diagrams of the measurement process and of the hazards to measurement confidence of considerable value in the evaluation of proposed changes in H-44.

Definition of the process and its hazards also contributed to the establishment of some principles upon which later recommendations were based.

You will find on appendix A22 a tabulation of the princiles which are cryptically summarized as follows:

First, a desirable system attains specified standards in actual operating circumstances.

Second, reasonably available tests of small error must provide precise measurement to precise standards.

Third, Field testing is the required foundation for our purpose. Earlier activity reduces system cost and workload. Contrary to early O.I.M.L. thinking, type examination does not increase measurement confidence at the point of use but reduces the amount of Fiela inspection necessary to that purpose.

An acceptable control system for legal metrology must use performance standards. Design standards throttle innovation, stifle competition among suppliers, and deprive the marketplace of improvement to measurement capability.

We believe federalization of the U.S. system of weights and measures is neither necessary nor desired. Previous federalization of meat and recently grain has contributed to a proliferation of standards, a duplication of regulatory functions, and the dilution of knowledgeable input to those regulatory processes. Consider the workload imposed upon the scale manufacturers in trying to provide knowledgeable technical input to the considerations of U.S.D.A., F.G.I.S., and the National Conference on Weights and Measures, in addition to the states and the regional conferences. Now we must also establish our credentials with O.I.M.L. and the E.E.C., if those agencies affect U.S. standards or if our members attempt international marketing.

We believe the National Conference on Weights and Measures can provide the initiation of the legislative foundation and the coordination of the public and private resources required to improve the U.S. system of weights and measures. 
And we fully believe, especially in the post-Proposition 13 era, that cost effective enhancement of commercial measurement confidence must use the combined public and private resources available.

Such a system of assuring measurement confidence should be at direct user cost. Private companies can check equipment, public agencies can verify the result of equipment used by people in the real market.

That concludes my simplified restatement of the principles. I am sure you will want to consider and debate them in the coming months as they appear in more complete form on appendix A22 of our paper.

Referring again to the process of supplying commercial measurement we adapt O.I.M.L. terminology to the phases of control which are necessary for economic achievement of confidence. First, and at the earliest stages, is pattern approval. Intended, as I indicated before, not so much to provide measurement confidence as to reduce the cost of later Field inspections, this approval examines the characteristics of a particular type of measuring equipment before it is introduced to the market and in the expectation that it will be produced in considerable numbers.

Second, is the initial verification of each installation of measuring equipment. This assures proper installation, interfacing with other equipment, instruction of using personnel, and freedom from adverse local environment effects.

Last is the stage of subsequent verification which is the periodic examination of measurement confidence during the life of the particular installation. We add to the O.I.M.L. definition the recognition of equipment examinations and the examination of the yield of the process. By that we mean, does the equipment in combination with its users at the place of use really deliver measurements in which we can have confidence. One form of this is the package weighing you accomplish at the retail market in the case of prepacked foods.

I've talked about a process by which the ability to measure in commerce comes into being. We talked about the hazards to confidence and accuracy in that process and we have talked about some principles of technology, of economics, and of political theory to which the members of the SMA subscribe. Ultimately, we are talking about a system of quality control. But unlike the the classic industrial systems of quality control, we are speaking of one applied to a process involving many elements of our society. Consumers, retailers, and industries, large and small, may all be involved in the process affecting one scale or gas pump at the corner of one of our streets anywhere in the United States. No such system can work without an agreed philosopy, involvement of many people, and considerable communication between those people. 
And so we propose, with some trepidation, the recommendation of Exhibit XII on appendix A25 of the SMA recommendation which was reprinted in the Conference announcement on page 43 .

We portray here a block organizational relationship with proposed resource assignments which appear appropriate to an evolving, coordinated system of weights and measures. Central to the diagram is shown a verification office. That role we believe is assigned to the states. There are, of course, a multiplicity of such offices. They are concerned with the initial and subsequent verification functions. Supporting them are private and their own resources conducting equipment and process tests of equipment as it goes into the Field in the initial system and thereafter in the subsequent system.

Those offices are provided a framework of policy, model regulation, and authority by the National Conference which receives feedback and input from the states for the continuing evolution of policy and regulation.

Similarly related to the National Conference is the pattern approval subsystem which we believe is best managed by the National Bureau of Standards. The Bureau of Standards, however, would go further in the direction of its effort with California and use both state and private resources in the conduct of appropriate tests.

At the left side of the page is also shown a role of the National Bureau of Standards in international coordination with O.I.M.L., E.E.C. and other organizations which are sure to come into being.

The SMA adopted this position on the fourteenth of November, 1978. We are providing to you this exposure now in July, 1979. We would suggest that you study it, consider it at your regional conferences, and consider its refinement and adoption at the July, 1980, 65th National Conference.

We believe that your consideration and hopefully adoption will result in these benefits to the system of weights and measures in the United States.

Better proposals will flow to the National Conference for its consideration. These considerations will be more consistent. All of the many resources in the U.S. will have more defined roles and those roles will be universally understood. We believe that that will lead to economic management and that the results will be measurable in terms of the confidence levels of measurement accuracy actually achieved in commerce in the United States. Thank you. 
(A1)

AN SMA RECOMMENDATION

FOR A

LEGAL METROLOGY CONTROL SYSTEM

APPLICABLE TO

THE U.S.A.

Approved as an SMA position by vote of nembers $11 / 14 / 78$. 


\section{INTRODUCTION}

The object of any system for control of legal measurements in commerce should be the specification of the accuracy required of such measurements and a provision for assurance of the degree of certainty that such accuracies are attained in actual comercial measurement practice.

Control of the quality of measurements for legal use in commerce requires an understanding of the process which yields the measurements. We examine and define the process by which the capability for such measurements is created and used. The resulting "map" of the process to be controlled is useful in defining at the beginning the purposes of a regulation, and the zones of the responsibility/authority.

$\begin{array}{llll}\text { Exhibit I } & - & \text { Component Supply } & \text { Pg. } 4 \\ \text { Exhibit II } & - & \text { Component Application } & \text { Pg. } 6 \\ \text { Exhibit III } & - & \text { Commercial Use } & \text { Pg. } 8\end{array}$

We then examine the hazards to quality measurements in commercial use which remain, regardless of the degree of control asserted in each stage of the process. This "map" of hazards facilitates critical evaluation of proposed regulations, authority delegations, and organizational relationships.

$\begin{array}{llll}\text { Exhibit IV } & - & \text { Hazards During Component Supply } & \text { Pg. } 10 \\ \text { Exhibit V } & - & \text { Hazards During Component Application } & \text { Pg. } 12 \\ \text { Exhibit VI } & - & \text { Hazards During Commercial Use } & \text { Pg. } 14\end{array}$

We then define the efforts of verification and qualification which seem to be required.

$\begin{array}{llll}\text { Exhibit VII } & - & \text { Subsequent Verification Sub-System } & \text { Pg. } 16 \\ \text { Exhibit VIII } & - & \text { Initial Verification Sub-System } & \text { Pg. } 18 \\ \text { Exhibit IX } & - & \text { Pattern Evaluation Sub-System } & \text { Pg. } 20\end{array}$

We provide a summary of principles serving as a foundation for, and included within, this proposal.

Exhibit X - $\quad$ Suminary of Principles

pg. 22

We then conclude with a model organizational arrangement of the elements necessary for improved control of commercial metrology in the U.S. coordinated with developing international trends.

$\begin{array}{llll}\text { Exhibit XI } & - & \text { Control Systems Overlaid on Process } & \text { Pg. } 24 \\ \text { Exhibit XII } & - & \text { Suggested Roles in a U.S. System } & \text { Pg. } 26\end{array}$

In all following material, the graphic representation on a left page matches the facing right page verbal amplification. 


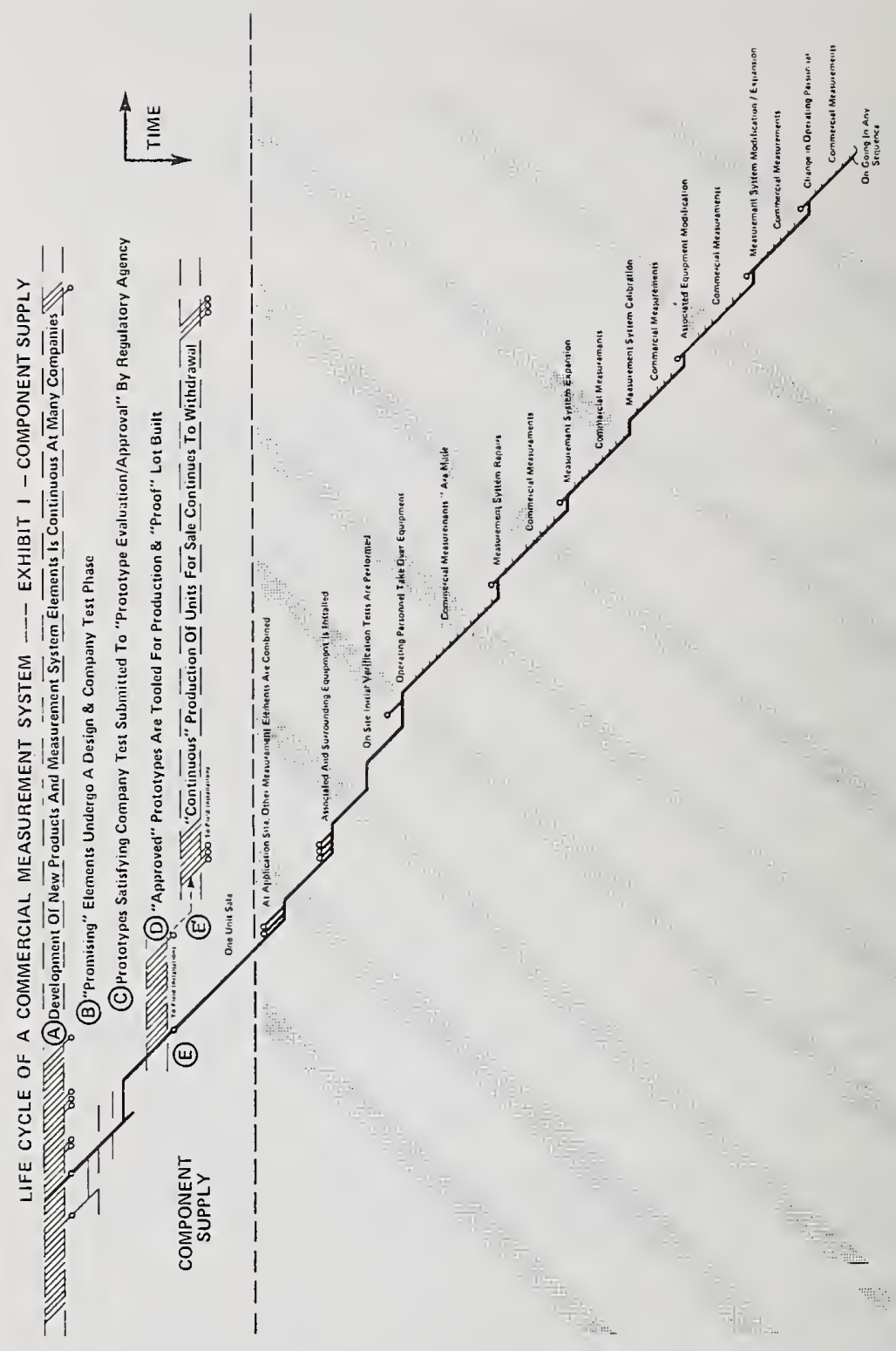


A. Invention and development of measuring equipment systems, and elements thereof, proceeds concurrently and continuously with many companies in several nations.

B. Some of those developments show promise and continue further in development and test within the originating companies. Security of intent remains a significant motivation. There exists today, great variations in company testing programs. Some companies place greater reliance on "Regulatory Body Testing" than do others for product evaluation.

C. "Prototypes," usually pre-production models built in engineering laboratories, are submitted for regulatory testing and "blessing." Such models are preferred by submitting companies because economic investment is minimized and changes specified are more easily incorporated into production designs.

D. Production design details are finalized, component sources and tooling are established, acceptance test procedures are established, and a production "proof" lot is made.

E. The units of the "proof" and subsequent (E') lots are available for application to individual customer orders. 
(A6)

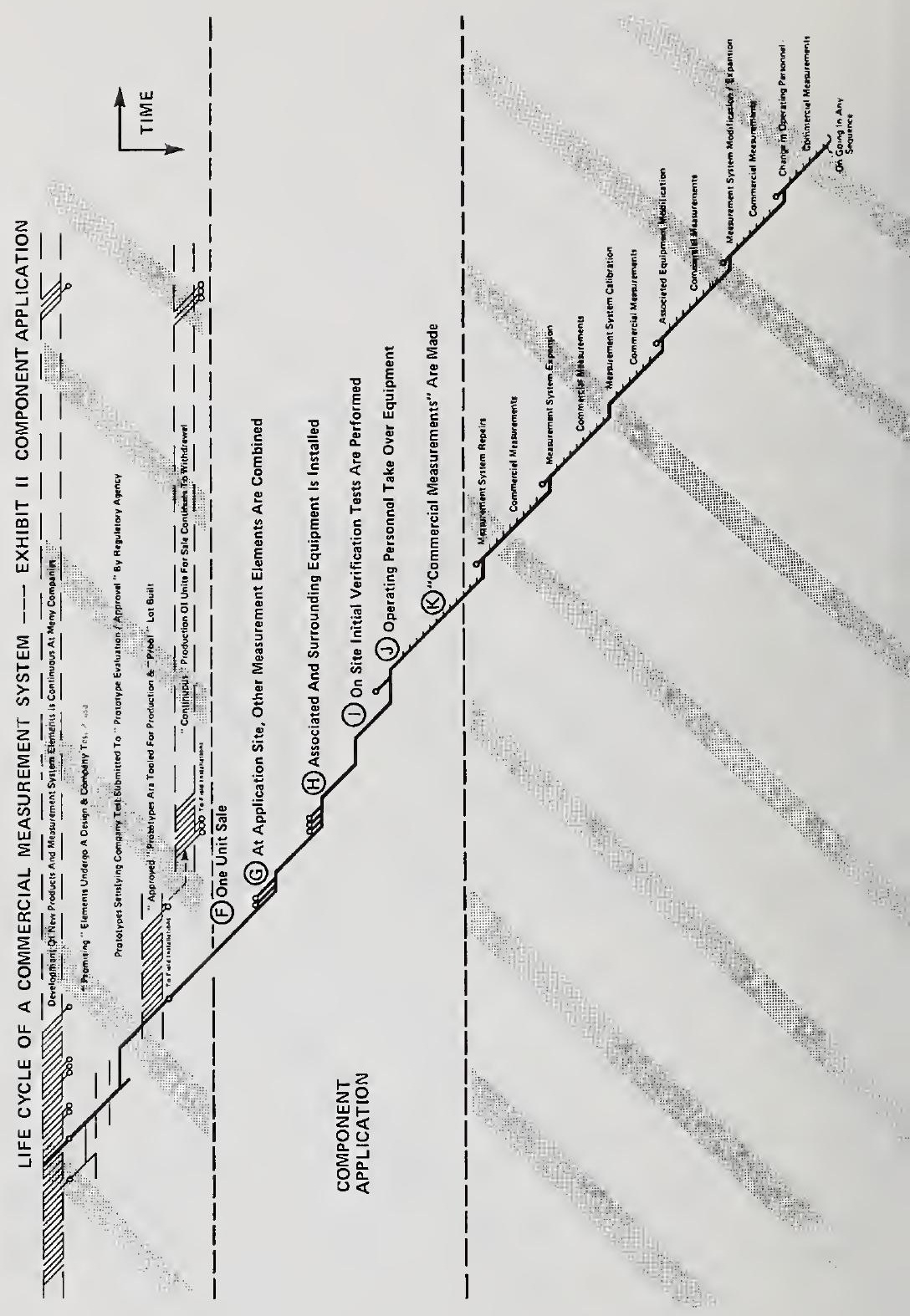


EXHIBIT II - COMPONENT APPLICATION

F. Sale is made to customer, by sales representative employed by manufacturer or by employee of an intermediary company(ies) to whom the manufacturer has sold equipment, for use in a particular application.

G. The subject equipment is combined with other measurement elements, i.e. displays and recording equipment. Such combination may occur at manufacturing or application sites.

H. Associated equipment, i.e. conveyors, hoppers, grinders, mixers, and equipment adjacent to and apparently unrelated to the measurement process is installed.

I. Tests for "initial verification" of the measuring equipment accuracy, and repeatability are performed.

J. Personnel who will use the equipment in actual practice begin operation.

K. The intended "commercial measurements" begin on the actual object product. Assuring the quality of these measurements is the true purpose of any system of legal metrology. 
(A8)

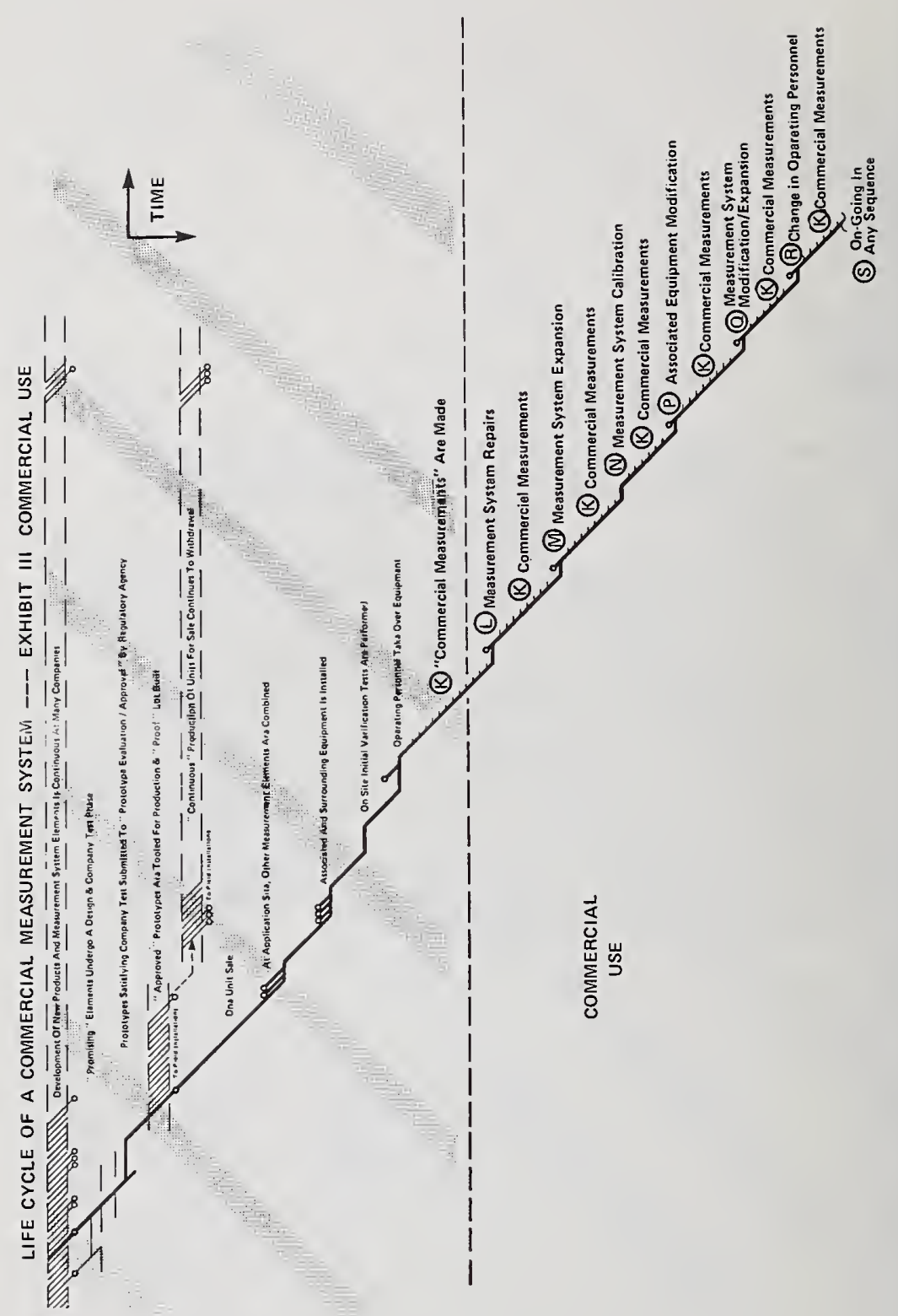




\section{(A9)}

EXHIBIT III - COMMERCIAL USE

K. The repetitious rendering of discrete measurements is interrupted unpredictably by:

L. Repairs to the measurement system required by failure to function, failure to repeat, noticeable inaccuracy, or unauthorized/inadvertent intrusion.

M. Capability expansions ordered by the owner, i.e. display/record addition, remote/automatic operation, etc.,

N. Routine, periodic calibration and inspection,

P. Change/modification/addition of associated equipment,

Q. Further modification like $M$,

R. New operators replacing those originally trained/qualified.

S. Through time all of the above aberrations recur. 
(A10)

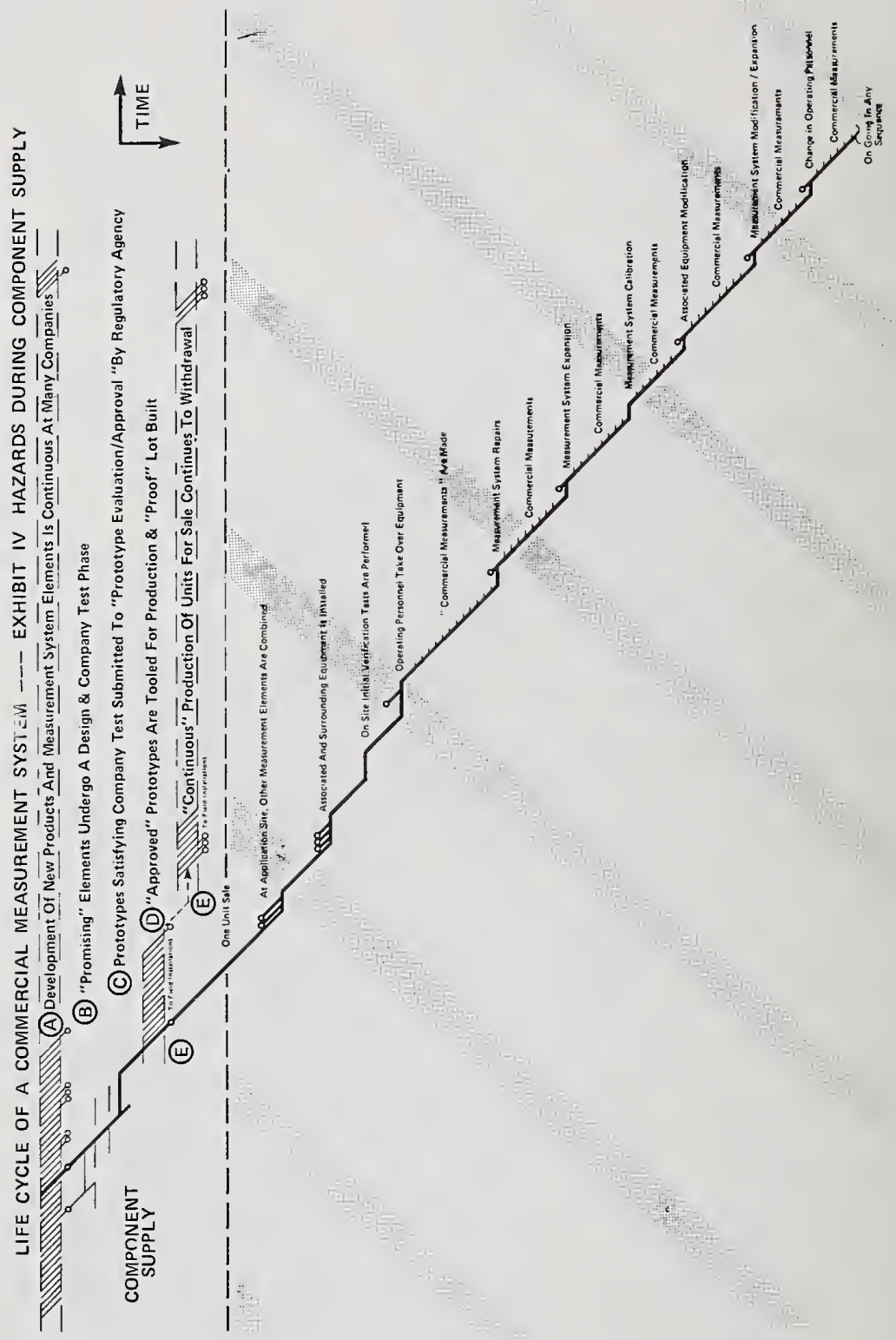


EXHIBIT IV - HAZARDS TO COMMERCIAL MEASUREMENT DURING COMPONENT SUPPLY

A. Design objectives do not anticipate all environmental hazards. Design objectives do not anticipate all equipment combinations. Designs cannot anticipate parts obsolescence during life.

B. Tests do not replicate all conditions of use.

Tests cannot anticipate future environmental hazards.

c. Prototype models are not duplicates of production units. Tests do not replicate all conditions of use. Tests cannot anticipate future environmental hazards.

D. Production units contain subtle design differences. Tolerances create differences from the "approved" prototype.

E. Units are "customized" for sold order application. Production tests do not fully replicate exhaustive "type" tests. Untested part parameters differ from original characteristics. Changes introduced in production create unanticipated/untested side effects. Process changes introduce unanticipated/untested side effects. 
(A12)
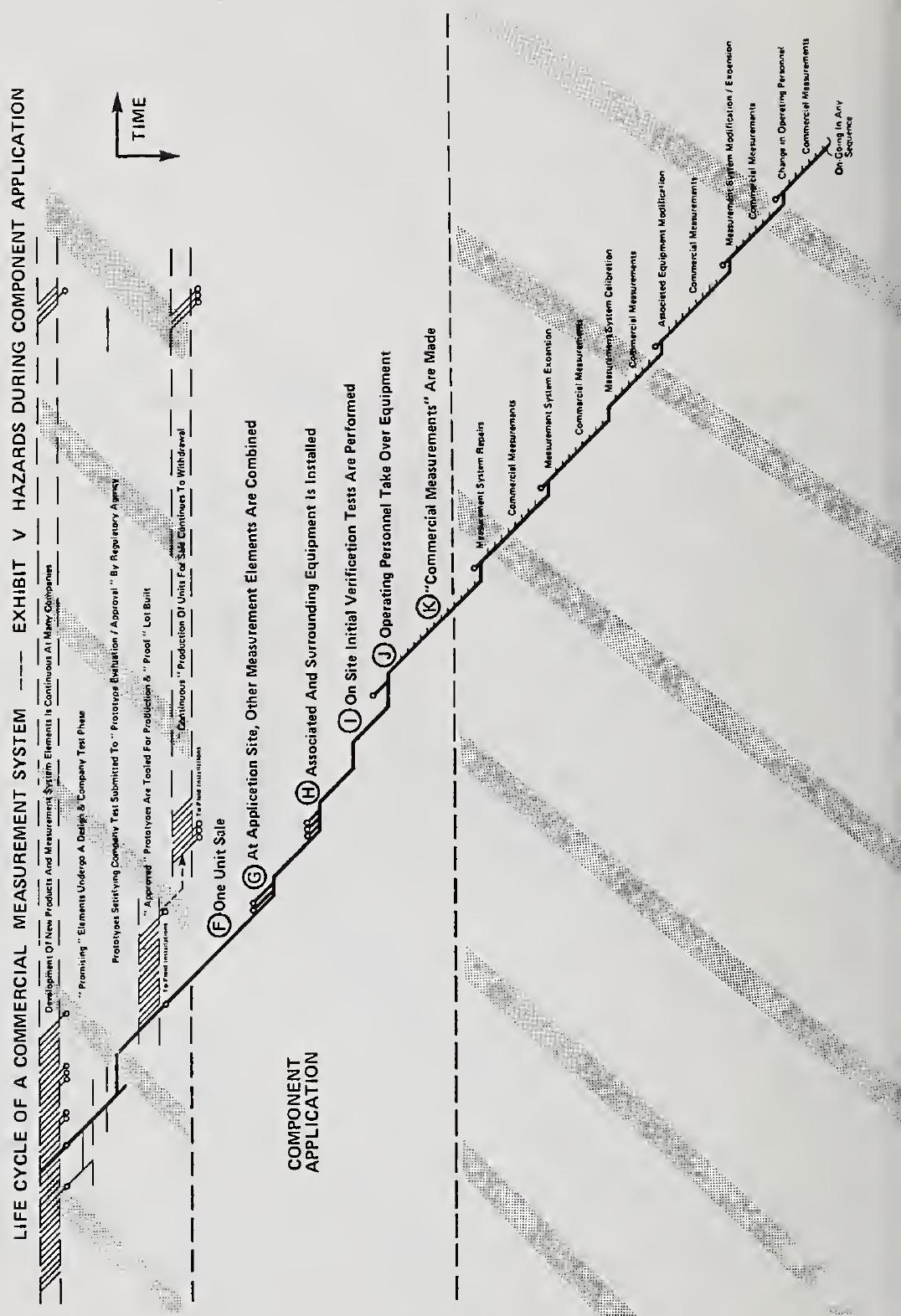
EXHIBIT V - HAZARDS TO COMMERCIAL MEASUREMENT QUALITY INTRODUCED DURING COMPONENT APPLICATION

F. Salesman fails to perceive environment. Sells wrong model. Salesman sells untested combination of components.

G. Additional measurement elements interact. Cable interconnects add antennas. Ambiguity created regarding proper operations.

H. Surrounding equipment adds mechanical/electrical influences. Interlocks insufficient to prevent unintended situations.

I. Tests seldom examine range of real environment. A11 surrounding equipment may not be operating. Tests don't examine all modes of operation.

J. Operators not trained. Operators fraudulent to own benefit. Operators fraudulent to owners benefit. Operators biased toward speed rather than accuracy. 


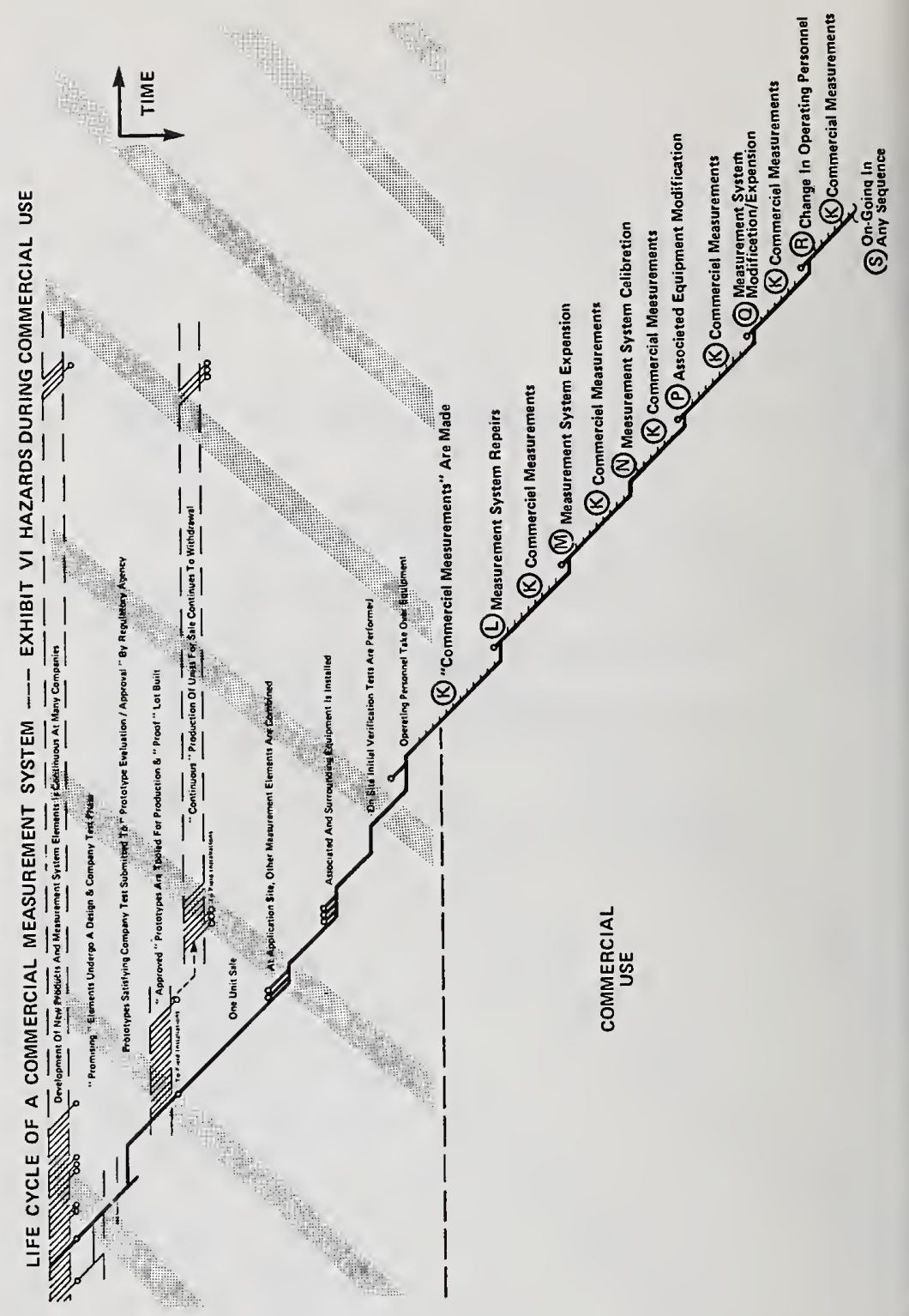


EXHIBIT VI - HAZARDS TO COMMERCIAL MEASUREMENT DURING COMMERCIAL USE

K. Random effects. Equipment, process, or operator.

L. Repairs introduce environmental sensitivity, Repairs affect calibration.

M. Expansion violates - structural integrity. environmental sensitivity.

N. Field calibration introduces random errors.

Field calibration ignores modes of true use.

Calibration delayed past time of true need.

P. Modification of associated equipment changes measurement environment.

Q. Same as $M$ and $P$.

R. New operators subject to same hazards as J with greater risk.

S. The foregoing events continue throughout equipment life. 
(A16)

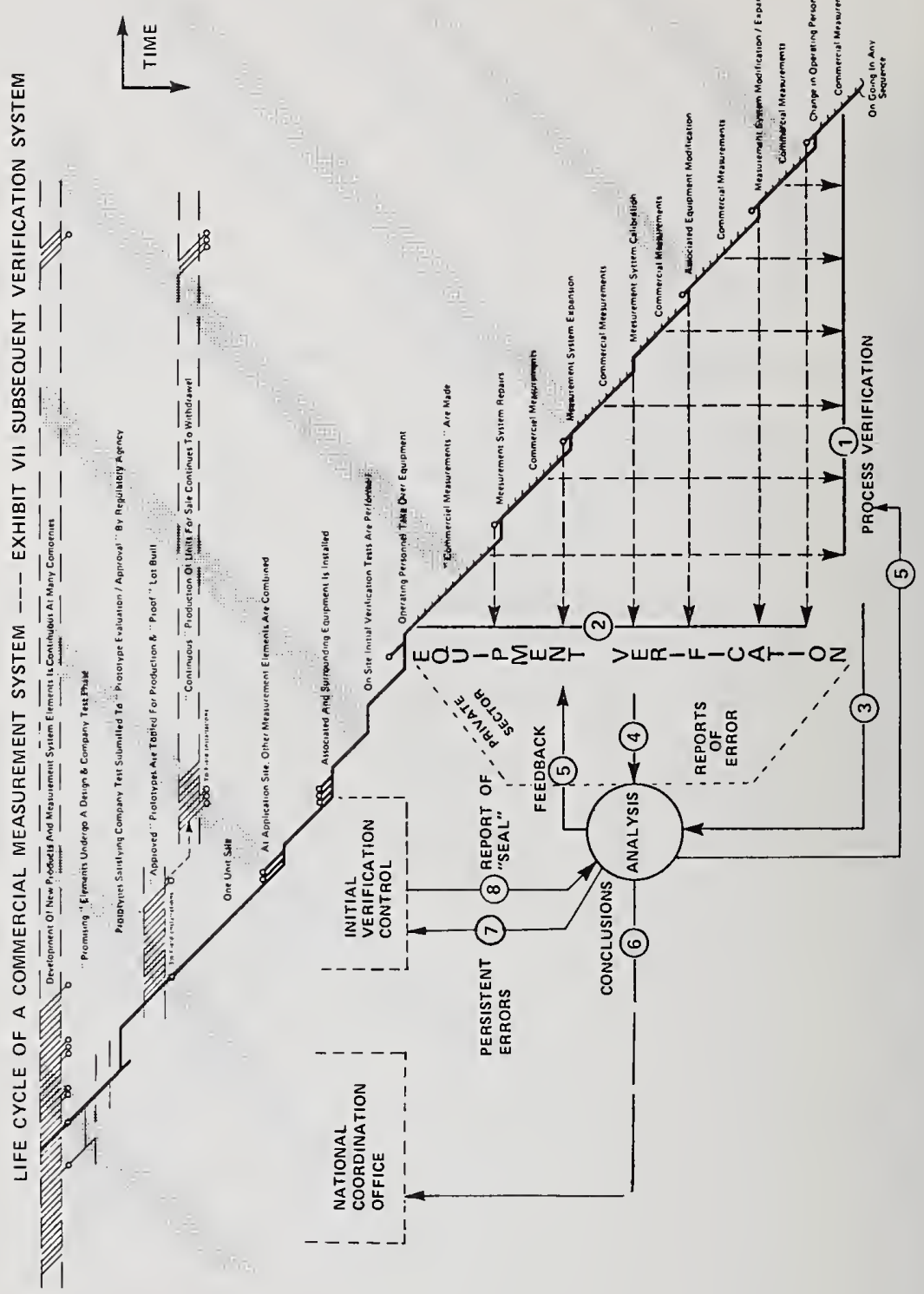




\section{EXHIBIT VII - SUBSEQUENT VERIFICATION SUB-SYSTEM}

Process verification (1) of measurements actually made in commerce is the end-result of the whole system. New methodology is needed to provide this "end-result" capability. Process verification requires random surprise and the force and authority of law to be meaningful.

Equipment verification (2) and correction is becoming too complex for accomplishment by the generalist and can/must be accomplished as convenient to the process user. Periodic evaluation is a necessity. Periodicity is a function of equipment, use, and environment. Private sector employment is appropriate.

A network of communications providing reports of error ( $3 \& 4)$, changed regulations and procedures (5), is required.

Analysis within the sub-system yields the changed local procedures (5), and observations/recommendations (6) regarding performance/method of the earlier sub-systems.

Persistent error and lack of durability (7) is reported to intensify future initial verifications.

Notice of "initial verification" and appropriate methodology is provided (8). 
(A18)

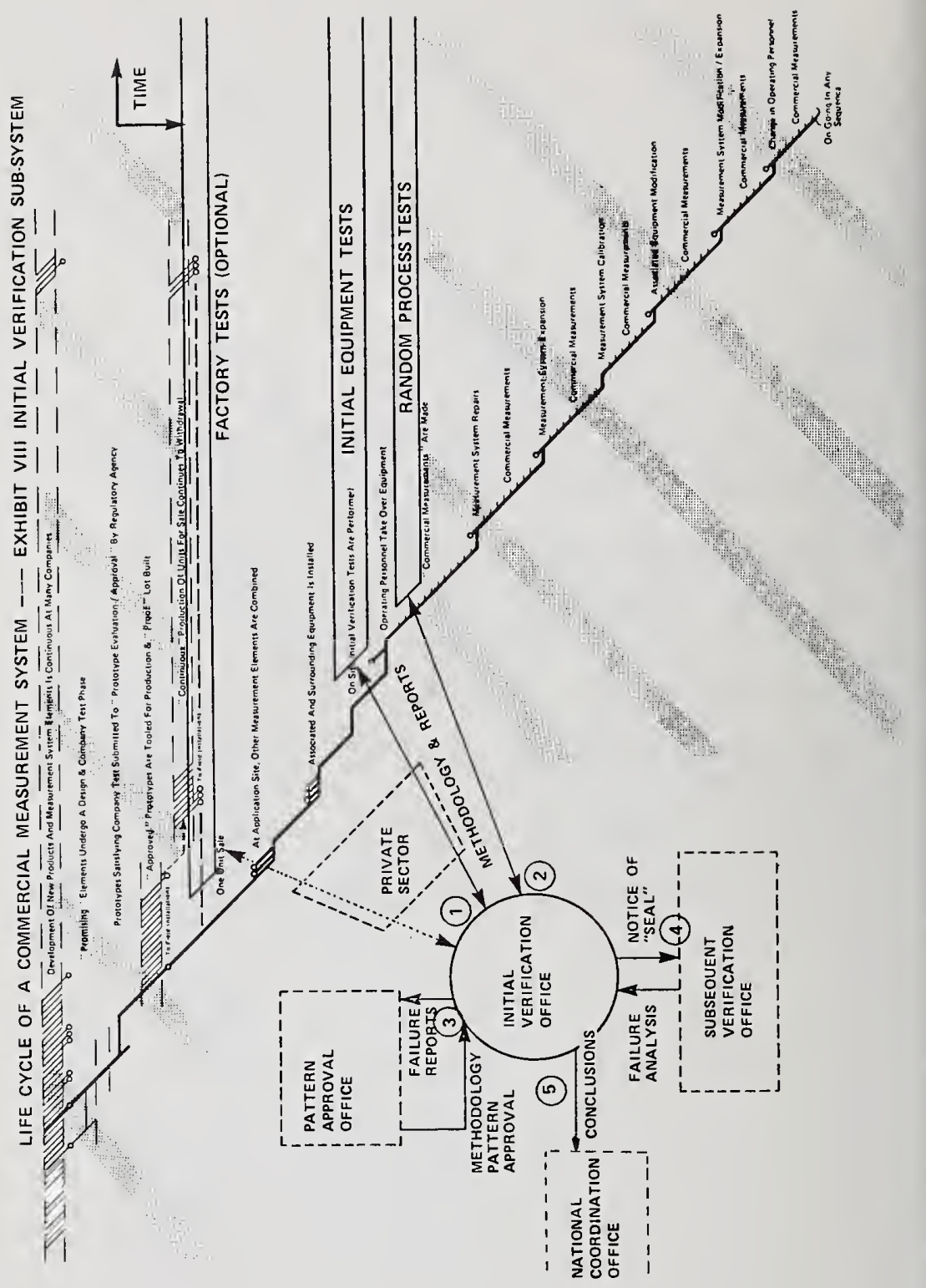


EXHIBIT VIII - INITIAL VERIFICATION SUB-SYSTEM

Purpose is to shelter the subsequent verification system from excessive failure incidents through startup of qualified process.

Equipment verifications (1) are a part of the process, may be done in field or supply factory as specified in prior pattern approval, and may be delegated to competent private sector entities.

Real verification (2) evaluates the process as actually used through new methods of output comparison measurement.

Acceptance yields report (3) to Subsequent Verification Office for later control.

Methodology and knowledge of pattern approval flows in from pattern approval office (4) and repetitive failure reports flow back.

Policy and practice conclusions (5) flow to National Coordination office for consideration.

In some political jurisdictions, the Initial and Subsequent offices may be the same, but the separate functions must be recognized. 
(A20)

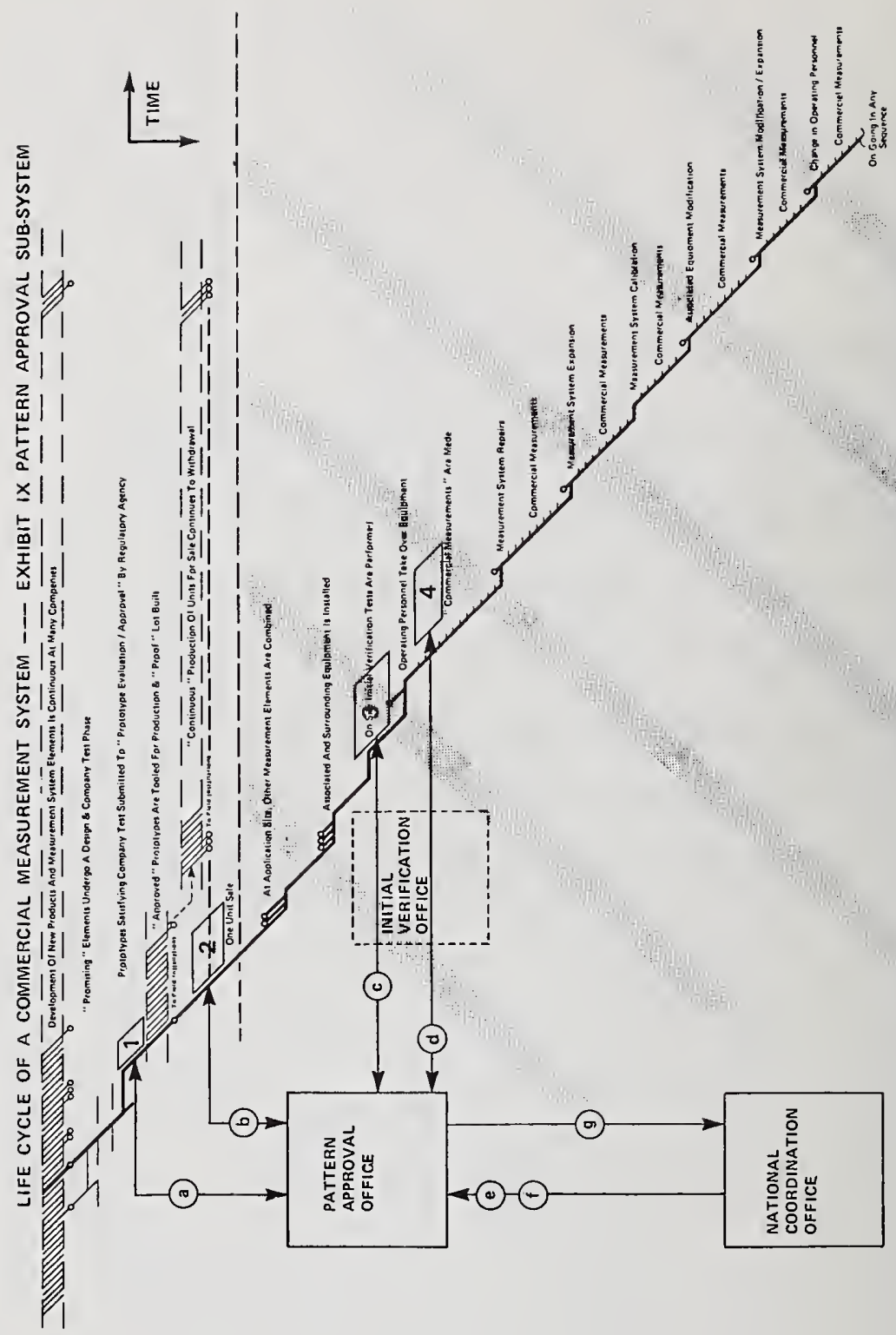


(A21)

EXHIBIT IX - PATTERN APPROVAL SUB-SYSTEM

Paper and laboratory evaluations (1) may suffice.

Evidence of reproducibility (2) is highly desirable.

Most larger equipment requires a small number of application site demonstrations, (3), and process evaluations, (4), to verify appropriateness of $\mathrm{lab}$ and paper examinations. Such field evaluations can utilize resolirces of verification sub-systems.

Regulations, (e), and procedures, (f), must derive from policy of National Coordination Office (coordinated with International bodies).

Reports of approval/rejection ( $g$ ) flow through national offices for dissemination to local and international agencies. 
EXHIBIT $X$ - SUMMARY OF PRINCIPLES FOR COMMERCIAL METROLOGICAL CONTROL

1. The fundamental objective of a desirable system is attainment of specified standards in actual operating circumstances.

2. Standards are precisely defined. Compliance is determined by application of precisely defined measurements. Equipment and techniques do not contain intrinsic measurement error greater than the standard to be measured and can be made reasonably available to the item under test.

3. Achievement of the objective (see \#1) is attained by field testing ("Subsequent Verification"). Earlier stages of testing (such as "Initial verification" and "pattern approval") enhance system cost effectiveness by serving to pre-screen and reduce workload at the field testing level.

4. Performance standards are used in preference to design standards. Performance standards focus directly on the fundamental objective of the control system and admit technological advance with minimal disruption to the control system.

5. U.S. federalization of weights and measures regulations is not mandatory or desirable in order to achieve the fundamental objective of a coordinated national control system or to arrive at a working accommodation with O.I.M.L.

6. A concensus of informed public opinion, as provided by NCWM, can provide impetus for an optimum control system, including initiation of required legislation and incorporation of appropriate public and private resources.

7. A combination of private and public resources (at several levels of the control sysitem) can be coordinated to achieve optimum system objectives, provided there is agreenent on a coordinated system concept.

8. "Subsequent Verification," as required by law, could be provided by pụblic resources or private resources (at direct cost to user) with appropriate audit by public resources. A distinction between "subsequent process verification" (public) and "subsequent equipment verification" (private) is useful in determining the best economic utilization of public and private resources. 


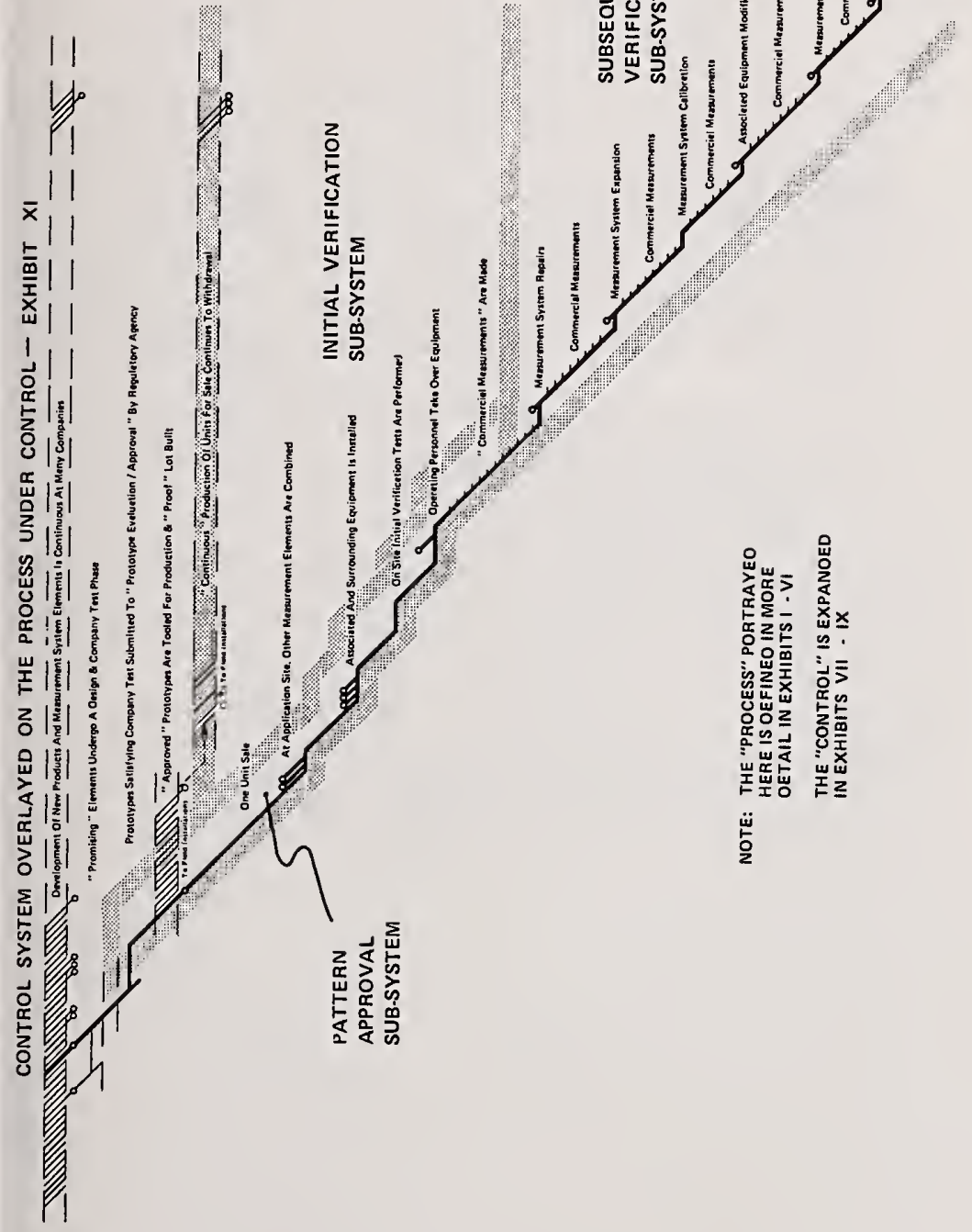


Recelves applications.

Evaluates on paper.

Decides extent of evaluation; i.e. paper, lab, and/or fleld and in uns. Can use private or state capability for lab and field tests. Issues approvals/denials.

Provides time/units duration protection.

Issues parameters and methodology for Initial and Subsequent Verification. Purpose is to protect verification sub-systems from excessive deficiency situations and relieve requirement for environment/stability testing.

Initial Verification Sub-System:

(See Exhibit VIII for Expansion.)

Verifies equipment and process performance of each production unit as applied at user site.

Can substitute factory acceptance on units prescribed during pattern approval sub-system.

Uses combination of state and private resources for process and equipment verification.

Purpose is to protect Subsequent Verification Sub-System from excessive deficiency situations.

Subsequent Verification Sub-System: (See Exhibit VII for Expansion.)

Evaluates equipment performance.

Evaluates process output for compliance to commercial trade intent. Purpose is to provide the commercial/legal system with accuracy assurance. 
EXHIBIT XII

SUGGESTED ASSIGNMENT OR ROLES IN US SYSTEM

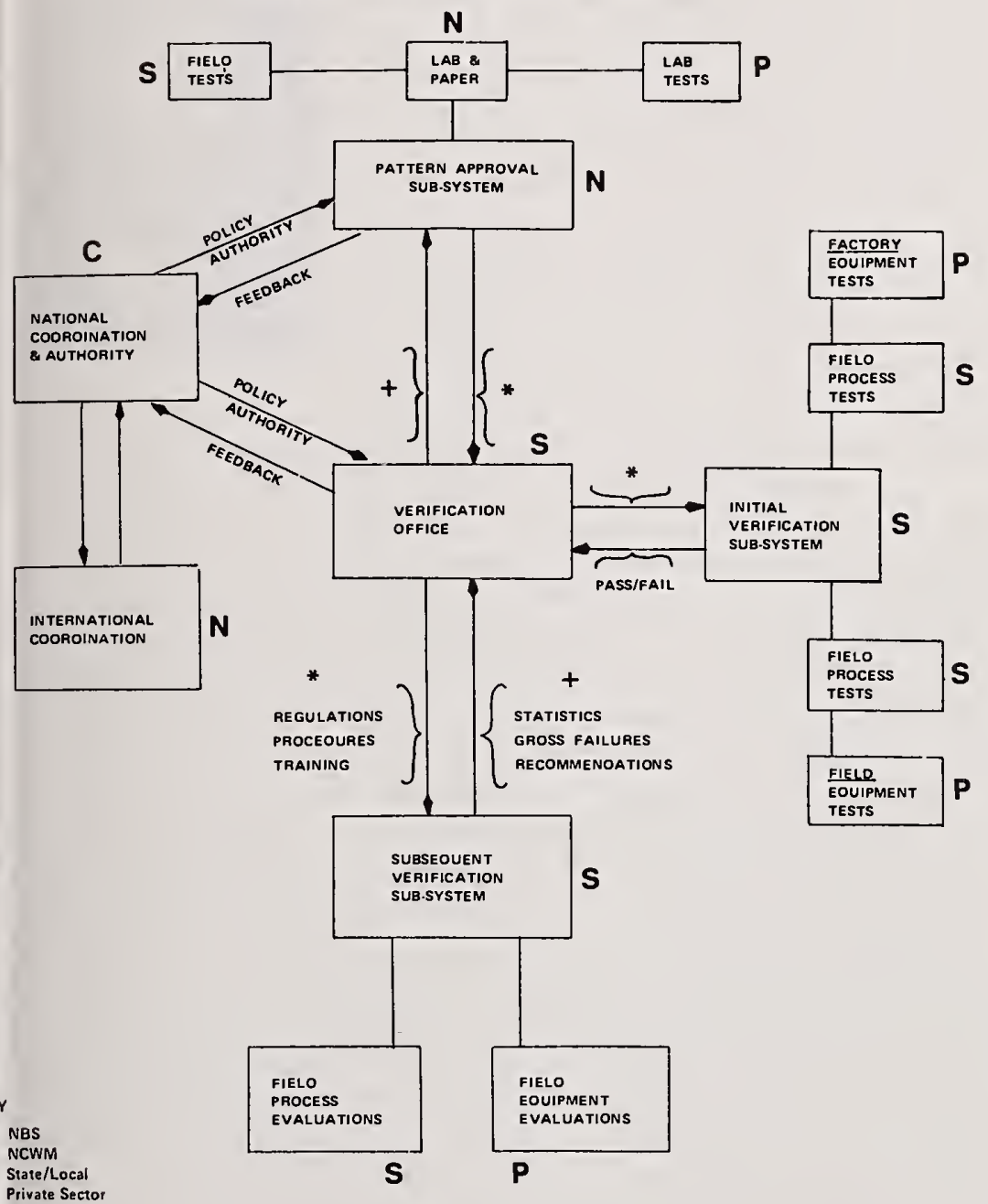





\section{METRIC UPDATE-USA}

Presented by Sydney D. ANDREws, Director, Division of Standards, Department of Agriculture and Consumer Services, State of Florida

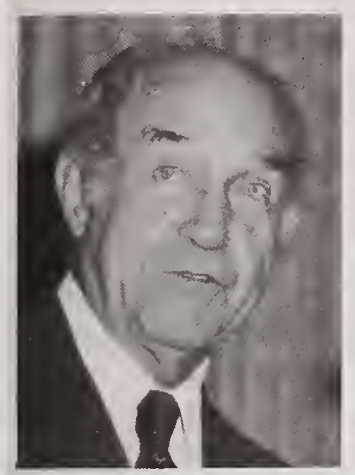

This is my first opportunity to give a report to the National Conference delegates on my appointment to the United States Metric Board and the work in which we have been engaged. We were privileged last year to have Dr. Polk, the chairman of the United States Metric Board, speak to the group. At the interim meeting of the standing committees I was privileged to give a brief report, and so I am quite proud at this opportunity to be able to speak to all of the delegates on what is happening within the United States Metric Board and to again express my appreciation for the honor you have done me in the recommendation and ultimate selection to represent you on the seventeen member United States Metric Board.

My serving on the board has really been quite a unique experience. Other boards that I have served on are groups banded together for a common cause and we have no difficulty in setting our objectives and agreeing on the method by which we will accomplish those objectives. Much to my surprise, I found that the United States Metric Board is made up of a rather heterogeneous group, perhaps rightly so, because it is obvious that the feeling of this country is not yet unified on whether or not we should adopt the metric system, and certainly some of the members of the board represent that thinking. Some of them are very strong willed people representing this wide diversification of interest and they do not hesitate to express their opposition to virtually anything that would further the cause of metrication in this country. So it has at least slowed down the process of the Board, but I hope that it will not completely bring to a halt the efforts of this country to adopt the metric system. Some of the people on the Board appear to be quite knowledgeable regarding the metric system and anxious to see conversion take place in an expedient manner within the framework of the law on a voluntary basis. Others appear to know very little about metric, and certainly have no enthusiasm for converting this country to the metric system of measure and take every opportunity to express those thoughts.

I hope that each of you at one time or another will have an opportunity to sit in on one of the meetings to see exactly the make-up of the Board and how we are trying to overcome the objections that are offered to furthering the cause of metrication. I offer you this invi- 
tation because I would like for you to know that all meetings of the Board are open to the public, with the exception of those occasions at which we are discussing the budget preparation prior to presenting it to the OMB. Under the Federal system you are restrained from making public this information until the OMB authorizes its release. Also, we have a closed session for the discussion of personnel matters, and these are about the only two situations granted to the United States Metric Board for closed meetings under the Government in the Sunshine Act. At all other meetings you are welcome. As a matter of fact, we have devoted a portion of each public meeting to a forum for representatives from groups who wish to appear, as well as individuals who would like to express their views of metrication or the Board. I assure you that we have had some rather vivid expressions of what some people think of the Board. I particularly hope that all of the members of the National Conference on Weights and Measures, Weights and Measures officials, as well as our associate members and those interested in the work of the National Conference will take advantage of the opportunity to attend one of these open meetings when it is in your area. If you wish to make a presentation to the Board, you are required to notify our secretary well in advance so that time can be allotted for your presentation; also we must have at least some outline of what you plan to present.

I am pleased to report that we have now held two meetings of the Board outside of Washington, one in Dallas, Texas, in February and the other in June in Boston, and they have been very helpful in getting input from various sections of the country. The Board has plans to hold the remaining sessions for this year outside of Washington. Next month we will be meeting in San Francisco, in October we will be in Detroit, and in December we will be in Orlando, Florida. We are trying to avoid the image of being just another Washington agency. We would like to be recognized as a citizens group trying to carry out the mandate of the Metric Conversion Act of 1975.

We now have had quite a few special meetings in between our regularly scheduled sessions at which specific items are taken up. Perhaps the most important of these was the open hearing May 2 and 3 in Washington on the feasibility of the option to convert motor fuel dispensers to a metric mode, rather than the expense of converting them to compute over one dollar a gallon. I am pleased to report that this meeting was well attended by all interested parties, and most especially am I happy to say that your representative from the $\mathrm{Na}$ tional Conference on Weights and Measures made an excellent presentation on behalf of the Conference. Also there were several individual states represented who stated their feelings on this particular issue. The participation on the whole was excellent and we received a lot of useful information. The testimony was, as you can well imagine, rather voluminous, coming from all of the affected sec- 
tors and it has taken considerable effort on the part of the board's staff and the members to digest this testimony and come forth with any kind of conclusion; but after digesting this sea of testimony we discussed the matter at the Boston meeting and the board approved the following declaration:

"The petroleum retailing industry generally indicates a willingness to dispense gasoline by the liter. Several States are taking independent action in requiring or recommending liter dispensing.

"Therefore, the U.S. Metric Board declares that this is an opportune time for the development of a planned and coordinated volunteer program of dispensing gasoline by the liter and the Board urges all affected parties to participate in the planning process. It called attention to the need for adequate public information in connection with liter dispensing.

"Without taking this action, metric usage is likely to proceed in a haphazard fashion, leading to public confusion, disparate end results and the negation of the positive cost advantages that a nationally planned and coordinated program offers."

The National Conference on Weights and Measures had taken a position on the conversion to metric mode retail fuel dispensers as early as, I believe, 1974, and so I am not going to say that the Board's action prompted our most recent work in this endeavor, but I do hope that the Board at least set the tone for the resolution which is before the Conference at this meeting. It is my further hope that before leaving here this week, this Conference will have addressed this subject in the form of a resolution that will set the tone for metric conversion of motor fuel dispensers in this country.

Now back to the work of the board. The three principal duties of the United States Metric Board as described under the act are to devise and carry out a comprehensive program of planning and coordinating metric conversion, to conduct a program of public education at all levels of society, and to conduct research and submit recommendations to Congress and to the President. I am pleased to say that we are beginning to make progress in each of these areas. We have committee structured the Board to handle various aspects of this work. In addition to an Executive Committee which acts on behalf of the Board on matters of interest between meetings, subject of course to the ratification of the full board at the subsequent meeting, we have a Research and Coordination Committee, a Private Sector Committee, an Administration and Budget Committee, and a Standards Liaison Committee. The latter, I am pleased to announce, 
Dr. Polk has asked me to chair. I hope that within the area of this particular committee those matters of concern to the National Conference, and other standards organizations which I represent on the board, will be addressed to me so that I can express your needs and your wishes adequately to the board.

In addition to those committees, we have an Annual Report Committee which like our P\&C committee is made up of the chairmen of all other committees, and this is the committee which is to put together our first annual report to Congress which is mandated in the act one year after funds are appropriated. Now at this point in time one of the most important needs is to remove obstacles from those who choose to go metric. Laws and regulations must be amended or repealed which are now obstacles to those who voluntarily decide that they would like to go metric. This is a tremendous job. I think that we probably more than any other body recognize this, because in the past the National Conference has made several attempts to identify the many laws and regulations that need to be amended. We have found it an extremely hard task to carry out; it is difficult to get the handle on. It is a large job even to identify them, and an even larger job to make the necessary changes through the legislative process. The Board has, in its first contract, awarded this to Middlesex Research Corporation as a project for identifying these many laws, regulations, and ordinances that must be changed if we are to remove the barriers to voluntary metrication. They have submitted to us their first prelininary report which indicates that they are making progress in this area, and they will be asking many of you in this audience for assistance in identifying those laws, regulations, and ordnances withir your jurisdiction. Also, the contract calls for a recommended procedure for bringing about these changes, because we recognize the diffirulty in dealing with various local legislative and promulgating autnorities. We feel this is absolutely essential if we are sincere about providing for voluntary metrication. The final report from Middlesex is due in time to be incorporated into our report to Congress, and because of the difficulties that have been experienced in this, we are hoping that the Congress will allow us a slight extension of time. It is virtually impossible now for us to meet the one year deadline which would fall about September and for that reason I, as you will recall if you were here on Monday, made a proposal to this Conference through our Liaison Committee to pass a resolution from this Conference directed to the Board to include in that report the repeal of those sections of the Federal Fair Package and Labeling Act which do present very real obstacles for those that choose to go metric. It is my hope that somehow within the mechanism of our committee structure, or our resolutions, before we leave here this week, that will be addressed to the Board, and the Board will see fit to incorporate it in their legislative recommendation. 
Now I would like to, at this point, say that using the popular expression, there is good news and bad news. The good news is that our most recent budget request for the coming year has been approved by the Senate in its entirety. The request was for 3.3 million dollars with an expanded staff which we feel is essential if we are to carry out our mission. The bad news is we have learned that the house has approved a budget calling for absolutely no increase over this year's budget, in either funds or positions. This will now go to a Conference committee and it is our sincere hope that the Senate's interpretation of our needs will prevail. We solicit the help of all of you to influence your Congressman to support the budget request of the United States Metric Board.

Now on the subject of liaison with the state, county, and local governments, I am pleased to announce that we have assigned a full time staff man on the Board to work with the state and local jurisdictions in their metric tion plans and programs. Larry Chisholm, who for a time was employed by the National Bureau of Standards, has been given that assignment as Director of State Programs. Larry is here today and in case there are those in the audience who do not remember Larry from his days at the Bureau I would like at this time to ask Larry if he would stand and give everybody a chance to know him. I encourage you to speak with Larry while he is here. I am sure he will be attending all future Conferences; between Conferences he will be at the disposal of states to assist them in any metrication plans that they have. It is essential, in my opinion, that gnvernment at all levels play a major part in metrication. Perhaps even a le: ding role, but I do not believe that government at any level should be over zealous in forcing metrication. We should be in the role of facilitating, rather than imposing metrication. I feel that it is especially important that there be good cooperation between the United States Metric Board and the Weights and Measures Officials. Those working officials that are going to have the day to day responsibility of helping to educate the public, I think need to be keved in to this program from the very beginning, and I know of no better vehicle for developing that liaison than the National Conference on Weights and Measures. The Act took special note of the importance of having input from the National Conference on Weights and Measures by providing one of the seventeen positions on the Board specifically assigned to the National Conference on Weights and Measures and other standards organizations.

I am afraid that I still have considerable work to do in convincing some of the members of our Board how essential Weights and Measures Officials are in the metrication program within this country. Many of them had never heard of the National Conference on Weights and Measures, and an even greater number do not thoroughly understand the role of the National Conference nor the officials and the 
associate membership that make up the Conference. I hope to be able to convince them in the future of the historical part that Weights and Measures Officials have played in policing the marketplace in this country to prevent fraud and deception. Because some confusion is inevitable during metrication, I think the Weights and Measures Official is going to have an even more prominent role in protecting both buyer and seller during this transition period.

It is my feeling that the ultimate measure of success of converting this country to the metric system rests with its acceptance and proper use in commercial weighing and measuring operations in the marketplace. I have no doubt about the conversion process within industry because there is an economic incentive for them to convert to the metric system, especially if they are engaged in international commerce. We have not yet come up with sufficient economic incentive in the marketplace to make the average housewife or the average shopper anxious to convert. I think we are right now working on one that can be demonstrated as at least a cost avoidance to the consumer in our metric conversion of the fuel dispensers, because it has been demonstrated on numerous occasions, including testimony before our meeting, that it is more cost effective to convert the gasoline dispenser to the metric mode than it is to convert it to compute over a dollar a gallon. I think for this reason we need to capitalize on this opportunity because we may never get another opportunity to so dramatically show the consumer that it is to their advantage to go metric. One of our really difficult roles is going to be converting the consumer, and yet I think it can be accomplished principally through education. The United States Metric Board has a commitment to the education of the people in this country about the metric system so that they can make an intelligent decision.

There will be many problems in changing people because the average person is not anxious to make the change. As a matter of fact, I think that I can characterize it better by saying that most are reluctant to do so, and realistically they will probably adopt the metric system only when they have no other viable alternative. Opposition to the metric system is growing in this country. I do not know whether it is because we have awakened a sleeping giant, or whether people are now learning that there are going to be some problems in making the transition. This opposition ranges all the way from humorous cartoons in the newspapers to the introduction of bills in Congress to repeal the Metric Conversion Act. The latest that we have had was the introduction of legislation in the Congress to deny all funds to the United States Metric Board. I am happy to report that that amendment to the Appropriations Act was defeated, but we must keep in mind that opposition to metrication comes not from stupid people, but from the uninitiated. Those of us who believe that metrication is in the best interest of the country have an obligation to acquaint these 
people with the benefits, because it is only natural to resist change. I find no fault with this. As I get older I find that I resist change more vigorously than ever, but if we are to have success of the metric system in this country, we must familiarize people with it so they can make an intelligent choice. The psychological aspects of the change to metric, to me, are much more formidable than the technological, because it is often more difficult to get people to think differently than it is to act differently. But it is a worthwhile goal, and I think we can accomplish it.

I sometimes find myself in the dilemma that Ken Simila described yesterday of his young son. Often at night when I lie down after a hard day with the United States Metric Board I find myself asking the question, "Am I going to be alive when we get there?" At my age it is questionable, but it is a worthy goal and I am willing to fight for it. Since ours is a voluntary program it is necessary for us to avoid even the appearance of force, and especially by any branch of the government, federal, state or local. We must do it by persuasion, and since the Metric Act is very specific that it shall be a voluntary program, the progress is going to be slow, and we must be patient. We must be very careful not to be over zealous and offend those who are a little less enthusiastic.

In conclusion, I would like to plead with each of you, who I feel have gone on record at least collectively within the Conference as favoring the metrication of the weights and measures of this country. We passed a resolution many years ago indicating our preference for it, and I am assuming that you still feel that way. I solicit your earnest effort to help because it cannot be done by the United States Metric Board alone. We are very limited in what we can do, the law is so specific about the Board having no mandatory powers, and quite frankly I do not think we want any. We are limited by the very make up of the membership of the Board as to how forceful we can be, and again I do not think we want to be too forceful. I hope that we can serve as a focal point for incentives that will hasten metrication in this country, but we must remember always that it is a voluntary program. Many people have been awaiting the formation of the Board, because as you know it took several years even after the Act was passed to bring the Board into existence. Many people were thinking that once the Board was appointed and in motion, they would wave a magic wand and we would have metrication in this country. Well, it is not going to happen that way. I can assure you after the description I gave you today of the Board, and their feelings individually, the Board is going to be rather slow in their progress. We need your help to convince those who are hesitant. We find ourselves in the position of a pilot coming on board a ship to help guide it through a very difficult reef to a safe harbor. We can provide guidance to those 
who seek it, encouragement to those who need it, and enlightment to those who still doubt very seriously the wisdom of this voyage.

\section{DISCUSSION}

LyMAN Holloway (State of Idaho, Bureau of Weights and Measures): Will there be available funds, time for travel, upon request from the state to have Larry visit that state to cooperate and coordinate whatever question there may be from that state, or must it be through communications?

SYDNEY ANDREwS: Within the limitations of our budget, Larry will be traveling to individual states to help them develop their plans, and certainly to serve in any capacity possible to provide a better liaison between the board and the state organizations. I am happy to say that most states now do have some form of metric committee or metric council. Regretfully, very few of them are funded so they do not have the money to do any traveling. It is all within their state. Larry has already made visits to several states and has developed rapport with their metric committees. I hope, if we have a little more liberal budget than we have had in the past, that we will be able to allow Larry to do this almost constantly. It is my hope, at least, that he can serve almost full time in this capacity. I did not mention, although I think I mentioned it in my report to the interim committees, that one of the casualties of our limited budget was our plan to have a west coast branch office in San Francisco. That was denied us. For the foreseeable future, I think we are going to have to operate out of Washington, although as I mentioned we will be meeting around the country. Incidentally, I did not mention the fact that next year's schedule has already been adopted and we do not plan to hold even a single meeting in Washington all next year. They will all be out around the country and we encourage people to come and talk. Meanwhile, Larry will be at your disposal.

LARRY CHISHOLM: In working out the budget at the staff level there is a strong recognition that you cannot have a state program without having travel money to go around to the states. We do hope that we can do as much as possible for reasons of economy by phone and letter, of course, but I think we all face that same thing. There are plans to have travel money for getting around to the states to work out any metric problems that may be appropriate.

LYMAN HollowaY: Then upon request, this would be the main thoroughfare as to whether you would come to my state or wherever.

SYDNEY ANDREWS: I do not know if you have been identified as the state representative or not, but a letter went out from the Metric Board office some months ago to the Governor of each state asking 
them to identify the contact between the state and the United States Metric Board. Our plan is to work through that contact, whomever the Governor designated. In many states I think the Weights and Measures Director was designated as the liaison with the United States Metric Board, in others perhaps the chairmen of the states' Metric Council, and so forth, but there will be one person that probably will serve as the focal point of contact for the state with the United States Metric Board. If you are not that person and you have an interest, I would suggest that you learn from Larry, or the Board, who he is so that you can interface with that person and get your message into the Board.

DAN OFFNER (City of St. Louis): It has been made rather clear that the Board overall is not enthusiastic about a general and rapid conversion to the metric system. I would like to ask you this. Is there a recognition on the part of the Board generally, or at least a significant segment of the board, that metrication in all areas is not necessarily equally possible, equally desirable? There are different paces at which different segments of the economy may very well be converted to metrication without undue disruption of the wife buying porkchops in the supermarket.

SYDNEY ANDREWS: I think the Board recognizes this fact. We have discussed this on numerous occasions and I do not want my presentation here this morning to be characterized by my friends on the Board as a dissertation against their viewpoints. They certainly are entitled to those viewpoints. I am beginning to understand better the United States Metric Board because as I pointed out earlier I expected to serve with a group of people who were enthusiastic about getting on with the job. I now recognize the fact that this Board was appointed to represent the varied interests in the country, and there are many people who are not in favor of metrication and they are entitled to representation on the Board. We have to face the fact that it's a democratic Board. Yes, we are well aware of the fact that the pace will vary from sector to sector.

LoUIS SoKOL (U.S. Metric Association): I would just like to remind the Conference members that one of the conclusions of the GAO Metric Study was that the nation cannot continue to exist very long efficiently using two major measurement systems and, of course, they implied that it has to go one way or the other. They did not say which way one should go. It is uneconomical and wasteful to continue working with two different major measurement systems. You have to decide one way or the other which one will be predominant and go that way in all sectors of the economy eventually.

SYDNEY ANDREWS: You may be interested to know that on the agenda for the San Francisco meeting next month is what perhaps should be characterized as a debate among members of the Board as to whether or not the policy of this country is to go metric. This has been such 
a controversial issue on the Board, we have decided to try once and for all to settle that issue because it has been a stumbling block for us ever since we had our first meeting. I have never ceased to be amazed at the number of interpretations there are of that one simple sentence in the Metric Conversion Act as to what the purpose of this act is. It says to plan and to coordinate the increasing use of the metric system in this country. You would not believe the number of interpretations we get of that one simple statement. We are going to have it out at the San Francisco meeting. So if you are in that area and would like to hear the debate, please come.

KEN Simila (Chairman, National Conference, Oregon): Just following up on what Lyman mentioned, and what you alluded to earlier, I think it would be appropriate for any jurisdiction to write to their Congressman, particularly if they have someone sitting on the House or Senate Appropriations Committee, or one who will be on the Joint Conference Committee on the United States Metric Board budget. Whether or not they are enthusiastic, we need to have the Metric Board functioning to coordinate what is going on. I was encouraged to learn, because of the letters that were written on behalf of the Conference to the delegation from Oregon, that both of our United States Senators were supportive of the Metric Board budget. I think in the next thirty days, or whenever that Conference Committee will be meeting, if those of you that have State Metric Boards or Councils or if you have a State Governors Task Force Representative, or whatever, if you can get some kind of letter of encouragement to them, that will make a significant difference in the outcome of that decision on the Board budget.

SYDNEY ANDREWS: We certainly solicit that kind of support and this is what it's going to take. I am not a politician, but I have had the dubious distinction of operating a technical program in a political climate now for forty-five years. One of the things I have learned is elected officials listen to the people who vote for them. I have absolutely no influence with anyone in the Congress except the congressman who represents me from the state of Florida and I encourage you, if you are in sympathy with us, to contact those people who represent you in the Congress and urge their support, or a favorable consideration of the Metric Board budget request.

JoHN MAYs (Miami): The Conference Committee that is considering the budget; I think it would be well for members that care to write to have the names of the members of that conference committee. If they have senators or congressmen from their area that they can write to personally on this, it might help.

SYDNEY ANDREWS: That is a very good suggestion. I am not sure who the Conference Committee members are at this time. Maybe Larry has some better information on that but I am sure we can get that from the Board office. 


\section{METRIC-UPDATE-CANADA}

Presented by John D. Buchanan, Departmental Metric Coordinator, Department of Consumer and Corporate Affairs, Ottawa, Canada

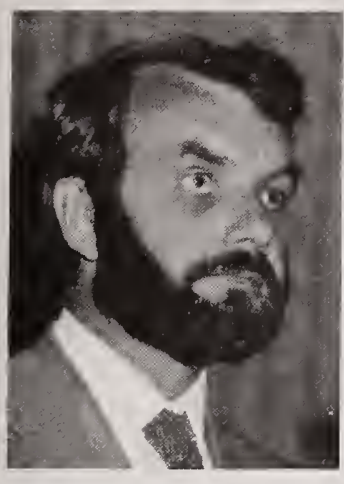

ference.

It is impossible in the time allowed to me to cover all the progress that has recently been made in Canada towards adopting the metric system in everyday life. Metric units are now being offered to Canadians in most domestic situations and are increasingly being accepted-albeit with more resignation than enthusiasm. As the exposure to the units increases so the resistance to change seems to decrease.

I have chosen four topics that I think would be of particular interest to the National Con-

1. Gasoline pumps. The conversion of gas pumps started on 1 January 1979 and in most areas at least half are now selling by the litre. In one province (Nova Scotia) conversion has been slow starting because of a peculiarity in the tax legislation. The conversion of provincial tax legislation has been the major legislative problem. Conversions of tax rates that are both equitable and easily expressed with a minimum of decimal places are generally not possible. Dates for the beginning and end of conversion were set by the federal government after discussion with the industry. Because of anti-trust concerns by the oil companies, each company has set its own plan within the overall start and finish dates. This means that price-conscious consumers are faced with having to compare price per gallon with price per litre over an extended period. Gas stations where the price per (Canadian) gallon was at or over $\$ 1$ have been the most eager to convert and this has caused some comments that prices have risen because of conversion. The technical side of conversion has proceeded very smoothly with both kits and labour readily available. Many pumps were given metric capability in advance of actual conversion by fitting a gearbox which could be inserted irreversibly into the gear train to the computer at the time of conversion by cutting a wire or pushing a button. All new pumps for some three years before conversion were given this metric capability. The conversion of terminal meters has been proceeding on a voluntary basis at the same time as the retail pumps. Thus the entire system from refinery to service station will soon be in metric units. Truck meters for heating oil deliveries are being 
converted rather slowly because of the unwillingness of independent agents to make a commitment and, in some cases, a shortage of the necessary parts.

2. Retail food scales. The conversion of three pilot areas started at the beginning of July and it is too early to comment on any problems or difficulties. The plan was devised by scale industry and retail trade representatives and legislated under the federal Weights and Measures Act. Canada was divided into 100 areas and three dates wore set for each area. After the first date, which can be called the start of conversion, all advertising outside of the stores must include the price per kilogram if a price per pound is mentioned. Conversion of scales must be completed by the second date and after the third date all advertising must be in metric units alone. Learning from the Australian experience we believe that the control of price advertising is a key element in a successful conversion. Dual price advertising should not be unduly prolonged, but it is a necessity during the transition period in order to prevent accusations that retailers are taking advantage of conversion to raise prices. The federal government has given an exemption from sales tax for conversion parts and also a provision that enables purchasers of new scales to set off the total cost against tax in a single year.

3. Piece goods and home furnishings. This was not an area that was originally considered for legislation. The conversion of the retail sale of piece goods (formerly known as yard goods) began on a voluntary basis in July 1978. By the end of 1978 it was clear that a minority of retailers were not intending to convert and the result was a confusion of prices for consumers. The majority of the trade then requested a legislated cut-off date and this request was included with a similar request from the home furnishing retailers. However, the regulations on home furnishings have been delayed because of continuing discussions regarding the dual labelling of prepackaged goods but the cut-off date for the sale of piece goods in traditional units has been set for 30 September 1979.

4. Prepackaged foods. The conversions of the previous three items have all been assisted by legislation, but these are the only areas where this method has been used. The vast range of prepackaged goods is being converted voluntarily. Of necessity this is a slower, more piecemeal approach and is resulting in some problems for manufacturers and consumers. Typically a product group chooses a date to start conversion that is agreed by most or all of the major companies in that group. However one or more companies (often importers) decide to retain the former sizes which, for products sold 
by mass, are usually $10 \%$ smaller than the new metric sizes. Consequently there is a duplication of sizes on the market-tracitional and metric. The only way to prevent this is to have legislation available that can readily be used to limit the number of sizes if a situation leading to proliferation appears to be developing. This conflicts with the principle of a voluntary conversion and a policy decision has to be made as to which is the lesser evil-proliferation or compulsion. In Canada net quantity declarations in metric units are mandatory (any other units may be added voluntarily) and so a comparison is always possible between products of different sizes even if the soft-converted numbers are frequently far from round. Many products in flexible packaging (paper, board, polythene, cellophane, etc.) are now in hard metric units, but rigid metal containers and returnable bottles pose particular problems. Returnable soft drink bottles are following a "compatible" conversion where bottles of similar size are on sale side-by-side at the same price. Gradually, by attrition, the old bottles are being replaced by the new metric sizes, which are slightly larger. The number of complaints about this type of transition are very small. The majority of complaints arise from a reduction in size and no reduction in price. The conversion of rigid metal containers is ultimately dependent on the adoption of metric sizes by can manufacturers and their customers in the United States. However rounded conversions of existing can sizes are being considered as a possibility.

These four "case histories" represent four different approaches to the sale of commodities at the retail level. My ambition has been to give you an idea of the progress being made in Canada and, of course, the different legislative backgrounds between Canada and the United States preclude direct comparisons. Nevertheless I hope that you will find my remarks of some interest. 


\section{STANDARDS—LOVE THEM OR LEAVE THEM}

Presented by RoDney E. LEONARD, Deputy Director, U.S. Office of Consumer Affairs

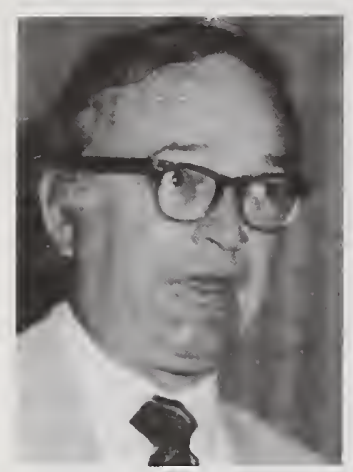

It is a pleasure to be with you. I bring special regards from Esther Peterson, who asked me to extend her greetings. She has a warm place in her heart for you and the Conference. She spoke to the Conference a year ago in Washington, a town you will remember as a warm, if not hot place. It still is, in several senses of the word. For those of you from Washington, let me assure you that your jobs are still there-and the people who have them want you to know that they are taking good care of them. I must admit it has been a bit con-

fusing to some. We had to send a number of memos last week to Energy, Transportation, and HUD but we weren't sure the people we knew would be there. My Secretary has been around Washington long enough to know the solution-she addressed them to "occupant". The standard in Washington is that change is the norm.

That is good for some things, but change is not a very good standard for standards making-at least not routinely. For the consumer, standards are the consumer's best friend. They give consistency to our lives, and continuity to the economy. We love them and don't leave them. At least not all the time.

When I was preparing for this speech, Al Tholen, who most fortunately has come into the present and future of weights and measures, asked me for the title of my speech. That is like asking the name of your new baby 10 months before birth. I said, "Love them but don't leave them." "No," I said, "Love them or leave them." "No, that's not always true. The title is 'Love them and leave them'."

I realized that all three phrases are true-some of the time. Standards-weights and measures-are as dynamic as our society. We love them always, because society cannot exist, cannot function, without them. Some we should not leave ... some we cannot leave ... and some we must leave.

One standard we must leave is the English or non-metric system of weights and measures. We love our inches, yards, ounces, and pounds, but the time has come when we must recognize that the metric system is better. The point was brought home to me most vividly when my daughter returned from a trip last week which took her into Canada. The Canadians, she said, use metric measures on gas pumps. Dad, they are so simple to use, and they are easier to understand. I really like them much better. When are we going to go metric? 
I said I wish I knew, and told her I was going to speak to a group next week that could do something about it.

You have a policy statement to consider on the conversion of gas pumps to metric, and I hope you will endorse this. I was very encouraged when the U.S. Metric Board after extended public hearings on the matter, endorsed the conversion of gas pumps to metric. California has adopted metric units for gas pumps and has begun an orderly conversion. Others will follow, and the acceptance of a model standard by the Conference will not only encourage the orderly adoption of metric in gas retailing, but also contribute to broader public support for and acceptance of metric conversion throughout our economy.

The Federal government can and should and will do more to support metric weights and measures. President Carter, as you know, has given his support to a strong interpretation of the Metric Conversion Act, and a Presidential endorsement can be translated into a progression of actions. The first among them is to change the current regulations enforced by the Food and Drug Administration, by USDA, by the Federal Trade Commission, and by other agencies which prohibit metric units. Regulations which protect consumers from fraud, deceit, injury, and harm should not be used to prohibit the substitution of metric for avoirdupois. Syd Andrews referred to this problem earlier.

I refer to the code of regulations issued by the Food and Drug Administration which requires that food labels specify the type size and nomenclature in English units. Metric units may also be listed, but only in addition to the conventional units. Similar mandatory use of English units is required by the FTC. This condition illustrates one reason why standards go unloved. If the Government demonstrates minimal faith, how can the public have any faith in testaments to the value of metric units ... or any other standards, for that matter? The answer, quite clearly, is a careful assessment of how the processes of Government may impede a useful program, and development of a methodical strategy to remove, or modify, those impediments. I am glad to hear from Syd Andrews that such an effort is under way. Our office, more than most, has some experience with such impediments, and will assist the Metric Board, the Conference, and the OWM in this direction.

Another area where improvement may contribute to a more loving relationship toward standards is research and funding for research to develop the technology of weights and measures, research to develop more precise tools and procedures of measurement, and research to develop concepts for standards that will enable consumers to better utilize the marketing system-or, to put it differently, to improve the ability of the marketing system to better serve the economy. 
For example, we are more aware today of the relationship between food and health than ever before, but we are unable to effectively relate the nutritional value of the food products we buy in the food system to the cost of those products. The information that we place on food labels today, regardless of the unit nomenclature, does not easily or effectively translate nutritional value into economic value. The food label is a billboard for information which the seller wants to convey to the buyer, but the quality standards-i.e., standards of identity - we have long accepted, are meaningless to consumers who seek to relate nutrition and health to cost. The problem is not whether the billboard is partly or wholly public property, but whether we can develop standards to convey these new concepts of quality-of nutritional values. Ingredient labeling is part of this new system of standards, as is nutritional labeling, but we only know enough now to proceed voluntarily toward a solution, and that is simply to say that we are doing broad scale field research.

Another problem which causes the consumer to withhold love, if not affection, from standards is the confusion which has grown around the process by which standards are adopted. It is not so much that a process exists as it is the lack of a process.

Congress enacts the Fair Packaging and Labeling Act, but not much happens. Packaging sizes seem to continue to proliferate and to be in confusing array. The Conference adopted the 1978 Model State Packaging and Labeling regulation, the latest of several model packaging regulations. Thirty-Five States have adopted one of these models, and fifteen have none. Diversity sometimes is a sign of strength, but here it is only confusion.

There is also confusion when States develop standards for food products, and for labeling criteria, only to be told by the courts that Federal standards preempt the States. Further, the firms that market interstate-and most do-are asking the Congress to preempt State standard-setting authority more often than ever before. The situation can be framed as a States Rights issue, but that only begs the practical questions. The problem is that Congress cannot legislate specific standards without the danger of casting them in concrete; but neither does the present process serve the legitimate needs of the economy. Legislatures must authorize the development of standards, but they should resist the temptation to develop standards. The temptation, however, is minimized if there is an efficient, responsive, and effective mechanism to develop standards and the technology to make them work. The development of model statutes and regulations, in which this Conference is engaged, is an essential part of that process; but it does not assure the uniform and timely implementation of the standard. The problem, in part, is implementation and follow through. That in part is an aspect of management, but it also has organizational elements which many agencies overlook. 
I am referring specifically to citizen participation, to participation in the planning and preparation for the work of the Conference as well as in the adoption and implementation of model statutes and regulations. The citizen should be in on the takeoff as well as the landing.

We in government can easily lose touch with the people we serve unless we establish active mechanisms to insure citizen participation in the decision-making process. I urge you to reflect on this notion and, if you are not already doing so, to explore and institute innovative mechanisms to bring more consumers and citizens into the process of standards development and implementation by State and local authorities. It will repay your efforts many times over in gaining understanding and support for your programs, in identifying areas where new or improved standards may be needed in shaping a government procedure which will effectively serve the interests of all the people. With the advent of metric coming directly into our lives, now via gasoline dispensing, this may be a good time to establish or improve channels to seek and obtain consumer views on fitting the standards to their lives.

Gasoline conversion can be the first sustained exposure to metric units which the American consumer will encounter. It should be a positive experience in the use of metric symbols to practice consumer skills, and to apply them in the consumer interest. The conversion of liquor bottles to metric for example was a disaster because the consumer perceived the industry conversion as a campaign to raise prices by reducing the volume of containers. It may have been a conspiracy to drive the metric advocates to drink.

Some people contend that public participation is a sure way to drive public employees to drink. The record, however, does not bear this out; what it does show is the appearance of public acceptance, and support for the program and its objectives. It may also lead to better public education programs and activities.

If this project does not create love, then it leads at least to trust, if not affection, and that is a standard for relationships we all seek. As John Buchanan said: the important thing is to minimize confusion.

In closing, let me assure you that the Office of Consumer Affairs is willing to follow up on activities which I have mentioned in my speech. We are willing to help on these, and on other projects you may propose. We do not propose to love you and leave you. 
Presented by John A. Stitzell, Manager, Planning \& Economics, Amoco Oil Company

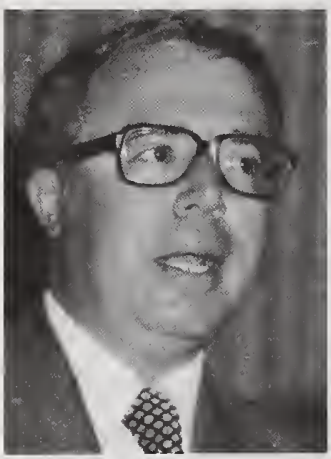

On behalf of Amoco, I am happy to participate in this conference. Amoco's immediate interest in metric conversion arises from the fact that most of our current gasoline pumps are not equipped to display and calculate today's product prices.

Like the song says, "something's gotta give." Amoco has spent considerable time in trying to find the most economical and socially acceptable solution as to just what should give.

Under the broad question of conversion to metric, I'd like to discuss three considerations: First, the cost differentials between alternate solutions; second, the question of consumer acceptance of such a basic change in the mode of gasoline marketing; and third, the issue of who might initiate such a change. Today, I hope to show how the answers to these questions point in the direction of a conversion to metric, even in the short run.

With respect to alternate solutions, one assumption must be kept in mind: Whatever the short run strategy, in the long run, Amoco believes there will be metric gasoline dispensing in the Un1ted States.

Two facts highlight the current situation: Fact one is that in many parts of the country today, gasoline is now selling for a dollar or more a gallon; fact two: this comes at a time when as many as 95 percent of all the gasoline outlets in the country are not equipped to display and compute a dollar or more per gallon price on their meters.

What is the cost of converting to $\$ 1$ per gallon pricing? Amoco's estimates of the costs of the industry's alternatives are fairly consistent with the $\$ 200$ per pump estimated by the U.S. Metric Board. However, we estimate that our own cost penalty from postponing a change to metric is about one-third higher than industry numbers would indicate. In current dollars, Amoco estimates its cost would be about $\$ 13$ million more to make a two-stage conversion-first to a dollar or more a gallon, and then later to a metric system-than it would be to convert to metric now.

The second consideration was that of the consumer's acceptance of a conversion to metric. Amoco's marketing research studies show that 70 percent of the population is very much aware that the U.S. shift to metric is going on. Because of the lack of familiarity with metric units, however, there is a good deal of skepticism about changing the mode of gasoline sales. In fact, attitudinally-and I stress the word "attitudinally"-only 7 percent of the population is strongly in favor 
of metrication. By contrast, 32 percent strongly oppose going metric in gasoline sales.

These attitudes, however, do not necessarily translate into actual purchase behavior. To study actual purchase behavior, we examined the purchase records of our National Motorist Diary Panel of 5,000 cards during the period April 1978-March 1979; the results of the study are summarized in Figure 1. These motorists made 218,052 purchases of over 2 million gallons during the year. Only 33,387 purchases, or about $15 \%$, were in exact, whole gallon amounts. 12,257 purchases were exact gallon purchases, which were also in exact dollar amounts. The remaining $10 \%$ or 21,130 purchases were made in whole gallons at uneven dollar amounts. Purchases made in convenient five gallon multiples amount to only 6,503 purchases or 3 percent of all purchases. Of the 21,130 purchases in whole gallons at uneven dollar amounts, we found that by far the most common whole gallon purchase was at the ten-gallon level with small but significant peaks at five and fifteen gallons.

The point I wish to make is that no fewer than 85 percent and most likely as many as 90 to 97 percent of all gasoline purchases are made in dollar amounts or fill-ups.

The clear implication is that the gallon unit is not a critical or even a significant volumetric consideration with motorists at the point of purchase. These data strongly suggest there would be no serious problems for the public stemming from a conversion of gasoline dispensing to metric units.

The third area I wish to address is how a change to the metric system should be accomplished. In spite of our analysis of actual motorist purchase patterns, Amoco believes the job is too big for any one company to convert unilaterally. The problems could be quite complicated when one considers the multiplicity of local and state governmental units-many of which are directly or indirectly involved with per-gallon tax revenues or monitoring weights and measurements. Dealing with customer resistance on one hand and with the requirements of government units on the other requires coordination and centralized direction. No single company or industry association can provide such direction of the scope required.

In the absence of such centralized coordination, companies such as Amoco will, of necessity, continue to implement higher cost interim solutions. At present, for example, we are retro-fitting our pumps as needed with equipment that permits sales of gasoline at a dollar or more a gallon. The retro-fitted equipment also has the potential for later conversion to metric. Even this approach will present problems. In many locations today, dollar per gallon gasoline is a reality. When equipment to handle dollar per gallon pricing cannot be delivered and installed in time, sales have to be made temporarily on a half-gallon basis. Many of you, I'm sure, have noticed this solution in your home areas or in traveling here. 
The half-gallon pricing approach has problems with uniformity and communication with the public.

Figure 2 is a photo of a set of dual Amoco pumps in the Chicago metro area. This hand lettered information generally adheres to the recommendations contained in the National Bureau of Standards memorandum of May 9, 1979, pertaining to half-gallon pricing. In spite of good intentions, the results are difficult to read, at best.

The close-up view in Figure 3 shows that a service station operator has to be ingenious to find someplace on the pump where half-gallon pricing signs do not violate the intent of other posting regulations. The half-gallon signage must also compete for the motorist's attention with digital meters, the state weights and measures sticker, the FTC octane posting, and the DOE ceiling price sticker.

The set of dual pumps in Figure 4 displays half-gallon pricing using a decal kit provided by Amoco. The decals are printed and will enhance uniformity, but many problems will remain. For example, the double signage on the dual pumps adds extra confusion. The pump face is more readable, but still remains cramped and cluttered. We believe there must be a better way.

Amoco is aware of the formidable problems in converting to the metric marketing of gasoline. Ultimately, we may have to change our accounting procedures and install different metering equipment on delivery trucks and at other locations. But we believe the time has come to make a decision.

Our recommendations are: The motoring public should be spared paying inflationary, non-productive costs of converting to $\$ 1$ a gallon equipment. Therefore, Amoco recommends a timely, coordinated, centralized effort for metric conversion.

We would expect that a U.S. conversion to metric gasoline dispensing would be complex and not free of problems as the change is made. But that would be the case whenever the change is made. Consequently, we believe the best course of action would be to do now economically what we will otherwise do later at greater expense. 

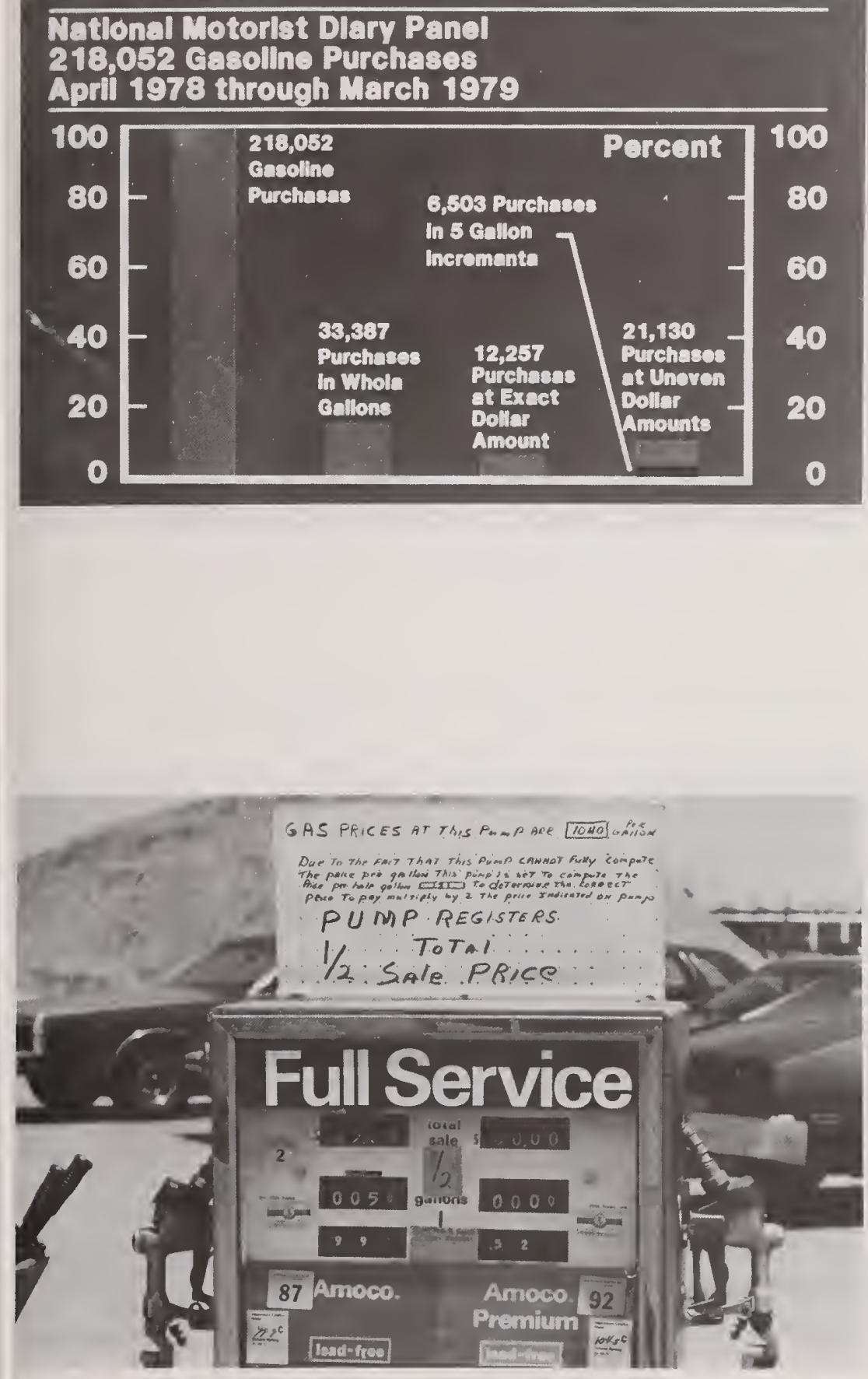

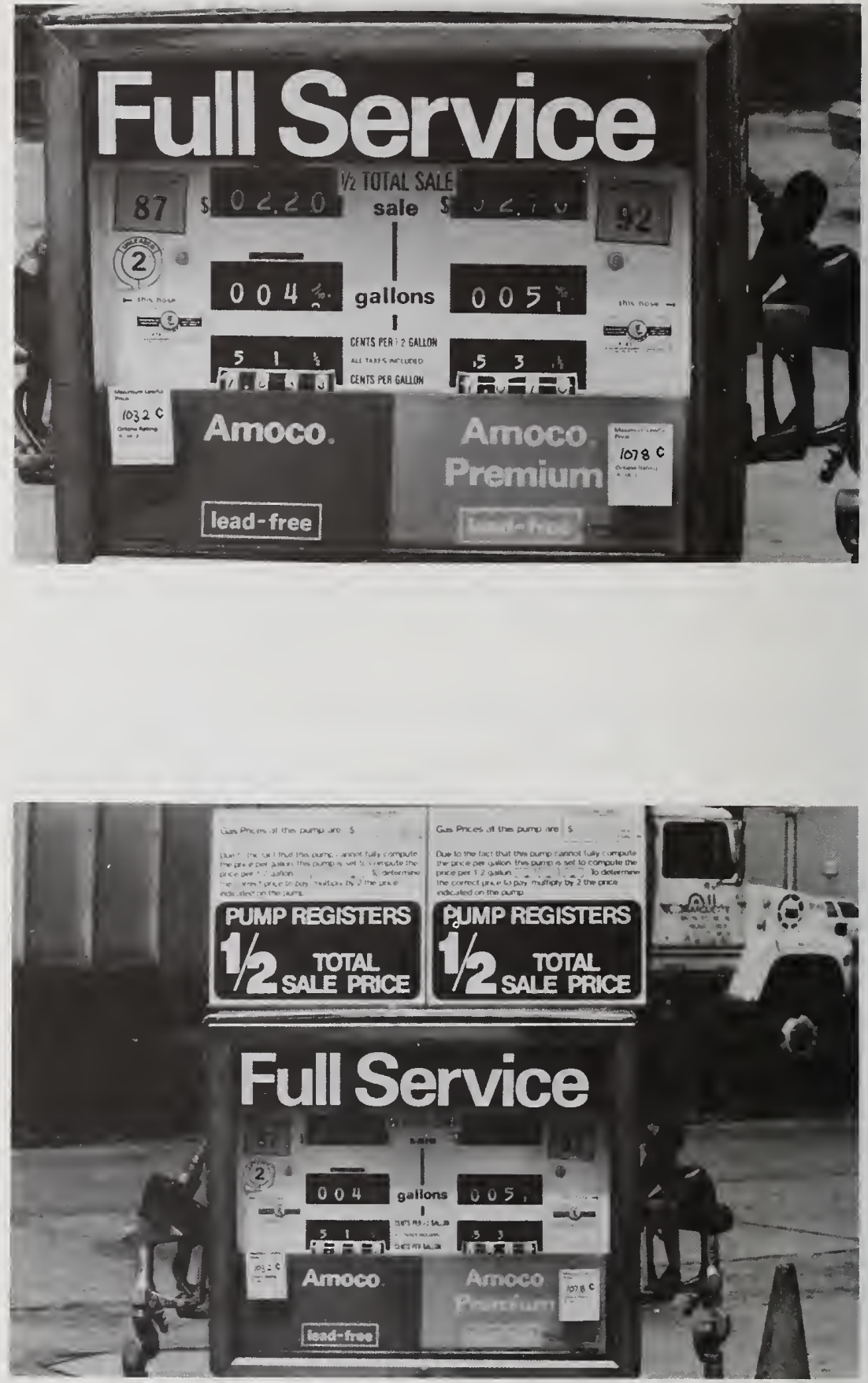


\section{ASSOCIATION'S SPOT REPORTS}

\section{AMERICAN PETROLEUM INSTITUTE}

\section{Presented by RichaRd SouthERS, Manager, Operations and Engineering, API}

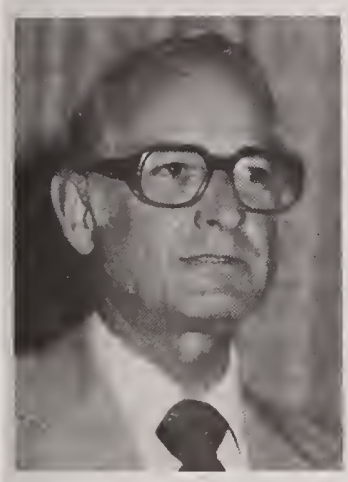

following statement:

It is my pleasure to be included in this new item on this year's program. Bud Wollin is to be congratulated for coming up with his idea.

The American Petroleum Institute is a trade association with membership from all segments of the industry. There are other trade associations in the industry with more narrow areas of interest such as refiners, pipeliners or independent, marketers, but we are the only one with the broad coverage.

API was established in 1919 and one of the objectives in the original charter included the

"The Institute should in all lawful ways afford a means of cooperation with the Government in all matters of national concern."

Our participation in the National Conference on Weights and Measures is a means of fulfilling this obligation. We also have branch offices in thirty-seven states which generally use the name of (Ohio) Petroleum Council or Association. Their activity is strictly statewide in nature. I hope that most of you not only know of the existence of these organizations but also know some of the people staffing them. They can be of particular use to you when you find the need to communicate with our members in your area.

Recently we sent to all states a copy of the temperature compensation study of retail gasoline marketing which was done for us by the Radian Corporation. Harold Harris, chairman of our Weights and Measures Task Force, presented a synopsis of this report at the recent Symposium on Temperature Compensated Volumes in the Sale of Petroleum Products. The report is not the type of document that every official needs for personal reference. However, any jurisdiction who would like a copy can secure one by either contacting me or Gary Hirschl during the conference or by writing to me at our office in Washington.

Currently, API is carefully monitoring the metric movement to see what our role might be in providing assistance to those marketers who want to make the change. Because of the potential effect in the market place that metric may have, the legal constraints of a trade 
association have precluded any direct action. We are participating in the activities of the American National Metric Council.

I hope that most of you know me, or at least who I am, and if you feel that there is some way in which I can be of service to you please don't hesitate to call upon me. 


\section{NORTHEASTERN WEIGHTS AND MEASURES ASSOCIATION}

Presented by Sidney A. Colbrook, Chairman, NEWMA

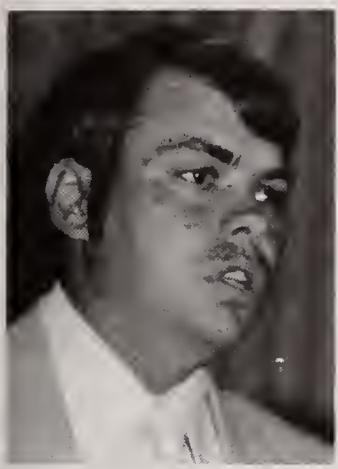

The Northeastern Weights and Measures Association is having their 8th Annual Conference in Springfield, Illinois, April 28th through May 1st, 1980. I would like to take this opportunity to invite all National Conference on Weights and Measures Members to participate in our Regional Association Meeting.

Our past Chairman, Allan Nelson, introduced the workshop concept of arranging various topics related to weights and measures officials. The workshop consisted of representatives from industry and regulatory officials to discuss topics relative to all. Subject matter included items such as net weight, temperature compensation and weights and measures administrative problems. The members of this workshop consisted of Al Tholen, Harold Wollin, Robert Probst and John Bennett. Allan attempted to have all present chairmen of the various regions serve on this panel so that an exchange of ideas could be obtained from the different regions.

We were very fortunate to have Dr. Louis Polk, Chairman of the U.S. Metric Board, address our 7th Annual Conference on the views and goals of the board.

Veeder-Root provided our association with a tour of their Hartford plant. This tour certainly was interesting, especially with the escalating costs of petroleum products.

Tom Geiler from Hyannis, Massachusetts, has agreed to host the 9th Annual Conference in 1981.

Again, I would like to take this opportunity to invite any National Conference participants to Springfield for our 8th Annual Northeastern Weights and Measures Association Conference. 


\section{NORTHWEST WEIGHTS \& MEASURES ASSOCIATION}

\section{Presented by Alden M. Lemke, President, Northwest Association}

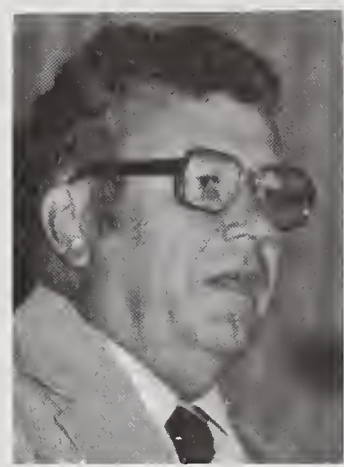

The Northwest Weights and Measures Association is one of the oldest regional associations in that we have just held our 42nd Annual Meeting in Madison, Wisconsin, last March. The Northwest Weights and Measures Association was formed by a splinter group that left the Northwest Division of the National Scalemens Association because they wanted to include gas pump and truck meter people in the group.

The broad objective of our association is the same as that of weights and measures personnel world-wide; i.e., that "Equity Prevails in the Marketplace." However, we were more specific in our constitution and stated objectives that call for uniformity between jurisdictions, continued training and education for the inspector and the service agencies, realistic and fair laws and regulations, and an informed educated consumer. While these are fairly noble objectives we feel they properly represent the dedication of our members to their chosen profession.

The membership of our association consists of regulatory officials and industry personnel concerned with improving and gaining more uniformity in the complete weights and measures field. This membership includes representatives from all parts of the United States and even a few members from Canada but comes predominatly from the seven northwest states of North and South Dakota, Nebraska, Iowa, Minnesota, Michigan and Wisconsin. In 1978 our paid membership was 234 members.

Our constitution was changed in 1978 to more closely follow the pattern of the National Conference in that the officers and board of directors of our association consist of regulatory officials. At the present time I serve as President and the Vice President is Vince Meuwissen of Minnesota.

Our Secretary and Treasurer is Bruce Adams, also of Minnesota Weights and Measures. The Seargent-at-Arms is Steve Malone of Nebraska. He is also Chairman of our Education Committee. Robert Probst of Wisconsin is the head of our L \& R Committee, and Frank Nagele of Michigan chairs the S \& T Committee.

These committees have the task of screening input from the various states and then submitting those changes or ideas that the Northwest Association as a whole supports, to the National Conference committees. We, of course, do not always have the whole committee in agreement on what is to be submitted but suggest, when an individual 
state disagrees with the majority, that it act independently on that issue.

Also, the committees have the responsibility to bring before our membership at our Annual Meeting those items from the interim committee meetings of the National Conference that need explanation and discussion.

Our meetings of the S \& T, L \& R, and Education Committees will be held September 24-25-26 at Omaha, Nebraska. We would welcome any input that you people in industry may have and if anyone wishes to present an idea please contact one of the committee chairmen or me and we will make the necessary arrangements.

I also wish to inform you that we are returning our Annual Conference to the Twin City area next year and will be meeting March 3-4-5, 1980, at the Midway-Twins Motor Inns in Saint Paul. At this time I would like to extend an invitation to all of you to join us in what has always been a very informative and interesting meeting. 


\section{NATIONAL SCALE MEN'S ASSOCIATION}

\section{Presented by William V. GoodPaster, President, NSMA}

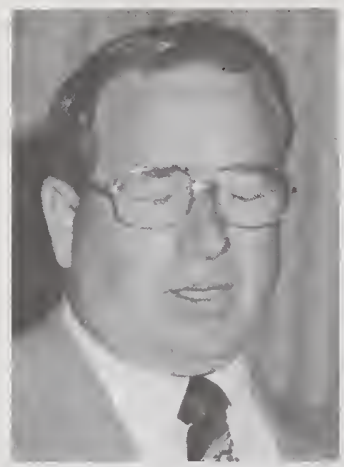

The National Scale Men's Association is a non-profit corporation incorporated in the state of Illinois. It has approximately 2000 members made up of people from 14 countries all involved in weighing.

The qualifications for membership as stated in the NSMA constitution are:

"Any person engaged in the manufacture, construction, repair, installation, design, sale or use of scales, or who is engaged in weighing or the direction of weighers, or who is a Weights \& Measures official or deputy, or who is teaching or a student of weights \& measures."

I'm pleased to report that all of these classifications are well represented in the membership.

The first of the four objectives stated in the NSMA constitution is: "To create a better understanding of the importance and scope of the weighing industry by the public, thus furthering the welfare of those engaged in weights and measures activities."

We sponsor weights and measures week which is strongly supported in the weighing and measurement field. Coverage by newspapers and TV stations, special school demonstrations, and the display of emblems calling attention to this week of special emphasis, are used all over the country.

I would propose to you that the public still does not recognize the importance of weights and measures activities, and our objective should be to rectify this situation. If the proper priority is placed on this objective, we would not see cuts in weights and measures budgets.

I am convinced that there is no sector of our government that has such a far reaching effect on industry, agriculture, transportation, and consumer protection as weights and measures. We know this because we are involved in this special field. The public doesn't. It certainly seems to me that on this objective NSMA and the weights and measures jurisdictions of this conference are in complete accord.

At a recent meeting with some California officials, the statement was made that the total budget for all of weights and measures activities in California was approximately 7 million dollars and that the consumer protection agency had a budget of approximately 14 million dollars. I feel that weights and measures enforcement as a by-product does twice as much consumer protection. The public should know this. 
The second objective is: "To make available information on the proper use and application of weighing devices which will help industry and commerce achieve their goal of higher standards and greater efficiency." Here is an area where a unique free exchange of information regarding techniques that are often competitive is shared by people. Almost all manufacturers of weighing equipment cooperate by supplying application examples in written form, slide presentations, and lectures by top technical members of their organizations. These presentations are made at the NSMA annual technical sessions. Many of these presentations are now edited and narrated by the original producer and are made available at no charge to NSMA local divisions. There are funds available now to supply top technical speakers to local divisions for their seminars. This presents an excellent opportunity for all of us involved in weighing to increase our knowledge and, as a result, do our jobs better. Some of you are aware of this but we could use a great deal more participation by weights and measures officials.

The third objective is: "To promote weights and measures work by encouraging legislation which will produce better laws and better recognition of weights and measures officials."

I'm sure that most of you are aware that the NSMA does make its voice heard on issues when a consensus opinion can be reached. Due to the structure of NSMA, it is generally not possible nor desirable to lobby for or against an issue. However, the scope of our membership allows an issue to be considered from several viewpoints. This will enable individual members to establish their own position.

The fourth objective is: "To benefit the scale man by providing an exchange of ideas, a common meeting ground for understanding and cooperation, and an opportunity to keep abreast of technical advancements."

This is one of the most important contributions of NSMA to weights and measures. A high school student can get courses in automotive mechanics, machine shop, aeronautical service, etc, in his industrial arts programs, but there are almost no courses dealing with weighing. There are no text books written on this subject. Almost all knowledge of weighing principles and applications comes from a person to person exchange. The NSMA was responsible for the first formal study program in measurement science instituted at Alfred University in New York State. A scholarship fund was established and financial assistance is available to students who are interested in a career in the weighing field. NSMA was responsible for the measurement science courses introduced at Yuba College and several scholarships have been issued to students there. A "Scales on Saturday" program where a full day's training seminar is held at Yuba College is the result of the Northern California division's interest in this objective to provide education in the technical advancements of the industry. 
The "Scales on Saturday" program is a composite of lectures, handson training with devices, application examples of how to apply new device innovations, and inspection, testing and enforcement procedures. I'm pleased to report to you that this idea has now spread to NSMA divisions all over the U.S. Successful seminars are being held in New England, New Jersey and the Southeastern and Northwestern divisions. California was host to the 57th Technical Conference in Los Angeles and will be host to the 61st conference in 1980 at San Francisco. The theme of our 1980 conference will be education. Development of that theme will be accomplished by lectures from the top experts in the world. Our lab classes will feature exhibits of devices used in our industry.

Weights and Measures officials are a vital part of the NSMA program. There is no other organization where all segments of our industry can meet together for the exchange of information and ideas. I wish to invite all of you to the 1980 conference. I will be president at that time, and I need all the support I can get. 


\section{THE SCALE MANUFACTURERS ASSOCIATION}

\section{Presented by RAYmond J. LLOYD, Executive Director, SMA}

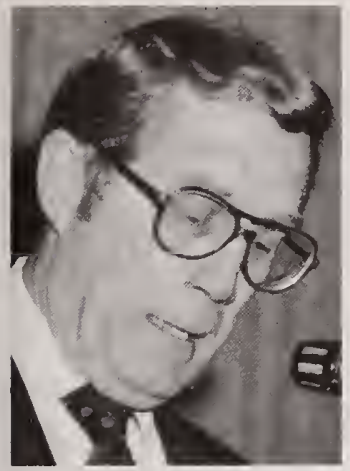

It is my privilege to introduce to you this year's elected leaders of the Scale Manufacturers Association:

President: RoBert M. ZweIG, President of John Chatillon \& Sons, Inc., Kew Gardens, New York:

Vice President: William J. Lifka, President of Howe Richardson Scale Company, Clifton, New Jersey.

Other members of our Board of Directors this year are:

Kenneth F. Hammer, President of Fairbanks Weighing Division, Colt Industries, St. Johnsbury, Vermont. Peter R. Perino, President of Transducers, Inc., Cerritos, California.

William H. Perry, President of Cardinal Scale Manufacturing Company, Webb City, Missouri.

Joseph R. Schaeffer, Vice President of Thurman Scale Company, Columbus, Ohio.

GUY W. WILSON, Corporate Manager of Marketing Development, Analogic Corporation.

We appreciate this opportunity to tell you about SMA's programs and activities, and we commend the leadership of the National Conference for this innovation on your program.

The National Conference on Weights and Measures provides one of the most effective, productive vehicles for cooperative effort between industry and government in America today.

The Scale Manufacturers Association commends and congratulates you for that. We thank the weights and measures community and the Office of Weights and Measures for this opportunity to exchange views and information. It benefits everybody!

SMA has never been stronger or more active in its 34-year history than it is today. Representing the greatest concentration of weighing industry expertise in the world, the 24 member companies of SMA are working together to develop consensus industry positions in many important areas.

Following is a brief review of our recent and current activities:

\section{Metrology Control Plan}

You heard Kenneth F. Hammer, immediate past president of SMA, 
discuss one of the important results of this cooperative effort this morning in his presentation on, "A Legal Metrology Control System Applicable to the United States."

\section{NCWM}

You also heard from SMA at this Conference-as you have in the past and will at future National Conferences and interim committee meetings-in connection with $\mathrm{S} \& \mathrm{~T}$ Committee proposals and other matters.

\section{Weights and Measures Week}

You are familiar with our efforts to help you make National Weights and Measures Week a meaningful recognition of the important role of weights and measures officials in every jurisdiction in America. I have heard from several of you in recent weeks about your success in using the SMA press kit this year.

\section{Weighing Industry Tolerances}

A blue ribbon Tolerance Subcommittee of the SMA Technical Committee is working hard on a comprehensive review of tolerance provisions in various scale codes, including Handbook 44. The objectives are simplification and consolidation of these provisions, along with compatibility with OIML.

\section{International Standards}

SMA has taken the lead in such major OIML initiatives as the drafting of proposed International Recommendations on load cells and electronic weighing. Our representatives also have been very active in the National Working Group for Pilot Secretariat 7 on Measurement of Mass.

\section{Federal Grain Inspectional Service}

The Scale Manufacturers Association has commented in considerable depth on scale standards proposed by the Federal Grain Inspection Service and continues to follow this situation closely.

\section{Metric Conversion}

SMA has provided the secretariat for the Weights and Measures Sector Committee of the American National Metric Council since the committee was organized several years ago. Although the com- 
mittee presently is reconsidering its future direction, SMA continues to monitor developments closely, not only in the U. S. but in Canada and elsewhere in the world.

\section{Publications}

Another SMA activity of significance to the weights and measures community is our publications program. You are familiar, I'm sure, with SMA documents endorsed by the National Conference-last year's RFI/EMI Field Test Procedures, for instance.

Our newest publication is a new edition of Load Cell Terminology and Test Procedure Recommendations, published within the last few weeks. These two and six others are shown on a new list of SMA publications. Copies are availatile at this Conference.

In closing, I want to reconfirm SMA's commitment to uniformity in weighing industry regulations and our support of the National Conference on Weights and Measures to that end. 


\section{SOUTHERN WEIGHTS AND MEASURES ASSOCIATION}

\section{Presented by JoHN L. O'NEILL, Director, Southern Association}

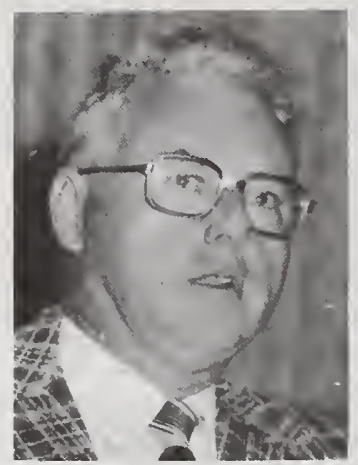

It is my pleasure to invite you to the 34 th Southern Conference on Weights and Measures to be held October 21-25, 1979 in Kansas City, Kansas.

The association, a 34-year old organization, is made up of weights and measures officials at all levels of work from the inspector up to the Commissioner of a department of State Government. Officials come from eighteen states, the District of Columbia and numbers of city and county jurisdictions.

Each of our jurisdictions has its own problems, many unique, not necessarily all weights and measures problems, but we have found that most, if not all, can be solved more easily working cooperatively with our neighbors and friends within the association. Along the way we have found all problems could not be solved on a regional level so we have developed strong ties with other regions in our working within the National Conference on Weights and Measures. Over the years our Southern Division leaders have staffed the many offices and committees of the National Conference, providing strong support, leadership and direction throughout the National Conference's much longer history.

Concerned counsel and support offered by the affiliate membership composed of industry, business, professional and consumer interests have provided us with a vital tie to reality. The Southern Weights and Measures Association invites your membership in the associa tion and continued participation in its activities. 


\section{WESTERN WEIGHTS AND MEASURES ASSOCIATION}

\section{Presented by JosEPH W. JONES, Director, Western Association}

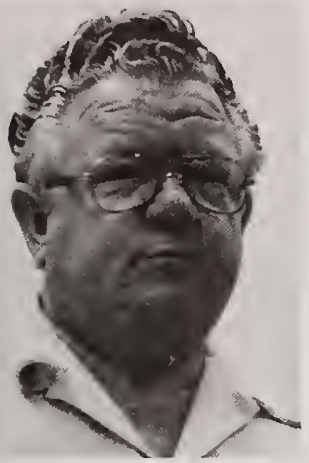

I have the pleasure of adding my welcome to those already expressed. I welcome you here and also to the Western Weights and Measures Association Territory. As outstanding as this meeting place is, it is just one of many in the Western Association region. We wish you a happy time while you are here and say hurry back to visit us again.

The Western Association will be holding its annual meeting August 5-10, which is a week after next in Scottsdale, Arizona. We invite you to stay over and join us.

In the last year we have lost, by retirement, two of our most able members: Fred Morgan of Utah and Earl Prideaux of Colorado. They are missed but have been replaced by able men who are in attendance at this conference. We have added to our association the State of North Dakota and the Navajo Nation.

The Western Association is an active entity, taking an active part in this Conference by serving when asked, by presenting weights and measures problems and their possible solutions to the National Conference's several committees, and by actively advocating our position in open committee meetings and in writing.

By vote we have decided that the new format of Handbook 44 is not as good as the old and would suggest additional intercourse between NBS and the States to resolve these apprehensions. I feel that there is nothing static about weights and measures, that everything can be changed for the better and this, I find, is the view of the Western Association membership. With proposition 3 in California and its impact in other jurisdictions, new methods of accomplishing our goal "that equity may prevail" must be found. Some of us are trying different methods and I am sure you are seeking and trying new programs. Sharing of information is one of the major reasons for meetings such as this. Hopefully we can exchange ideas as we meet to conduct the business for which we have gathered. What has happened before is history. We should study and learn from history but we cannot relive it. We must be moving forward and the Western Association does plan on progressing. 
Presented by James A. Graham, President, NASDA, and Commissioner, Department of Agriculture, State of North Carolina

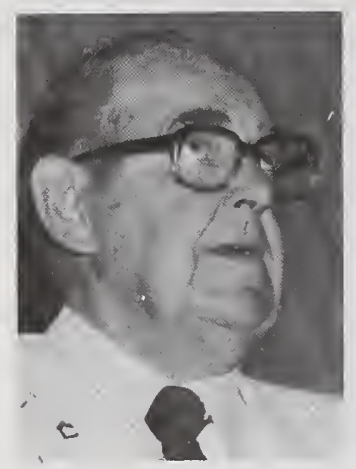

Thank you for inviting me to be here with you for the Annual Meeting of the National Conference on Weights and Measures. As President of the National Association of State Departments of Agriculture (NASDA) this year I am becoming increasingly aware of the importance of the job you people do in guaranteeing fair weights and measures in our country's marketplaces.

As the costs of goods and commodities continue to rise across the country, the job that the people in weights and measures do becomes more and more important. It is vital that representatives from each state get together at meetings such as this to compare notes and air problems which we all share. The information and insight gained at meetings such as these help all of us do a better job.

Your National Conference Meeting is the place to thrash out problems you have in weights and measures regulation and I understand our man Marion Kinlaw often does this.

The important thing is to leave this meeting completely unified and in agreement with final positions taken by this national conference

Do , nur disagreeing here and not when you get back home on the job.

$\mathrm{C}$.e of the things I was asked to comment on today is how weights and measures and NASDA can work more effectively together.

My first response was "How can we improve on the great relationship we already have?" But then I started thinking "If it's good now, imagine what it could become!" Communication is one of the most important aspects of good relationships and the Conference onWeights and Mcasures is quickly moving toward better communication with NASDA because the weights and measures NASDA meeting is now scheduled on Wednesday afternoon. This makes it a more integral part of the Conference Meeting rather than just being incidental to the program.

This change to make the NASDA meeting more a part of the program is a big step toward working together more effectively.

Another way NASDA and the National Conference on Weights and Measures can work together more effectively is to require regional weights and measures organizations to approve any resolutions before they are presented to the National Conference. The objective here is 
to allow resolutions to originate as close to the people as possible. Local people experience things first hand and have a better grasp of problems than do those sitting in offices somewhere completely removed from a situation.

One of the biggest complaints I hear when I am traveling is that the people in Washington, or the people in a State Capital, are trying to force things on the local people without any first hand knowledge of the problem.

Somehow I've always had this strange notion that Government was developed to serve the people-to solve problems rather than cause them. Well, this is the point, if resolutions and changes originate locally and evolve through the system, they stand to scive problems more effectively.

Another point that needs mentioning is that the Office of Weights and Measures in the National Bureau of Standards should be enlisted to a greater extent by trie States and State Weights and Measures officials as a permanent sounding board to NASDA. The Bureau of Standards is the last word in standards in our country and through them, the States, individually and collectively, can have a greater voice. I encourage more meetings and more communications between the Office of Weights and Measures and the Conference officials and the NASDA Board of Directors.

I also feel NASDA can serve as a helping hand to weights and measures in getting national legislation across to Congressmen. The reason for this is that NASDA is made up of elected and appointed representatives from each state in the nation. Cungressmen gent ally can identify with them more than with weights and measures employees because they are coming from the same place. For example, Congressmen are elected and many Commissioners of Agriculture are elected. A Congressman might be more inclined to accept another elected official's opinion than to blanketly accept the opinion of a Government employee who does not have to answer directly to the people every four years.

Weights and Measures can work through NASDA to gain Congressional support which can help resolve major National Weights and Measures issues.

In closing, I would like to say that from all the information I am getting, Weights and Measures jurisdictions throughout the country need more personnel and equipment to continue doing the kind of job we need. The marketplace is ever-changing and progressing and we need to stay on top of that change.

As the unit price increases, as has been the case, the incentive to defraud the public is increased and we can't allow that.

NASDA, working with each state, is willing to do whatever we can to help the National Conference on Weights and Measures do the best job possible. Thank you. 


\section{WEIGHING PROGRAMS OF THE FEDERAL GRAIN INSPECTION SERVICE}

Presented by Richard R. Pforr, Chief, Scale Testing and Weighing Branch, Weighing Division, Federal Grain Inspection Service

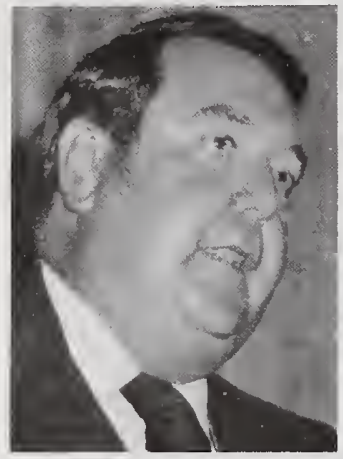

It is indeed a pleasure for me to have the opportunity to address this joint session this afternoon. Although I think the subject of my presentation titled "Weighing Programs of the Federal Grain Inspection Service" to be rather broad, I will endeavor to provide you with as much detail as possible in the time allowed. You will find that many of the programs developed or being developed by FGIS are very compatible with the policies and programs of both NASDA and the NCWM. We have many common goals.

I think perhaps a brief profile of FGIS would be appropriate prior to detailing our weighing programs in order to give you an overview of the whole Service.

The FGIS, under the direction of its Administrator Dr. Leland Bartelt, is presently headquartered in the Department of Agriculture building in Washington, D.C. I indicate "presently headquartered" because there is a feasibility study being made to determine whether FGIS should be moved closer to the grain belt. Kansas City is one of a number of locations being considered.

Our operations are conducted through forty field offices and five regional offices in twenty-three states and Canada. Conducting these operations, as of March of this year, were 1,663 full-time permanent employees and 262 part-time employees. When completely staffed, we will have approximately 1980 full-time employees with 87 percent, or approximately 1720 , assigned to field locations.

The cost of all field services, except supervision, is financed from fees charged for service performed. Headquarters functions and field supervision are financed from Federal appropriations.

Directly under Dr. Bartelt is our Deputy Administrator, David R. Galliart who headed the old Grain Division which was replaced by FGIS in late 1976. Reporting to Mr. Galliart are two Assistant Deputy Administrators. One is David C. Mangum who is in charge of field operations. And the other is Leslie E. Malone who heads up the four staff divisions in Washington. These Staff Divisions are the Standardization Division, the Compliance Division, the Inspection Division, and last but not least, the Weighing Division.

It is the programs of the Weighing Division which I will further describe in more detail. 
The Weighing Division, which is directed by Mr. George Lipscomb, consists of 36 staff employees making up four branches. These are, the Policies and Procedures Branch, the Scale Testing and Weighing Branch, the Grain Monitoring Branch, and the Program Analysis Group.

The Policies and Procedures Branch, which is the largest of the four branches, has as it's primary objective the development and implementation of a nationwide, uniform, officially supervised weighing program. This includes the issuance of all instructions and establishment of standard field weighing policies for the two classes of weighing supervision that FGIS provides. These two classes are:

1. Class X Weighing which includes 100 percent supervision and is mandated by the U.S. Grain Standards Act to be performed on all inbound and outbound weighing at export port locations.

2. Class Y Weighing which includes a minimum of 25 percent supervision of weighing and is offered as a service for a fee to any inland facility requesting it.

The Policies and Procedures Branch also works closely with all Delegated States and Designated Agencies to assure implementation of uniform procedures for weighing.

All official policies and procedures are being issued in the form of a Weighing Handbook which will cover all phases of the weighing program. Interim chapters 1 . and 2. of the handbook have been issued covering proper weighing procedures and proper documentation of weighing records. I think few people realize the complexities of developing nationwide, uniform, compatible instructions when dealing with weighing involving the normal carriers such as ships, trucks, railroad cars, and barges, and special situations such as containers, lash barges, sacked grain, and floating elevators.

Another program which supports the main thrust of the Policies and Procedures Branch is the development of custom or specially designed Official Weight Certificates for inbound weighing. Through the use of specially designed weight certificates, grain facilities can make use of a wide variety of custom weighing equipment as well as all kinds of data processing equipment which provides for faster weighing and processing of weight information.

Also this branch has developed a presentation on the potential uses of closed circuit television for reduction of manpower in the supervision of the weighing process. Closed circuit television is presently being tested in some facilities.

In an effort to provide a means of internally reviewing the Weighing Supervision Program, a number of unscheduled and unannounced visits are made to Field offices to review their methods of operation and how well they are complying with Official policies and procedures. We refer to these group visits as (E.R.T.) Export Review Teams and 
(D.R.T.) Domestic Review Teams. The feedback from these teams provides input on problem areas that require correction.

In addition to the internal review teams, FGIS has an International Monitoring Program to investigate and review foreign complaints with regard to quality and quantity of grain delivered. Regular overseas trips are made, working closely with the Department's Foreign Agricultural Service.

Described above are the main programs of the Policies and Procedures Branch. The Scale Testing and Weighing Branch directs another area of the overall Weighing Program which we feel is extremely important. Its primary function is to develop a nationwide, uniform, scale testing and certification program along with all necessary support functions. To implement scale certification, the FGIS presently has approximately 25 Scales and Weighing Specialists located in major field offices and regional offices. More of these types of specialists are expected to be hired.

Present proposed regulations require Official testing and certification of all scales under the jurisdiction of FGIS to be performed twice annually at approximately six-month intervals. It is the job of the Scales and Weighing Specialist to attend every Official test to assure compliance with FGIS regulations.

The Scale Testing and Weighing Branch will add its instructions and procedures to the Weighing Handbook. An interim Chapter 3, has already been distributed.

I'm sure that most of you here today are aware that some portions of the proposed regulations pertaining to Specifications, Tolerances, and Technical Requirements do not agree with the Handbook 44 . Specifically in the areas of minimum division size and tolerances. I would like to comment on this subject only to this extent. Just as the NCWM receives input and opinions from many sources prior to determining its recommendations, FGIS feels it must do the same before finalizing the regulations. There have been many regulatory groups involved in the weighing of grain, some going back to the years when the NCWM was beginning. We feel we must receive and review input from all sources prior to finalizing the regulations.

Another area in which the Scale Testing and Weighing Branch is involved is the development of a Test weight reverification program. A fairly high percent of export terminal elevators own their own large block test weights. Many of these weights were not being reverified on a regular basis, in some cases for good reasons such as the inability to remove the weights from the elevator. But there were also many instances where there was no program to assure that the weights were periodically checked.

In an effort to provide the grain industry with the means to comply with the proposed regulations on field standards, we are testing a prototype of a beam which we hope will give us the ability to at least 
tolerance test these large block weights in the elevator. Harry Johnson, who comes to FGIS from the National Bureau of Standards, is presently developing this capability:

Early in the development of our scale testing program, we ran into a problem with which I'm sure many of you are familiar; that is the testing of Railway track scales. As you are aware, with the exception of a few state programs, the railroad companies have been the primary source of getting railway track scales tested.

Because the U.S. Grain Standards Act mandates that FGIS must certify all scales used for Official weighing, we began to look into how we might accomplish this mandate. Fortunately at about that time, the Office of Weights and Measures was looking for a new home for the Master Scale Program. With the patient help of Mri. Tholen, Chief of the Office of Weights and Measures, and Mr. John Robinson of the Association of American Railroads, we have pretty much finalized a Railway Track Scale testing program that will include the testing of all Master Scales annually and all railway track scales under the jurisdiction of FGIS. This will be accomplished by using two NBS type test cars, one of the old cars that is being refurbished and a new test car that will be ordered shortly. We have received strong support for this program.

A tentative date of October 1, 1979 has been set to officially begin the program. We are presently advertising for two Scale specialists to operate the test cars and perform the testing. Supervision of the program will come from Ben Banks who comes to FGIS from the Office of Weights and Measures and was involved with the Master Scale Program for many years.

Another program which we will be developing during the next year is an equipment approval program. I hesitate at this time to call it a prototype evaluation program but it will include requirements to be assured that all weighing equipment used for Official weighing complies with FGIS regulations.

And finally, the Scale Testing and Weighing Branch has the responsibility of overseeing theAgencies Radio Communications Program. Presently FGIS has in excess of 1.5 million dollars in VHF and UHF radio equipment in the field. This figure is made up primarily of the cost of portable hand-held radios but also includes base stations, repeater stations, and mobile equipment. We have dedicated frequencies for use by Delegated States and FGIS only. One full-time Communications Technician works in this area. These are the main programs that make up the majority of this year's annual work plan for the Scale Testing and Weighing Branch.

Portions of the U.S. Grain Standards Act require inventory monitoring of exporting elevators. The Grain Monitoring Branch has the responsibility of developing instructions and procedures for monitoring elevator inventories. This is a new branch and a relatively new 
program. They are presently developing plans for performing inventories annually at approximately 88 export facilities presently under FGIS jurisdiction.

And finally let me briefly mention the work of the remaining branch of the Weighing Division which is the Program Analysis Group. The Program Analysis Group performs a wide variety of studies and projects in areas that are not covered by the other branches. Some examples of the work being performed by this branch are:

1. A study on the accuracy that can be expected in performing draft surveys on exporting ships.

2. A nationwide volume reporting system.

3. The determination of allowable grain dust particle size.

That Ladies and Gentlemen covers the four branches of the Weighing Division and all the major Weighing Division programs.

Being a relatively new agency, we realize we have a long way to go. However, looking back over the past year, I believe we have accomplished much. 


\section{NET WEIGHTS, PART II}

Presented by Sydney J. Butler, Deputy Assistant, Secretary for Food and Consumer Services, U. S. Department of Agriculture

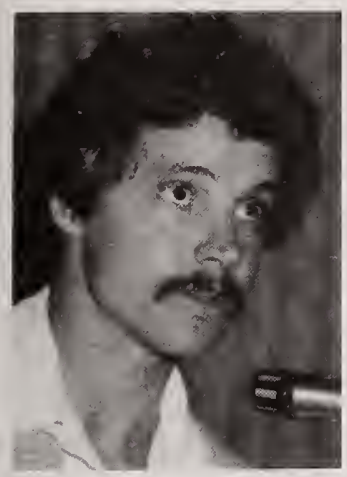

Good afternoon. I'm pleased to be here. Some of you may remember that just over a year ago I addressed this conference on the subject of USDA's proposed net weight regulations. This year I've been asked to speak on the same subject. After this past week in Washington, I'm happy not only that you'll be hearing about the same subject, but also that you'll be hearing from the same speaker you heard from last year.

There's a story in Washington-apocryphal I'm sure-about a government official who was able to make a good living for many years giving the same speech on the same subject. Every two years a particular bill would be introduced in Congress, and the official would be called upon to testify. He happened to know more about the bill than anyone else. The bill never passed, but every time a new Congress convened, the process would repeat itself. After several years, the official even began to branch out and deliver speeches on the bill at annual meetings of various trade groups and associations of government officials. He made a career out of a bill that never became law.

This sort of thing is not about to happen on our proposed net weight regulations. We do plan to have final net weight regulations on the books, in the foreseeable future. I would like to give you a precise date, but I'm not in a position to give you an exact deadline, or to tell you what the final regulations will look like. But I do want you to know that we are acutely aware of the need for state and local officials to have enforceable Federal standards in place. I also want you to know that we have not been spinning our wheels this past year. A great deal has transpired since I spoke to you last July in Washington. I would like to use this opportunity this afternoon to bring you up to date.

Most of you are familiar with the proposed regulations we published in December, 1977. We discussed them at some length last year. These regulations were in part a response to a petition from the State of California and cosigned by 47 other States. State officials felt they had been disarmed by the Supreme Court decision in Rath, which kept States from imposing net weight standards different from those prescribed by USDA. The USDA standard was-and is-based simply on "reasonable variation." Since the Department had not spelled out 
a clear standard, States felt they were unable to perform a valuable consumer protection service. The proposed USDA net weight regulations were intended to remedy this situation.

When I spoke to you a year ago, the proposed regulations had been out for comment for more than 6 months, and we had received more than 3,000 comments. We realized that some changes would have to be made in the proposal, but quite frankly, I was optimistic about being able to publish final regulations within a year. We soon discovered, however, that the issue of net weight was more complicated than we had thought. The complications fall roughly into three main areas: political, economic, and, for lack of a better word, inter-Departmental.

Let me begin with the political complications. By "political" I am simply referring to the free play of the forces that make our constitutional system work. In this sense, the main political complication had to do with the interest of Congress in the proposed net weight regulations. The Congress, of course, has a very legitimate interest in such matters, by virtue of its responsibilities to oversee vigorously the actions of the Executive branch.

There has been a particularly intense interest recently in regulation. This interest has been fueled over the past year or two by the intense desire on the part of elected officials to do something about inflation. In fact, when it comes to putting a stop to sky-rocketing prices, it sometimes appears that we have exchanged a pro-regulatory bias for an anti-regulatory fervor. It was not too long ago that government-imposed wage and price controls were considered the cure to inflation. Now, government regulations of any sort are thought by some to be the root of the problem. Neither of these attitudes is wholly defensible, but regulatory officials must obviously come to terms with the present concern over potentially burdensome regulations.

Congress has not been alone in its concern over the inflationary impact of excessive regulation. One of the primary goals of this Administration has been regulatory reform. Quite clearly, regulatory reform can lead to lower costs for government and lower prices for consumers. The deregulation of the pricing and route structure in the airline industry offers a prime example.

Given the climate of regulatory reform and given Congress's oversight responsibilities, it is quite understandable that Congress would take a rather high degree of interest in our proposed net weight regulations. As you know, industry has contended from the outset that these regulations would result in significant new costs for packers and higher prices for consumers. This type of argument created some active concern on the Hill. Last July, when Assistant Secretary Foreman appeared before the Livestock and Grains Subcommittee of the House Agriculture Committee, the members had a number of 
questions concerning the impact of the proposed net weight regulations. There was a full and frank discussion, and a number of legitimate issues were raised.

Soon after the hearing, the subcommittee asked the General Accounting Office to do a study of the proposed regulations. We told the Congress that we would not go ahead with final regulations until receiving the report from the GAO study. The GAO report was published in December. The report reached the conclusion that our proposed regulations were based on insufficient data, and raised particular concern over the possible inflationary impact of the regulations.

This leads to the second area where we have encountered some complications: the economics of the proposed regulations. In response to the issues raised in the GAO report, we went to the Department's Economics, Statistics and Cooperative Service last December and asked them to review the evidence on the potential impact of the regulations. The Department's economists concluded that indeed additional data and analyses were needed prior to making final decisions. ESCS then embarked on a careful study in an attempt to pinpoint the exact economic impact of the proposed regulations. The study is now nearing completion, and will be published in the near future. Like most careful, objective studies, it presents us with some difficult regulatory decisions. Preliminary findings indicate that the world is not quite what we had thought it to be. For that matter, it is not what many industry or consumer groups have thought it to be.

The most controversial portion of our proposed regulations has been the provisions relating to drained weight. Under our proposal, free liquid as well as juices, fats and solids absorbed by packaging material would no longer be counted as part of a product's net weight. Net weight would, therefore, equal drained weight. In addition, the present allowance for moisture loss due to evaporation would be eliminated.

Producer groups have argued that these provisions would result in the need for significant additional over-packing, which in turn would mean higher costs for industry and higher prices for consumers. Many consumer groups, on the other hand, have said that drained weight labeling is necessary to assure that consumers are not paying meat prices for water.

The study indicates weaknesses in both sides of this argument, and I'm afraid it leaves us right in the middle looking for somewhere to go. Costs to industry of the proposed regulations do not seem to be nearly as great as some of their representatives have contended. The American Meat Institute, for example, estimated the additional cost for a limited number of red meat products to be $\$ 380$ million. The National Broiler Council estimated $\$ 177.5$ million for their industry. The National Turkey Federation estimated $\$ 88$ million. These estimates seem to be vastly overstated. 
Indications are that the real price to consumers for meat and poultry products would remain the same under the new regulations. Very little overpacking would be necessary to compensate for evaporation, since this type of moisture loss is slight for meat and poultry products. It is true that some "overpacking" would be necessary to compensate for the exclusion of free liquid from the net weight and that these costs would be reflected in higher labeled prices per pound. However, these higher labeled prices would be offset by the fact that consumers would be receiving more usable product per pound because of the exclusion of free liquid.

The pre-drained weight economic arguments of consumers seem to fare no better under analysis than the anti-drained weight arguments of industry. Findings thus far show that the economic benefits often attributed to a drained weight system would probably not occur. Under the present regulations, for example, there is little or no evidence to indicate that consumers are receiving a significant amount of short weight product. It is true that under a drained weight system, a labeled pound would include more usable product. However, the price per pound would increase by a corresponding amount. Again, the real price would remain the same. The consumer would come out about even.

Where does this leave us? I believe there are some clear advantages as well as some clear disadvantages to a drained weight system. What is not yet clear is just where the edge lies. I think it is a very close call. Let me enumerate the advantages as well as the disadvantages.

First, the plus side of a drained weight system. The main benefit to consumers would be increased ability to make accurate comparisons at the market place based on the price of usable product. Because the labeled weight of some products now includes an unspecified amount of the liquid, it is difficult to determine the value of these products. In addition, some consumers may not even realize that the present labeled weight of these products refers to usable product plus free liquid.

Secondly, the drained weight portion of the proposal would provide incentives for industry to reduce the amount and variability of moisture loss in their products. This would increase the accuracy of the labeled weight on meat and poultry products. Let's say a particular product now loses between 4 and 8 percent of its weight as drained liquid. Under the present system, the packer has no economic incentive to reduce the amount of drain because all of it can be counted as part of the net weight. Under a drained weight system, however, the packer would have to reduce the labeled weight by a full eight per cent to make certain the product remained in compliance. He therefore would have an incentive to reduce the variation to, say, four to six per cent, and thereby gain 2 per cent in the amount of labeled weight. 
On the minus side, there may be an additional cost for new equipment to enable state and local governments to enforce the drained weight inspection procedures. State and local agencies would have to purchase a stainless steel sieve and two receiving pans for each inspector. Most officials surveyed said they believed that these additional costs would have to be absorbed out of current budgets. Only about $10 \%$ felt their states might appropriate new funds for net weight inspection.

There may also be some additional labor costs because drained weight procedures are more time consuming. States and local agencies might also incur costs resulting from the need to purchase more prepacked packages for weighing. As you know, a drained weight system requires that packages be opened and the product drained before weighing. Costs for such a procedure probably would have to be absorbed out of current budgets.

One of the main disadvantages involves a somewhat nebulous problem of "perceived inflation." The problem in this: Even though the real price per pound for meat and poultry products would remain the same, the labeled price per pound would go up. Many consumers, not realizing that they were receiving more usable product at the higher price, may look upon the apparent price increase as a real one. To make matters worse, this apparent price increase would have an effect on the Consumer Price Index, simply because the CPI does not take into account such esoterica as wet tares, dry tares, and drained weight. Over at the Bureau of Labor Statistics a pound of chicken is a pound of chicken. If the labeled price goes up because the free liquid has been excluded, then so does the CPI. And I am sure you know when the CPI goes up, so do many wages, benefits and other costs that contribute to inflation.

This all may sound a little like Alice in Wonderland. We must, however, face the fact that there is now a great burden of proof upon any new regulation that contributes even a small amount to inflation-whether perceived or real. ESCS estimates that the drained weight portion of our proposed regulations may add as little as 4 one hundredths of one percent to the CPI. That seems small, but we'd better be able to show a pretty clear benefit to justify even that amount. I've mentioned the benefit to consumers of enhanced ability to make value comparisons at the market place and the incentives to industry for increased accuracy in net weight declarations. Do these benefits outweigh the costs? Arguments on both sides will be long and loud.

Whatever we decide to do on drained weight labeling, I should emphasize that we will shape an objective Federal net weight standard that the States will be able to enforce. The main problem with enforcement at the retail level has been that a standard based on "reasonable variation" is not sufficiently objective. 
To overcome this serious limitation in the present Federal standard, the proposed USDA regulations provide: that the present allowance for moisture loss due to evaporation would be eliminated; that average weights for products from the same lot be required to equal or exceed the labeled net weight, and that single packages be permitted to fall below the labeled weight, but only by an amount specified in the regulation (which is called the "maximum allowable variation"). These provisions are logically independent of the drained weight provisions. Both the average weight of products and the maximum allowable variation can be determined on the basis of dry tare, wet tare, or drained weight.

The ESCS study notes that the averaging provisions and the maximum allowable variations are both in line with the recommended procedures in the National Bureau of Standards' revised Handbook 67 on checking prepacked commodities. These changes would have only a minor effect on industry. With respect to eliminating the allowance for evaporation loss, by far the largest moisture loss for meat and poultry products is due to seepage into the package rather than shrinkage or moisture loss to evaporation. Therefore, eliminating the allowance for moisture loss due to evaporation would require only a small additional overfill or underlabeling beyond that already required.

So I believe that, regardless of the outcome of the drained weight issue, USDA will soon establish objective standards based on minimum averages for products from the same lot, and a quantifiable maximum allowable variation for single packages from a lot. The very notion of quantifiable variations, however, leads to the third area of complications. These complications arise from the fact that USDA's net weight jurisdiction extends over only meat and poultry products, while FDA has responsibility over most other food products. Obviously, the standards that might reasonably apply to some products may not make sense for others. For example, meat and poultry products are known to lose very little weight due to evaporation in the course of distribution and marketing. Therefore, it may be reasonable for USDA to propose elimination of any allowance for shrinkage due to evaporation. FDA, on the other hand, must set net weight standards for flour, which can lose a significant amount of moisture from evaporation. For such a product, it may be reasonable to allow at least a quantifiable amount of moisture loss due to evaporation.

Because of these differences in the products each agency regulates, and also because of the difficult position of the States after the Rath decision, USDA decided in late 1977 to go ahead with its own net weight regulation for meat and poultry products. FDA would proceed separately to develop its own approach for the products under its jurisdiction. However, in the time since we published our proposed net weight regulations, it has become apparent that there is a great 
deal to be gained from a complementary approach. Consumer understanding would be enhanced if the net weight standards for all food products were as consistent as possible. Enforcement by state and local officials would be simplified with greater congruence of standards and procedures. And the task of compliance on the part of the food industry would be made easier if the two agencies were to develop similar approaches.

For these reasons, we have been meeting with FDA this past year in an effort to reach as many points of agreement as possible. I can report that we have reached tentative agreement in a number of areas, and at the time USDA next publishes its regulations or proposal, FDA will probably be ready with a companion proposal. The two sets of regulations will reflect a common effort and set of agreements between the agencies.

It may be necessary to have different allowable variations because of differences in the properties of the products being regulated. These variations will be based on a common, explicit rationale. There presently are differences between the two agencies in such technical areas as the definition of lot and the statistical criteria for sampling. I think we should be able to arrive at a common approach in these areas, and this should make life a bit easier for both industry and for state weights and measures officials. Finally, FDA has agreed to address the issue of a drained weight for some products, such as fresh fish and seafood, assuming that is the approach USDA ultimately decides to take for meat and poultry.

That should, I think, just about bring you up to date on our proposed regulations. There has been a great deal of activity since I talked with you a year ago. For the most part, that activity has been entirely beneficial. We may not have been able to proceed as quickly as we would have liked, and we still will have to make one or two additional decisions, particularly with respect to the drained weight issue. But I believe we now are in a much better position to establish sound, workable regulations based on the best information available. 


\section{NET WEIGHT LABELING REGULATIONS}

Presented by TAYLOR M. QUINN, Associate Director for Compliance, Bureau of Foods, Food and Drug Administration

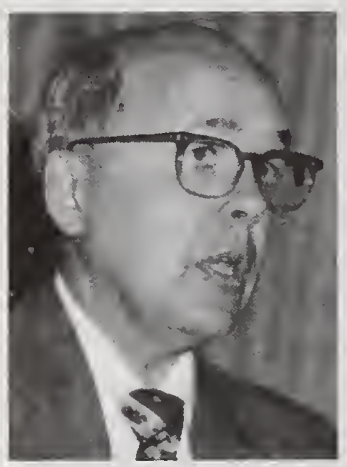

Your theme "Equity on the Move" is an altogether fitting and proper focus not only for this national conference but for non-safety regulatory action emanating from the Food and Drug Administration. As you have stated in the program, "equity is subject to interpretation...." and its meaning changes as our collective perception of what is fair and reasonable changes. Equity is dynamic, and government regulations based on equity are therefore dynamic. The topic of net weight labeling functions is an excellent example of the dynamic nature of federal regulations.

As we examine FDA's current activities directed toward amending the net weight labeling regulations, it is apparent that the stimulus for such alterations was the Rath Supreme Court decision in March 1977. At that time the Court said, as you are undoubtedly aware, that federal regulations on declaration of quantity of content of food preempt state and local regulations when differences or conflicts exist. Feeling unarmed from an enforcement standpoint, the State of California petitioned the federal agencies responsible for net weight labeling practices to amend the existing regulations.

At an early stage both FDA and USDA recognized the merits of a coordinated resolution to the net weight issue. However, the sense of urgency prompted USDA to publish its own proposal in December 1977. Formal joint discussions were suspended. Resulting at least in part from discussions with officials from the State of California and from unsolicited comments from individuals and consumer groups, two public hearings were convened in December 1977 to air, on a broader scale, the feelings and perspectives on net weight labeling. Based on the testimony, data, and opinions received from state and local government officials, weights and measures associations, several consumers and consumer groups, and various industries, FDA identified areas of concern that should be addressed more fully because of the impact on the development of the net weight labeling proposal. The various areas of concern and accompanying proposals can be summarized into two principal areas:

(1) consumer protection from short weight practices, and

(2) enforcement of the net weight labeling regulations. 
Let's address each of these topics separately. Not surprising, those most vocal regarding actual or potential short weight practices associated with "reasonable variations due to moisture loss" are consumers or their representatives. Most of these individuals claim that such practices are deceptive to the consumer and that adequate label representation is needed or that consumers are not receiving the full food value for their purchase. Not all consumers, however, share this view. Some expressed concern that food costs would increase unnecessarily if required changes were instituted.

In response to this concern over short weight packages, FDA examined both state and nationwide survey data on actual net weights versus declared net weights dating from 1959 through mid-1977. These surveys indicate that no chronic shortweight problem has existed for food commodities for well over a decade and that compliance levels were high, exceeding $97 \%$ in most cases. Furthermore, consumers, on the average, receive $104 \%$ of the declared label weight with the range consisting of $102 \%$ to $108 \%$. In other words, the average package was overfilled by $4 \%$. Therefore, the available evidence pertaining to net weight labeling compliance fails to substantiate the claim that consumers have been subjected to sustained or intentional short weight practices.

Why are compliance figures high for net weight labeling regulations? In all likelihood, a combination of two factors is responsible.

(1) technological developments, including sophisticated automatic filling machinery and checkweighing equipment, and

(2) government enforcement operations, particularly state and local enforcement of quantity of contents requirements in retail stores. The on-going surveillance by state and local agencies provides an incentive to businesses to comply with the regulations.

This leads us directly into the second major area of concern that surfaced as a result of the hearings-enforcement operations. Regardless of the effectiveness of the enforcement operations prior to the Rath decision, FDA is aware that an acute enforcement dilemma has been precipitated by the Supreme Court ruling. At the present time, inspectors must address the question of whether or not moisture loss may be the basis for detected weight shortages. Once such packages are identified, the inspector must then assess whether or not the extent of moisture loss was "reasonable." Because the regulations have not quantitatively defined "reasonable variations," the subjective nature of this operation places a very diffficult burden on the inspector. The inspector recognizes that his judgment may very well be challenged and overturned in court. 
Regarding enforcement procedures, state and local officials pointed out that valid procedures that are explicitly defined and lend themselves to rapid and accurate determinations would be particularly beneficial. For example, the use of scales in retail stores would be much preferred over laboratory analyses for water content.

In developing a net weight labeling proposal, it is apparent that the lack of enforcement capability represents a significant deficiency in the net weight labeling regulations. Our proposal will attempt to remedy this deficiency by either incorporating or reinforcing statistical validity and practicality while affording public protection from unscrupulous practices. Along these lines, careful examination is being given to the sampling plans and procedures outlined in the NBS Handbook 67. The proposed regulation should address such issues as desired lot sizes, tare definitions, number of tares, maximum allowable variations, and other pertinent topics.

Other areas of concern were detailed in two petitions submitted to FDA, FTC, and USDA regarding net weight labeling. One petition submitted by the California Department of Food and Agriculture, which was supported by many other states, proposed to require a minimum declared weight, suggesting either overfilling to compensate for moisture loss or improved food packaging to impede moisture loss. Such an approach would insure a minimum weight of food at any point during distribution, including the retail store.

GMA's petition, which was supported by several other industries and industry groups, included a proposal establishing a list of foods subject to moisture loss along with identifying acceptable levels of moisture loss for these foods; fostering the determination of net weight compliance through periodic inspections at the time of packaging; and developing procedures for cooperative inspections and the exchange of enforcement data between federal and state officials. GMA contends that retaining an allowance for "reasonable variations" due to moisture loss is essential and that consumers are actually receiving full value based on nutritional food "solids." In addition, GMA maintains that the suggestions to overfill packages or improve food packaging would result in higher food costs.

The FDA has been reviewing the legislative background in order to determine and implement the intent of Congress in passing the Food, Drug, and Cosmetic Act, and the Fair Packaging and Labeling Act.

Thus, there are several points of interest to be considered in formulating the proposed regulation on net weight labeling. Careful scrutiny is being given to these arguments. In addition, during the past several months, discussions have resumed with USDA regarding coordination of respective net weight proposals. Concerted efforts have been and are being made to make the two respective Government proposals identical, when possible, or at least mutually compatible. 
Both agencies do recognize that fundamental differences in food characteristics exist with regard to the food products regulated by the respective agencies. This shows up most dramatically with the concern over free flowing liquid that is found in some meat and poultry products. On the other hand, most foods subject to FDA net weight labeling regulations do not have free flowing liquid. While every effort has been made to coordinate our strategies, however desirable that may be for the food industries and enforcement efforts, a single proposal encompassing the view of both agencies may not be possible.

We are well along in our discussions. We have both received preliminary drafts of proposed regulations and are in the process of revising the drafts to take care of the problems that surfaced during the discussions. I hope that we can resolve the remaining problems and publish proposed changes in the regulations in the near future.

The results of all this will be published as a proposed regulation in the Federal Register. Let me emphasize the document will be just that, a proposal, not a final regulation. We hope that all of you will study it very carefully and give us constructive suggestions for mistakes or problems you see. 


\section{NATIONAL NET WEIGHT OR FEDERAL "RULE OF THUMB"?}

\section{Presented by JERRY ScRIBNER, Deputy Director, California Department of Food and Agriculture}

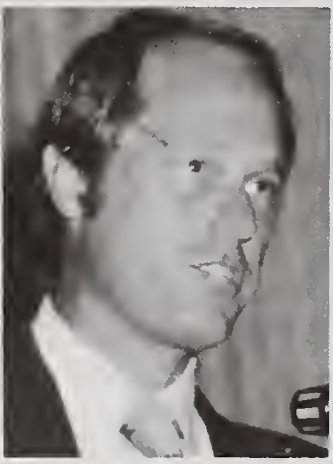

Good afternoon! I am pleased to be here in Portland. My wife was born in Portland and nearly all of her family still reside here. They are not residing here this week, however, because they all are down in Sacramento having a family reunion at our house.

This is a distinguished panel and I am honored to particpate and to once again have an opportunity to rail against the drift toward the 15-ounce pound and 35-inch yard. After this morning's discussion, I should probably say the 950-milliliter liter and the 950-millimeter meter; each of which is, by the way, only five percent below stated measure.

I have entitled my remarks "National Net Weight or Federal 'Rule of thumb?" which I think accurately describes the critical choice before us this year. As I was typing a draft of these remarks, I hit the letter " $W$ " instead of "T" on the word net in net weight. It came out "National New Weight" which may even more aptly describe some of the proposals quietly being drafted in Washington.

It sounds like I am biased in favor of maintaining net weight as just that, rather than the FDA standard of variations not being "unreasonably large." I may not be scrupulously neutral, but I am a lawyer and so I can usually see both sides of an issue-mine, the right, just and proper view; and the other person's, the wrong or misguided view.

Seriously, what drives me nearly crazy on this issue is that I can't honestly, rationally understand why anyone would really favor throwing away the public's confidence in honest weights and measures, nor can I comprehend the reasoning behind trading in the enforceability and reliability of our present full weight at retail standard for an invariably variable and unenforceable standard of full weight at time of pack; or, is it time of introduction into interstate commerce; or time of arrival at port of entry? Actually, the point of inspection may not be too important because the truth is that there is little or no Federal net weight enforcement at any of these points.

In these cynical days, I suppose the obvious retort to my concern about public confidence is: What public confidence? Have you seen the look on people's faces when they read on the cereal box about how the large empty space between the top of the box and the point where 
the cereal starts is the result of "settling during shipment"? A little settling, yes ... but, one third of the box? When the Government says it's safe, do people really believe it is? If the labels begin to read "... This package of flour (or dried fruit, or whatever) may be five to eight percent less than the net weight shown on the package due to unavoidable moisture loss ..." Do you think the public will have the same feeling? Or will they feel "They're doing it to us again"?

I think the public will feel as I do, that what they are being asked to bear is not the burden of an impossible situation; not the burden of unavoidable loss, just the burden of being powerless to stop those with more power from shifting their burdens and responsibilities in the marketplace to those who have no choice but to take it.

There are a lot of things that can and do happen to products between the time they are packed and the time someone buys them. Trucks and trains have accidents. Butterfingered clerks drop boxes and sometimes whole pallets off the loading dock. Bugs get into the packages, as does dirt. Most foods start spoiling the minute they are picked and continue to deteriorate all through the distribution chain. Nearly all these situations are unavoidable, at least to some degree.

If we assume, for the sake of argument, that moisture loss, like these other situations, is a fact of life, and that it imposes some economic burden on someone, then as a society we have to decide how to most fairly allocate the responsibility or economic burden involved. We in California have noted with respect to other aspects-safety, for example-that the most efficient societal mechanism for maintaining the quality and safety all the way down the commercial chain is to place some responsibility on the person or entity that introduces the product into commercial trade. Those of you in the audience who are lawyers know that for many years persons injured by defectively manufactured automobiles could not sue the manufacturer because there was no privity of contract between the purchaser and the manufacturer, inasmuch as the purchaser had bought the automobile from a local dealer, and since the local dealer did not cause the problem, while he could be sued, he had no liability. The courts, and I think the legislatures, over the years have seen both the unfairness and unworkability of allowing the manufacturer, or packager in this case, to shift the burden of errors or lack of safety or lack of quality to people who have, in many cases, no control over that. To graphically illustrate this, if you had on one side of the chart the manufacturer and then a long chain going across the page and on the other end the ultimate purchaser, and you assume that a product will lose moisture over this chain, the question becomes: "Who should take the responsibility for this problem?" The ultimate purchaser has no control over how the package is filled, how it is stored, to whom it is shipped, or when it is sold.

The packager generally has control over some of these factors and, 
in some instances, virtually all of them. To the extent compliance with the standard imposes economic burdens or risks, these costs can be allocated to the product.

Reputable businessmen have historically stood behind their products all the way to the dining room table. Now, suddenly, the argument is: Hey, I can't be responsible for what happens to Scribner's cheese pizza or Scribner's bacon after it leaves my factory gate. Let the buyer, whoever he or she may be, bear the burden of all that may go wrong between this day and the day they have to go to the store and buy it.

In the past, when American business seemed less intent on technological corner-cutting, a baker's dozen was 13 . For the last several years, weights and measures officials have been attempting to hold the line at 12 , despite charges that all they really cared about was protecting their turf, and that accurate labeled weight was impossible or, at least, economically unjustified. Now, FDA stands ready with proposals to, in effect, make the baker's dozen 11 or $11 \frac{1 / 2}{2}$. That is a 4- to $81 / 2$-percent allowance for less than stated weight. I think it is crazy. It is crazy for business to think this makes sense. It is incomprehensible that public officials can find such a step in the best interests of the citizenry.

What does industry gain by a switch to moisture loss variable net weight? They don't have to overpack. Great! Think of all the product you can save. But for what? It doesn't change your position with competitors, they no longer have to overpack either. Over time, the momentary something-for-nothing feeling of a reduction in raw product cost per unit will wash out so there is no long-term benefit there either. It is like a hundred-yard dash with the finish line artificially set at 95 yards. You have everything you had before, except now it's a 95-yard dash.

And how about those competitors? With a squishy standard like variations that are not "unreasonably large" can you be sure their not unreasonably large is not larger than your not unreasonably large? Unless there is a dramatic increase in Federal in-plant net weight enforcement, the competitors may not be inspected at all. Even if there is an increase, what about the overseas competitors? Who's inspecting them? What's four or five or even eight percent? I'll tell you what it is ... It's a lot of people's profit margin that's what!

Well, all this is speculation because we will have state inspectors inspecting at the plants and also at retail, and they can use the new net weight loss tables to calculate any egregious short-weight situations.

I have one of the new tables with me. It is not too hard to use. First, look for your product in the table of the thousands of products which are hygroscopic. Use the index if you need to. Then you find where in the world it was packaged and what its original moisture content 
should have been or probably was when packaged and on what date. Then, you check the temperature and humidity conditions chart for that day and location. Next, you plot the distribution pattern correcting as you go for temperature and humidity at various points along the way. You may need to write a few letters to get this information. Finally, you determine how long it has been on the shelf and compare that with the temperature and humidity of your own local community over time. Then, you feed all this into a computer for the final result.

Is this crazy or am I? Obviously, the only real intelligent solution is to forget about moisture loss and simply allow the maximum possible moisture loss as a tolerance. I believe that is exactly what FDA is proposing to do. Once you do that, then the new moisture loss line is the standard. If you are packing and shipping locally, you pack to that line. If your product has to go far away then you have to overpack so that it will weigh out at not more than five percent (or whatever the tolerance is) below stated weight at the time of sale.

Net result: You have all the same problems with overpack you have now.

The whole point here, the bottom line, as Governor Brown is fond of saying, is: No measurement is perfect. You have to draw the line somewhere. We feel and I sincerely believe the public feels that the most rational and logical place to draw the line is at the point stated on the label. If it is a hundred-yard dash, let the finish line be at 100 yards, rather than at 95 . If we are going to allow hygroscopic products to be sold at $95 \%$ of what they were packed at then simply relabel them as weighing $95 \%$ of what they formerly weighed.

Without packaging, the rule is "What you see is what you get." With packaging, the rule should be "What you see on the label is what you get inside."

I would like to close with one further thought on this subject, and that is the question of enforceability.

One of the real tragedies of the net weight dialogue has been the tendency of some participants to see it as a turf battle between Federal inspection and State inspection. That it could be seen this way is surprising since, in reality, there is very little Federal inspection, period. What we should be talking about is a Federal-State inspection, rather than Federal or State inspection.

Symptomatic of the disarray among enforcement agencies is the fact that local weights and measures officials recently learned from industry that our Federal counterparts in FDA were readying net weight proposals for hearing without the slightest communication or consultation with local officials who ultimately must enforce them. Our understanding is that these proposals will allow fixed percentage reductions below labeled weight for various products. 
I sincerely believe that standards which are enforced are in the best interests of the industry itself, as well as the public generally. America is one of the few countries in the world where we have believable standards and honest officials.

We need to hold on to these standards and we need to work together as state and local officials and with industry to develop solutions that bring together, rather than set apart, our differing enforcement agencies. We're spread thin as it is.

We have a proven and reliable standard and an effective, but improvable, network of Federal-State inspection. The standard of full weight is not without its burdens, but neither is it without its benefits. It has served us well for 40 years. Discarding this standard and the enforceability and public confidence that go with it would be a step backwards for commerce in the United States.

President Carter the other night touched eloquently, I thought, on the terrible and debilitating cynicism and distrust which is eating like cancer on this country's historical self-confidence and faith in the future.

A Governmental decision to allow five percent or so slippage between what is represented and what is delivered in products which Americans buy every day can only erode further the trust the public has in American business ethics and in American Government integrity. 


\section{THE NEED FOR AN EQUITABLE AND PRACTICED NET WEIGHT SYSTEM}

Presented by Dr. Mahlon A. BuRnetTe, Director, Scientific Affairs, Grocery Manufacturers of America

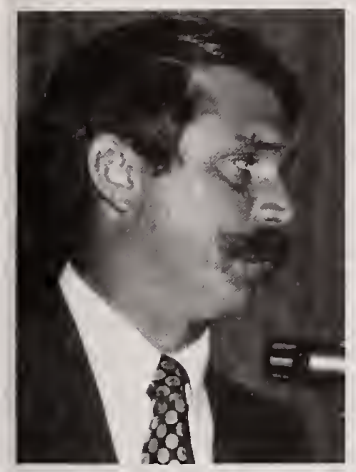

Good Afternoon Ladies and Gentlemen. It is a pleasure to be back here at the National Conference on Weights and Measures. I think everyone in the room is familiar with the history of the net weight compliance debate, so these remarks will be brief.

The first net weight law was passed by the United States Congress in 1913. The Congressional committees which acted on that legislation gave every indication of having known exactly what they were doing when they wrote in the report language: "It being apparent to everyone that it is impossible to make packages of exactly the same size or to pack them with exactly the same quantity of contents, and it being also apparent that the exact weight and measure of the contents of a package may undergo slight changes from natural causes, it is also apparent that legislation requiring similar packages to contain the same exact quantity in terms of weight or measure, without allowing for any variation, would be destructive and would prevent the putting of food in packages."

It is obvious from this Committee record that the United States Congress intended for manufacturers to do the best possible job of labeling accurate net weight on their products and it is also clear that the United States Congress intended that these manufacturers be allowed certain reasonable variations for machine filling differences and also variations for the loss or gain of moisture during distribution. It is primarily this latter variation which has been the subject of our discussion for the past eight years.

The issue of machine variation has been dealt with admirably through the cooperative efforts of manufacturers, this National Conference on Weights and Measures and the National Bureau of Standards in revising the statistical procedures used in Handbook 67. It is to the detriment of all parties involved that we have not had a similar cooperative effort in dealing with gain or loss of moisture during distribution, and it is that subject which we are addressing here today.

The proposed net weight regulations issued by the United States Department of Agriculture late in 1977 contain issues which pertain to moisture. The first is the absence of an allowance for moisture loss or gain during distribution of products. This resulted from the petition to the Department of Agriculture from the State of California which many of you in this room cosigned. 
The second issue is the use of wet tare/drain weight, which is an issue that neither the California Department of Agriculture nor Weights and Measures officials brought before the United States Department of Agriculture but, rather, one which various consumer groups over the years have attempted to impose upon national net weight standards.

The ironic part of the first issue is that the United States Congress discussed the issue of variation for gain or loss of moisture 63 years ago, and the Supreme Court decided in 1977 that not allowing for moisture loss or gain in net weight compliance would in fact be inherently misleading, since the consumer would have no way of comparing products. When products are all of a similar composition, the products should be of comparable weights. Reasonable allowances for the variations that occur subsequent to that packing should be taken into account in net weight compliance so that the consumer is assured of a system of comparability between the weights of different packages in the supermarket. Notwithstanding the sense of Congress and the findings of the Supreme Court, the California Department of Agriculture petition was filed in 1977 and USDA issued its regulations.

On the second issue in the USDA proposal, that of wet tare/drained weight, many of the states in this country, the General Accounting Office, the Consumer Federation of America, and, I expect, the Economic Stabilization and Conservation Service of USDA, all either find that this system is very expensive without providing any substantial benefit to the consumer or question the cost/benefit relationship of such a method of determining net weight compliance. However, because the United States Department of Agriculture published its proposal, and because many of the states supported that part of the proposal which deals with allowances for moisture loss or gain, Sylvia Porter of the Washington Star implied that state weights and measures officials want a system of wet tare/drained weight in order to stop the practice of short-weighting. In a column entitled "Short Weighting Drives Consumer Costs Higher," she states that when the natural biological fluids from a packaged chicken or a piece of beef liver are counted as part of the net weight, this practice is called short-weight. And this Miss Porter says and I quote, "Vaguely worded federal regulations permit this and if they aren't corrected soon, worried state officials fear they'll end up costing shoppers, wholesalers and retailers as much as $\$ 1$ billion." While there may be officials in this room who feel that way, the predominance of the comments at the United States Department of Agriculture does not support that finding. Such a finding is a deliberate misstatement of the situation to try to confuse the net weight issue and to try to prevent you and the food industry from reaching a fair solution to net weight compliance systems.

I am sure there are many of you who will contend that the proposal 
which you asked USDA to accept was in fact not a change in net weight standards but was, in fact, a change in the regulations to be commensurate with existing practices. For those of you who were not in attendance at the NCWM interim meetings in January, I think you would be interested in knowing that a United States Department of Agriculture official told the National Conference on Weights and Measures Liaison Committee that, in fact, the USDA proposal was a change in the definition of net weight. I think, therefore, that you should not find it surprising that there was such a flurry of activity when this proposal was published.

When the General Accounting Office held interviews on the net weight issue with Food Safety and Quality Service officials of the United States Department of Agriculture, they found that these officials did not have, and I quote, "any knowledge or data on the extent of moisture loss under various conditions." This is rather disconcerting when you consider that this proposed change in net weight regulations was not an innocuous change at all. USDA, in its initial economic assessment, estimated costs upwards of $\$ 97$ million a year, and there has been general agreement by everyone, from the meat and poultry industries to the Consumer Federation of America, that that estimate was much too low. The combined estimate of the cost of this system for just meat and poultry alone from the American Meat Institute and the National Broiler Council is that this proposal would cost the American consumer in excess of $\$ 600$ million per year just for packaged meat and poultry.

Now let's look at the alleged problem that these regulations were intended to solve. In December of 1977, before the Food and Drug Administration hearings in Atlanta, Georgia, on net weight which were attended by Mr. Butler, Mr. Scribner stated that over $98 \%$ of all products were in compliance at retail with net weight standards. When the Consumer Federation of America questioned state weights and measures officials, fully two-thirds of the states that responded stated that the Supreme Court decision had little or no effect on their net weight programs. It is no surprise then that even after Assistant Secretary Foreman went on national television to request consumer comments on the net weight proposal that well over two-thirds of the comments that USDA received were opposed to USDA's changing the net weight regulations. Most of those negative comments were based primarily on the increased costs in food. In fact, the report of the Consumer Federation of America discusses the increased costs that state and local officials would have to incur and the additional costs which CFA states that industry would absorb. We all know that there is no place that additional costs go other than on to the food bill or the tax bill of the American consumer, and so even the Consumer Federation of America report proves that food prices would rise if the USDA proposal was implemented. 
There is in the USDA record a National Family Opinion poll of 5000 homes in which homemakers were asked if they would be willing to pay more in order to guarantee that the delivered weight at retail of packaged chicken would equal or exceed the amount stated on the label. $75 \%$ of the respondents said that they would not be willing to pay anything for a change in the net weight system. $12 \%$ of the respondents said they'd be willing to pay no more than 1 to 2 cents per pound. $6 \%$ of the respondents said that they would not be willing to pay more than 3 cents per pound, which leaves only $5 \%$ of the respondents who said they would be willing to pay 4 cents or more per pound. Thus, it is not important for us to determine whether or not the increase in the cost to the consumer would be 1 cent, 2 cents, 3 cents, 5 cents, or 10 cents per pound; $75 \%$ of those households said they were not willing to pay any additional costs in order to change the existing net weight system. It is for this very reason that 30 of the 46 members of the United States House of Representatives Agriculture Committee requested that USDA delay any further activity on net weight regulations until more data on the economic impact and the need for any change in existing regulations could be determined.

The results of all this concern over the proposed change in the National Net Weight Standards has resulted in a series of questions, both within the USDA itself and from the General Accounting Office. At the end of 1978 the Economic Conservation and Stabilization Service of USDA recommended to Assistant Secretary Foreman that there were three additional studies which needed to be done in order to assess the potential impacts of the Department's proposals to change the net weight regulations.

The first of these was to measure the variability of free liquid across processors of fresh poultry products. This study would be needed in order to determine a need in the definition of tare.

The second was to develop an estimate of the impact of the proposal on state and local inspection costs and, to date, no one has come forward with firm estimates of what it would cost you at the state and local level to change the net weight compliance system.

The third recommendation was to assess the costs and benefits of the mandatory industry quality control program which was included in the USDA proposal, particularly since there is a significant difference between the estimates of the industry and the estimates of USDA.

The General Accounting Office in its report has suggested that there is insufficient data to justify changing the National Net Weight Standards and suggests that there are four areas in which better data must be determined.

The first area is information which would support the need for making any change in existing regulation. 
The second area would be to decide how to deal with the very real and natural problem of moisture loss or gain during shipping and distribution of a product. Within this area GAO asks five subquestions:

A. Will industry be able to make a practical determination of anticipated moisture loss for each shipment and package so that net weight compliance will be achieved under varying circumstances, or will it have to overpack each product for each shipment to comply with net weight requirements under the worst possible variables? What would be the effect of each of these practices on the product's retail price and on industry competition?

B. Will the benefit to the consumer of possibly receiving more product per package outweigh the increased cost resulting from overpacking?

C. Do consumers use the free liquid in the package in food preparation? If most consumers use the liquid in food preparation, should the liquid's weight be included in the product's net weight?

D. Will frozen meat poultry products-many of which contain at least the same moisture level as fresh products-have a price advantage because their moisture will not seep out until the consumer defrosts or cooks the product?

E. Will the meat and poultry industry find it more practicable to produce frozen products if the proposed regulations are finalized? What effect will such a move have on energy use and product cost?

The third need was for data to determine the actual economic impact of proposed changes in the net weight system.

The fourth, and the one which I hope will be the subject of the remainder of our discussions, is to comparatively evaluate all alternative net weight compliance systems.

I am not going to stand up here this afternoon and say that the National Net Weight Assurance Program which GMA proposed is a perfect system or is the one against which all other possible alternatives should be measured. However, when the GMA plan was first proposed at the hearings in December of 1977, it was perhaps wisely stated that it would take two to four years to see if it was a reasonable alternative. I am forced to point out that it is now two years later, and we are still in the same situation in which we were in December of 1977. 
The Chairman of the National Conference on Weights and Measures this year has stated that any system which would rely on inspectors monitoring net weight compliance systems at the point of pack in the plant would automatically result in a hands-off attitude by state and local measures authorities, even if the products were short-weight at retail, because there would not be any method for these inspectors to protect the public. I must contend that this is simply not true on at least three counts.

One, there is nothing to prevent the host state from inspecting those same net weight systems at the plant, and we pointed out several instances in our original petition where states are willing to trust the health and safety of their citizens to inspections performed in other states. Therefore, I do not believe that net weight compliance cannot be handled in the same fashion.

Secondly, we have proposed a system in which local inspectors could test products to determine whether they had undergone normal and reasonable moisture loss or gain, or whether or not in fact the product had been incorrectly labeled or packaged at the plant.

And thirdly, we have proposed a system whereby state and local weights and measures inspectors could cross check one another to determine if in fact a particular lot of product had been tested by mutually acceptable net weight compliance procedures.

It has also been said repeatedly that any system such as the one proposed by GMA which necessitates a moisture determination of products would be time and manpower prohibitive and, therefore, of no value at the state and local level for net weight enforcement. Well, I would like to quote a statement if I may: "In order that inspectors utilize their time most effectively, California has employed an audit sampling procedure for years. The use of surveillance tares in small samples expedites this screening process and requires full sampling only on those lots which the audit indicates as suspect." That statement, made by Mr. Richard Rominger, Director of the California Department of Food and Agriculture, was intended to support the fact that you could use an expensive wet tare/drained weight system because you wouldn't really have to inspect very many products. (In fact we already know that we are working with less than $2 \%$ of the products to start with.) Well, if an audit screening procedure, such as was proposed in our petition, can help save money and make a wet tare/drained weight system workable for the inspector, then that same audit screening procedure can be used for the few products in which it would be necessary to run a very quick and very simple moisture analysis for legal action. I do thank Mr. Rominger for putting this statement in the record of the United States Department of Agriculture.

We have all of the state and local officials right here in this organization available to work with the food industry on net weight 
compliance systems. We know this can work, since we have seen it work on statistical procedures in revising Handbook 67.

All of the concern in net weight is caused by the fact that the law of the land uses the word "reasonable" in identifying the variations which should be part of our net weight compliance systems. I honestly believe that our time would have been better spent over the last eight years trying to arrive at a consensus on the meaning of the word "reasonable" and developing workable systems for testing "reasonableness." I hope today's conversation will put us on the road toward that type of cooperation and I look forward to the day when the National Conference on Weights and Measures, the food industry and the four agencies of the Federal government that are involved in net weight can sit down and start working on an equitable and practical system. 


\section{WORKING OF THE INTERGOVERNMENTAL AFF AIRS OFFICE OF U.S. DEPARTMENT OF AGRICULTURE}

Presented by Roger SANDMAN, Deputy Director, Intergovernmental Affairs, U.S. Department of Agriculture

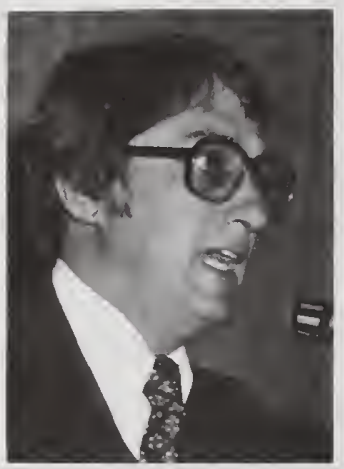

I would like to thank all those responsible for inviting me to be with you. I believe that this is the first time that the Office of Intergovernmental Affairs of the United States Department of Agriculture has been involved in a National Conference on Weights and Measures.

First of all I would like to explain a little bit about the Office of Intergovernmental Affairs so you realize our function and then go into a few details on what I think we can do for you. We are part of the Governmental Pub-

lic Affairs Office of the USDA which is located in the Secretary's Office. There are three basic branches to GPA, these being Intergovernmental Affairs which I run, then Congressional Affairs and Public Affairs. We become the external arms of the Secretary's Office and these very important areas of the operation of the USDA.

The responsibilities of Intergovernmental Affairs are quite varied, but the one and the most important that I know that you want to hear about is the work we have with various agencies of state and local government. We are responsible to keep local, county, and state governments aware of activities within the USDA that could affect them. We also act as problem solvers and issue directors. If a local or state government needs an issue looked into either we follow up on it ourselves and determine the answer, or we direct it to the local official of the various agencies within the USDA that has jurisdiction. Even if we do direct these particular problems or issues we will follow up to insure that local government official that a satisfactory conclusion has been reached. We maintain a very close relationship with all organizations involved in state and local government. Of course, on the top of our list is the National Association of State Departments of Agriculture.

From time to time Commissioner Jim Graham and I talk on issues that affect State Departments of Agriculture which many of you in this room are affiliated with. Beyond that we also work very closely with the National Association of Governors, the National Association of State Legislatures, of which I am just returning from their nationaI meeting in San Francisco, and the National Association of County Officials. 
Each and everyone of you has a different problem, has a different set of situations you work under. We in the Office of Intergovernmental Affairs in Washington can help you if a problem does come up within the USDA. At times it seems easier to work with one of your national organizations. That does not preclude us from working directly with you as state, local, or county officials. One service that we provide, which is basically new within the USDA, is the publication of the semi-annual agenda of rules and regulations. This document is issued every six months. I know your Commissioners of Agriculture and your Governors' Offices have copies, or if you need them we can get them for you. This document is a list of all proposed rules and regulations that will be coming out of the USDA during the next six months. It is important because it includes not only the rules and regulations that have been set for hearing and those that are open for comment at that particular time, but it also includes the rules and regulations that will be coming up. So by going through that document and finding areas that are of interest to you, you will be able to determine in advance when some of them are even written. You may have comment or have contact with the various agencies that are working on them so that your input can have the greatest amount of meaning. The USDA started this process approximately eight months ago. We just published the second semi-annual agenda. As I said, if you would like a copy of this we would be happy to provide it for you.

I think Jim Graham had the right idea when he hit on a very important issue that faces each and everyone of us, and that is communication. Communication can be the link between us that brings about a stronger relationship, that can bring about a better situation for the people that we all serve, and that is the public. I hope that my presence here and the continued presence of the Office of Intergovernmental Affairs can bring about a new era of communications between the Weights and Measures Officials, whether you are county oriented, State Departments of Agriculture, or officials at the USDA. Now by no means do I mean to say that we wish to preclude a relationship that you have already established with people like Sid Butler, the grain inspection people. I think we can add to that. Many times issues will come up that cross all boundaries within the USDA and I think that is when we can be of assistance to you.

We are basically a service oriented organization within the USDA. We are one of the very few totally service groups within that organization, and we can only be as good and as effective as you allow us to be. So if you have a problem or see an issue you feel we can help you with, my name and address are in your program; feel free to contact us and one of us at the office will be able to help you with whatever your particular situation is. Again, thank you for the opportunity to be here. Thank you. 


\section{REPORTS OF STANDING COMMITTEES}

The following is a list of designated State representatives who were present and voting on the reports presented by the Conference standing and annual committees:

State

1. Alabama (AL)

2. Alaska (AK)

3. Arizona (AZ)

4. Arkansas (AR)

5. California (CA)

6. Colorado (CO)

7. Connecticut (CT)

8. Delaware (DE)

9. District of Columbia (DC)

10. Florida (FL)

11. Georgia (GA)

12. Hawaii (HI)

13. Idaho (ID)

14. Illinois (IL)

15. Indiana (IN)

16. Iowa (IA)

17. Kansas (KS)

18. Kentucky (KY)

19. Louisiana (LA)

20. Maine (ME)

21. Maryland (MD)

22. Massachusetts (MA)

23. Mirhigan (MI)

24. $\mathrm{Min}$ ،esota (MN)

25. Mississippi (MS)

26. Missouri (MO)

27. Nontana (MT)

28. Nebraska (NE)

29. Nevada (NV)

30. New Hampshire (NH)

31. New Jersey (NJ)

32. New Mexico (NM)

33. New York (NY)

34. North Carolina (NC)

35. North Dakota (ND)

36. Ohio $(\mathrm{OH})$

37. Oklahoma (OK)

38. Oregon (OR)

39. Pennsylvania (PA)

40. Puerto Rico (PR)

41. Rhode Island (RI)

42. South Carolina (SC)

43. South Dakota (SD)

44. Tennessee (TN)

45. Texas (TX)

46. Utah (UT)
Representative

John B. Rabb

Joseph L. Swanson

Pat M. Fullinwider

Sam F. Hindsman

Ezio F. Delfino

Leo Letey

John T. Bennett

Eugene Keeley

Absent

Sydney D. Andrews

Thomas E. Kirby

Absent

Lyman D. Holloway

Sidney A. Colbrook

Robert W. Walker

James O'Connor

John L. O'Neill

George L. Johnson

William H. Daniels

Gaylon M. Kennedy

Lacy H. DeGrange

Edward H. Stadolnik

Edward C. Heffron

Edward Skluzacek

Gene Williams

Bob Merrick

Gary L. Delano

Steven A. Malone

Absent

Absent

James R. Bird

Charles H. Greene

John J. Bartfai

Marion Kinlaw

Elvin Skaarvold

Kenneth R. Adcock

Absent

Raymond Fleischmann

Fred A. Thomas

Maria A. Maldonado GarciaJuan A. Rios

Edward R.Fisher

John V. Pugh

Bruce Farus

Robert M. Reeves

Charles E. Forester

Edison V. Stephens
Alternate

D.W. Sorensen

Darrell A. Guensler

Guy J. Tommasi

-

Stan J. Darsey

John Peacock

Allen D. Hurd

Wayne W. Behrns

Francis W. Daniels

Kermit L. Toland

Donald L. Lynch

Ron Egnew

Marshall White

Frank C. Nagele

George W. MacDonald

Mark Freeman

Louis Stephens

-

$-$

John M. Chohamin

Fred A. Gerk

Ken Gridley

Thomas W. Scott

James C. Truex

Leo Weber

$-$

Allen L. Christie

Robert G. Williams

Charles H. Vincent

Daniel Mays 


\section{State}

47. Vermont (VT)

48. Virginia (VA)

49. Virgin Islands (VI)

50. Washington (WA)

51. West Virginia (WV)

52. Wisconsin (WI)

53. Wyoming (WY)
Representative

Trafford F. Brink James F. Lyles

Absent

John H. Lewis

David L. Griffith

Robert W. Probst

Elvin R. Leeman
Alternate

Marion W. Cain

Gunnar Magnuson

Alden Lemke 


\section{REPORT OF THE COMMITTEE ON NATIONAL MEASUREMENT POLICY AND COORDINATION}

Presented by KendRICK J. Simila, Administrator, Weights and Measures Division, Department of Agriculture, State of Oregon

(Thursday, July 26, 1979)

VOTING KEY

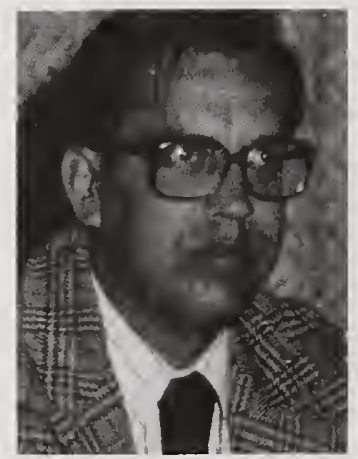

100

INTRODUCTION

The Committee on National Measurement Policy and Coordination (P \& C Committee) submits its final report to the 64th National Conference on Weights and Measures (NCWM). The report represents recommendations of the committee that have been formed on the basis of written and oral comments received during the year and oral presentations made during the open meeting of the committee.

The P \& C Committee included in its agenda for the interim meetings several items that were referred to the Executive Committee for action during the 64th NCWM. Consideration of these items at this time by the P \& C Committee, and in joint session with members of other standing committees who attend the interim meetings, allows for the development and reporting on such items in the committee's tentative report and for publication in the Announcement Booklet. The items referred to the Executive Committee were (1) Revision of Voting System Requirements to Debate and Adopt Amendments to Committee Final Reports, (2) Recognition of Weights and Measures Jurisdictions Under the Auspices of Indian Tribes, (3) Appointments to Standing Committees, and (4) Future Conference Plans. The recommendations and actions on these items are included in the report of the Executive Committee.

(Item 101 was adopted)

102 CONFERENCE RESPONSE TO FEDERAL NET WEIGHT LABELING DEVELOPMENTS

The issue of developing a Conference response or position on the December, 1978 General Accounting Office (GAO) Report on the USDA's Net Weight Labeling Proposal was examined by the P \& C 
Committee. It was generally held that the Conference definitely should make a response as lack of response could be interpreted as lack of interest. It was initially decided that the States represented on the committee would, after analyzing the GAO report, provide some suggested questions that could be used in a survey questionnaire to all States. The thrust of the questionnaire would be to bring out points missed or errors that could be raised in support of the USDA Net Weight proposal.

Since the interim meetings, it has been announced by USDA that its Economics, Statistics and Cooperative Service will evaluate during the next 6 months not only the GAO report but also the original hearing record and Consumer Federation of America's report on the proposal's economic impact. This action has apparently extended the time in which a Conference response or position can be developed.

During the open hearing at the Conference the Chairman reported that instead of a written response, he met with Mr. Charles Handy, USDA Economics, Statistics and Cooperative Service (ESCS), who is responsible for the economic evaluation of the USDA's Net Weight Labeling Proposal in Sacramento, California in March, and was able to present NCWM viewpoints at that time. ESCS has contacted many individual States for additional information. The ESCS Report has not yet been released by USDA.

(Item 102 was adopted)

103 REPORT ON THE U.S. METRIC BOARD

The Committee was pleased to have Mr. Sydney D. Andrews, Director, Division of Standards, State of Florida, and NCWM Representative on the United States Metric Board, attend the interim committee sessions and provide valuable input on metric matters. A Summary of his report on the plans and progress of the U. S. Metric Board follows:

The organizational meeting of the U. S. Metric Board was held May 10,1978 , in Washington, D. C. All seventeen members have now been confirmed by the Senate and sworn in by the President. Dr. Malcolm O'Hagan, former President of the American National Metric Council, has been employed as Executive Director, and other key staff members are now on the job also. Temporary office space has been provided at 1815 Lynn Street, Arlington, Virginia 22209. (Telephone No. 703235-1933.)

A schedule has been adopted for regular meetings of the Board on the third Thursday and Friday of even numbered months. The first out-of-Washington meeting is planned for Dallas, Texas in February. After that, it is planned to alternate meetings out of Washington on a regional basis. 
Cuts in the budget request for Fiscal Year 1979 authorize only 25 positions and approximately $\$ 1.6$ million which will prevent employing the staff hoped for and entering into work contracts tentatively planned. Also, it will not be possible to open the West Coast office in San Francisco that was planned. A contract has been entered into with Middlesex Research Corporation to develop a plan for identifying laws and regulations at the Federal, State, and local levels which prevent those who choose to go metric voluntarily from doing so and for amending or repealing them.

The Chairman of the United States Metric Board is now chairing a new Interagency Committee on Metric Policy. This is a committee of high level representatives of Federal agencies to plan and coordinate metrication of their activities. In addition to an Executive Committee, several standing committees of the Board have been formed. They are Standards Liaison (Syd Andrews is chairman of this one), Research Coordination, Administration and Budget, Public Information, Private Sector Coordination, and Annual Report. The Annual Report Committee is made up of the persons chairing the other standing committees.

The Board has adopted a policy of openness and hopes to make an open forum a part of future meetings. It has expressed a special concern over the needs and interests of consumers, and some thought is being given to forming a standing committee on Consumer Affairs.

Mr. Andrews provided an update on the work of the U. S. Metric Board during his presentation to the Conference at the July 25 general session.

(Item 103 was adopted)

\section{4} NCWM PARTICIPANTS IN OIML MEETINGS

The National Conference or Weights and Measures has been called upon to increase its participation in the work programs of the International Organization of Legal Metrology (OIML). Funding will be made available to support the cost of travel by State and local weights and measures officials to OIML meetings in the United States and, in some cases, to foreign countries as well. Since the NCWM is the principal mechanism for adopting the outputs of OIML which impact on the U.S. commercial measurement system, the Committee feels that it is extremely important for weights and measures regulatory officials to be involved in the technical activities of OIML. Such activities are being accelerated at this time and will continue to grow over the next few years-primarily because the United States will host the next plenary meeting of the International Conference of OIML in June of 1980 in Washington, D. C.

Several important meetings have already been held and steps were taken to have representatives of NCWM participate in these meetings 
that were held in Paris, France, last fall and that will be held in London, England in the spring of 1979. These meetings involved the work of the NCWM Committee on Specifications and Tolerances and, therefore, members of that Committee were selected for these assignments.

With the increase in activity on OIML matters, the time has come to develop certain guidelines and policy for the selection of participants in OIML meetings and work programs. Obviously, officials should be well qualified to represent the NCWM in such meetings and specific work programs. It is also advisable to provide for close coordination between the scope and work of NCWM Committees and those activities which are similar in OIML.

The following criteria were developed for the selection of NCWM representatives to the meetings previously mentioned. The Committee recommends the adoption of these criteria as the policy of the Conference in the future:

\section{CRITERIA FOR THE SELECTION OF NCWM REPRESENTATIVES TO OIML MEETINGS}

1. The NCWM Chairman, NCWM Representative to U.S. Advisory Committee for International Legal Metrology (ACILM) and Executive Secretary shall jointly receive, coordinate, and manage all invitat1ons or requests for Conference participation in OIML meetings and work programs. They will refer such requests to the appropriate standing committee of the Conference.

2. The standing committee will select the member who they feel is fully qualified to handle a particular assignment. The Committee will have the prerogative to select someone who is not a member of the committee but who is particularly knowledgeable and expert in a certain area or on a specific subject.

3. These selection criteria apply primarily to State and local weights and measures officials who are active members of the NCWM. Officials from other Federal agencies and industry representatives will also participate but they generally will be representing their own agency or company (or industry association) and their selection, travel expenses and the like are matters which will be coordinated through the Office of Domestic and International Measurement Standards of NBS. The Chief of that office has responsibility for administering the activities with OIML by interested parties in the United States.

4. Insofar as possible, participants will usually be limited to one meeting outside the continental limits of the United States per 
Conference Year (August 1-July 31), to allow for the participation of as many weights and measures officials as possible.

5. The role of the NCWM representative to the U. S. Advisory Committee for International Legal Metrology is not affected by the above criteria. He and the NCWM Chairman may well attend and participate in OIML meetings in line with their overall Conference responsibilities.

6. The Chairman of a standing committee shall advise the NCWM Chairman by letter whom his committee has selected to represent the NCWM in an OIML meeting. The NCWM Chairman, in consultation with the ACILM representative and the Executive Secretary, shall be responsible for the final approval and notification of the official selected. Participants will be formally accredited as a member of the U.S. delegation by the Office of Domestic and International Measurement Standards of NBS.

7. Recognizing that foreign travel is appealing to many persons, we believe the criteria set forth here will provide for the fair and orderly selection of qualified participants.

In 1976, the Conference approved a recommendation of the Executive Committee to appropriate $\$ 2,000.00$ each year to cover expenses by NCWM representatives in the work programs of the International Organization of Legal Metrology. The Committee recommends that the appropriation be increased to $\$ 8,000.00$ annually to cover the expanded activities in OIML.

\section{(Item 104 was adopted)}

105 OIML UPDATE

Mr. James F. Lyles, NCWM representative to the U. S. Advisory Committee for OIML, presented the following report to the Committee on the highlights of OIML activities since the last National Conference in Washington:

Since the last National Conference in July there have been seven meetings of OIML Technical Pilot and Reporting Secretariats. These were as follows:

Sept. 1978-PS21/RS1, 2, 4, \& 5-Standardization of the Metrological Characteristics of Measuring Means (Instruments) 
Oct. 1978 -PS5/RS16 -Water Meters

PS16/RS2 — Secondary Standards Dosimetry Laboratories

PS30 -Physico-Chemical Measurements

PS5/RS13 -Measuring Systems for Liquids Other Than Water

Nov. 1978 —Joint PS7/PS8-Measurement of Mass/Weights

The meetings of principal interest to the weights and measures community were PS5/RS13 on fluid measurement and the joint PS7/ PS8 meeting on mass and weights. Both of these meetings were attended by OWM and by a member of the NCWM Committee on Specifications and Tolerances. A discussion of the meeting results is included in the Tentative Report of the S \& T Committee.

It is expected that 1979 will be a very active year in OIML as many secretariat committees are trying to complete work on draft International Recommendations for presentation to the International Conference of Legal Metrology scheduled for June 1980 in Washington. Since the interim meetings in January, OWM has received the following schedule of OIML meetings for 1979. The list includes eleven meetings of interest to the weights and measures community. These are indicated by an asterisk:

\section{Pilot and Reporting Secretariats} and Other OIML Working Groups

Dates

Places

SP.4/SR.1 End measures of length

SP.4/Sr.4 Hierarchy schemes for length measuring instru-

Mar. 20-22 Leningrad ments

SP.22/Sr.2 Principles of the choice of parameters and characteristics to be verified

*SP.7/Sr.5 Automatic weighing instru- May 8-11 London ments

*SP.7/Sr.8 Load cells June 5-8 B.I.M.L. ${ }^{1}$

SP.12/Sr.8 Thermal energy meters Apr. 25-26 Berlin June 12-14 Hanover

${ }^{1}$ The International Bureau of Legal Metrology-Paris, France 
*SP.7/Sr.4 Non-automatic weighing in- Sept. 18-21 struments

Braunschweig

*SP.18/Sr.1Instruments for measuring Oct. 24

Paris the moisture content of cereal grains and oilseeds

SP.23

Methods and means used

October

B.I.M.L. for certification of verifica- (provisional) tion devices

SP.12/Sr.7 Clinical thermometers

Oct. $22-23$

Braunschweig

SP.26

Measuring instruments used in the field of public health

*SP.5/Sr.16Water Meters

October

(provisional)

*SP.25/Sr.3Equipment necessary for the operation of a National Nov. 13-16 Riga Service of Legal Metrology $\begin{array}{llll}\text { *SP.5/ } & \text { Meters for liquids other } & \text { November } & \text { Paris } \\ \text { Sr.13-19 } & \text { than water with measuring } & \text { (provisional) }\end{array}$ chambers and turbines

Electronic devices applied to the measurement of liquid quantities

SP.1 Terminology

SP.1/Sr.1 Vocabulary of legal Metrology. Fundamental terms

SP.1/Sr.2 Vocabularies of various measurement fields

*Developmental Council June 11-12 B.I.M.L. *Ad hoc Group "OIML Mark" June 13-15 *Presidential Council 
During the Conference, Mr. David Edgerly, Chief of the Office of Domestic and International Measurement Standards, National Bureau of Standards, described the planning for the 1980 International Conference of Legal Metrology which will meet in Washington, D.C., June 16-20, the week preceding the 65th National Conference on Weights and Measures also to be held in Washington in 1980.

Mr. Wollin, Executive Secretary of the National Conference on Weights and Measures (NCWM), described the plans for conduct of the 65th NCWM.

Mr. Lyles, NCWM Representative to the U.S. Advisory Committee for OIML, reported that Dr. Carroll Brickenkamp of the NBS has been asked to head the delegation to the OIML meeting of SP.18/Sr.1 in Paris, October 2-4, 1979, and that an NCWM delegate to that meeting has been chosen by the Liaison Committee. Mr. Sam Hindsman, National Coordinator for the Task Force on Grain Moisture Measurement, has been asked by the Liaison Committee to represent the NCWM at this meeting. Additional representation by industry and the U.S. Department of Agriculture will supplement the U.S. delegation to this meeting.

On September 18-21, 1979, there will be an important meeting of PS7/RS4 Non-Automatic Weighing Instruments in Braunschweig, Federal Republic of Germany. The subjects for discussion will be draft amendments to IR \#3 and IR \#28. Mr. Edgerly has indicated that funds are available from his office to assume one-half of the expenses of a NCWM delegate. It is requested that the NCWM assume the remaining half and select an appropriate representative.

(Item 105 was adopted)

106 NATIONAL TYPE APPROVAL TASK FORCE

Task force members under the chairmanship of Ezio Delfino, Chief, Division of Measurement Standards, State of California, met on January 22 and again on January 23 with members of the S \& T Committee. The task force recommends that its immediate goals be to work toward reciprocity between type approval jurisdictions to accept the examination results of other jurisdictions concerning type approval. This will require establishing uniform criteria and test procedures to be used during prototype examination. The task force suggests a pilot program be established to develop the mechanics of such a system.

Plans are underway for NBS and California to begin a pilot program for specific devices. The NBS and California plan to enter into an agreement whereby each would accept the other's prototype examination results. Uniform checklists for prototype examination of electronic scales and cash registers have been developed and were 
distributed during the interim meetings. The checklists reflect most of the existing requirements being applied by California and NBS. Copies are available from either agency.

It is likely that a field test for equipment will be required to demonstrate a minimum degree of permanence. In this case an initial examination of the equipment will be conducted and if the device complies with NBS Handbook 44, a temporary certificate of compliance will be issued pending the result of the field test. A final report would be issued after all the tests are completed. The actual parameters of the field test have not yet been established.

It is suggested that weights and measures officials review the criteria and determine if they have requirements in addition to or different from the checklists. Suggestions for changes to the checklist will be reviewed by the S \& T Committee.

All States are encouraged to change their laws to permit cooperative prototype agreements between their States and NBS and other weights and measures jurisdictions. As the pilot program is developed, it is the intention of the task force to encourage other jurisdictions to participate in the program.

Mr. Delfino provided the following update to the Task Force report at the open hearing of the Conference.

Following the January 22-23, 1979, meetings of the Task Force, NBS and California developed an agreement whereby each accepts the other's prototype examination results, initially involving electronic scales and cash registers.

Currently the agreement is at NBS for final drafting and submission to California for their approval.

Highlights of the agreement are:

1. Draft examination check lists for both Electronic Digital Scales and for Electronic cash registers have been developed and are available through either NBS or California.

2. Field endurance testing will initially be conducted under the auspices of NBS for the eastern part of the country and by California in the west.

3. Initially, payments for the tests will be made to NBS by companies requesting the service. NBS in turn will reimburse California for their work performed under the agreement.

4. Each agency will accept each other's prototype examination and provide each other with complete documentations of approvals awarded.

All States are encouraged to change their laws to permit cooperative prototype agreements between all jurisdictions. 
California currently has such a law change being considered by their legislature. The law would permit California to:

1. Accept the testing and sealing of devices by other States.

2. Enter into agreements with NBS and other weights and measures jurisdictions to accept the certification of each other for prototype examinations.

3. Charge and collect fees directly from persons submitting devices for approval.

4. Compensate county sealers, other weights and measures jurisdictions or private laboratories for furnishing equipment or assisting in conducting type approval activities.

\section{TASK FORCE PERSONNEL CHANGES}

Since the appointment of the Task Force in 1976 there have been several personnel changes in both weights and measures and industry representation. On July 12, 1979, your Chairman appointed the following as Task Force members:

\section{NATIONAL BUREAU OF STANDARDS}

Albert D. Tholen

Office of Weights and Measures National Bureau of Standards Washington, D.C. 20234
Harold F. Wollin

Office of Weights and Measures National Bureau of Standards Washington, D.C. 20234

\section{DEVICE INDUSTRY}

\section{SCALES AND WEIGHING}

William V. Goodpaster (NSMA) Raymond J. Lloyd (SMA) Murphy Cardinal Scale Company Scale Manufacturers Association 1610 North "C" Street 1000 Vermont Avenue, NW. Sacramento, California $95814 \quad$ Washington, D.C. 20005

\section{LIQUID METERING}

Walter F. Gerdom (GPMA) Tokheim Corporation 1600 Wabash Avenue Fort Wayne, Indiana 46801
Emmett F. Wehmann (NMTC)

Neptune Measurement Company P.O. Box 792

Greenwood, South Carolina 29646 
Eric Allen

The Measuregraph Company 4245 Forest Park Boulevard St. Louis, Missouri 63108
Robert E. Nix

Veeder-Root Company

70 Sargeant Street

Hartford, Connecticut 06102

AT-LARGE

Kenneth F. Hammer

Fairbanks Weighing Division

711 East St. Johnsbury Road

St. Johnsbury, Vermont 05819
Thomas M. Stabler

Toledo Scale Division

P.O. Box 1705

Columbus, Ohio 43216

\section{WEIGHTS AND MEASURES JURISDICTIONS}

\section{WESTERN}

Ezio F. Delfino (TASK FORCE Kendrick J. Simila (NCWM CHAIRMAN) CHAIRMAN)

Division of Measurement Stand- Weights and Measures Division ards Department of Agriculture

Department of Food and Agricul- Salem, Oregon 97310 ture 8500 Fruitridge Road Sacramento, California 95826

\section{SOUTHERN}

Richard L. Thompson

Weights and Measures Section

Department of Agriculture

Symons Hall, Room 3205

College Park, Maryland 20742
Sam F. Hindsman

Division of Weights and Measures Department of Commerce 4608 West 61st Street

Little Rock, Arkansas 72209

\section{NORTHWESTERN}

Dr. Edward Heffron

Food Inspection Division

Department of Agriculture

Lewis Cass Building, Box 30017

Lansing, Michigan 48909
Edward Skluzacek

Division of Weights and Measures

Department of Public Service

1015 Currie Avenue

Minneapolis, Minnesota 55403

\section{NORTHEASTERN}

John J. Bartfai

Bureau of Weights and Measures

Department of Agriculture

1220 Washington Avenue

Albany, New York 12235
Fred A. Thomas

Bureau of Standard Weights and Measures

Department of Agriculture 2301 North Cameron Street

Harrisburg, Pennsylvania 17120 
Marion L. Kinlaw

Consumer Standards Division

Department of Agriculture

P. O. Box 26056

Raleigh, North Carolina 27611
George E. Mattimoe

Division of Measurement Standards

Department of Agriculture

P. O. Box 22159

Honolulu, Hawaii 96822

(Item 106 was adopted)

\section{POLICY STATEMENT ON METRIC CONVERSION OF RETAIL MOTOR-FUEL DEVICES (GAS PUMPS)}

\section{7-1 BACKGROUND OF THE STATEMENT}

The 94th Congress of the United States passed Public Law 94-168 on December 23, 1975, that is cited as the "Metric Conversion Act of 1975". This Act declared a national policy of planning and coordinating the increasing use of the metric system in the United States, and established a United States Metric Board to coordinate the voluntary conversion to the metric system.

A principal function of the U.S. Metric Board is to devise and carry out a broad program of planning, coordination, and public education, consistent with other national policy and interests, with the aim of implementing the policy set forth in the Act.

The U.S. Metric Board in carrying out its programs under the Metric Conversion Act of 1975 is directed to:

1. Consult with government agencies at the Federal, State and local level,

2. Provide appropriate procedures whereby various groups may formulate and recommend specific programs for coordinating conversion in an industry,

3. Encourage activities of standardization organizations to develop standards, and take advantage of opportunities to promote improvement of design and increases in economy, and

4. Assist the public through information and education programs, and one such program calls for consultation by the Secretary of Commerce with the National Conference on Weights and Measures in order to assure that State and local weights and measures officials are (a) appropriately involved in metric conversion activities and (b) assisted in their efforts to bring about timely amendments to weights and measures laws. 
The National Conference on Weights and Measures, an organization comprised of State and local weights and measures regulatory officers, and other officials of Federal, State, and local governments, and representatives of manufacturers, industry, business, and consumer organizations has taken a positive stand in support of metric conversion in the United States as called for in the Act.

The National Conference on Weights and Measures has provided the basis for national uniformity of weights and measures laws and regulations and has been a major factor in serving the interests of industry and consumers who need reliable standards of measurement in the marketplace.

The National Conference on Weights and Measures is interested in providing the necessary leadership and guidance to the States and all others who seek a solution to the problems of price computation by retail motor-fuel devices as prices rise to a level (over $99.9 \phi$ per gallon in most cases) that exceeds the computing capability of devices now in service.

The U.S. Metric Board conducted hearings on May 2-3, 1979, to determine the feasibility and practicality of converting retail motorfuel devices to compute prices on the basis of metric measurement and on June 21, 1979, issued a declaration which stated that this is an opportune time for the development of a planned and coordinated voluntary program of dispensing gasoline by the liter, and noted that without taking this action metric usage is likely to proceed in a haphazard fashion, leading to public confusion, disparate end results and the negation of the positive cost advantages that a nationally planned and coordinated program offers.

\section{7-2 Statement of Conference Policy}

The National Conference on Weights and Measures as assembled during its 64th annual meeting in Portland, Oregon on July 22-27, 1979 , adopts as its policy the recommendation that each state, county and city in the United States implement a three-phase general plan and timetable for the eventual metric conversion of all retail motorfuel devices. In establishing this plan and timetable, it is recognized that the conversion time within any jurisdiction will be dependent upon such factors as: local area price increases, existing device computing capabilities, replacement parts availability, and availability of "pump" repair or service personnel. It is recommended that each jurisdiction:

\section{7-2-1 Phase I-Up to January 1, 1982}

- Allow gallon measurement and price computation per gallon.

- Allow liter measurement and price computation per liter. 
- Allow "half-pricing per gallon" wherever devices are not capable of computing in whole gallons and total dollars. In each jurisdiction the duration of half-pricing should be held to a minimum period determined by economic and other factors in that jurisdiction.

- Require each establishment to use exclusively only one of the measurement methods of sale (gallon, liter, or "half-pricing"). A change from one method to another must be carried out for all devices dispensing motor fuels in the establishment.

- Require all roadside signs and similar advertisements of motor fuel offered for retail sale to be by the price per gallon or price per liter.

- Require in the case of liter sales suitable posting of per gallon and per liter prices at the device, service island, and premises of the establishment in accordance with State and local laws, regulations, and ordinances, and in a manner which facilitates consumer comparisons between the per gallon price and the per liter price.

\section{7-2-2 Phase II-From January 1, 1982 Through December 31,1982}

- Allow gallon measurement and price computation per gallon.

- Allow liter measurement and price computation per liter.

- Discontinue "half-pricing per gallon" methods still in use effective January 1, 1982.

- All other requirements remain unchanged.

\section{7-2-3 Phase III-On January 1, 1983 and Thereafter}

- Encourage only liter measurement and price computation per liter.

\section{7-3 Further Policy Considerations}

In adopting this policy, the National Conference on Weights and Measures recognizes:

1. That the U.S. Metric Board is the logical entity to act as the focal point for the coordination and planning of all necessary details for the orderly and efficient transition to liter measurement in the sale of motor fuels at retail, and

2. the advice and assistance of the American National Metric Council, the American Petroleum Institute, the North American Gasoline 
Tax Conference, State Metric Councils and/or Boards, and such other organizations as may be interested in participating in the effort are essential in addition to that of the National Conference on Weights and Measures, and

3. that comprehensive and appealing public education programs must be conducted by both government and industry to fully familiarize the public with the changeover to metric measurement in motor fuel dispensing.

(Items 107 through 107-3 were adopted)
K. Simila, Oregon, Chairman-NCWM
J. BIRD, New Jersey, Chairman-S \& T Committee
R. Probst, Wisconsin, Chairman-L \& R Committee
S. Malone, Nebraska, Chairman-Education Committee
C. Greene, New Mexico, Chairman-Liaison Committee
H. Wollin, NBS, Executive Secretary-NCWM

\section{Committee on National Measurement Policy and Coordination}

(On motion of the committee chairman, the report of the Committee on National Measurement Policy and Coordination voting key items 100 through 107-3 was adopted in its entirety by the Conference. The results of the voting in the House of State Representatives and the House of Delegates under the Conference voting system are totalized in the table that follows. The Conference also authorized the executive secretary to make any appropriate editorial changes in the language adopted by the Conference, provided that the requirements thus adopted are strictly adhered to.)

VOTING RESULTS-Committee on National Measurement Policy and Coordination

\begin{tabular}{l|c|c|c|c}
\hline \hline \multirow{2}{*}{ Voting Key } & \multicolumn{2}{|c|}{$\begin{array}{c}\text { House of State } \\
\text { Representatives }\end{array}$} & \multicolumn{2}{c}{ House of Delegates } \\
\cline { 2 - 5 } & Yes & No & Yes & No \\
\hline 100 & 42 & 0 & 70 & 0 \\
101 \\
102 \\
103 \\
104 \\
105 \\
106
\end{tabular}




\section{REPORT OF THE COMMITTEE ON LAWS AND REGULATIONS}

Presented by RoBert W. Probst, Director, Bureau of Weights and Measures, Department of Agriculture, Trade and Consumer

Protection, State of Wisconsin

(Thursday, July 26, 1979)

VOTING KEY

200

INTRODUCTION

The Committee on Laws and Regulations submits its report to the 64th National Conference on Weights and Measures. The report consists of the tentative report as offered in the Conference Announcement and as amended by this final report.

The report represents recommendations of the committee that have been formed on the basis of written and oral comments received during the year and oral presentations made during the open meeting of the committee.

\section{METRIC CONVERSION OF MODEL REGULATIONS}

The National Conference on Weights and Measures remains committed to the support of metric conversion as called for by the Metric Conversion Act of 1975 (Public Law 94-168). The Conference in this regard continues to pursue its goal of removing barriers for those wishing to go metric and making such decision in a voluntary manner as prescribed by the Metric Act.

In 1978, the Conference adopted a joint metric/inch-pound version of its Model State Packaging and Labeling Regulation as an initial step to removing barriers in its model State laws and regulations. At that same 63rd National Conference first drafts of the remaining models with significant metric impacts, the Model State Regulation for the Method of Sale of Commodities and Model State Unit Pricing Regulation, were distributed. Recipients of these drafts were encouraged to provide input for consideration by the Committee concerning the details of the recommendations. The Committee received a limited amount of such input and has revised the drafts accordingly. 


\section{1-1 Method of Sale of Commodities Regulation}

The Committee amends its Tentative Report to include an effective date of January 1, 1982, in all Sections of the draft Model State Method of Sale of Commodities Regulation wherein specified quantities in the metric system are set forth-Section 1., Subsections 1.1.(b), 1.2.(b), 1.3.(b), 1.4.(b), 1.6.(b), 1.6.(c), 1.7.(b), and 1.7.(c).

Further, the Committee amends its Tentative Report by spelling out the term "milliliter" in Section 1.1.(b) of the Regulation and notes that all other Sections contain full spellings of metric terms.

(Items 201 and 201-1 were adopted)

\section{1-2 Unit Pricing Regulation}

The Committee amends its Tentative Report by withdrawing the recommendation for adoption of the revision of the Model State Unit Pricing Regulation. At the open meeting, the Committee received the first substantive comments on this proposal and feels there is sufficient merit to reconsider the units selected for many of the commodities listed. The Committee was also made aware of the fact that certain categories of products designated to be sold by weight in the metric system are sold by both weight and fluid measure in the inchpound system.

To clarify these matters and to make available additional time for input, the Committee proposes to keep this item on its agenda for the next Conference.

(Item 201-2 was adopted)

202

MODEL STATE METHOD OF SALE OF COMMODITIES REGULATION

\section{2-1 Baler and Binder Twine}

The Committee amends its Tentative Report to specifically delete Section 2.1. This will have the effect of removing the previously established tolerance of 5 percent of the declared length.

The Committee also wishes to point out that knot strength in terms of pounds or kilograms is an element of product identity and not quantity. The standard submitted by the Cordage Institute to the Conference has been reviewed and found to be appropriate. The method of test incorporated in the standard for determination of knot strength may be employed by those jurisdictions wishing to check this element of product identity. 
The Committee also requests that the National Bureau of Standards, in its work on the handbook, Checking Prepackaged Commodities, recognizes in an appropriate manner the 5 percent variation in length for agricultural twines.

(Item 202-1 was adopted)

\section{2-2 Insulation}

In 1977, the Conference adopted a guideline for the sale of insulation. In 1978, the Southern Weights and Measures Association and the State of California requested that a provision be added to the Model State Regulation for the Method of Sale of Commodities in 1979.

Accordingly, the Committee recommends that the guidelines be accepted as a part of the Model regulation, as follows:

\section{SECTION 2.X. Insulation}

2.X.1. Packaged Loose Fill Insulation.-Packaged loose fill insulation shall be sold on the basis of coverage in square feet or square meters, the recommended installed thickness, the insulation resistance " $R$ " value obtained, and net weight.

Example: Contents will cover 26 square feet when installed at a thickness equal to $6 \frac{1}{2}$ inches with a resistance value of $\mathrm{R}-19$. Net Weight $30 \mathrm{lb}$.

2.X.2. Batt or Roll-Type Insulation.-Shall be sold on the basis of coverage in square feet or square meters, the designated " $R$ " value and the width and length of the batt or roll.

Example: Covers 26 square feet and provides a value of R-19. Roll is 12 inches wide by 26 feet long.

2.X.3. Installed Insulation.-Installed insulation shall be sold on the basis of coverage in square feet or square meters, and the insulation resistance obtained; the seller or applicator shall provide the purchaser with an application statement.

Example:-Insulation covering 120 square meters of area has been installed in conformance with manufacturer's recommendations to provide a value of $\mathrm{R}-19$.

The effective date of this regulation for insulation shall be January $1,1980 .[1979]$

(Item 202-2 was adopted)

\section{2-3 Mail Order Shipping}

The report of the Committee from the 63rd National Conference requested all weights and measures jurisdictions to provide infor- 
mation if the problem of inaccurate catalog package weights, when a shipping charge is based on indicated rather than actual weight, is of concern to them. Only the city of Chicago provided any such data. However, the Mail Order Association of America, in response to a request from the Committee in its 1978 report, provided a position paper that described the problems that would be caused by requiring every package shipped to be individually weighed. The Association also stated:

"All members of the Mail Order Association of America herewith express their commitment towards refinement of their systemswithin all practical limitations-so that they yield the most precise shipping weight information feasible."

The Committee appreciates the cooperation of the Association and accepts this statement as an indication of the industry's concern about this problem. It calls upon the Association to advise the Conference in one year of the progress their members have made towards meeting this commitment.

(Item 202-3 was adopted)

\section{2-4 Produce}

The report of the Committee from the 63rd National Conference also requested weights and measures jurisdictions to supply information about current regulations pertaining to the sale of produce. Several states have provided such data and the Committee plans to recommend acceptance of the following Method of Sale Guideline, in 1980 , to be distributed as one of the Conference's "Guidelines and Interpretations." During the next year, the Committee solicits comments from all parties about the specific details in this proposal. The Committee will consider recommending adoption as a part of the Model State Regulation for the Method of Sale of Commodities after a period of testing in this form.

Guideline: Method of Retail Sale for Fresh Fruits and Vegetables

Commodity

Apples

Apricots

Artichokes

Asparagus

Avocados

Bananas

Beans

\section{Method of Sale}

Weight or Count, or by Dry Measure in Units not less than 1 peck

Weight

Weight or Count

Weight or Bunch

Count

Weight

Weight or Dry Measure, in units not less than 1 peck 


\section{Commodity}

Beets

Berries (all) +

Broccoli

Brussel Sprouts

Cabbage

Cantaloupes

Carrots

Cauliflower

Celery

Cherries +

Coconuts

Corn on the Cob

Cranberries +

Cucumbers

Currants +

Dates

Egg Plant

Escarole

Figs

Garlic

Grapefruits

Grapes

Greens (All)

Kale

Kohlrabi

Leeks

Lemons

Lettuce

Limes

Mangoes

Melons (whole)

Melons (cut or pieces)

Mushrooms +

Nectarines

Okra

Onions (Spring or Green)

Onions, Dry

Oranges

Papaya

Parsley

Parsnips

Peaches

Pears

Peas

Peppers

Persimmons

Plums

\section{Pineapples}

Pomegranates

Potatoes (Irish or Sweet)
Method of Sale

Weight or Bunch

Weight or Measure

Weight or Bunch

Weight

Weight

Weight or Count

Weight or Bunch

Weight or Bunch

Weight or Count

Weight or Measure

Weight or Count

Count

Weight or Measure

Weight or Count

Weight or Measure

Weight

Weight or Count

Weight or Bunch

Weight

Weight or Count

Weight or Count

Weight

Weight

Weight

Weight

Weight

Weight or Count

Weight or Count

Weight or Count

Weight or Count

Count

Weight

Weight or Measure

Weight or Count

Weight

Weight or Bunch

Weight

Weight or Count

Weight or Count

Weight or Bunch

Weight

Weight or Count, or by Dry Measure in

Units not less than 1 peck

Weight or Count, or by Dry Measure in

Units not less than 1 peck

Weight

Weight or Count

Weight or Count

Weight or Dry Measure, in units not less than 1 peck

Weight or Count

Weight or Count

Weight 
Prunes

Pumpkins

Radishes

Rhubarb

Rutabagas

Spinach

Tangerines

Tomatoes

Tomatoes (Cherry) +

Turnips
Weight

Weight or Count

Weight or Bunch

Weight

Weight

Weight or Bunch

Weight or Count

Weight or Dry Measure, in units not less than 1 peck

Weight or Measure

Weight or Bunch

+ Commodities sold by measure must be sold in containers standardized by the Berry Basket and Box Code inNBS Handbook 44.

(Item $202-4$ was adopted)

\section{2-5 Tolerances on Paper and Plastic Products}

The Committee withdraws this item from its Tentative Report. The Federal Trade Commission has pointed out that packaged plastic bags and wraps are subject to the requirements of the Fair Packaging and Labeling Act. The establishment of tolerances for products covered by that Act conflicts with Section 12 which preempts State laws and regulations that are less stringent than or require information different from the FPLA.

The Committee suggests that the industry provide appropriate data for incorporation in the handbook, Checking Prepackaged Commodities.

Additionally, the Committee proposes to reexamine those sections of the Regulation wherein tolerances were established for specific products to determine if there is any conflict with the requirements of the Fair Packaging and Labeling Act.

\section{(Item 202-5 was adopted)}

\section{2-6 Ice Cream and Similar Frozen Products}

The Commonwealth of Virginia raised the question of the method of sale of frozen yogurt. This product is similar to ice cream but the Model regulation in Section 1.7, Other Milk Products, provides for the sale of yogurt by weight only. To remedy this situation, the Southern Association recommends the addition of a new section 1.7.1 that specifies that frozen yogurt be treated as an ice cream and also that brings ice cream and other frozen products under the Model State Method of Sale of Commodities Regulation for the first time. The Committee agrees and recommends the adoption of the following addition to the model, with the note that the term "packaged" refers to commodity 
put up in a package form in advance of sale and not at the time of sale.

\subsubsection{Prepackaged Ice Cream and Similar Frozen Products} Ice cream, ice milk, frozen yogurt, and similar products shall be packaged for sale in terms of fluid measure.

(Item 202-6 was adopted)

\section{2-7 Softwood Lumber}

The Committee received a request from the State of New Jersey to revise the method of sale for softwood lumber (Section 2.9). The New Jersey proposal would effect these changes:

A. Extend the regulation from softwood lumber to cover all types of lumber.

B. Require mandatory grading in accordance with the U.S. Department of Commerce Voluntary Product Standard 20-70.

C. Require grade stamping of each piece of lumber by independent agency grader at the mill.

D. Require that the quantity, grade and species be listed on the delivery ticket.

The Committee heard a thorough presentation by the State of New Jersey and reviewed testimony from several lumber and forest product associations as well.

The Committee appreciates the extensive effort on the part of the State of New Jersey in this area but feels that no action should be taken on such wide-reaching proposals until much careful study is given to this issue by all concerned parties. The Committee would welcome comments from all weights and measures jurisdictions on the need for the proposed changes as outlined above.

(Item 202-7 was adopted)

\section{2-8 Wallcoverings}

The Committee received a request from the Guild of Professional Paperhangers to standardize the size of a roll of wallcovering through a provision in the Model Regulation. An old U.S. Department of Commerce Voluntary Product Standard (VPS) had called for a standard 36 square foot roll. This was withdrawn in 1972 due to an indicated lack of need. Since that time, the paperhangers have experienced confusion and problems since wallcoverings are now sold in roll sizes 
from $271 / 2$ to 36 square feet. They also stated that they have problems due to split or pieced rolls not allowing full usage of a given roll. They therefore also requested that the regulation specify that the coverage labeled be for usable area.

During the interim meeting the Committee heard from the Guild of Professional Paperhangers, who displayed samples of pieced wall coverings and various wrappers with a variety of roll sizes. A representative from the Wallcovering Manufacturers Association presented their position that a clear, affirmative disclosure of roll size by all manufacturers would alleviate the problem. Further, they opposed the adoption of a standard roll size because they believe it would reduce the choice of products available.

The Committee also heard from a representative of the Department of Commerce's Voluntary Product Standards program. He stated that a new wallcovering standard is in the process of being developed and that this work should be completed in the next year. Both the paperhangers and manufacturers will participate in this process.

The Committee is quite sympathetic with the Guild of Professional Paperhangers' request and agrees with the need for a standard size for rolls of wallcovering. However, the Committee prefers to wait for one year for the development of the VPS now in the works. If the problem is not resolved by that process, the Committee will consider adoption of a method of sale in 1980 .

(Item 202-8 was adopted)

\section{2-9 Solid Fuel Products}

The State of Maryland proposed, and the Southern Weights and Measures Association concurred, that a provision be added to the Model regulation to cover the sale of packaged solid fuel products. The Committee agrees and recommends the adoption of the following regulation:

SECTION 2.X.-Solid Fuel Products-Anthracite, Semi-Anthracite, Bituminous, Semi-Bituminous, or Lignite Coal, and any other natural, manufactured or patented fuel not in liquid or gaseous form, except fireplace and stove wood, shall be offered, exposed for sale or sold by net weight when in package form.

(Item 202-9 was adopted)

\section{2-10 Fence Wire}

The Southern Weights and Measures Association proposed that a provision be added to the model regulation to cover the sale of fence 
wire products. The Committee agrees and recommends the adoption of the following regulation:

SECTION 2.X. Fence Wire Products-Rolls of fence wire products shall be sold by:

(a) Identity in terms of gauge

(b) Height in terms of inches or centimeters, if applicable

(c) Length in terms of rods, meters or feet

(Item 202-10 was adopted)

\section{2-11 Railroad Car Tare Weights}

The Western Weights and Measures Association requested, by resolution, that the National Conference on Weights and Measures seek more compliance with the requirement of the Model Regulation, Section 3.4, that all railroad freight cars be stenciled with tare weight by January 1, 1978. Data received from the Association of American Railroads indicate that by that date, approximately $86 \%$ of all freight cars have been appropriately stenciled with tare weight. The Committee urges the Association to continue its efforts at reaching total compliance, and wishes to remind weights and measures officials that they can take legal action against cars that do not meet the requirements of Section 3.4.

(Item 202-11 was adopted)

\section{2-12 Fast Food Sold by Count}

The Western Association also raised the issue of prepared food such as fried chicken being sold by count in groceries and fast food takeout restaurants rather than by weight. The Committee feels that this is covered as adequately as possible by Section 1.5 of the model regulation. For further clarification, it suggests the adoption of a guideline based on a Wisconsin regulation, as follows:

Ready-to-Eat, Carryout Foods and Delicatessen Items

Pre-prepared ready-to-eat, carryout foods and delicatessen items not in liquid form shall be sold by weight; provided, that food items offered for sale and sold in separate and distinct units as a single ready-to-eat meal, or part of a meal for consumption off the premises where sold, are exempted.

EXPLANATION: Except for situations wherein restaurants, "fast food" operations, or similar establishments offer individual meals "to 
go," ready-to-eat carryout foods must be sold by weight just as they would be if they were in their unprepared form. The preparing of food is a merchandising option taken by the food retailer and should not alter the manner in which food is sold to the buyer. There is no reason to permit items packaged in a store to be sold by the piece or by the pint or quart, for example, and to require factory-packaged items of the same type to be sold by weight.

(Item 202-12 was adopted)

\section{2-13 Wiper Blades}

The Committee received a request from a manufacturer of automobile wiper blades that had a problem with one state concerning the measurement of length as labeled on their packages. The state felt that the proper designation should be the length of the blade itself; the manufacturer said that traditionally the industry measured the length of the metal backing or vertebra.

The Committee, after some discussion, determined that since there was no intent to mislead customers, the traditional measurement of the metal backing or vertebra was acceptable. A guideline to this effect will be issued.

(Item 202-13 was adopted)

\section{2-14 Butter and Margarine: 2-oz size}

The Committee received a request from the manufacturer of butterand margarine-packaging equipment to amend Section 1.3 of the model regulation to allow a 2-ounce and 62.5-gram size. They also suggested that it be amended to allow other sizes so long as they are not deceptively packaged.

The Committee noted that simply because the technology exists to package a given commodity in a new size is not reason enough to allow that new size. On the basis of the information received, the Committee is not convinced there is any need for this new size and therefore recommends no change to the model.

(Item 202-14 was adopted)

\section{2-15 Fishing Sinkers}

The Committee received a request from the State of New Jersey concerning the sale of fishing sinkers. They found the weight reference on blister cards to be inaccurate and that the numbers cast into the sinkers to have no consistent meaning from one manufacturer to another. 
The Committee notes that the problem of inaccurate weights on packages is simply an enforcement problem. On the issue of the numbers cast into the sinkers, the American Fishing Tackle Manufacturers Association indicated that they would be willing to explore the idea of a standard if it is needed. The Committee invites weights and measure officials to inform it if they see such a need or are having any related problems.

(Item 202-15 was adopted)

\section{MODEL STATE PACKAGING AND LABELING REGULATION}

\section{3-1 Aerosols}

The Committee received several communications on the subject of the content declarations of aerosol products. Most of the discussion relates to the use of weight or volume as the labeled quantity. INuch of the present confusion is related to a Food and Drug Administration (FDA) requirement that allows either weight or volume, while all Conference requirements specify weight only.

The Committee joined the Liaison Committee to discuss this issue with a representative of FDA. The FDA spokesperson indicated that they would be happy to receive a petition from the Conference requesting a change in their requirements to bring them into conformity with current conference policy. The Committee is encouraged by this indication and supports the efforts of the Liaison Committee as they pursue this effort. This activity was supported by the Chemical Specialties Manufacturers Association which continues to be on record as favoring a weight only approach.

On a separate matter, the State of California requested a change in the Model regulation to bring aerosol commodities labeled "for professional use" under the weight only provision by amending Section 7.3.

The Committee feels that Section 7.3. is a general requirement applying to all non-consumer products and that Section 10 was intended to deal with exceptions to the general requirements set forth in Sections 6.4. and 7.3. The Committee notes that the heading of Section 10 is ambiguous and wishes to remove the ambiguity by amending the heading. It should also be noted that Section 10 already includes a reference to non-consumer packages in Section 10.9.5(d). Amend Section 10 heading as follows:

SECTION 10. Requirements: Specific Consumer Commodities, Non-Consumer Commodities, Packages, Containers. 


\section{3-2 Definition of "Entertainment Value"}

The State of California also requested that Section 11.22(b) be amended by adding a definition for the entertainment value of exposed movie film. The Committee agrees and recommends that Section 11.22(b) be amended as follows:

(b) The net quantity of contents on packages of movie film is expressed in terms of the running time of the exposed film for that portion of film which is of entertainment value.

"Entertainment value" is defined as that portion of a film that commences with the first frame of sound or picture, whichever comes first after the countdown sequence and ends with either: (a) the last frame of credits; or (b) the last frame of the phrase "The End", or (c) the end of sound, whichever is last.

(Item 203-2 was adopted)

\section{3-3 Additional Sizes for Ice Cream}

The Committee met jointly with the Specifications and Tolerances Committee to consider a request to allow the sale of both a 5-quart and a 6-quart container of ice cream. The Committees agreed that any multiple of either a quart or a liter should be permitted. Accordingly, the Specifications and Tolerances Committee is recommending appropriate changes in the Measure Container Code of Handbook 44.

The Committee amends its Tentative Report by deleting the recommendation to change labeling requirements on ice cream packages through amending Section 11.9. It has been determined that the proposed labeling changes cannot be effective unless the Food and Drug Administration first recognizes the proposed exemptions under the Fair Packaging and Labeling Act because of the preemption provisions of the Act.

(Item 203-3 was adopted)

\section{3-4 Multi-Unit, Variety, and Combination Packages}

At the request of the Committee and with the concurrence of Conference, the Committee on Liaison undertook to review and compare the Model Packaging and Labeling Regulation and the regulations of the Food and Drug Administration, Federal Trade Commission, and U.S. Department of Agriculture pertaining to quantity declarations on multi-unit, variety, and combination packages. The purpose was to be the promotion of a uniform federal-state regulatory scheme. 
The need as expressed by the Laws and Regulations Committee was to "distill order from the suggested regulatory chaos and to react responsibly to a plague of frustrating and frustrated letters and petitions suffered" by that committee.

The Liaison Committee completed this review and developed proposed changes to Sections $2.8,10.4,10.5,10.6,11.12$ and 11.18 of the Model regulation. They also noted that there was no real indication of need to enact these changes at this time. The Laws and Regulations Committee appreciates this thorough study by the Liaison Committee and agrees with their recommendation of no action at this time. The recommendations are available from the Committee upon request, and they will be kept on file for future use as necessary.

\section{(Item 203-4 was adoptèd)}

\section{3-5 Correction to Section 6.8.1(a)}

The Committee notes that in the 1978 revision of the model regulation, subsection 6.8.1(a) was amended to include metric but that by oversight the centimeter as a prescribed unit was omitted. Accordingly, the Committee recommends amending Section 6.8.1(a) as follows:

6.8.1 (a) in the case of length measure of less than 1 meter, centimeters or millimeters;

(Item 203-5 was adopted)

204

OTHER ITEMS

\section{4-1 Resolution on Spelling of Metric Units}

The Committee met jointly with the Liaison Committee to consider adoption of a resolution that would indicate the support of the Conference of the "modification and interpretation" of the International System of Units by the Department of Commerce. The text of such a proposed resolution and a supporting statement appears in the report of the Liaison Committee.

(Item 204-1 was adopted)

\section{4-2 Model Grain Measurement Regulation}

The Southern Weights and Measures Association offered the National Conference a proposal for a Model State Regulation for Grain Moisture Measurement Program. At the interim meeting, the Task 
Force on Grain Moisture Measurement Assurance met and modified that proposal. The Laws and Regulations Committee includes that amended proposal as a part of its report and requests comments on the following draft for future action:

\section{MODEL STATE REGULATION FOR GRAIN MOISTURE MEASUREMENT PROGRAM}

1978

SECTION 1. POLICY.-It shall be the responsibility of the Director of Weights and Measures, hereinafter referred to as "Director," to administer the regulations for commercial grain moisture determination within this jurisdiction.

\section{SECTION 2. DEFINITIONS.}

2.1. Grain Sample.-The term "Grain Sample" shall be construed to mean that portion of grain, seed, or other agricultural commodity taken for the purpose of moisture content determination from the bulk of grain, seed, or other agricultural commodity to be bought or sold.

2.2. Grain-Test Scale.-The term "Grain-Test Scale" shall be construed to mean such devices as are necessary to be used to determine accurate weight for any grain sample for the purpose of determining moisture content.

2.3. Moisture Content.-The term "Moisture Content" shall be construed to mean the percentage content of moisture on a wet basis in a grain sample or official grain sample.

2.4. Moisture Meter Chart(s).-_The term "Moisture Meter Chart(s)" shall be construed to mean charts and tables used to interpret, interpolate or extrapolate value indications on a particular moisture-determining device into moisture content values.

2.5 Moisture Testing Device.-The term "Moisture Testing Device" shall be construed to mean all equipment and accessories required for determining the moisture content in a grain sample.

2.6 Official Grain Sample.-The term "Official Grain Sample" shall be construed to mean that portion of grain, seed, or other agricultural commodity which the jurisdiction shall use as the 
official transfer standard to test the accuracy of commercial grain moisture meters. The moisture content of the official grain sample shall be determined by reference to the USDA official laboratory method.

2.7 Placement in Service.-The term "Placement in Service" shall be construed to mean placing in use any new, used, or previously rejected device which is being returned to service after repair.

\section{SECTION 3. REGISTRATION OF COMMERCIAL MOIS-} TURE TESTING DEVICES.-The Director shall be notified of placement in service in the State of within

24 hours of such placement. Written notice for registration shall be completed as soon as practical by the owner/operator, giving full information as to make, model, serial number and other identifying information. Each device shall require a separate registration.

SECTION 4. THERMOMETERS.-A laboratory thermometer, or electronic temperature measuring device, accurate to within $2{ }^{\circ} \mathrm{F}$ (and possessing at least 1-degree graduations) for the full range of the thermometer scale, shall be used for making temperature determinations if necessary for making compensations or adjustments to grain moisture meter indications.

\section{SECTION 5.TENTATIVE DEVICE-TOLERANCE LIMITS.-}

A tentative tolerance of four hundredths, plus or minus, $( \pm 0.04)$ of the moisture content. Examples: at $10 \%$ tolerance is $\pm 0.4 \%$; at $15 \%, \pm 0.6 \%$; at $25 \%, \pm 1.0 \%$.

SECTION 6. WEIGHING AND WEIGHTS.-The scale or balance used to weigh the sample, if this determination is necessary for obtaining a moisture content, must meet current National Bureau of Standards HANDBOOK 44 requirements. The weights used with a grain-test scale must meet the requirements of $\mathrm{H}-$ 44.

\section{SECTION 7. TABLES, CHARTS AND OPERATING IN-}

STRUCTIONS.-The operator of the moisture meter equipment shall be responsible for having and using current editions of tables, charts and operating instructions pertaining to the grain moisture determination equipment in use.

SECTION 8. SAMPLING.-Sampling procedures recognized by USDA shall be used to obtain grain samples for moisture content determination from the bulk of grain to be bought or sold. 
SECTION 9. BULK DENSITY APPARATUS.-Those moisture measuring devices that require bulk density correction, shall be equipped with either (a) an automatic bulk density (test weight) compensator or (b) a bulk density (test weight) apparatus and charts having the applicable correction factors. This apparatus shall consist of a scale, with which to measure weight, and a dry measure container, with which to measure volume. The basic maintenance tolerances for the scale and the dry measure container are those stated in NBS Handbook 44.

\section{SECTION 10. LICENSED OPERATORS AND DEPUTY OP.}

ERATORS.-The manager and one full time operator shall be licensed by the Director and shall register on forms provided by the Weights and Measures Division. Deputy operators may be employed on a seasonal basis; however, the responsibility for operation shall remain with the licensed operators. Lists of operators shall be available to State officials.

SECTION 11. VIOLATIONS.-The employment of unlicensed operators, the operation of rejected grain weighing equipment or a rejected moisture testing device, the use of inaccurate thermometers or outdated charts, and the employment of improper operational procedures shall be prohibited. Punishment for these violations shall be of the same range of severity as for violations of othei sections of the Model State Weights and Measures regulations.

\section{SE 'TION 12. RESPONSIBILITY FOR ENFORCEMENT.-} The Director of the Weights and Measures Division may designate other employees of the Division to perform necessary duties ur to represent him in the carrying out of the enforcement of these regulations.

(Item 204-2 was adopted)

\section{4-3 Model State Laws and Regulations Handbook}

The Committee noted with interest the plans of the National Bureau of Standards to issue annually a handbook of all model laws and regulations adopted by the National Conference on Weights and Measures and as amended that year. Each model would be preceded by a map showing the extent of adoption by State. The Committee endorses this proposal and looks forward to receiving the first edition in 1979. 
The Committee is of the view that there is little, if any, need for the existing Standard Barrel Acts and implementing regulations. The Committee recommends that this matter be referred to the Policy and Coordination Committee for study and possible final action next year.

(Item 204-4 was adopted)

\section{4-5 Temperature Compensation}

The Committee wishes to acknowledge receipt of recommendations from the Committee on Specifications and Tolerances on the matter of temperature compensation. The Committee proposes to place this particular recommendation on its agenda and to explore the need for method-of-sale requirements for home heating oils.

(Item 204-5 was adopted)

\section{4-6 Adoption By Citation}

It has been recommended to the Committee that it consider providing some method that would permit adoption of the National Conference on Weights and Measures model regulations by citation. Adoption by citation has been a feature of the process by which Handbook 44 has achieved wide acceptance. The Committee would lih 3 to explore the possibility of providing the same mechanism for adoption of the other models developed by the Conference.

Accordingly, the Committee is proposing consideration of the following:

Amend the Model Law to include the following language:

The methods of test, inspection procedures, moisture determinations, measurement system changes, units, terms and other requirements for the packaging, labeling, method of sale, unit pricing, and open dating of commodities, as adopted by the National Conference on Weights and Measures and published in the National Bureau of Standards Handbook 130, and supplements thereto or revisions thereof, shall apply to all commodities kept, offered, or exposed for sale in this State except insofar as specifically modified, amended, or rejected by a regulation issued by (insert appropriate authority).

You will note that the proposed amendment is very similar to the language of Section 4 in the Model Law. The Committee will place this matter on its agenda for the next interim meeting. We would appreciate receiving your comments on the approach and the suggested language.

(Item 204-6 was adopted) 
R. W. Probst, Chairman, Wisconsin

J.J. BARTFAI, New York

S.F. HINDSMAN, Arkansas

D.I. OfFNER, St. Louis, Missouri

J.T. BENNETT, Connecticut

E.A. VADELUnd, Staff Assistant, NBS

H.F.Wollin, Exec. Secy., NBS

\section{Committee on Laws and Regulations}

(On motion by the committee chairman, the report of the Committee on Laws and Regulations voting key items 200 through 204-6 was adopted in its entirety as amended by the Conference. The results of the voting in the House of State Representatives and the House of Delegates under the Conference voting system are totalized in the table that follows. The Conference also authorized the Executive Secretary to make any appropriate editorial changes in the language adopted by the Conference, provided that the requirements thus adopted are strictly adhered to.) 
Voting RESULTS-Committee on Laws and Regulations

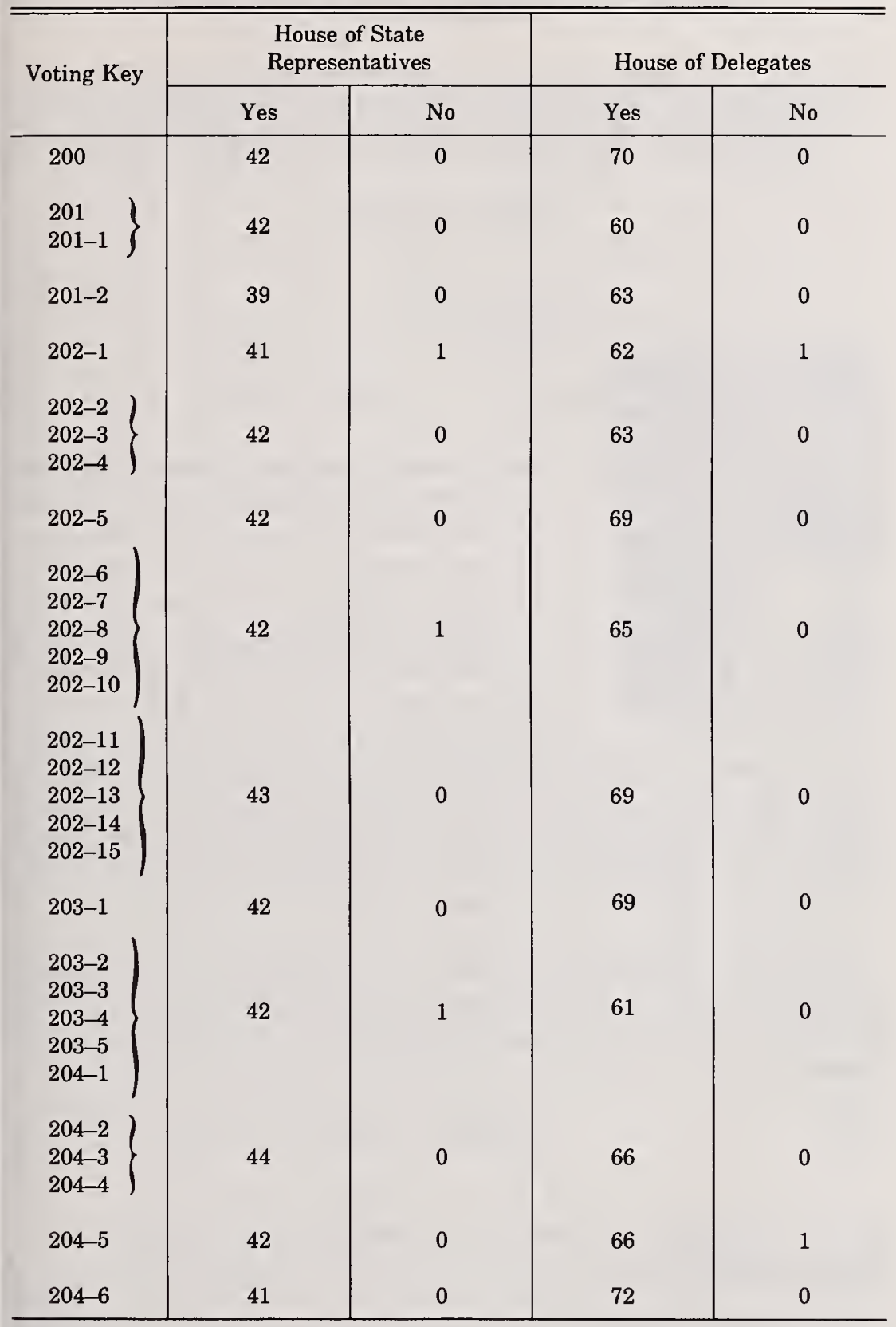




\section{REPORT OF THE COMMITTEE ON SPECIFICATIONS AND TOLERANCES}

Presented by James R. Bird, Deputy State Superintendent, Office of Weights and Measures, Division of Consumer Affairs, Department of Law and Public Safety, State of New Jersey

(Thursday, July 26, 1979)

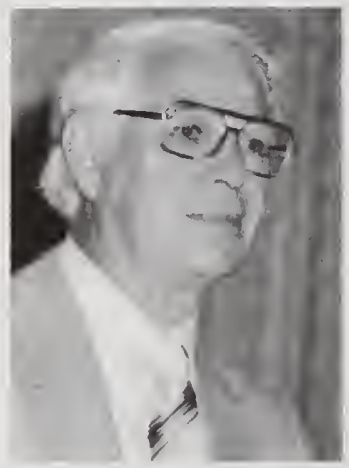

\section{VOTING KEY}

300

INTRODUCTION

The Committee on Specifications and Tolerances submits its report to the 64th $\mathrm{Na}$ tional Conference on Weights and Measures. The report consists of the tentative report as offered in the Conference Announcement and as amended by this final report. The report represents recommendations of the committee that have been formed on the basis of written and oral comments received during the year and oral presentations made during the open meeting of the committee. All recommended amendments are to appropriate provisions of the codes of the National Bureau of Standards Handbook 44, Fourth Edition, "Specifications, Tolerances and Other Technical Requirements for Commercial Weighing and Measuring Devices."

NOTE: Except where paragraphs are to be added or completely revised as indicated, changes are shown as follows: that which is to be deleted is shown lined out, and that which is to be added is underlined.

301

GENERAL CODE

\section{1-1 G-S.5.2. Graduations, Indications, and Recorded Representations}

The committee received several comments recommending changes to two paragraphs of this section. In all instances the committee decided that a code change was not necessary and that interpretations of the existing requirements would resolve the issues mentioned. 
During last year's interim meeting the committee had discussed a suggestion that this paragraph be amended to require mathematical agreement consistent with the criteria expressed in Handbook 44Fundamentals paragraph 10.2(d). This paragraph establishes the methodology used in rounding off when the next figure beyond the last figure to be retained is 5 and there are only zeros beyond this 5 . This principle is commonly referred to as "the odd-even method" and is used to eliminate any rounding bias. During the year the committee had continued to explore this possibility and had received comments from many interested parties. It is the view of the Committee that this method is entirely feasible on those devices utilizing micro-processor technology; the committee will continue to carry this item in anticipation of recommending that this principle be adopted on a nonretroactive basis in 1982 .

\section{(Item 301-2 was adopted)}

\section{1-3 G-S.6. Marking, Operational Controls, Indications, and Features}

A suggestion was received that standard abbreviations or symbols be established for specific functions on weighing and measuring equipment. The committee agrees that this may seem desirable, but cannot agree that it is necessary to attain the ultimate end (e.g., are the symbols used in each application clear, definite and easily understood under any conditions of normal operation?). This item was also included in the tentative report of last year (see 63rd NCWM Announcement, pages 15 and 16). The Scale Manufacturers Association has established a subcommittee to deal with this issue. The committee recommends no code amendment at this time and that all interested parties from all segments of the industry consider the possibility of uniform symbols and maintain communications with the committee as to any progress made.

(Item 301-3 was adopted)

\section{1-4 Marking/Non Commercial and Other Special Purpose Devices}

The committee once again received a suggestion that equipment manufactured not in compliance with Handbook 44 codes be permanently and conspicuously marked with the term "Not Legal for Trade." Another condition referenced was the marking sometimes found on scales which do not meet the requirements of Handbook 44, "Legal 
for Fruits and Vegetables." All of the ramifications were discussed throughout the interim meetings by all interested parties. It is the view of the committee that any reference such as "Legal for Fruits and Vegetables" is clearly inappropriate under the existing code and that action should be taken by the States to eliminate this condition.

The committee does feel that there are situations in which it is clearly appropriate to mark devices which are designed for specific applications. This philosophy is expressed in Scale Code paragraph S.6.2. Marking/For Prepackaging Scales Only. A particular design the committee has in mind are those devices designed to classify applied loads into predetermined rate or weight increments.

(Item 301-4 was adopted)

302 CODE FOR SCALES

\section{2-1 S1.1. Zero Indication}

A comment was received that an indication of a negative balance condition on an electronic digital indicator by means of inhibiting the display of any values was not clear, and this paragraph should be amended to read "positively indicate an out of balance condition on both sides of zero." It is the committee's view that in certain applications it is appropriate to inhibit the display to indicate a negative balance condition and on others it is not. The key in making the decision is based on General Code paragraph G-S.5.1 which requires primary indications to "be clear, definite, accurate and easily read under any conditions of normal operation."

(Item $302-1$ was adopted)

\section{2-2 S.2.1.3. Zero-Load Adjustment/For Scales Designed with Automatic Means to Maintain a Digital Zero Balance Indication.}

The committee discussed at length the comments received and the technology used for "automatic zero maintenance" (AZM). One method indicates either no displayed weight values or only a momentary display and then an almost immediate zero indication. Another method is that which displays the total value of out of balance and then returns to zero in increments equal to one-half or whole scale divisions. It is the view of the committe that any technical constraint should apply equally to both technologies, that this present requirement should be amended to more appropriately reflect weighing applications and that the varying methods of zero-setting should be defined and used in the specification paragraphs. To accomplish 
this the committee recommends that the following definitions and non-retroactive paragraphs be considered over the ensuing year for action by the 65th NCWM.

Zero setting mechanism-means provided to attain a zero balance indication with no load on the load receiving element.

Manual zero setting mechanism-means provided to attain a zero balance indication requiring the intervention of an operator.

Semi-automatic zero setting mechanism-means provided to attain a zero balance indication by the manual operation of an electronic control.

Automatic zero setting mechanism-means provided to maintain a zero balance indication without the intervention of an operator.

Amend S.2.1.2. to read:

S.2.1.2. On Scales Used in Direct Sales.-A manual zero setting mechanism shall be operable or accessible only by a tool outside of and entirely separate from this mechanism or enclosed in a cabinet. A balance ball shall either meet this requirement or shall not itself be rotatable.

A semi-automatic zero setting mechanism shall be operable or accessible only by a tool outside of and entirely separate from this mechanism or enclosed in a cabinet, or shall be operable only when the indication is stable within:

(a) plus or minus one scale division $\left(d_{d}\right)$ for all scales other than axle load, railway track, and vehicle scales.

(b) plus or minus three scale divisions $\left(d_{d}\right)$ for axle load, railway track, and vehicle scales.

Amend S.2.1.3. to read:

S.2.1.3. On Scales Equipped with an Automatic Zero Setting Mechanism.-Scales equipped with an automatic zero setting mechanism shall have a clear indication when this mechanism is in operation.

Under normal operating conditions, the maximum load, when placed immediately on or removed from the platform, which can be "rezeroed", shall be: 
(a) For bench, counter and livestock scales- 0.6 scale division

(b) For axle load, railway track, and vehicle scales-3.0 scale divisions

(c) For all other scales-1.0 scale division.

(Item 302-2 was adopted)

\section{2-3 T. Tolerances}

The committee received many comments concerning tolerances. Among them are:

(a) Add more illustrative tables.

(b) Clarification is needed to determine the tolerance application to devices equipped with more than one indicating element, and especially one equipped with both an analog and a digital indicator.

(c) The entire tolerance section should be amended to provide a clearer understanding and to eliminate the problems caused by minimum tolerance value determinations, digital tolerances, and tolerances applied to decreasing load tests.

(d) Digital scales should not be allowed larger errors than analog scales.

The committee appreciates the time and effort spent by those submitting these suggestions and agrees with them for the most part. The Scale Manufacturers Association has established a task force to attempt to develop clearer tolerance requirements. OIML PS 7/ RS 4 is in the process of developing amendments to IR \#3, which will include a revision of the tables in that document.

The committee solicits comments from everyone and will carefully review all information available. The committee intends to offer its recommendations to the 1980 NCWM.

However, the committee feels that a certain code amendment is needed at the present time and recommends the following for clarification purposes.

Amend paragraph T.1.2. to read:

T.1.2. To Scales with Multiple Elements.-Tolerances shall be ap- 
plied independently to each separate indicating and recording element of a scale. However, the following requirements pertaining to analog and digital elements within the same element shall also apply.

With respect to the application of this paragraph, the committee wishes to remind the Conference that, in an instance where a scale is equipped with two indicators, one analog and one digital, and the operator, to gain an advantage, could be using one indicator for buying or determining gross loads and the other for selling or determining tare loads, enforcement action should be taken to preclude this practice.

The S \& T Committee will work cooperatively with the recently formed SMA Tolerance Subcommittee to develop specific recommendations for revising scale tolerances and anticipates proposals for action by the 65th NCWM.

(Item 302-3 was adopted)

\section{2-4 T.3.6.3. Basic Tolerance Values/For Railway Track Scales/Weighing Coupled in Motion-}

To clarify misunderstandings that have developed in the interpretation of this paragraph, the committee recommends it be amended to read:

T.3.6.3. Weighing Coupled in Motion.-The basic maintenance and acceptance tolerances shall be as follows:

(a) The difference between the motion gross weight value and the static gross weight value of the test train shall not exceed two pounds per 1,000 pounds ( 0.2 percent).

(b) The difference between the motion gross weight values and the static gross weight values on 100 individual car weights shall meet the following conditions.

(1) At least 70 percent of the individual car weight differences shall be within plus or minus 0.2 percent.

(2) Not more than 5 percent of the individual car weight differences shall exceed plus or minus 0.5 percent.

(3) No individual car weight difference shall exceed plus or minus 1.0 percent.

This means that at least 70 of the car weights must be within plus or minus 0.2 percent, that 25 car weight differences can be more than plus or minus 0.2 percent up to and including plus or minus 
0.5 percent, and that 5 car weight differences can be more than plus or minus 0.5 percent up to and including plus or minus 1.0 percent.

(Item 302-4 was adopted)

\section{2-5 UR.1.1.6. User Requirements/Selection Requirements/ For Vehicle Scales and Axle-Load Scales Used in Combination}

To clarify the issues raised during last year's conference and in response to the suggestions received since that meeting the committee recommends the following:

Amend paragraph UR.1.1.6. to read:

UR.1.1.6. For Vehicle Scales and Axle-Load Scales Used in Combination-The value of the smallest division on a scale or scales used to determine the weight of a vehicle shall be greater than 20 pounds as follows:

(a) For Scales with a capacity up to and including $200000 \mathrm{lb}$, not greater than $20 \mathrm{lb}$.

(b) For Scales with a capacity greater than $200000 \mathrm{lb}$, not greater than $50 \mathrm{lb}$.

Change the definition of Vehicle scale to read:

Vehicle Scale.- One A scale adapted to weighing highway, farm or other large industrial vehicles, (except railroad freight cars), loaded or unloaded.

Amend paragraph UR.4.4. by striking the word highway in the first and second lines. (See also item 302-7.)

(Item 302-5 was adopted)

\section{2-6 UR.3.2. Minimum Load on Vehicle Scales}

The committee received two communications recommending amendment to this paragraph. The committee had listened carefully to the comments made on this item during the presentation of its final report at last year's Conference. The committee believes that the Conference is not prepared to "bite the bullet" on this issue and refuses to compromise what it considers to be the only logical and technically correct interpretation. That is, a vehicle scale should not be used to weigh net loads less than 1000 pounds or 50 scale divisions, in spite of the 
problems which this may cause the Boy Scouts when selling newspapers. Therefore the committee does not recommend code amendment.

(Item 302-6 was defeated)

\section{2-7 UR4.4. Single-Draft Vehicle Weighing}

The committee received a communication that the present wording of this paragraph would not preclude the two-draft weighing of farm tractors and trailers. The committee agrees that this could cause a problem and feels that the amendment to this paragraph recommended in item 302-5 will clarify this issue.

(Item 302-7 was adopted)

\section{2-8 Code Revision for Electronic Devices}

The committee received a recommendation that a new section be established in Handbook 44 applicable only to electronic digital scales, and that requirements applicable to this equipment on temperature effects, stability, return to zero etc., be developed. The committee is not in favor of establishing a separate section applicable only to electronic digital scales, but is studying the possibility of developing requirements addressing the other factors referenced. This will be included in the overall tolerance study along with the review of OIML documents and the committee solicits comments from all interested parties.

(Item $302-8$ was adopted)

\section{2-9 "Warm up" Time}

The committee received a recommendation concerning this problem and also reviewed the results of last year's report in which action was delayed on this issue. It is the view of the committee that any value displayed on any device at any time which appears to be valid, should in fact, be valid. Although the problem seems to center around scales, it is the view of the committee that there is a possibility of a similar situation with other measuring equipment. For the present, the committee recommends amendment to the Scale Code as indicated below, but is considering recommending that this become a General Code paragraph in the near future.

Add the following non-retroactive paragraph:

S.1.4.2. Values Displayed, Temperature Conditions.-A digital indicating or recording element shall not display or record any usable values until the operating temperature (warm-up time) 
necessary for accurate weighing and a stable zero balance condition has been attained. (Non-retroactive and effective January 1, 1981.)

(Item 302-9 was adopted)

\section{2-10 On-board Weighing Systems for use in the Household Moving Industry}

The committee received a request to develop requirements applicable to systems which may be considered appropriate for weighing household goods for tariff purposes. These systems, although their performance capabilities are not as good as those presently required in Handbook 44, do have other characteristics that may offset this seemingly detrimental effect. There are a number of agencies interested in such a project since there is some indication that fraudulent practices do exist in weight determinations of household goods. At the present time the committee does not have sufficient information to present to the Conference on the availability of, or the design and performance capabilities of, such equipment. The committee will continue this item for study, with the probability of having more complete information to present in its tentative report of next year.

(Item 302-10 was adopted)

\section{2-11 Counting Scales}

The committee discussed the necessity of including specific requirements in Handbook 44 for counting scales. With the approval of the Conference the committee will develop specific code requirements for action by the 65 th NCWM.

(Item 302-11 was adopted)

\section{2-12 Grain Test Scales}

As indicated in last year's tentative report (63rd NCWM announcement, pages 17-18) the committee has developed what it considers to be appropriate requirements for these devices. The background information and philosophy considered is presented in last year's announcement.

The committee recommends amendment to the code as follows:

Change all present code references to, and the definition of "moisture test scale" and "cream test scale" to, "dairy product test scales," and combine these definitions to read as follows:

Dairy product test scale-A scale designed to determine the 
moisture content of butter and/or cheese or to determine the butterfat content of milk, cream, and butter.

Delete the code reference to and the definition of "grain-moisture scale" and add the following definition:

Grain test scale-A scale adapted to weighing grain samples used in determining moisture content, dockage, weight per unit volume, etc.

Amend SR.2. General to read:

SR.2 General.-Except for equipment specified in paragraphs SR.3 through SR.8. the SR on a nonautomatic-indicating scale shall be twice the value of the minimum graduated interval on the weighbeam, 0.2 percent of the nominal capacity of the scale, or 40 pounds, whichever is least.

Amend SR.5. and SR.6. to read:

SR.5. For Dairy Product Test Scales

SR.5.1. For scales used in determining butterfat content the SR shall be 0.5 grain (32 milligrams)

SR.5.2. For scales used in determining moisture content the SR shall be 0.3 grain ( 19 milligrams)

SR.6. For Grain Test Scales.-The SR shall be the value of the minimum graduated interval or 0.05 percent of the capacity of the scale, whichever is less.

Amend T.2.1. General to read:

T.2.1. General.-Except for equipment specified in paragraphs T.2.1.1. through T.2.9., the maintenance tolerance and the acceptance tolerance applied to a scale shall be not smaller than the appropriate value shown in Table 3 or one-half the value of the minimum graduated interval, whichever is less.

Change the title of T.2.4. to read:

T.2.4. For Dairy Product Test Scales.

Delete T.2.5. For Grain Moisture Test Scales

Renumber paragraphs T.2.6., T.2.7., T.2.8., T.2.9., and T.2.10. to T.2.5., T.2.6., T.2.7., T.2.8., and T.2.9 respectively. 
Change the title of Table 3 to read:

Table 3-Minimum Tolerance Values for Scales Except for Equipment Specified in Paragraph T.2.1.1. through T.2.9.

Change the title of T.3.4. to read:

T.3.4. For Dairy Product Test Scales.

Change the title of Table 5 to read:

Table 5-Basic Tolerances for Scales Indicating or Recording in Either Apothecaries or Metric Units Except for Equipment Specified in Paragraphs T.3.2. through T.3.10.

Add a new paragraph and a new Table 6 as follows:

T.3.5. For Grain-Test Scales.-The basic maintenance and acceptance tolerances shall be as shown in Table 6 .

TABLE 6-Basic Tolerance Values for Grain Test Scales.

(Applicable to increasing and decreasing load tests.)

\begin{tabular}{|c|c|c|c|}
\hline \multicolumn{2}{|c|}{ Test Load } & $\begin{array}{c}\text { Maintenance } \\
\text { Tolerances }\end{array}$ & $\begin{array}{c}\text { Acceptance } \\
\text { Tolerances }\end{array}$ \\
\hline from & $\begin{array}{c}\text { to and } \\
\text { including }\end{array}$ & $\begin{array}{c}\text { in scale } \\
\operatorname{div}(\mathrm{d})\end{array}$ & $\begin{array}{c}\text { in scale } \\
\operatorname{div}(\mathrm{d})\end{array}$ \\
\hline $\min$ & $500 \mathrm{~d}$ & 1 & 0.5 \\
$500 \mathrm{~d}$ & $2000 \mathrm{~d}$ & 2 & 1.0 \\
$2000 \mathrm{~d}$ & $1000 \mathrm{~d}$ & 3 & 1.5 \\
\hline
\end{tabular}

Renumber paragraphs T.3.5. through T.3.8. to T.3.6. through T.3.9.

Add the following new User Requirement:

UR.1.2. For Grain Test Scales Only.-The design of a scale selected for use as a grain test scale shall be:

\begin{tabular}{|c|c|c|c|}
\hline \multirow{2}{*}{$\begin{array}{c}\text { Scale Division } \\
\text { (d) }\end{array}$} & \multicolumn{2}{|c|}{$\begin{array}{c}\text { Number of Divisions } \\
(\mathrm{n}=\text { Max/d) }\end{array}$} & $\begin{array}{c}\text { Minimum Capacity } \\
\text { (Min) }\end{array}$ \\
\cline { 2 - 3 } & Minimum & Maximum & \\
\hline $0.1 \mathrm{~g} \overline{<} \mathrm{d} \overline{\mathrm{<} 0.5 \mathrm{~g}}$ & 500 & 10,000 & $20 \mathrm{~d}$ \\
\hline
\end{tabular}

Change the title of N.1.3.2. to read: 
N.1.3.2. On Dairy Product Test Scales.

Change S.2.5. to read:

S.2.5. For Dairy Product Test, Grain Test, Jewelers and Prescription Scales Only.

S.2.5.1. Balance Indicator. A dairy product test, grain test, jewelers, and prescription scale shall be equipped....

(Item 302-12 was adopted)

\section{2-13 Postal Scales}

After two years of study and deliberation during which the committee attempted to consider all of the ramifications of the design and use of Postal Scales (see Conference Reports 1977 and 1978) the committee recommends the following:

All of the existing applicable requirements of Handbook 44 apply except as follows:

Add a new tolerance paragraph to read:

T.3.10. For Postal and Parcel Post Scales. The basic maintenance and acceptance tolerances shall be as specified in Table 4 except:

T.3.10.1. For Postal and Parcel Post Scales Designed and/or Used to Weigh Loads Less Than 2 Pounds. The basic and minimum, acceptance and maintenance tolerances shall be:

\begin{tabular}{|c|c|c|c|c|c|}
\hline \multicolumn{2}{|c|}{ Test load } & & & \\
\hline from & $\begin{array}{c}\text { to and } \\
\text { including }\end{array}$ & grains & grams & ounces & pounds \\
\hline 0 & $\begin{array}{c}2 \mathrm{lb} \\
\text { Max. }\end{array}$ & 15 & 1 & $\begin{array}{c}1 / 32 \\
\text { (see table 4) }\end{array}$ & 0.002 \\
\hline
\end{tabular}

(Itern 302-13 was adopted)

\section{2-14 Federal Grain Inspection Service (FGIS)}

Since the last Conference, the committee prepared a response to the recommended tolerances and test procedures published by FGIS. Copies of this response were circulated to all State offices and certain 
other interested parties. Representatives of the Service were in attendance at the interim meeting and reported that their final recommendations would be published in the Federal Register in the near future with a 60-day comment period. The committee and all others in attendance urged the service to recommend those tolerances and procedures now included in Handbook 44 and other weights and measures publications.

The final recommendations, which were published in the Federal Register of March 2, did not reflect the recommendations made at the interim meeting. The committee responded, taking exception with these proposals once again, and the principles and philosophy which formed the basis of the recommendations of the Service.

Copies of the committee's response are available on request, and the committee urges the Service to reconsider and publish final rules consistent with the requirements of NBS Handbook 44.

(Item 302-14 was adopted)

\section{2-15 S.1.8. Provision for Sealing Adjustable Components on Electronic Devices}

Since the adoption of this requirement last year, a number of problems concerning its application were brought to the attention of and discussed by the committee.

One of the first problems is that the paragraph requiring adjustable components not to be adjustable from outside the scale is in the section entitled "Weighing Elements." Since Handbook 44 considers a scale to be composed of an indicating element, a recording element, a weighing element and a load receiving element, how is this requirement applicable to the adjustable components located within the indicating element? This paragraph references components such as a nose-irons, pendulums, springs, or potentiometers, which for the most part are generally located within or on an indicating element.

Other questions are since the title of S.1.8. states specifically "Electronic Devices" is the paragraph applicable to electromechanical scales? Is it applicable to electronic cash registers? What about span adjustment by means of a key board?

The committee did recall that this amendment was adopted last year with only a one-vote majority and therefore is not certain that the views of the Conference are still the same; the committee itself has mixed opinions on this issue.

It was the committee's intention, in recommending this amendment last year, (1) to make it clearly evident whenever a serviceman adjusted a scale and (2) to prevent any fraudulent adjustment on the part of the scale user. It is the committee's view that these are valid concerns and recommends the definition of security seal in the General Code to read: 
security seal. A lead-and-wire seal, a sufficiently permanent pressure sensitive seal or similar eviee means, attached to a weighing or measuring device for protection against or to indicate access to removal of or adjustment of the device.

(Item 302-15 was adopted)

\section{2-16 Uniformity of Interpretations and Prototype Examinations}

Since NBS Handbook 44 is basically a field manual and a cooperative prototype examination program may develop, it is the view of the committee that a prototype manual and a methodology for arbitrating conflicting interpretations are necessary.

The committee intends to begin work on the development of such a manual and solicits the aid of all interested parties. As this work progresses, it will be widely circulated for comment.

The committee also feels that the proper resource for interpretations and arbitration is the committee itself and recommends that the committee be contacted whenever necessary.

\section{(Item 302-16 was adopted)}

303

\section{CODE FOR LIQUID MEASURING DEVICES}

Impact of Rapidly Escalating Petroleum Product Prices.-The committee reviewed the events which took place several years ago when the retail price of gasoline exceeded $\$ 0.499$ per gallon. The interim measure recommended was to set the variator at the price per $1 / 2$ gallon, require the price per gallon to be separately posted, and to multiply the displayed total price by 2 and so indicate on the face of the dispenser. At that time the $\$ 0.499$ unit price capability existed on only 200,000 of the $1,500,000$ dispensers in the U.S. The problems confronting the petroleum industry at the present time are of a far greater magnitude.

It is the committee's view that the most cost-effective solution to those technological problems and many others is a change to metric. The committee strongly urges that immediate steps be taken toward that conversion.

To facilitate this change, the committee recommends the code be amended by adding the following new paragraph:

S.1.1.2.1. Units/On Retail Motor Fuel Devices.-A retail motor fuel device shall indicate, and record if the device is equipped to record, its deliveries in terms of liters or gallons and decimal subdivisions or fractional equivalents thereof.

The committee has recommended this change with the view that it is not wholly necessary because of paragraph G-A.4. Metric Equip- 
ment. It is the opinion of the committee that this paragraph is intended to eliminate any technical constraint to any change to metric and is not superseded by paragraph G-A.2. Code Application. This decision was made on the basis that if paragraph G-A.2. was intended to supersede G-A.4., paragraph G-A.4. would be meaningless. Therefore, paragraph G-A.4. should be applied whenever necessary.

The committee has referred to the $\mathrm{P} \& \mathrm{C}$ Committee the responsibility of resolving all of the logistics with respect to short-term solutions and time frames in the conversion of petroleum dispensers not capable of computing on the basis of the correct unit price. (See Report of the Committee on National Measurement Policy and Coordination.)

In the event that it becomes necessary to test retail dispensers with a 5-gallon test measure, the committee recommends a test draft of 19 liters, which is 5 gallons plus 4.5 cubic inches, and apply the existing tolerances of \pm 3.5 cubic inches and \pm 7 cubic inches. Thus, the acceptance tolerance band would be +1 cubic inch to +8 cubic inches and the maintenance tolerance band would be -2.5 cubic inches to +11.5 cubic inches, as per Figure 1 .

During the ensuing year the committee will review the present Table 1, Tolerances for Retail Devices, and recommend tolerances for a 19-liter draft for action by the 65th NCWM.

\section{9-LITER TEST \\ USING 5-GALLON FIELD MEASURE}

\section{5-GALLON STANDARD \\ CUSTOMARY GAGE PLATE}

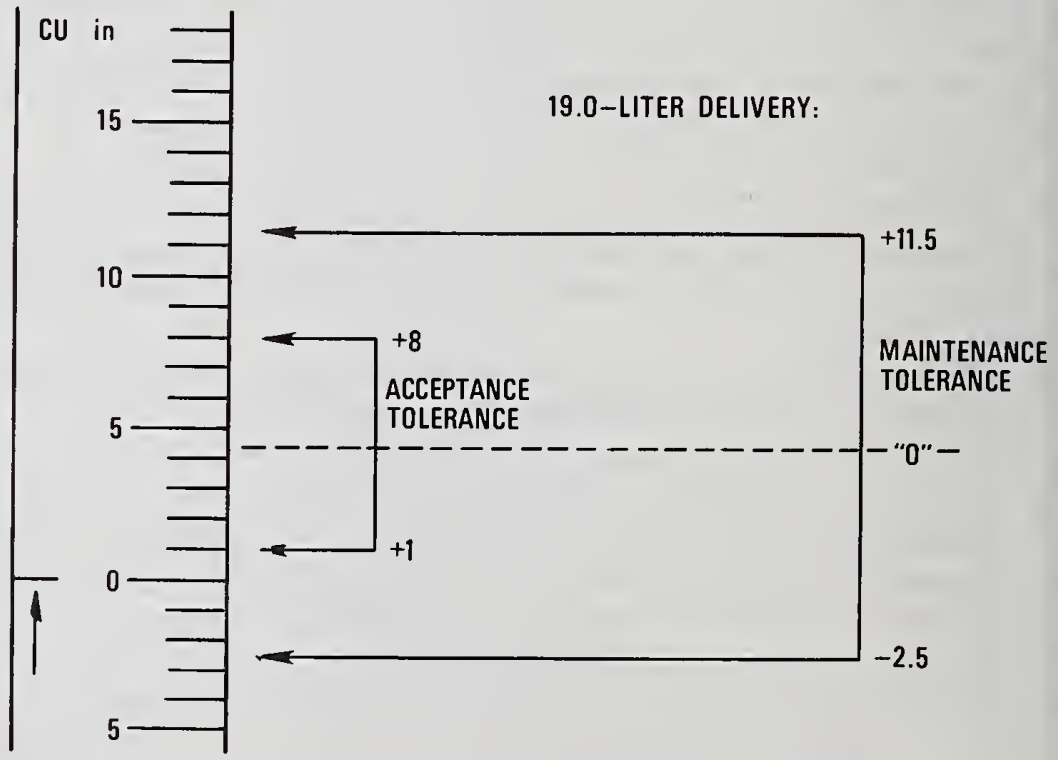


A motion was made and seconded to amend this item as follows:

Add the words "if legal" after the word "liters" in the recommended paragraph S.1.1.2.1.

In a lengthy discussion during the hearing it was clearly brought out that the recommended amendment was not necessary, since if metric were "in fact" illegal in a particular State, then the reference to liter in this paragraph would not be applicable.

(The amendment was defeated)

(Item 303 was adopted)

304 TENTATIVE CODE FOR WATER METERS

Since this code has been tentative since 1975 and no criticism or comment has been received, the committee recommends this code be changed to a permanent status.

(Item 304 was adopted)

305 CODE FOR LPG LIQUID-MEASURING DEVICES

\section{5-1 S.1.4.4. Money-Value Computations}

See Code for Vehicle-TankMeters, Item 307-2

(Item 305-1 was adopted)

\section{5-2 Printed Tickets}

The committee received a suggestion that this code should be amended to be consistent with other codes dealing with this situation. The committee agrees and recommends amendment as follows:

Delete paragraph UR.2.5. Printed Ticket

Renumber UR.2.6. to UR.2.5.

Add the following new paragraph:

S.1.1.6. Printed Ticket-Any printed ticket issued by a device of the computing type on which there is printed the total computed price, shall have printed clearly thereon the total volume of the delivery in terms of gallons and the appropriate fraction of the gallon and the price per gallon. 
S.1.4.2. Money-Value Computations.-See Code for Vehicle-Tank Meters, Item 307-2.

(Item 306 was adopted)

307 CODE FOR VEHICLE TANK METERS

307-1 Since automatic temperature compensators that interface with vehicle-tank meters are apparently readily available from several manufacturers, it is the view of the committee that this technology should be recognized in the Code for Vehicle-Tank Meters. It is also the committee's view and intent that this action neither requires this equipment to be used, nor does it make its use entirely voluntary. It merely removes an obstacle if, in the sale of any product measured by a vehicle-tank meter, it is considered appropriate and legal to compensate for temperature variations.

In order to provide for the sale of products at a reference temperature, further changes to weights and measures laws and/or regulations will be required. The committee offers the following as a guide when this action is to be taken.

The gallon is defined as being equal to 231 cubic inches. Providing for the measurement of volume at specified temperatures can be done in a manner similar to that followed in the Model State Packaging and Labeling Regulation which specifies reference temperatures for various kinds of commodities. An example of a suggested regulation is:

TERMS: LIQUID MEASURE, HOME HEATING OILS.-Whenever home heating oil is sold or delivered to a consumer by liquid measure, the volume sold and delivered shall be in terms of the United States gallon of 231 cubic inches and the volume shall be expressed at $60{ }^{\circ} \mathrm{F}$. This may be accomplished through the use of an approved meter equipped with an automatic temperature compensating mechanism, or the use of an appropriate volume correction table.

This regulation will result in equitable, efficient and uniform marketing of fuel oil in that all buyers and sellers will be on the same basis at all times.

The specific changes recommended for adoption in the Code are as follows:

S.2.4. THERMOMETER WELL.-Means shall be provided for inserting, for test purposes, a mercury-in-glass thermometer either

(a) in the liquid chamber of the meter, or 
(b) in the meter inlet or discharge line and immediately adjacent to the meter.

S.2.5. AUTOMATIC TEMPERATURE COMPENSATION.-A device may be equipped with an adjustable automatic means for adjusting the indication and registration of the measured volume of product to the volume at $60^{\circ} \mathrm{F}$.

S.2.5.1. PROVISION FOR DEACTIVATING-On a device eqipped with an automatic temperature compensating mechanism that will indicate or record only in terms of gallons compensated to $60^{\circ} \mathrm{F}$, provision shall be made to facilitate the deactivation of the automatic temperature compensating mechanism so that the meter may indicate, and record if it is equipped to record, in terms of the uncompensated volume.

S.2.5.2. PROVISION FOR SEALING.-Provision shall be made for applying security seals in such a manner that an automatic temperature-compensating system cannot be disconnected and that no adjustment may be made to the system.

S.5.5. TEMPERATURE COMPENSATION.-If a device is equipped with an automatic temperature compensator, the primary indicating elements, recording elements, and recorded representation shall be clearly and conspicuously marked to show that the volume delivered has been adjusted to the volume at $60^{\circ} \mathrm{F}$.

N.4.1. NORMAL TESTS.-The "normal" test of a device shall be made at the maximum discharge rate that may be anticipated under the conditions of installation. If the device is equipped with an automatic temperature compensator, this test should be conducted with the compensator deactivated.

N.4.1.2. AUTOMATIC TEMPERATURE COMPENSATION.If a device is equipped with an automatic temperature compensator, the compensator shall be tested by comparing the volume indicated or recorded by the device with the compensator connected and operating, with the actual delivered volume corrected to $60^{\circ} \mathrm{F}$.

N.5. TEMPERATURE CORRECTION.-Corrections shall be made for any changes in volume resulting from the differences in liquid temperatures between time of passage through the meter and time of volumetric determination in the test measure.

UR.2.4. TEMPERATURE COMPENSATION.

UR.2.4.1. USE OF AUTOMATIC TEMPERATURE COMPENSATORS.-If a device is equipped with an automatic temperature 
compensator, this shall be connected, operable, and in use at all times. Such automatic temperature compensator may not be removed, nor may a compensated device be replaced with an uncompensated device, without the written approval of the weights and measures authority having jurisdiction over the device.

UR.2.4.2. WRITTEN INVOICES.-Any written invoice based on a reading of a device that is equipped with an automatic temperature compensator shall have shown thereon that the volume delivered has been adjusted to the volume at $60^{\circ} \mathrm{F}$.

\section{UR.2.4.3. NONAUTOMATIC TEMPERATURE COMPENSA-} TION.-If the volume of the product delivered is adjusted to the volume at $60^{\circ} \mathrm{F}$, the product temperature shall be taken during the delivery in the liquid chamber of the meter or in the meter inlet or discharge line adjacent to the meter. The accompanying invoice shall indicate that the volume of the product has been adjusted for temperature variations to a volume of $60^{\circ} \mathrm{F}$ and shall also state the product temperature used in making the adjustment.

(After a lengthy discussion, a motion to table the entire Item 307-1 was made, seconded and passed.)

\section{7-2 S.1.4.3. Money Value Computations}

The committee reviewed this paragraph and decided that it was directed primarily to mechanical analog equipment and did not properly respond to electronic digital devices. Their concern centered around that part requiring 1-cent money value graduations. It is the committee's view that a digital electronic vehicle-tank meter which indicates quantity values to the nearest tenth gallon, and then multiplies this quantity by the unit price in obtaining a total price value which is mathematically correct to the nearest one cent is an appropriate design. To recognize this technology the committee recommends code amendment as follows

Add the following sentence to paragraph S.1.4.3. Money Value Computations:

On electronic devices with digital indications, the total price may be computed on the basis of the quantity indicated when the value of the smallest division indicated is equal to or less than 0.1 gallon.

(Item $307-2$ was adopted)

\section{7-3 S.2.1. Vapor Elimination}

The committee received a comment that this requirement, although it referenced the permanence of the vent line, neglected to consider 
the fact that if the vent opening was readily accessible, the effectiveness of the air eliminator could be completely negated by placing a finger or other object over the vent line opening. It is the view of the committee that there is no need for code amendment to control this situation and that the determination as to the appropriateness of the accessibility or location of the vent opening could be made on the basis of G-S.2. Facilitation of Fraud.

(Item 307-3 was adopted)

308

CODE FOR FARM MILK TANKS

\section{8-1 Quantity Charts}

The committee received three suggestions that this code be amended to provide for charts with quantity values in pounds. These comments included three different suggestions as to how this should be accomplished. The committee agrees that a weight chart is useful, but since the measurement process is determined on the basis of fluid measurement the official or primary chart should be in gallonage values. So that an auxiliary chart with weight values can be used, the committee recommends the code be amended by adding the following new paragraph:

UR.3. Weight Chart.-An auxiliary weight chart may be provided, on which shall be prominently displayed the pounds per gallon value used to derive the weight values from the official gallonage chart.

(Item 308-1 was adopted)

\section{8-2 Capacity}

The committee was informed that milk tanks are being calibrated for capacities greater than the manufacturers' rated capacity. It is the committee's view that although the values may be correct at the time of calibration, there is no guarantee that it will remain so. Filling the tank with product above the manufacturers' rated capacity may result in tank distortion or metal fatigue and cause errors after the tank has been in use. Since the manufacturer must have a valid reason for establishing and marking the rated capacity, it is the committee's view that the tank should not be calibrated beyond that amount and recommends the code be amended as follows:

Add the following new nonretroactive paragraph:

S.2.4. Capacity.-A farm milk tank shall be clearly and permanently marked on a surface visible after installation with its capacity as de- 
termined by the manufacturer. The capacity shall not exceed an amount which can be agitated without overflowing and which can be measured accurately with the liquid at rest. (nonretroactive as of 1979)

Add the following new paragraph:

UR.4. Use. A farm milk tank shall not be used to measure quantities greater than an amount which can be agitated without overflowing.

(Item 302-2 was adopted)

309 CODE FOR MEASURE CONTAINERS

The Specifications and Tolerance Committee and the Laws and Regulations Committee received requests from the private sector that all codes and regulations be amended to allow for five-quart and sixquart measure containers in the sale of ice cream, and to provide metric sizes. The committees, in a joint meeting, discussed this request at length and considered all of the ramifications impacting on the change. It was the view of these committees, that the principal reason for restricting sizes is to facilitate value comparisons for consumers; further, that quantities based on multiples or binary submultiples of a quart or a liter rather than on the present one gallon basis, do not make value comparisons more difficult. Therefore, the Specifications and Tolerances Committee recommends code amendment as follows:

Amend S.1. Units to read:

S.1. Units. The capacity of a measure container shall be a multiple of or a binary submultiple of a quart (in inch-pound units) or a liter (in metric units), and the measure shall not be subdivided. However, for prepackaged measure-containers, any capacity less than $1 / 2$ liquid pint or $1 / 4$ liter shall be permitted.

Delete present paragraphs S.1.1. and S.1.2.

Amend the title and first sentence of paragraph N.2.2.1. as follows:

N.2.2.1. For Rectangular Containers of One Quart or One Liter or Less. Bulging of the sides of a rectangular measure container of one-quart or one liter capacity or less may be. . .

Amend the title and first sentence of paragraph N.2.2.2. as follows:

N.2.2.2. For Rectangular Prepackaged Measure-Containers of One Half-Galten Two Quarts or Two Liters or Greater.-A 
rectangular prepackaged measure-container of ene half gallon twoquart or two-liter capacity or greater. . . .

Delete present T.1. and Table 1 and insert the following new paragraphs T.1., T.2., and Table 1:

T.1. Tolerances on an Individual Measure. The acceptance tolerances in excess and in deficiency on an individual measure shall be as shown in table 1 .

TABLE 1.-ACCEPTANCE TOLERANCES, IN EXCESS AND IN DEFICIENCY, FOR AN INDIVIDUAL MEASURE-CONTAINER

\begin{tabular}{|c|c|c|c|c|}
\hline \multirow{3}{*}{ Nominal capacity } & \multicolumn{4}{|c|}{ Tolerance } \\
\hline & \multicolumn{2}{|c|}{ In excess } & \multicolumn{2}{|c|}{ In deficiency } \\
\hline & $\begin{array}{c}\text { Fluid } \\
\text { drams }\end{array}$ & $\begin{array}{l}\text { Cubic } \\
\text { inches }\end{array}$ & $\begin{array}{c}\text { Fluid } \\
\text { drams }\end{array}$ & $\begin{array}{l}\text { Cubic } \\
\text { inches }\end{array}$ \\
\hline $\begin{array}{c}1 / 2 \text { pint or less } \\
1 \text { pint } \\
1 \text { quart } \\
2 \text { quarts } \\
3 \text { quarts } \\
4 \text { quarts } \\
\text { Over } 4 \text { quarts }\end{array}$ & $\begin{array}{c}3 \\
4 \\
6 \\
9 \\
10 \\
12 \\
\text { Add per } \\
\text { quart- } \\
3 \text { fluid } \\
\text { drams }\end{array}$ & $\begin{array}{c}0.6 \\
1.0 \\
1.4 \\
2.0 \\
2.4 \\
2.8 \\
\text { Add per } \\
\text { quart- } \\
0.7 \text { cubic } \\
\text { inch }\end{array}$ & $\begin{array}{c}1.5 \\
2.0 \\
3.0 \\
4.5 \\
5.0 \\
6.0 \\
\text { Add per } \\
\text { quart- } \\
1.5 \text { fluid } \\
\text { drams }\end{array}$ & $\begin{array}{c}0.3 \\
0.5 \\
0.7 \\
1.0 \\
1.2 \\
1.4 \\
\text { Add per } \\
\text { quart- } \\
0.35 \text { cubic } \\
\text { inch }\end{array}$ \\
\hline & \multicolumn{2}{|c|}{ Milliliters } & \multicolumn{2}{|c|}{ Milliliters } \\
\hline $\begin{array}{c}1 / 4 \text { liter or less } \\
1 / 2 \text { liter } \\
1 \text { liter } \\
\text { over } 1 \text { liter }\end{array}$ & add $\mathrm{p}$ & L & add & iter- \\
\hline
\end{tabular}

T.2. Tolerance on Average Capacity. The average capacity on a random sample of ten measures selected from a lot of 25 or more shall be equal to or greater than the nominal capacity.

Amend UR.1. as follows:

UR.1. Limitation of Use.-The use of a measure-container of with a rectangular cross section of a capacity of $1 / 2$ gallon two quarts or two liters or greater shall be limited to the packaging, in advance of sale, of ice cream, sherbet, or other similar frozen desserts. 
(The committees recommendations on this code was deleted from its final report)

S.1.1.1. Primary Elements/General.-A comment was received that certain laundry driers are not equipped with an inservice light indicating the device is in operation; however, this presented no problem since the devices are equipped with a glass door through which the operation of the device is readily observable. It is the view of the committee that the intent of this paragraph is to clearly indicate to users that devices are in operation. The committee also agrees that in the instance mentioned above, users could readily determine when the equipment was in operation. On that basis, the committee recommends S.1.1.1. be amended to read:

S.1.1.1. General.-A timing device shall be equipped with a primary indicating element, and may also be equipped with a primary recording element. However, A readily observable in-service light or other equally effective means that automatically indicates that when laundry driers, vacuum cleaners, and car washes are in operation shall be deemed an appropriate primary indicating element.

(Item 311 was adopted)

T.1. Tolerances.-The tolerances on berry baskets and boxes were reduced in 1976 because measures submitted for prototype examination were found to be consistently short within the tolerance limits. The latest technology used to form berry baskets, i.e., formed plastic, could apparently produce measures more accurately than the original wooden ones on which the tolerances were based. Since the publication of those new tolorances by the State of California, three manufacturers of berry boxes sent letters to that State indicating that there is a variability in raw materials and wear in molds that can cause greater variations in accuracy than the new tolerances allowed.

The tolerance reduction in 1976 was simply an elimination of the tolerance in deficiency. On the basis of the comments made by those manufacturers, the committee is recommending tolerance amendment. To provide a clear understanding of this recommendation, the tolerance table as it appeared prior to 1976, the tolerances adopted in 1976 and the new recommendation are as follows: 


\begin{tabular}{|c|c|c|c|}
\hline \multirow{2}{*}{} & \multirow{2}{*}{$\begin{array}{c}\text { Nominal } \\
\text { Capacity }\end{array}$} & \multicolumn{2}{|c|}{ Tolerance } \\
\cline { 3 - 4 } & & $\begin{array}{c}\text { In Excess } \\
\text { cu in }\end{array}$ & $\begin{array}{c}\text { In Deficiency } \\
\text { cu in }\end{array}$ \\
\hline 1975 & $1 / 2$ pint & 1 & 0.5 \\
$\&$ & 1 pint & 2 & 1.0 \\
Before & 1 quart & 3 & 1.5 \\
\hline & $1 / 2$ pint & 1 & 0 \\
1976 & 1 pint & 2 & 0 \\
& 1 quart & 3 & 0 \\
\hline
\end{tabular}

Recommended amendment:

T.1. Tolerances on Individual Measures.-Maintenance and acceptance tolerances in excess and deficiency on an individual measure shall be as shown in table 1. (NOTE: Table 1 as it was in 1975.)

T.2. Tolerances on Average Capacity.-The average capacity on a random sample of ten measures selected from a lot of 25 or more shall be equal to or greater than the nominal capacity.

(Item 312 was adopted)

OTHER ITEMS

\section{3-1 National Bureau of Standards Handbook 44}

The committee has received numerous helpful suggestions for a new format for the next edition of Handbook 44. On the basis of those suggestions and the committee's own ideas the committee is pleased to recommend a new format.

The Handbook will be divided into five sections numbered 1 through 5. Each code or part of each section will be numbered sequentially. Thus the outline of contents will appear as follows: 


\section{Outline of Contents}

\section{Section 1}

1.10. Introduction

1.11. Fundamental Considerations

1.12. Units and Systems of Weights and Measures

1.13. Tables of Weights and Measures

1.14. General Code

Section 2.

2.20. Scales

2.21. Belt-Conveyor Scales

2.22. Weights

Section 3.

3.30. Liquid-Measuring Devices

3.31. Vehicle-Tank Meters

3.32. LPG Liquid-Measuring Devices

3.33. LPG Vapor-Measuring Devices

3.34. Cryogenic Liquid-Measuring Devices

3.35. Milk Meters (tentative)

3.36. Water Meters (tentative)

Section 4.

4.40. Vehicle Tanks Used as Measures

4.41. Liquid Measures

4.42. Lubricating-Oil Bottles

4.43. Farm Milk Tanks

4.44. Milk Bottles

4.45. Measure Containers

4.46. Graduates

4.47. Dry Measures

4.48. Berry Baskets and Boxes

Section 5.

5.50. Fabric-Measuring Devices

5.51. Wire- and Cordage-Measuring Devices

5.52. Linear Measures

5.53. Odometers

5.54. Taximeters

5.55. Timing devices

A few of the advantages of this format are:

1. Each Section is a grouping of similar or related subjects. It is likely that most private-sector users will need only two sections. 
2. Each paragraph will have an individual identity. For example, scale code paragraph S.1.1. can be identified as 2.20.S.1.1., and liquid-measuring device paragraph S.1.1. can be identified as 3.30.S.1.1., etc.

3. The size $812^{\prime \prime} \times 11^{\prime \prime}$ will provide more information per page, in a clear and easily readable manner.

4. The use of modern word processing techniques may enable an annual reprinting of Handbook 44, thus eliminating replacement sheets and assuring the possession of an up-to-date Handbook 44 when the date on the cover is the same as the year of the last NCWM.

5. Illustrations and S \& T Committee interpretations are planned to be included.

6. New Codes can be added easily. For example, if a code were to be developed for electric meters, it would be numbered 5.56 .

All of these changes will not take place immediately. It is anticipated that each change or changes will take place when it is most efficient and economical to do so.

The committee wishes to express its appreciation to all those offering comments, which aided them greatly in the development of this recommendation.

(Item 313-1 was adopted)

\section{3-2 OIML}

Since the Conference last year, resources have been made available for NCWM participation in certain OIML activities and meetings. The criteria for the selection of NCWM participants are included in the Report of the Executive Committee.

Two members of the $\mathrm{S} \& \mathrm{~T}$ Committee had the privilege of participating in recent OIML meetings. A brief report of each follows.

James Bird, Chairman, attended a meeting of the International Working Groups for PS 7, Measures of Masses, and PS 8, Weights. The results of that meeting are as follows:

The review and acceptance by the International Working Group for PS 7 of two draft documents to be submitted for action by the 6 th International Conference to be held in the United States in 1980. They are, "Continuous Totalizing Automatic Weighing Machines" and "Automatic Check Weighing and Weight Grading Machines". 
The review and acceptance by the International Working Group for PS 7 of certain amendments to IR \#28, "Technical Regulations for Nonautomatic Weighing Instruments". This draft revision is to be circulated to the collaborators of PS 7/RS 4 for vote and, if approved, will be submitted for action by the 6th International Conference.

A decision by the PS 7 International Working Group that IR \#3, "Metrological Regulations for Nonautomatic Weighing Instruments", should be revised and a request that the PS 7/RS 4, Co-RS, France and the Federal Republic of Germany, begin work immediately.

A decision by the PS 7 International Working Group that a need exists for an IR applicable to electronic devices and that this work should be carried out by PS 7/RS 2, a responsibility of the United States.

The review and acceptance by the International Working Group for PS 8 of the draft document, "Hexagonal Weights-Accuracy Class $\mathrm{M}_{3}-100$ grams to 20 kilograms", to be submitted for action by the 6th International Conference.

A decision by the PS 8 International Working Group that all of the IRs applicable to weights be combined, if possible, into one IR. This is the responsibility of the U.S.

Daryl Guensler, attended a meeting of the International Working Group for PS 5, "Measures of Liquid Volumes". The results of this meeting are as follows:

A decision to submit to PS 5/RS 13 collaborators for vote certain revisions to IR 5, "Meters for Liquids (other than water), with measuring chambers". The U.S. position on this revision is to "abstain" for the following reasons:

(1) A refusal on the part of the Co-RS, France and the Federal Republic of Germany, to accept an amendment to the scope of this document to include electronic devices. The Co-RS refused to accept this amendment on the basis that electronic technology reliability has not yet been proven, consequently more study and data are necessary to determine if electronic equipment should be included or if new and different requirements need be developed.

(2) A recommendation of the U.S. that meters for certain measuring applications need only be designed to operate over a $5: 1$ 
flow rate ratio rather than the all inclusive 10:1 ratio was not accepted by the Co-RS.

The review and acceptance by PS 5 International Working Group of a draft document, "Measuring Assemblies for Liquids, other than water, Equipped with Volume Meters". This draft is to be circulated to the PS 5/RS 13 collaborators and if accepted, submitted for action by the Sixth International Conference.

The U.S. position on this revision is to "abstain" because a field test for the performance evaluation of an air separator, submitted by the U.S., was not accepted by the Co-RS.

Both $\mathrm{S} \& \mathrm{~T}$ members expressed the view that there is a tremendous resource of knowledge and information in OIML and the NCWM participation in OIML should prove mutually beneficial.

(Item 313-2 was adopted)

\section{3-3 SMA Recommendation for a Legaỉ Metrology Control System Aplicable to the U.S.}

The committee received this 26-page document, but time did not permit a complete review and consequently the committee cannot offer any comments on it. The committee feels that this material should be reviewed by all Conference members and has requested the author to present this paper at this Conference.

(Item 313-3 was adopted)

\section{3-4 Nonretroactive Requirements to be Reviewed}

In accordance with the rules stated in the Introduction, Part 6 . Classification of Requirements, each nonretroactive requirement is to be reviewed after it has been effective for a period of 10 years or more to determine the appropriateness of changing that status to retroactive. This 10-year interval is provided to prevent any severe economic hardship on device manufacturers and owners, and is generally considered to be a sufficient time for those devices in use at the time of the adoption of a nonretroactive paragraph to be replaced by normal attrition. This is not always the case, however; therefore it is imperative that all persons with information which can aid the Conference in determining the appropriateness of a change in status of any of these paragraphs provide the committee with that information as soon as possible.

The following is a list of nonretroactive requirements which have been in effect for 10 years or more: 
G-S 1. Identification.-That part of this paragraph requiring a nonrepetitive serial number has been nonretroactive since 1968 .

\section{3-4-2. Code for Scales}

S.2.3. Level Indicating Means.-That part of this paragraph requiring a level indicating means on portable scales has been nonretroactive since 1969 .

313-43. S.4.3. Multiple Load Receiving Elements.-This paragraph has been nonretroactive since 1969 .

313-4.4 S.6.3. Marking Requirements/For Livestock, Vehicle and Railway Track Scales Only.-This paragraph which requires the marking of the sectional capacity has been nonretroactive since 1969.

\section{3-4.5 Code for Liquid Measuring Devices}

S.2.2. Provision for Sealing.-That part of this paragraph requiring the adjusting mechanism to be readily accessible for affixing a security seal has been nonretroactive since 1965 .

\section{3-4.6 Code for Vehicle-Tank Meters}

S.2.2. Provision for Sealing.-(The same as S.2.2. above.)

\section{3-4.7 Code for Farm Milk Tanks}

S.2.2.1. Level Indication Means/On a Stationary Tank.-Certain portions of this paragraph dealing with spirit levels have been nonretroactive since 1969.

\section{3-4.8 Code for Milk Bottles}

S.4.1. Marking Requirements/Capacity.-That part of this paragraph regarding the location of this marking has been nonretroactive since 1969 .

313-4.9 S.4.2. Identification.-This paragraph requiring the year of manufacture to be marked has been nonretroactive since 1966.

\section{3-4.10 Code of Wire- and Cordage-Measuring Devices}


S.3.3. Design of Measuring Elements/Accessibility.-This paragraph concerning the accessibility of the measuring elements for cleaning purposes has been nonretroactive since 1969 .

The committee recommends items 313-4.2 (S.2.3) and 313-4.4 (S.6.3.) to be made retroactive.

(Item 313-4 was adopted)

\section{3-5 Code for Belt-Conveyor Scales}

Interest has been expressed in obtaining input relaiive to the performance of belt-conveyor scales and the possibility of reducing tolerances. All interested parties are requested to provide data to the S \& T Committee prior tu December 15, 1979, and the Committee will include its recommendations in the next tentative report for action by the 65 th NCWM.

\section{(Item $313-5$ was adopted)}

The committee expresses its appreciation to all who have contributed to and participated in the development of this report. It is only through this cooperative effort that the Conference can continue to attain uniform and equitable model standards.
J. R. BIRD, Chairman, New Jersey
D. A. GuENSLER, California
G. L. Delano, Montana
F. C. NAGELE, Michigan
L. H. Degrange, Maryland
O. K. WARNLOF, Staff Assistant, NBS
H. F. Wollin, Executive Secretary, NCWM

\section{Committee on Specifications and Tolerances}

(On motion by the committee chairman, the report of the Committee on Specifications and Tolerances voting key items 300 through $313-5$ was adopted in its entirety as amended by the Conference. The results of the voting in the House of State Representatives and the House of Delegates under the Conference voting system are totalized in the table that follows. The Conference also authorized the Executive Secretary to make any appropriate editorial changes in the language adopted by the Conference, provided that the requirements thus adopted are strictly adhered to.) 
Voting Results-Committee on Specifications and Tolerances

\begin{tabular}{|c|c|c|c|c|}
\hline \multirow[t]{2}{*}{ Voting Key } & \multicolumn{2}{|c|}{$\begin{array}{l}\text { House of State } \\
\text { Representatives }\end{array}$} & \multicolumn{2}{|c|}{ House of Delegates } \\
\hline & Yes & No & Yes & No \\
\hline 300 & 44 & 0 & 61 & 0 \\
\hline $301-1)$ & & & & \\
\hline $301-2\}$ & 44 & 1 & 76 & 0 \\
\hline $301-3$ & & & & \\
\hline $301-4$ & 44 & 0 & 75 & 0 \\
\hline $302-1$ & 45 & 0 & 76 & 0 \\
\hline $302-2$ & 45 & 0 & 76 & 0 \\
\hline $302-3$ & & & & \\
\hline $302-4$ & 44 & 1 & 75 & 1 \\
\hline $302-5$ & & & & \\
\hline $302-6$ & 15 & 30 & 20 & 55 \\
\hline $302-7$ & & & & \\
\hline $302-8$ & 45 & 0 & 81 & 0 \\
\hline $302-9$ & & & & \\
\hline $302-10$ & & & & \\
\hline $302-11$ & 44 & 1 & 77 & 0 \\
\hline $\begin{array}{l}302-12 \\
302-13\end{array}$ & & & & \\
\hline $302-14$ & 42 & 1 & 77 & 0 \\
\hline $302-15$ & 39 & 0 & 76 & 0 \\
\hline $302-16$ & 42 & 1 & 80 & 0 \\
\hline $303 \mathrm{~A}$ & 9 & 33 & 7 & 70 \\
\hline 303 & 36 & 2 & 69 & 4 \\
\hline 304 & & & & \\
\hline $305-1$ & 40 & 0 & 75 & 0 \\
\hline 305-2 & & & & \\
\hline $307-1 T$ & 32 & 9 & 58 & 12 \\
\hline $307-2\}$ & 43 & 0 & 72 & 0 \\
\hline $307-3$ & & & & \\
\hline $\begin{array}{l}308-1 \\
308-2\end{array}$ & 37 & 0 & 45 & 3 \\
\hline 309 & & & & \\
\hline 311 & & & & \\
\hline 312 & & & & \\
\hline $313-2$ & 42 & 0 & 72 & 0 \\
\hline $313-3$ & & & & \\
\hline $313-4$ & & & & \\
\hline $313-5$ & & & & \\
\hline $313-1$ & 39 & 4 & 70 & 2 \\
\hline $\mathrm{A}=$ Amen & & & & \\
\hline $\mathrm{T}=$ Table & & & & \\
\hline
\end{tabular}




\section{REPORT OF THE COMMITTEE ON EDUCATION, ADMINISTRATION, AND CONSUMER AFFAIRS}

Presented by Stephen A. Malone, Administrator, Division of Weights and Measures, Department of Agriculture, State of Nebraska

(Thursday, July 26, 1979)

\section{VOTING KEY}

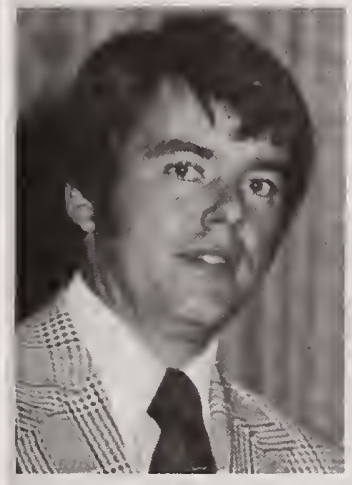

400

INTRODUCTION

The Committee on Education, Administration, and Consumer Affairs submits its final report to the 64th National Conference on Weights and Measures. The report consists of the tentative report as offered in the Conference Announcement, and as amended by the final report. The report represents recommendations of the committee that have been formed on the basis of written and oral comments received during the year and oral presentations made during the open meeting of the committee.

Mr. Anthomy Ladd of Akron, Ohio, who served as the national chairman for the week, is sincerely commended by the committee for the outstanding display of leadership that he portrayed in his very successful effort to secure promotional materials. Also a special salute to $\mathrm{Mr}$. Ladd for his work in gaining recognition by the U.S Congress and other high government officials of this week that is so important in the furthering of weights and measures work.

Mr. Ladd has been in contact with Mrs. Esther Peterson, Special Assistant to the President for Consumer Affairs, eliciting her support in having the President of the United States issue a proclamation officially proclaiming March 17, National Weights and Measures Week. Mr. Ladd also contacted all of the 50 States, District of Columbia, Puerto Rico, Virgin Islands and many of the larger cities and counties, plus the four regional conferences, concerning weights and measures week.

The committee gives special recognition and thanks to the four regional coordinators, namely, Mr. Elwood Corson, of Cape May, New Jersey, representing the Northeast Conference; Mr. Bruce Adams of 
St. Cloud, Minnesota, representing the Northwest Conference; Mr. James Blackwood of Texas, representing the Southern Conference; and Mr. Joseph Jones of Riverside, California, representing the Western Conference.

The committee would like to personally thank Tom Stabler of Toledo Scale, Fred Katterheinrich of Hobart Corporation, Bob Callihan of Fairbanks Weighing Division, Colt Industries, and Ray Lloyd of Scale Manufacturers Association, not only for their individual efforts and help, but also for the excellent promotional materials they provided for all of the coordinators for National Weights and Measures Week.

Due to the resignation from State service of Mr. Walter Junkins and in order to assure the continuity of future successful "Weights and Measures Week" the committee is happy to announce that Mr. Robert Walker of Indiana has very graciously accepted the chairmanship for "National Weights and Measures Week" for the year of 1980.

In recognition of the outstanding acceptance of the theme "Weights and Measures is Consumer Protection," the committee voted unanimously to continue this theme for 1980 .

(Item 401 was adopted)

402

PROMOTIONAL ACTIVITIES

1. The committee's supply of Conference neckties was completely sold out at the 63rd NCWM. The committee appreciates the support of the Conference members on this project.

2. Approximately half of the committee's supply of Conference membership plaques were sold during the 63rd National Conference. The remaining 100 plaques will be offered for sale at $\$ 5.00$ each during the 64 th Conference in Portland.

(Item 402 was adopted)

Since the release of the film, "The Marketplace", over 1200 loan requests have been honored which resulted in a total audience of over 46,000 people. It has also been viewed nationally on commercial and education television. Many requests have been received by local and State jurisdictions for purchase of the film.

The committee wishes to call attention to a change in the company and address for the loan requests for the film. Beginning September 1, 1979, all loan requests for "The Marketplace" should be directed to: 
Modern Talking Picture Service 5000 Park Street North

St. Petersburg, Florida 33709

This change applies to loan requests only; purchase information remains the same.

(Item 403 was adopted)

404 NATIONAL CONFERENCE MEMBERSHIP PROPOSAL

In furtherance of our goal of professionalism in weights and measures, the committee has reviewed a new membership proposal for this Conference.

The objective of this proposal is to offer membership in the Conference to all weights and measures officials, interested industry and government officials, users and consumers, and other persons interested in the objectives and activities of the Conference.

In addition, this proposal will provide a mechanism to insure that all of the members of the Conference, whether in attendance or not, will receive an appropriate membership card and all yearly outputs of the Conference, including a new NBS Handbook 44, copies of the Model Laws and Regulations, Conference proceedings, tentative committee reports and any other appropriate material.

It is the committee's sincere belief that this proposal, by providing a much wider dissemination of Conference information, will create the basis of increased nationwide uniformity and professionalism of the membership.

The committee strongly endorses this proposal and urges that the necessary steps be taken by the Conference to implement these changes as soon as possible.

(Item 404 was adopted)

405 HANDBOOK OF STATISTICAL TECHNIQUES

Mr. Ed Wolski of Colgate-Palmolive Company met with the committee and discussed at length the need for a pamphlet dealing with Basic Statistical Data to be used as a resource for weights and measures officials in conducting enforcement activities.

At the committee's request, Mr. Wolski developed a pamphlet entitled "Statistics Made Uncomplicated" which was reviewed by the committee and briefly discussed by Mr. Wolski during the committee's open hearing.

In this same area, an informative slide presentation was given by Mr. Steve Hasko of the NBS Office of Weights and Measures entitled "Confidence in Package Checking Results." Both Mr. Wolski and Mr. Hasko conducted an open meeting on new package control procedures at which time the pamphlet was distributed and questions answered. 
The committee commends Mr. Wolski and Colgate Palmolive and Mr. Hasko of NBS for their important contributions to this project.

\author{
(Item 405 was adopted)
}

406

\title{
PROPOSED OWM NATIONAL TRAINING PROGRAM
}

The Committee has long recognized the need for a uniform nationwide training program for weights and measures officials. Education is the cornerstone of professionalism. With this truth in mind, it is the intent of this committee to foster professionalism by establishing the basis for continuing education and training.

The committee has reviewed and endorses the following proposed OWM Training Program. The success of this program depends upon its acceptance by, and the full cooperation of, the members of the four regional weights and measures conferences.

\section{History}

The U.S. is the only country in the world in which weights and measures enforcement is not a Federal function but a State and local responsibility. With this system, the need for central coordination and direction is obvious. The National Bureau of Standards (NBS), through its Office of Weights and Measures (OWM), serves State and local weights and measures officials much as a trade association serves its membership. Weights and measures officials must rely on NBS to furnish needed interpretations and explanations of National Conference Laws and Regulations which serve as the basis for uniform control throughout the U.S. The OWM staff members serve as staff assistants to the various standing committees of the Conference and consequently this information is not available elsewhere. New technology in the form of electronics, digital indicators, and computers facing the weights and measures officials today makes assistance from NBS essential.

All of the States today have weights and measures laws, most of which are patterned after the Model Weights and Measures Law developed by the National Conference. Mississippi was the last State to enact their law in 1966. The enactment of uniform laws and regulations are the direct result of the OWM training effort. The training program serves as a catalyst for adoption of uniform laws and procedures and has been cited as an outstanding example of FederalState cooperation in a vital area of commerce.

The benefactors of the program in addition to the more than 3,000 weights and measures officials include manufacturers, service personnel, users, and consumers since the objective of the program is to attain a fair and equitable marketplace. 
In recent efforts to broaden the impact of the program and to spread our limited resources further, industry service personnel have been invited to participate in our seminars, both as instructors and students. An effort is also being made to group adjoining States together where possible to form regional training groups. Six such regional groups exist today in the Northeast, Northwest, South, and West. Under this plan a different State in each group hosts the seminar each year with all of their field staff participating and as many officials as possible from the other States in the region. Industry officials with National responsibility have been willing to participate in assigned specific areas as instructors in our regional seminars.

\section{Objectives}

1. To develop and conduct a nationwide training program that will offer OWM training on a completely equitable basis to all of the State and local jurisdictions. In the past OWM training has been conducted on an "as requested" basis with some of the jurisdictions receiving training each year and others receiving little or no training. This type of program is not considered to be making the best use of our resources and has not produced the desired results on a nationwide basis.

2. To seek the help and support of the National Conference Committee on Education, Administration, and Consumer Affairs in implementing and gaining Conference endorsement of this program.

The OWM training program is of vital interest and concern to the Committee and has been discussed at length during recent Committee meetings. All involved agree that OWM can spread their resources further by grouping States together into regional groups for the purpose of training and including local scale and meter service personnel as participants. The Committee has also endorsed the practice of including industry officials as instructors in certain specific areas.

3. Seek the help and support of the four regional conference committees on education on a continuing basis to implement and improve the program. Each of the regional committees (Northeast, Southern, Northwest and Western) will be asked to develop as a continuing program the implementation of this program.

4. Promote a much closer working relationship between the National Conference Committee on Education and the four regional conference committees in all areas of mutual interest such as the National Training Program, Weights and Measures Program Evaluation, and National Weights and Measures Week. 
The regional committees can provide a valuable and necessary service to their respective memberships and assist in promoting uniformity nationally by working closely with the National Conference in these important areas.

\section{Implementation and Timetable}

Beginning in 1979, Mr. R. N. Smith, Manager of OWM Training and Staff Assistant to the National Conference Committee on Education, Administration and Consumer Affairs will attend each of the four regional conferences for the purpose of outlining the program and asking for assistance in the following areas.

1. Ask each State in the region to name a State Training Officer or other person to act as coordinator of training in the State and be the OWM and Conference contact on all matters related to training. This person would also manage continuing in-house training for State and local officials in the State.

2. Assist OWM in forming regional State groups in those areas where they do not already exist. See the attached list of existing and proposed groups. Under this plan one State in the regional group agrees to host the training school each year on a rotating basis, affording the opportunity for all of the host State officials and supervisory personnel from the other States in the group to attend. This plan will guarantee the opportunity for all officials in each State in the group to attend periodically depending on the size of the group.

3. Assist OWM in setting up training sessions for the training officials during the regional conferences and workshop sessions at the National Conference similar to the Metrologists' Workshop. This phase of the program is targeted to start during 1981.

4. Assist OWM in developing State "Profiles" for each State in the regional conference. These "Profiles" would contain information regarding number of inspectors, level of enforcement activity, testing standards and equipment, program areas, needs, and levels of training. This phase of the program will, of necessity, be conducted on a continuing basis.

5. Work with OWM and National Conference in developing uniform "in-house" training programs for both new and experienced officials. 


\section{Conclusion}

The total program, with expected cooperation from all involved, will be completely operational by 1984 and should do much to upgrade and standardize commercial weights and measures activity in the U.S. Rapidly changing new technology and merchandising methods, ever changing and expanded legal requirements, and the fact that we have over 700 independent weights and measures jurisdictions in this country, make imperative the development of a uniform level of training for all officials.

\section{Attachment}

List of existing and proposed regional training groups.

\section{Existing Regional Groups}

1. Maine, New Hampshire, Vermont

2. Alabama, Tennessee, Mississippi, Georgia, Florida

3. Kansas, Missouri, Nebraska, Colorado

4. Montana, Wyoming, North Dakota, South Dakota

5. Utah, Arizona, New Mexico

6. Washington, Oregon, Idaho, Alaska

\section{Proposed Future Regional Groups}

7. Massachusetts, Connecticut, Rhode Island

8. Pennsylvania, New York, Ohio

9. Maryland, Virginia, West Virginia

10. North Carolina, South Carolina

11. Michigan, Indiana, Kentucky

12. Minnesota, Wisconsin, Iowa, Illinois

13. Texas, Oklahoma, Arkansas, Louisiana

14. Hawaii, California, Nevada

15. Puerto Rico, Virgin Islands

16. New Jersey, Delaware, District of Columbia

(Item 406 was adopted) 
In accordance with the timetable approved by the 63rd NCWM, the committee submits the following criteria for program evaluation.

\section{Laws and Regulations}

1.1 National Conference on Weights and Measures models. Is jurisdiction's law comparable to the Model State Weights and Measures Law or the Model Weights and Measures Ordinance, as the case may be, and does it contain the basic provisions found therein?

A. Does the law provide for uniformity with other jurisdictions by adopting NBS Handbook 44 for Commercial Weighing and Measuring Devices and does a recognized package control program exist?

B. The law must also provide adequate enforcement provisions.

1.2 Regulations of the jurisdiction should be evaluated on an individual basis to see if they provide the Department with the tools needed to enforce the requirements of the law that are not spelled out.

A. These regulations must provide for uniformity; therefore, they should be comparable to the model regulations adopted by the National Conference on Weights and Measures.

B. All other regulations adopted by the jurisdiction must provide for good weights and measures enforcement; however, they must not restrain new technology.

1. What type of review program does the Department have to update regulations to allow for new technology or inadequacy in regulations?

C. Does a complex library of weights and measures publications exist?

\section{Standards}

\subsection{Laboratory}


A. Are all NBS-provided standards maintained and handled in accordance with NBS requirements?

B. Is the laboratory enrolled in the NBS laboratory auditing program and maintaining a Class A Rating?

C. Does the laboratory provide the service to the weights and measures offices?

D. What type and amount of service is provided to business and industry in the jurisdiction?

E. Are other calibration services provided in addition to mass, length, and volume?

\subsection{Field Standards}

A. Do adequate field standards to perform the jurisdiction's responsibilities exist?

B. Are field standards maintained and handled in a proper manner?

C. Do field standards meet the specifications and tolerances of NBS Handbook 105-1, 105-2 and 105-3?

D. Are standards traceable? Frequency of calibration?

3. Personnel-Are all weights and measures positions career positions?

\subsection{Administrative}

A. Is the administrator a full-time position whose prime duties are weights and measures?

B. Does the administrator have a thorough knowledge of all laws and regulations enforced by the Department?

C. Does the administrator coordinate all Department activities?

D. Does the administrator provide supervision and training for all field staff?

E. Does the administrator regulate the budget, hire personnel, set policies, etc.? 
F. Qualifications?

\subsection{Clerical}
A. Is staff sufficient to handle duties?
B. Does clerical staff have a basic knowledge of the weights and measures activities?
C. Qualifications?

\subsection{Field Staff}

\subsubsection{Number}
A. Are positions full-time?
B. Is staff sufficient to accomplish mission?
C. Does staff include a competent full-time me- trologist?

\subsubsection{Qualifications}

A. Weights and measures employees

1. Minimum of high school education?

2. Mechanical aptitude?

3. Physically qualified?

4. Ability to deal with the public?

5. Communication ability, oral and written?

6. General management skills?

B. Weights and measures supervisors

1. All of the above?

2. Adequate weights and measures field experience?

3. Thorough knowledge of area of responsibility? 
3.3.3 Training

A. Does an adequate in-house training program
exist?

\section{Budget}

4.1 Is Department adequately funded?

4.2 Salary

A. Does salary paid to employees reflect adequate remuneration for that type of job based upon the cost of living for that area?

B. Is the salary adequate to attract qualified people?

C. Is the salary adequate to keep employees on, or is there a large amount of turnover?

\subsection{Physical Plant}

A. Is the physical plant (lab/office space) adequate enough to house the weights and measures functions?

B. Is the physical plant in good repair in order to protect the laboratory standards?

C. Are environmental conditions adequate in order to provide good laboratory and working conditions?

\subsection{Supplies}

A. Are adequate supplies maintained to keep the field staff supplied?

B. Are supplies adequate in nature to reflect the work performed?

\subsection{Equipment}

A. Is equipment adequate to perform the duties required by the laws and regulations?

B. Is equipment in good repair, necessary to handle the duties required and maintain proper image? 


\section{Administration}

\subsection{Policy}

A. Does the program have a policy statement for:

1. Program conduct (inspection conduct, device adjustment, etc.)?

2. Inaccurate devices and associated equipment?

3. Reinspection policy?

4. Package inspection policy (off-sales, hold, administrative hearings and legal action)?

5. Work policy (planning work areas, travel time, etc.)?

6. Lab policy (scheduling of work)?

7. Type approval?

8. Enforcement?

9. Public education?

\subsection{Records}

A. Are adequate records maintained?

B. Are they easily accessible?

C. Are records from inspectors properly maintained?

D. Are all other records maintained and complete so as to reflect the activities of the program?

(General correspondence, NBS prototype examination reports, OIML recommendations, metric activities, NCWM correspondence and activities, and all other information that may be required.)

\subsection{Planning}

A. Does the Department have a comprehensive plan which sets goals and objectives for the Department? 
B. Do these goals and objectives correspond with budget request information in order to provide for personnel, salaries, equipment, expenses, etc.?

C. Does the Department's field staff have a work plan for their individual areas?

D. Does the administrator review these plans?

\subsection{Training}

A. Does the Department have a written training program for the new employees? Does the program include:

1. Laws and regulations?

2. Departmental policies?

3. Personal conduct and appearance?

4. Handbook 44 and all other technical information necessary for the position?

5. Type and amount of field training using the above requirements?

B. Are all employees given group training dealing with new technology, specifications and tolerances, problem areas, departmental policies, etc.?

C. Does the Department have an independent training program where individual employees may advance themselves through education in the weights and measures field?

D. Is training uniform?

E. Is NBS training conducted?

5.5 Enforcement

A. Does the Department follow its enforcement?

5.6 Test Procedures

A. Does the Department follow recognized test procedures? 
A. Does the Department provide the needed supervision to the personnel to insure adequate training and uniformity of department activities?

B. Is supervision at a level to assure that the laws and regulations are being enforced as prescribed?

C. Does supervision encompass the education of industry, users, and the general public concerning the weights and measures laws and regulations, as well as the benefits of the weights and measures activities?

\subsection{Cost Benefit}

A. Does the Department utilize cost benefit data?

B. Has the Department researched new methods of inspection to see if the cost of the program can be used to provide more benefits to the consumer and industry?

\subsection{Public Education}

A. Does the Department follow its public education policy?

The committee feels that the above criteria will provide the basis for a much needed resource tool for program review and improvement.

Conference members are urged to give careful consideration and support to this program.

The committee appreciates the many oral and written suggestions for improving the Program Evaluation Criteria. However, the committee would like to stress that this is a pilot program. The Criteria developed is not set in concrete, it is subject to continual change and review as the need arises. The committee continues to solicit the comments and recommendations for improving the present criteria. Following the first pilot run, several changes and additions will probably be necessary. 
S. A. Malone, Chairman, Nebraska

S. J. DARSEY, Florida

R. W. WALKER, Indiana

A. J. LADD, Ohio

S. L. Swanson, Arkansas

R. N. SMITH, Staff Assistant, NBS

H. F. Wollin, Exec. Secy., NCWM

\section{Committee on Education, Administration, and Consumer} Affairs

(On motion of the committee chairman, the report of the Committee on Education, Administration, and Consumer Affairs, voting key items 400 through 407 was adopted in its entirety by the Conference. The results of the voting in the House of State Representatives and the House of Delegates under the Conference voting system are totalized in the table that follows. The Conference also authorized the executive secretary to make any appropriate editorial changes in the language adopted by the Conference, provided that the requirements thus adopted are strictly adhered to.)

Voting RESUlts-Committee on Education, Administration, and Consumer Affairs

\begin{tabular}{c|c|c|c|c}
\hline \multirow{2}{*}{ Voting Key } & \multicolumn{2}{|c|}{$\begin{array}{c}\text { House of State } \\
\text { Representatives }\end{array}$} & \multicolumn{2}{c}{ House of Delegates } \\
\cline { 2 - 5 } & Yes & No & Yes & No \\
\hline 400 & 36 & 0 & 47 & 0 \\
401 & 33 & 0 & 49 & 0 \\
402 & 37 & 0 & 50 & 0 \\
403 & & & & 1 \\
404 & 36 & 0 & 52 & 2 \\
406 & 35 & 1 & 48 & 0 \\
407 & 37 & 0 & 50 & \\
\hline
\end{tabular}




\section{REPORT OF THE COMMITTEE ON LIAISON}

Presented by Charles H. Greene, Chief, Division of Consumer and Marketing Services, New Mexico Department of Agriculture, Las

Cruces, New Mexico

(Thursday, July 26, 1979)

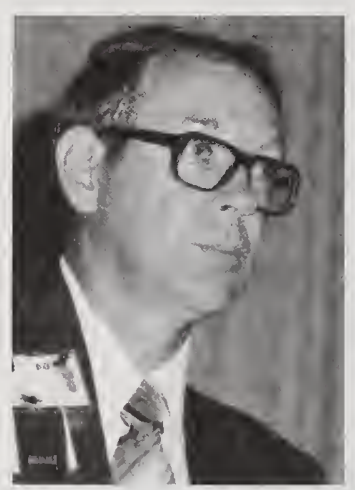

\section{VOTING KEY}

500

INTRODUCTION

The Committee on Liaison submits its report to the 64th National Conference on Weights and Measures (NCWM). The report consists of the tentative report as offered in the Conference Announcement and as amended by this final report. The report represents recommendations of the committee that have been formed on the basis of written and oral comments received during the year and oral presentations made during the open meeting of the committee.

\section{1-1 Multi-Unit, Variety, and Combination Packages}

The committee undertook an intensive review of Federal agency regulations and the NCWM Model State Packaging and Labeling Regulation. While the existing regulations do seem to reflect a multiple approach to draftmanship, they also appear to be basically functional if followed with care.

The subject regulations of the Model, Food and Drug Administration (FDA), Federal Trade Commission (FTC), and U.S. Department of Agriculture (USDA) have been in place now for almost ten years. During that time, they have been administered (interpreted) by numerous Federal, State, and local officials. Many thousands of labels have been designed with reference to them and hundreds of millions of packages have been sold bearing those labels. Since only two jurisdictional disputes have surfaced during the same period of time, it appears that we are not faced with a need for an amendment of any of the regulations.

It is the consensus of the Laws and Regulations (L\&R) and Liaison Committees that no changes to the Model State Packaging and La- 
beling Regulation be undertaken at this time in relation to this subject.

(Item 501-1 was adopted)

\section{1-2 Aerosol Package Labeling}

A review of aerosol package labeling regulations was held jointly with the L\&R Committee. Differences between the Model Packaging and Labeling Regulation and the FDA interpretations of the Fair Packaging and Labeling Act were reviewed with James Taylor of FDA. Mr. Taylor indicated that a petition from the NCWM concerning this issue may stimulate action on the part of FDA. A suggestion was also made that such a petition would have more impact if backed up by petitions from individual States. The committee prepared the following petition to FDA by the NCWM concerning the quantity statement labeling of aerosol packaged products:

\section{NATIONAL CONFERENCE ON WEIGHTS AND MEASURES' PETITION TO THE FOOD AND DRUG ADMINISTRATION}

The National Conference on Weights and Measures (NCWM) petitions the Food and Drug Administration (FDA) to make a change in its regulations pertaining to the labeling of aerosol packages of food and cosmetic products and to revise the FDA Fair Packaging and Labeling Manual Guide (FPLMG) 7563.7, Interpretations of 101.105(g), Quantity of Contents Declarations on Aerosols. We request that the mandatory quantity declaration on the principal display panel of aerosol packaged products and on similar pressurized packages be limited to statements in terms of net weight only.

The National Conference on Weights and Measures was established in 1905 by the National Bureau of Standards for the purpose of securing and maintaining uniformity among State weights and measures laws, regulations, and methods of inspection. The Bureau, which is an agency of the U.S. Department of Commerce, has continued its sponsorship of the Conference over these many years.

The Conference is an organization of State, county, and city weights and measures officials from throughout the United States. Meetings of the Conference bring together the weights and measures regulatory officials and representatives from business, industry, trade associations, and consumer organizations to hear, discuss, and take action on matters that relate to weights and measures technology and administration. The actions of NCWM provide the legal and technical basis for our system of weights and measures in the U.S., and the Conference has been cited on numerous occasions as a most effective example of Federal/State cooperative effort.

In 1961, at the request of the Chemical Specialties Manufacturers Association (CSMA), a trade association representing most of the aerosol packagers, a change was made in the NCWM Model State Packaging and Labeling Regulation specifying that aerosol packaged products be labeled by weight (including the propellant as part of the product). Reasons advanced at that time were that it was the only method of sale that is practical and can be used successfully in both the filling operation by the packer and the checking of quantity of contents by regulatory inspection officials. This weight only requirement for aerosols subsequently was adopted into law in many States. Thus, the labeling of aerosol packaged products by weight has been an industry-wide practice since then. About three years ago when the "ozone con- 
troversy" was at its peak, a few of the packagers changing over to a less dense (fluorcarbon-free) propellant decided to label their products by volume. It is safe to assume that this caused confusion in the marketplace because the consumer could not compare quantities labeled by volume (fluid ounces) with those labeled by weight (avoirdupois ounces). A product labeled as 14 fluid ounces by volume may be only 11 ounces by weight, thus giving undiscerning consumers the impression that they are getting more product for their money with a package labeled by volume than an identical product in a package labeled by weight.

While the consumer can verify the net quantity statement of an aerosol packaged product labeled by weight with a simple scale, there is no practical way for him or a regulatory official to verify the net quantity statement of such a product when labeled by volume.

Thus, the NCWM petitions the FDA to make the necessary changes to their regulations and interpretation of $\$ 101.105(\mathrm{~g})$, FPLMG 7563.7 pertaining to the quantity of contents declaration on aerosol packaged products. It is requested that the net quantity statement on aerosol packaged products or similar pressurized packages be made in terms of net weight only. The reasons for recommending such changes are as follows:

1. Net quantity labeling of aerosol packaged products in terms of net weight is a firmly established trade practice for such products.

2. Net quantity labeling of aerosol packaged products in terms of volume is difficult (if not impossible) to verify with consumer verification methods or by conventional package inspection methods. State or local enforcement action is discouraged by such labeling.

3. Since the labeling of aerosol packaged products by volume cannot be compared with the labeling of such products in terms of net weight, labeling in terms of volume and weight inhibits value comparisons and causes consumer confusion with respect to the quantity of product the consumer is buying; in effect it can be a form of deceptive labeling.

4. Uniformity between all State and Federal regulations is highly desirable both from the standpoint of enforcement and for purposes of fair competition in the marketplace. The Model State Packaging and Labeling Regulation and the Federal Trade Commission and Environmental Protection Agency Regulations require net quantity labeling of aerosol packaged products in terms of net weight.

(Item 501-2 was adopted)

\section{2-1 Octane Posting Regulations}

At the interim meeting, it was anticipated that on April 1, 1979, the FTC would require the certification of octane by distributors and the posting of octane ratings on all gasoline pumps. The requirement and the date are both set in Public Law 95-297, the Petroleum Marketing Practices Act (PMPA), passed in June, 1978. These require- 
ments will exist whether or not the FTC succeeds in the attempt to finalize its proposed regulations. The regulations will specify the specific means of complying with the law. Although the octane posting rule has no effect on most programs administered by State weights and measures officials with respect to checking gasoline dispensing devices for accuracy or octane numbers as they relate to gasoline grades, the Liaison Committee feels that the conference should be generally informed about the law and the anticipated FTC rule, if only to be prepared to answer inquiries about it or for some possible future enforcement demands. Keeping apprised of developments associated with the rule may be advisable. In addition, it will impact on States which have octane certification and posting programs.

The preemption section of PMPA (204) reads as follows:

Sec. 204. To the extent that any provision of this title applies to any act or omission, no State or any political subdivision thereof may adopt, enforce, or continue in effect any provision of any law or regulation (including any remedy or penalty applicable to any violation thereof) with respect to such act or omission, unless such provision of such law or regulation is the same as the applicable provision of this title.

It is said to have been so written because States which have programs employing other octane numbers (usually research octane numbers), which are somewhat higher than those arrived at by using the $(\mathrm{R}+\mathrm{M}) / 2$ Method will be forced to change their test methods.

There will be an effect upon State and local jurisdictions having octane labeling requirements which are not the same as those in this law. Section 204 prohibits States and other political subdivisions from enforcing requirements which are not the same as the applicable provisions of this law. Jurisdictions having octane requirements should carefully review with their legal advisors the effect of this law.

Notice of availability of the FTC staff's report and recommended rule was published in the Federal Register in December 1978. The rule was published in final form on March 30, 1979, in the Federal Register (Vol. 44, No. 63, Part V, pp. 19160-19172). The rule became effective June 1, 1979.

The law requires that refiners determine octane ratings of their products, and certify them to their distributors. The distributor must pass along the certification to the retailer, unless he blends the gas, in which case he may have to certify his blend.

A similar procedure, using the labels required to be passed along by the refiner or the distributor, or recalculating after blending, is set forth for the retailer.

The Environmental Protection Agency (EPA) is responsible for enforcement with respect to the accuracy of the certified ratings. The FTC is also empowered to check records which must be retained for one year by each link in the distribution chain. Neither FTC nor EPA is in a position to easily enforce the law. 
Another section of the law requires that in 1980 automobile owners manuals show octane requirements arrived at by the same formula.

The FTC is in need of help from the State and local jurisdictions in the area of surveillance and testing. Such assistance could occur at a number of levels. The simplest would be for weights and measures officials to report to FTC any instances of failure to post octane ratings by service stations. These would most likely occur during routine inspections of service station gasoline dispensers. Reports should be made to the appropriate FTC regional offices as listed:

FTC Regional Offices, Addresses, and Telephone Numbers:

150 Causeway Street

Boston, Massachusetts 02114

(617) 223-6621

26 Federal Plaza

New York, New York 10007

(212) 264-1207

118 St. Clair Avenue

Cleveland, Ohio 44114

(216) 522-4207

1718 Peachtree Street, N.W.

Atlanta, Georgia 30309

(404) $881-4836$

55 East Monroe Street

Chicago, Illinois 60603

(312) 353-4423

1405 Curtis Street

Denver, Colorado 80202

(303) 837-2271
2001 Bryan Street

Dallas, Texas 75201

(214) 749-3056

11000 Wilshire Boulevard

Los Angeles, California 90024

(213) 824-7575

450 Golden Gate Avenue

San Francisco, California 94102

(415) 556-1270

915 Second Avenue

Seattle, Washington 98174

(206)442-4655

Central Office:

6th Street \& Penn. Ave., N.W.

Washington, D.C. 20580

(202) 523-3598

Other levels of assistance would concern jurisdictions that have octane testing programs and would be interested in cooperating with FTC in testing or in reporting discrepancies in octane rating.

Mr. Mills offers his assistance in answering any questions concerning the FTC rule on octane posting, possible Federal-State cooperation, possible future State octane posting regulations, or any other related activity. Such communications should be directed to James Mills, Attorney, Division of Energy and Product Information, Bureau of Consumer Protection, FTC, Washington, D.C. 20580, Telephone: 202-724-1491.

(Item 502-1 was adopted)

$502-2$

NET WEIGHT

\section{2-2-1 U.S. Department of Agriculture (USDA)}

In a report to the committees in joint session at the 1979 Interim Meetings, representatives of the USDA indicated that the Depart- 
ment was preparing a response to a report by the General Accounting Office (GAO) to Congress on their Department's 1977 proposed regulations. The GAO reported lack of sufficient data to substantiate the need for the regulation, and requested further study before USDA promulgated their regulation.

The Liaison Committee recommended that the GAO report be made available to all member jurisdictions. It further recommended that the conference chairman, on behalf of the conference, communicate NCWM's continued support of the USDA proposed regulations requiring net weight at time of sale.

As a part of our recommendations, it was suggested that a survey approach be used. The survey, to be directed to member jurisdictions, would serve two purposes. It would inform members of the current situation regarding the proposed regulations. It would also provide a medium for collecting the kind of data USDA says it needs to answer the GAO report.

All member jurisdictions are urged to analyze the GAO report and review their own position regarding the proposed USDA net weight regulations and respond appropriately to the NCWM survey or directly to USDA. Communications to USDA should be directed to Charles Handy of the USDA Economics, Statistics, and Cooperative Services. Contact with Congressional members is also deemed advisable.

After the preparation of the tentative report, the Committee became aware of two developments that should be brought to the attention of the Conference. The first is that USDA is making a survey of States to develop a response to the GAO report. The second item is the availability of a "Net Weight Issue Paper" authored by FDA and USDA personnel.

(Item 502-2-1 was adopted)

\section{2-2-2 Food and Drug Administration (FDA)}

A representative of FDA reported that the agency is reviewing its net weight labeling regulations. The review is in the internal draft stage and not yet available for public information and comment. The present draft proposal does include recognition of deviations attributable to moisture loss. Representatives of NCWM and the Office of Weights and Measures (OWM) have met with agency officials since the 63rd Annual Conference, expressing the Conference's desire for uniformity among Federal and State regulations on net weight, and emphasizing that regulations should provide for net weight at time of retail sale. 


\section{2-2-3 Federal Trade Commission (FTC)}

An FTC representative informed the committee that the agency presently perceived no problem and is taking no action. The Liaison Committee will continue to keep the conference informed on developments in this area.

(Item 502-2-3 was adopted)

\section{2-3 Federal Grain Inspection Service}

The Federal Grain Inspection Service (FGIS) is a relatively new Federal agency of the USDA, charged with overall responsibility for supervision of grain inspection and weighing. The U.S. Grain Standards Act of 1976 mandates certain courses of action by the Service, and specifies some areas of permissive activity.

The FGIS consists of four major divisions: Inspection, Weighing, Compliance, and Standardization. The responsibilities and programs of the Weighing Division impact directly on many weights and measures jurisdictions. The Specifications and Tolerances Committee of the NCWM is working with the Weighing Division with respect to the Division's development of standards for grain weighing scales.

Grain marketing is a complex activity. The exchange functions are mostly carried out in the private sector. The public sector becomes involved in supervising, monitoring or performing certain functions. A number of State agencies are involved in such activities as inspection of grain, testing of scales, certification of testing standards, or providing other services. Agencies other than the State or local weights and measures offices are often involved within any one State or local area. Concerted efforts to achieve and maintain interagency cooperation are needed.

The committee met with George Lipscomb, Director of the Weighing Division, Dick Pforr, Chief of the Scale Testing Branch, and Ben Banks, Industrial Specialist of the Scale Testing Branch, of the Federal Grain Inspection Service (FGIS).

The FGIS representative indicated that they have essentially adopted NBS Handbook 44 with the exception of tolerances and minimum division size. In addition, they have expanded in some areas such as minimum test requirements where the problem has not been addressed. They also stated that NBS Handbook 112, Examination Procedure Outlines for Commercial Weighing and Measuring Devices, and NBS Handbook 94, the Examination of Weighing Equipment, were the foundation for the development of their procedures.

The Weighing Division would like very much to cooperate with the NCWM and its active members in areas of common concern and would welcome the opportunity to meet individually with those States or 
jurisdictions that are concerned or have a problem with the FGIS program. Such meetings have already been held with six States. They apologize for the confusion caused by letters sent to weights and measures jurisdictions. It is their feeling that they do not truly reflect the objectives of the FGIS program. The committee appreciates these assurances and will strive to foster cooperation on the part of the conference. Member jurisdictions are urged to maintain open lines of communication with FGIS and its various divisions. It would be most unfortunate if jurisdictional disputes were to hamper development of uniformity to grain weighing and handling.

The Weighing Division (FGIS) is making an effort to attend and participate in all meetings of the NCWM as well as meetings of the regional weights and measures associations and the International Organization for Legal Metrology (OIML). They also indicated that the FGIS program will be a valuable source of weights and measures data on a national basis and are willing to share this information with all concerned.

(Item 502-3 was adopted)

\section{2-4 Sphygmomanometers (Blood Pressure Measuring Devices)}

The committee continues to monitor the situation with regard to sphygmomanometers. Increasing availability of these devices as consumer products is of concern to some weights and measures officials. Of special concern are the automatic, coin-operated sphygmomanometers found in public places.

As of now there is no simple, reliable field test method for determining the accuracy of automatic sphygmomanometers. The National Bureau of Standards Product Performance Engineering Division is preparing a proposal for funding by the National Institutes of Health to develop physical reference standards and testing methods.

The Association for Advancement of Medical Instrumentation is developing standards for sphygmomanometers. These standards for construction, accuracy, use, and testing will cover consumer and medical applications, both nonautomatic and automatic.

The committee will continue to monitor this area and be prepared to recommend Conference action when warranted by new developments.

(Item 502-4 was adopted)

\section{2-5 National Highway Traffic Safety Administration}

The National Highway Traffic Safety Administration (NHTSA) has developed a Federal Safety Standard, Motor Vehicle Safety Standard 
No. 127, Speedometers and Odometers. The committee met with Kevin Cavey (NHTSA) concerning the impact of this standard on NBS Handbook $44(\mathrm{H}-44)$, Code for Odometers. There are differences in device and test specifications that should be resolved. The committee expressed concern that no effort was made by NHTSA to work cooperatively in developing uniform device and test specifications. Mr. Cavey stated that they were unaware of the $\mathrm{H}-44$ code on odometers. He suggested that a memo to the NHTSA administrator stating the committee's concerns would be the most appropriate approach to follow. The following memo was sent to the NHTSA administrator.

\section{Memorandum for Joan Claybrook, Administrator}

National Highway Traffic Safety Administration

From: Charles Greene, Chairman, Committee on Liaison, NCWM Subject: Motor Vehicle Safety Standard No. 127, Speedometers and Odometers

Thank you for the assistance provided to our organization by $\mathrm{Mr}$. Kevin Cavey who answered many questions at a meeting with the Liaison Committee of the National Conference on Weights and Measures.

Since one objective of our Conference is to assure uniformity, we are gratified to learn that your Speedometer and Odometer Standard $\$ 571.27$, Standard No. 127, is consistent with NBS Handbook 44, Specifications, Tolerances, and Other Technical Requirements for Commercial Weighing and Measuring Devices, Code for Odometers, in most areas except as follows:

S4.2.2 states in the first sentence "Each odometer shall be capable of indicating distance traveled either, at the manufacturer's option, (1) from 0 to not less than 99,999 miles in 1-mile units, or (2) from 0 to not less than 99,999 kilometers in 1-kilometer units, or (3) both."

It is the use of 1-mile or 1-kilometer units as the minimum unit of measure that is not in agreement with NBS $\mathrm{H}-44$ standards. This lack of uniformity could be eliminated by amending $\mathrm{S} 4.2 .2$ to read as follows:

"Each odometer shall be capable of indicating distance traveled either, at the manufacturer's option, (1) from 0 to not less than 99,999 in 1/10 mile units, or (2) from 0 to not less than 99,999 kilometers in $1 / 10$ kilometer units, or both."

It is our opinion that the $1 / 10$ mile or $1 / 10$ kilometer indication on an odometer is essential to permit calibration of odometer distance measurements. The failure to require $1 / 10$ mile or $1 / 10$ kilometer indications on odometers will increase by a magnitude of 10 any distance which must be traveled in order to perform calibration. This could result in enormous waste of energy, time, and money. 
The test procedures specified in the Code for Odometers $(\mathrm{H}-44)$ are a result of many years of weights and measures experience in automotive vehicle odometer proving. They have been used successfully by many State and local weights and measures officials in the examination and test of rental vehicle odometers.

We are greatly interested in promoting uniformity in areas impacting on weights and measures activities and would like to cooperate with your agency whenever possible. We would be happy to share our information and experience in subject areas covered by this standard or any future standard concerned with commercial measuring devices.

(Item 502-5 was adopted)

The committee met jointly with the L \& R committee to develop the following consensus and resolution concerning the spelling of meter and liter.

The NCWM favors the adoption and implementation of the International System of Units of weights and measures (metric conversion) in the United States in accordance with a national policy.

Furthermore, the Conference is convinced that the conversion to the International System will be facilitated and encouraged by the standardization of the vocabulary used.

For this reason the Conference has in past years formally urged a national policy of using the "re" rather than "er" spelling in words such as "metre" and "litre." The "re" spelling is used by most and possibly all English speaking weights and measures communities outside the United States.

In addition to the advantage of international uniformity, the "re" spelling of "metre" serves to differentiate the term from the phonetically identical word ("meter") which describes a common measuring device.

However, after due deliberation the United States Department of Commerce and the United States Metric Board have officially adopted the "er" spellings of "meter" and "liter," thereby creating a conflict with the policy of the Conference.

Though the Conference respectfully disagrees with the decisions of the Department and the Board, the Conference remains committed to uniformity and believes that uniformity within the United States is even more important than uniformity in relation to the vocabulary used by other countries. 
For the stated reason the Liaison committee and the $\mathrm{L} \& \mathrm{R}$ committee jointly recommend that the following resolution be presented to the next annual Conference for adoption.

"Whereas, the National Conference on Weights and Measures has preferred the use of the "re" spelling of "metre" and "litre" to serve the objectives of international uniformity and to differentiate between the unit of measure and the metering device; and

whereas, the United States Department of Commerce and the United States Metric Board have officially adopted the "er" spelling of "meter" and "liter," thereby creating a conflict with the policy of the National Conference; and

whereas, the National Conference believes that progress in the adoption of the International System of Units will be impeded if such conflicts are not held to a minimum

it is therefore resolved, that the National Conference on Weights and Measures will hereafter use the "er" spelling rather than the "re" spelling of International Units such as "meter" and "liter" so long as the objective of national uniformity is served; provided, however, that for purposes of the application of model laws and regulations of the National Conference, the use of the "re" spelling in trade shall continue to be permissible."

(After considerable discussion on this item, a motion was made to amend the item as follows:)

The NCWM favors the adoption and implementation of the International System of Units of weights and measures (metric conversion) in the United States in accordance with a national policy.

Furthermore, the Conference is convinced that the conversion to the International System will be facilitated and encouraged by the standardization of the vocabulary used.

For this reason the Conference has in past years formally urged a national policy of using the "re" rather than "er" spelling in words such as "metre" and "litre." The "re" spelling is used by most and possibly all English speaking weights and measures communities outside the United States.

In addition to the advantage of international uniformity, the "re" spelling of "metre" serves to differentiate the term from the phonetically identical word ("meter") which describes a common measuring device. 
The Conference takes note of the fact that the United States Department of Commerce and the United States Metric Board have officially adopted the "er" spellings of "meter" and "liter," thereby creating a conflict with the policy of the Conference.

The Conference respectfully disagrees with the decisions of the Department and the Board. It remains committed to uniformity and believes that in English speaking countries uniform spelling, like uniform usage, is important if we are to achieve the ultimate goal of a uniform international system of measurement.

For the stated reasons, the Conference recommends that the following resolution be adopted:

"Whereas, the National Conference on Weights and Measures has preferred the use of the "re" spelling of "metre" and "litre" to serve the objectives of international uniformity and to differentiate between the unit of measure and the metering device; and

whereas, the United States Department of Commerce and the United States Metric Board have officially adopted the "er" spelling of "meter" and "liter", thereby creating a conflict with the policy of the National Conference; and

whereas, the National Conference believes that progress in the adoption of the International System of Units will be impeded if such conflicts are not held to a minimum

now, therefore, be it resolved that the National Conference on Weights and Measures respectfully request that the Department of Commerce and the United States Metric Board reconsider their adoption of the "er" spelling, in the interest of uniformity in this country and with other English speaking countries; and

be it further resolved that the Department of Commerce be petitioned to use the "re" spelling of the word metre (and litre) in all printing of documents published on behalf of the National Conference on Weights and Measures."

(Item 503 was adopted as amended)

504 TASK FORCE ON GRAIN MOISTURE MEASUREMENT ASSURANCE

Pursuant to a recommendation of the committee adopted by the 63rd NCWM, a Grain Moisture Measurement Assurance Task Force 
(GMMATF) was formed. The initial meeting took place during the Southern Weights and Measures Conference in Little Rock, Arkansas. The second meeting was convened during the Interim Committee Meetings in January.

Regional Coordinators have been named: Sydney ColbRook, Illinois, representing the Northeastern Weights and Measures Association (NEWMA); JIM O'CoNNOR, Iowa, representing the Northwest Weights and Measures Association (NWMA); Charles Greene, New Mexico, representing the Western Weights and Measures Association (WWMA); and SAM HindSMAN, Arkansas, representing the Southern Weights and Measures Association (SWMA). Mr. Hindsman was elected national coordinator by the group during the interim meetings.

The Task Force has recommended to the $\mathrm{L} \& \mathrm{R}$ Committee a model State regulation on grain moisture meters. (See the $L \& \mathrm{R}$ report for details.)

Input regarding the above proposal, or any other matter which ought to concern the Task Force, is earnestly sought from member jurisdictions, other State and Federal agencies, users and manufacturers of moisture meters. Anyone who has an interest in this vitally important area is encouraged to participate in Task Force meetings.

A second meeting was held during the 64th NCWM at Portland, Oregon, July 24, 1979.

The Task Force set the following priorities for action:

- the evaluation of the reference standard for moisture content, especially for corn and soybeans;

- the establishment of laboratory and field standard procedures to be used to test grain moisture meters;

- the evaluation of the capabilities of the grain moisture meters in order to set reasonable tolerances at the national level.

The task Force will:

- issue a letter to the appropriate Federal agencies requesting immediate evaluation of the reference standard for moisture especially for corn and soybeans;

- conduct workshops to demonstrate and discuss the lab and field testing procedures and data collection required in order to evaluate the capabilities of the grain moisture meters. All interested parties will be invited to attend and participate. A Task Force 
meeting is scheduled in Washington, D.C. during the week of January 14-18, 1980.

(Item 504 was adopted)

505

OTHER ITEMS

\section{5-1 Ice-glazed Seafoods}

The agreement of FDA and the National Marine Fisheries Service on test procedures is a prerequisite before further action is contemplated.

(Item 505-1 was adopted)

\section{5-2 Political Action}

The Conference continues to meet challenges on which positions should be taken on behalf of its members. For example, the entire area of Federal regulations on net weight labeling is of broad concern. The committee is proposing that a mechanism or program be initiated by which a systematic and thorough approach to developing such positions can be undertaken. A proposal will be circulated when available.

(Item 505-2 was adopted)

\section{5-3 U.S. Metric Board}

Conference members have urged this Committee to initiate action whereby the Conference would approve the filing of a petition on behalf of the Conference requesting the United States Metric Board to include in its first report to Congress a recommendation that legislation be introduced to amend federal laws to permit labeling in metric units only, in accordance with an orderly and voluntary conversion.

The Committee believes that such a petition would be consistent with previously adopted policies of the Conference and therefore offers the following resolution for adoption:

\section{Resolution to the U.S. Metric Board on Amendment of Federal Laws}

Whereas, existing federal statutes such as the Fair Packaging and Labeling Act have been cited as legal barriers to the voluntary use of labels declaring quantity of contents in metric units only; and 
whereas, the National Conference on Weights and Measures does support an orderly and voluntary conversion to the use of the metric system in the United States; and

whereas, the Metric Conversion Act of 1975 created the United States Metric Board for the purpose of pursuing and implementing such a conversion; and

whereas, it is the responsibility of the Metric Board to make recommendations to the Congress and the President of the United States to initiate legislation which may be appropriate to facilitate conversion to the metric system:

Now therefore, be it resolved that the National Conference on Weights and Measures does hereby petition the United States Metric Board to include in their first report to Congress and to the President a recommendation that all federal statutes governing the expression of quantity declarations in connection with the distribution and sale of articles in commerce, such as the Fair Packaging and Labeling Act, be amended to permit such declarations in metric units only pursuant to an orderly and voluntary conversion.

(Item 505-3 was adopted)

\author{
C.H. Greene, Chairman, New Mexico \\ C.E. FORESTER, Texas \\ T.A. Hocin, Chicago, Illinois \\ M.S. Thompson, Chadwell, Kayser, Ruggles, McGee, \& \\ Hastings, Ltd. \\ J. WILSON, Federal-State Report, Inc. \\ S. HASKo, Staff Assistant, NBS \\ H.F. Wollin, Executive Secretary, NCWM
}

\title{
Committee on Liaison
}

(On motion of the committee chairman, the report of the Committee on Liaison voting key items 500 through 505-3 was adopted in its entirety and as amended by the Conference. The results of the voting in the House of State Representatives and the House of Delegates under the Conference voting system are totalized in the table that follows. The Conference also authorized the executive secretary to make any appropriate editorial changes in the language adopted by the Conference, provided that the requirements thus adopted are strictly adhered to.) 
Voting RESULTS-Committee on Liaison

\begin{tabular}{|l|c|c|c|c}
\hline \multirow{2}{*}{ Voting Key } & \multicolumn{2}{|c|}{$\begin{array}{c}\text { House of State } \\
\text { Representatives }\end{array}$} & \multicolumn{2}{c}{ House of Delegates } \\
\cline { 2 - 5 } & Yes & No & Yes & No \\
\hline 500 & 38 & 0 & 63 & 0 \\
$501-1$ \\
$501-2$ \\
$502-1$ \\
$502-2-1$ \\
$502-2-2$ \\
$502-2-3$
\end{tabular}

1-amendment. 


\section{REPORTS OF THE ANNUAL COMMITTEES}

\section{REPORT OF THE EXECUTIVE COMMITTEE}

Presented by Kendrick J. SimILA, Conference Chairman, Administrator, Weights and Measures Division, Department of

Agriculture, State of Oregon

(Thursday, July 26, 1979)

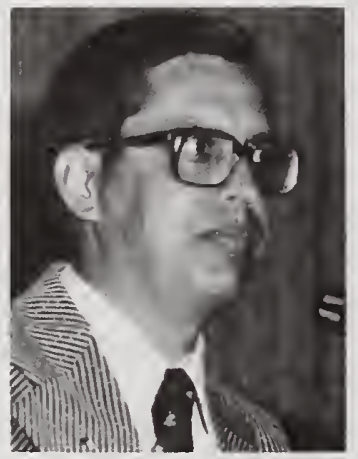

VOTING KEY

600

\section{INTRODUCTION}

The Executive Committee submits its final report for consideration by the 64 th National Conference on Weights and Measures.

601 NATIONAL MEASUREMENT POLICY AND COORDINATION COMMITTEE ITEMS

The following four items were referred from the Committee on National Measurement Policy and Coordination (P \& C) as detailed in the tentative report of the P \& C Committee.

The P \& C Committee included these items on the agenda for the interim meetings so that consideration of the items at that time by the Committee, and in joint session with members of other standing committees who attend the interim meetings would allow for the development and reporting on such items in the Committee's tentative report and publication in the Announcement Booklet.

\section{1-1 REVISION OF VOTING SYSTEM REQUIREMENTS TO} DEBATE AND ADOPT AMENDMENTS TO COMMITTEE FINAL REPORTS

The P \& C Committee reviewed and discussed proposals from a regional association to modify the Conference voting system requirements with respect to debating and adopting amendments to com miteee final reports. The proposals were to reduce the $2 / 3$ majority? requirement of those voting in each case down to a simple majority.

A number of points were brought out in the discussion which supported each side of this issue. Principal arguments for the proposals were based on concerns that, (a) the will of a majority of the states and delegates to debate and adopt an amendment can now be thwarted 
by the $2 / 3$ requirement, and, (b) the $2 / 3$ requirement results in extraordinary power residing with a committee to change the sense of an item after the open meeting, since such a change is then protected by a $2 / 3$ vote to undo it.

Principal arguments against the proposals were based on concerns that, (a) the current $2 / 3$ requirements are still so new, having been used only at the last conference, that it is too soon to evaluate their true validity, and, (b) the $2 / 3$ requirements are appropriate and necessary to prevent unwise and spur-of-the moment amendments from being adopted when emotions run high.

The Committee unanimously supported the proposed change for a simple majority of the voting delegates to approve debating a proposed amendment to a final committee report. In a split vote, the Committee also favored a change from the $2 / 3$ requirement for passage of amendments to the present voting requirements of each House on motions. The Committee recommends the adoption of these proposals for implementation next year.

(During the voting on this item an amendment was made to retain the $2 / 3$ requirement for passage of amendments. The amendment passed and Item 601-1 was adopted as amended)

\section{1-2 RECOGNITION OF WEIGHTS AND MEASURES} JURISDICTIONS UNDER THE AUSPICES OF INDIAN TRIBES

The unique situation of lack of specific guidance in Conference voting procedures for U.S. Indian Tribes, such as the Navajo Nation, was brought before the P \& C Committee for discussion. It was mentioned that in the case of the Navajo Nation, (a) they do operate their own weights and measures programs, (b) they are separate from and not governed by the weights and measures laws of the three States within which their reservation lies, and (c) they are not a Federal agency (the Bureau of Indian Affairs does not run the reservation). Moreover, a tribal weights and measures representative has been registering at and attending the National Conference. The Committee, after extended discussion of what the unique status of U.S. Indian Tribes means and implies, supported by a split vote a proposed change to the Conference Voting System that would specifically recognize representatives of U.S. Indian Tribes that have weights and measures responsibilities as having voting privileges within the House of Delegates. The Committee recommends the adoption of this proposal for implementation next year.

(Item 601-2 was adopted)

601-3 APPOINTMENTS TO STANDING COMMITTEES

The P \& C Committee thoroughly discussed a proposal from one of the regional associations that the four regional associations be given 
responsibility for appointing or selecting members to serve on the Conference Standing Committees. Arguments in favor of this role for the regional associations centered on the need for each region to, (a) be represented on each Committee, (b) democratically select its own best representative, and (c) assume a more significant role in NCWM matters.

Arguments in opposition to the proposal pointed out that, (a) on the whole, the Committee assignments have pretty well been spread out by OWM to cover each region already, (b) some very good Committee members, who are unable because of finances to attend the regional meetings, would be left out of the selection process, and (c) in the case of the Liaison Committee with only three weights and measures officials, it is not possible for all regions to be represented simultaneously.

To close discussion on the issue, a motion was made to recommend that the current NBS-OWM based Standing Committee appointment system be retained. The motion was adopted. It was also the expressed feeling of the Committee that the Bureau's track record in regard to balancing out Committee assignments was excellent. Moreover, there is nothing to preclude any regional association which wishes to play a more active role in the selection process from suggesting or recommending a slate of candidates it would like to see serving on Committees. OWM would welcome such input.

(Item 601-3 was adopted)

$601-4$ FUTURE CONFERENCE PLANS

The Committee takes this opportunity to remind the Conference membership of the schedule and plan for the 65th NCWM that will be held at the Shoreham-Americana Hotel in Washington, D. C. on June 21-27, 1980. Delegates who attend the Conference next year will have the unique privilege of meeting with weights and measures officials from the forty-three member nations of the International Organization of Legal Metrology (OIML) which has scheduled its International Conference in Washington, D. C. on June 16-20, 1980, the week prior to the NCWM. We anticipate that officials from OIML will attend and participate in the NCWM sessions and members of NCWM will likewise be involved in the OIML Conference. This may well be a once-in-a-lifetime opportunity as the OIML holds its conference plenary meeting only every four years and the United States is not likely to host the Conference for many years to come. An update on plans and arrangements for the 1980 OIML/NCWM Conferences will be provided this summer at the 64th NCWM in Portland.

Because of the earlier meeting of the 65th NCWM in June of 1980 , the Interim Meetings of the Conference Standing Committees have 
been moved up to January $14-18,1980$. All individuals and organizations who plan to attend or provide input to these committees are urged to make their reservations and submit proposals or information by no later than December 1, 1979.

The Committee heard proposals to hold the 66th NCWM in St. Louis, Missouri on July 12-17, 1981, and the 1982 Conference in Atlanta, Georgia. Both of these sites met with the approval of the Committee and others who attended the interim committee meetings at NBS.It is recommended that further information be gathered and plans be developed to hold the NCWM in these cities as proposed.

The Committee reports that rates have been established for the 65th NCWM and the OIML meetings in Washington, D.C., June, 1980 , at $\$ 40$-single; $\$ 45$-double.

Because of the size of the NCWM, arrangements with hotels and other organizations must be made very far in advance. The Committee recommends that the 1981 and 1982 locations be made firm so that negotiations with hotels and other groups may be begun for these conferences. The Committee also recommends that the Executive Secretary prepare for presentation to the next conference plans for the NCWM five years in advance.

(Item 601-4 was adopted)

\section{REPORT OF THE ASSOCIATE MEMBERSHIP COMMITTEE}

(Eric Allen: Chairman-The Measuregraph Co.)

The Associate Membership Committee held its annual meeting July 22,1979 , at which time items which were to be presented to the open meeting of the Associate Membership were discussed.

Since there has always been some confusion as to who should attend the meetings of the Associate Membership Committee it has been determined that there should be an open meeting of the Associate Membership, in addition to the Committee meeting.

The committee feels that the conference still does not make full use of the expertise which is represented by the Associate Membership and pledges its cooperation to make this expertise available.

The committee expresses its thanks to all who contributed generously in support of the Associate Membership sponsored Salmon Bake. We hope that all those who attend will enjoy the outing in the mountain air.

(Item 602 was adopted)

603 OLD BUSINESS

There is no old business on which to report. 


\section{4-1 Suspension of the Voting Rules}

Mr. Griffith, NCWM Parliamentarian, reports that a suspension of the voting rules may be voted upon by the NCWM in order to save time in the adoption of certain non-controversial annual committee reports (all such committees except Resolutions.) The text of his report follows:

\section{Parliamentary Procedure for Orderly Conduct of Business}

As in any deliberative assembly, there are a nurnber of minor or routine administrative matters, as well as non-controversial issues, that must be submitted to the main assembly in the forms of motions for subsequent voting and eventual adoption or rejection. In the interest of dealing with such matters expediently and when it is desired that the assembly take up a question or do something that would be in violation of a rule that applies, it can be proposed to Suspend the Rules to permit accomplishment of a desired purpose.

A motion to Suspend the Rules may be made at any time when no question is pending, or while a question is pending provided it is for a purpose connected with that question. The reason for asking for suspension must be stated. Meeting these criteria, a motion to Suspend the Rules is classified as an Incidental motion.

Incidental motions take precedence over all other motions according to the following principle: An incidental motion is in order only when it is legitimately incidental to another pending motion, or when it is legitimately incidental in some other way to business at hand; it then takes precedence over any other motions that are pending.

Rules that can be suspended are: Priority of Business, Procedure of Business and Admission to Meetings.

The Presiding Officer or Chairman prior to a grouping of several minor routine matters or issues or in connection with a main motion on a specific issue may entertain a motion to Suspend the Rules or any voting member may make a motion to Suspend the Rules.

Once the motion to Suspend the Rules has been made, it:

1. Requires a second.

2. Is Undebatable.

3. Is Unamendable.

4. Requires $2 / 3$ vote.

5. Cannot be reconsidered. 
If the motion to Suspend is passed by the required majority then a Main Motion on the matter or group of matters is in order to properly dispose of the issue or issues.

If the motion to Suspend is defeated then there is no choice but to handle each individual matter or issue by proper motion, second, debate and vote.

\section{(Item 604-1 was adopted)}

\section{4-2 Assistant Chaplain}

In the event either the Conference Chaplain or the Conference Treasurer may not be able to attend the annual conference, there would be no one to serve in either of these capacities. Therefore, the committee recommends the appointment of an Assistant Chaplain. Reverend Francis Daniels, Indiana, is recommended as Assistant Chaplain. The NCWM Organization and Procedure brochure will be modified to reflect this recommendation.

(Item 604-2 was adopted)

\section{4-3 Assistant Treasurer}

The Committee also recommends the appointment of an Assistant Treasurer. The selection of an Assistant Treasurer will be referred to the incoming Executive Committee. The NCWM Organization and Procedure brochure will be modified to reflect this recommendation.

(Item 604-3 was adopted)

K. J. Simila, Chairman

E. R. LeEman, ViceChairman

N. M Ross, Vice Chairman

J. V. Pugh, Vice Chairman

E. H. StadolnIK, Vice Chairman

A. H. AKEY, Treasurer

J. H. LEwIS, Chaplain

H. F. Wollin, Exec. Sec.
J. T. Bennett, Connecticut

A. Helgeson, North Dakota

F. W. DANIELS, Wade County, Indiana

G. M. KenNEDy, Maine

J. C. MAYS, Dade County, Florida

W. R. Mossberg, Los Angeles County, California

B. W. Sullivan, JR., Arkansas

A. B. Moody, JR., Richmond, Virginia

J. L. O’NEILL, Kansas

S. F. VALtrI, Philadelphia, Pennsylvania

Executive Committee 
(On motion of the committee chairman, the report of the Executive Committee voting key items 600 through 604-3 was adopted in its entirety by the Conference. The results of the voting in the House of State Representatives and the House of Delegates under the Conference voting system are totalized in the table that follows. The Conference also authorized the executive secretary to make any appropriate editorial changes in the language adopted by the Conference, provided that the requirements thus adopted are strictly adhered to.)

Voting RESULTs-Executive Committee

\begin{tabular}{l|c|c|c|c}
\hline \multirow{2}{*}{ Voting Key } & \multicolumn{2}{|c|}{$\begin{array}{c}\text { House of State } \\
\text { Representatives }\end{array}$} & \multicolumn{2}{c}{ House of Delegtes } \\
\cline { 2 - 5 } & Yes & No & Yes & No \\
\hline 600 & 43 & 0 & 78 & 0 \\
$601-1 A$ & 39 & 4 & 66 & 6 \\
$601-1$ & 43 & 0 & 75 & 2 \\
$601-2$ \\
$601-3$ \\
$601-4$ \\
602
\end{tabular}

$A=$ Amendment. 


\section{REPORT OF THE RESOLUTIONS COMMITTEE}

Presented by Dr. E. C. HefFron, Chairman,Chief, Food Inspection

Division, Department of Agriculture, State of Michigan

Thursday, July 26, 1979

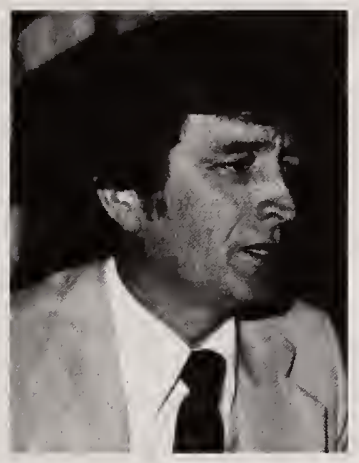

\section{VOTING KEY}

700

The following resolutions are presented for consideration of the Conference:

\section{RESOLUTION ON THE CONFERENCE POLICY CONCERNING THE METRIC CONVERSION OF RETAIL MOTOR-FUEL DEVICES (GAS PUMPS)}

Whereas, the 94th Congress of the United States passed Public Law 94-168 on December 23, 1975, that is cited as the "Metric Conversion Act of 1975" and which declared a national policy of planning and coordinating the increasing use of the metric system in the United States, and established a United States Metric Board to coordinate the voluntary conversion to the metric system, and

Whereas, the National Conference on Weights and Measures, an organization composed of State and local weights and measures regulatory officers, and other officials of Federal, State, and local governments, and representatives of manufacturers, industry, business, and consumer organizations has taken a positive stand in support of metric conversion in the United States as called for in the Act, and

Whereas, the National Conference on Weights and Measures has provided the basis for national uniformity of weights and measures laws and regulations and has been a major factor in serving the interests of industry and consumers who need reliable standards of measurement in the marketplace, and

Whereas, the National Conference on Weights and Measures is interested in providing the necessary leadership and guidance to the States and all others who seek a solution to the problems of design and price computation of retail motor-fuel devices as prices rise to a level (over $\$ 1.00$ per gallon in most cases) that exceed the computing capabilities of devices now in service, and

Whereas, the U.S. Metric Board conducted hearings on May 2-3, 1979 , to determine the feasibility and practicality of converting retail motor-fuel devices to compute prices on the basis of metric measurement and on June 21, 1979, issued a declaration which stated that 
this is an opportune time for the development of a planned and coordinated voluntary program of dispensing gasoline by the liter, and noted that without taking this action metric usage is likely to proceed in a haphazard fashion, leading to public confusion, disparate end results and the negation of the positive cost advantages that a nationally planned and coordinated program offers:

Therefore, be it Resolved, that the 64th National Conference on Weights and Measures as assembled during its annual meeting in Portland, Oregon, on July 22-27, 1979, recommends the encouragement and promotion of the Conference policy concerning the metric conversion of retail motor fuel devices.

(Item 701 was adopted.)

\section{RESOLUTION ON THE CONFERENCE POLICY CONCERNING THE SPELLING OF THE WORDS METER AND LITER}

Whereas, the National Conference on Weights and Measures has provided for uniformity and progress in the use of the metric system and

Whereas, the National Conference on Weights and Measures has recognized the necessity to act as a body in a uniform manner:

Therefore, be it Resolved that the 64th National Conference on Weights and Measures act to assimilate and promote the policy of this Conference concerning the spelling of the words meter and liter.

(Following considerable discussion regarding voting procedures to amend this item, Item 702 was adopted.)

703

\section{SPECIAL THANKS}

The Resolutions Committee wishes to express the appreciation of the 64th National Conference on Weights and Measures to each and every one who contributed their time and talents towards the arrangements for, the conduct of, and participation in this National Conference. A special vote of thanks goes to:

1. All speakers of the Conference for their expertise, information, and contributions to the program.

2. All officers and appointed officials of the 64th National Conference on Weights and Measures for their assistance and service towards a very successful Conference.

3. All committee members for their time and efforts throughout the past year to prepare and present their reports. 
4. The governing officials of the State and local jurisdictions for their interest and support in weights and measures administration in the United States.

5. Representatives of business and industry for their cooperation, assistance, and hospitality.

6. Consumer representatives, members of the public media, and other participants who have shown their interest and support for the National Conference on Weights and Measures.

7. The Conference hosts: State of Oregon, City of Portland, and Ken Simila and his staff of the Oregon Department of Agriculture for their hard work and many hours devoted to insuring a successful Conference and extremely enjoyable visit to their beautiful city.

8. The Portland Chamber of Commerce and Convention Bureau for their help at the Registration Desk and assistance on many Conference details.

9. The staff of the Red Lion Motor Inn for their fine facilities, assistance, and courtesies which contributed to the enjoyment and comfort of the delegates.

10. To the National Bureau of Standards and the Office of Weights and Measures for planning and conducting the work and program of the National Conference on Weights and Measures.

\author{
E.C. HefFron, Chairman, Michigan \\ P.M. Fullinwider, Arizona \\ S.A. COLBROOK, Illinois \\ M.A. Maldonado Garcia, Puerto Rico \\ J.L. SwANSON, Alaska \\ P.M. REEvES, Tennessee \\ T.W. ScotT, North Carolina \\ H.F. Wollin, Executive Secretary, NCWM
}

Resolutions Committee

(On motion of the committee chairman, the report of the Resolutions Committee, voting key items 700 through 703 , was adopted in its entirety by the Conference. The results of the voting in the House of State Representatives and the House of Delegates under the Conference voting system are totalized in the table that follows. The Conference also authorized the executive secretary to make any appropriate editorial changes in the language adopted by the Conference, provided that the requirements thus adopted are strictly adhered to.) 


\begin{tabular}{c|c|c|c|c}
\hline \multirow{2}{*}{ Voting Key } & \multicolumn{2}{|c|}{$\begin{array}{c}\text { House of State } \\
\text { Representatives }\end{array}$} & \multicolumn{2}{c}{ House of Delegates } \\
\cline { 2 - 5 } & Yes & No & Yes & No \\
\hline 700 & 34 & 0 & 43 & 0 \\
701 & 31 & 0 & 42 & 0 \\
702 & 30 & 1 & 48 & 0 \\
703 & 33 & 0 & 42 & 0 \\
\hline
\end{tabular}


3. Robert J. Cord, Prince Georges County, Maryland

4. Ezio F. Delfino, California

5. Patricia M. Fullinwider, Arizona

6. Maria A. Maldonado Garcia, Puerto Rico

7. Robert M. Reeves, Tennessee

8. Edward P. Skluzacek, Minnesota

9. Daniel R. Smith, Santa Clara County, California

10. Fred A. Thomas, Pennsylvania

(There being no further nominations from the floor, the chairman declared nominations closed and requested the Executive Secretary to cast a unanimous ballot for all nominees).
J.F. LyLES, Chairman, Virginia
R.L. ThompSon, Maryland
S.D. ANDREws, Florida
J.H. LEWIS, Washington
G.L. JoHnSON, Kentucky
K.R. ADCOCK, Ohio
K.R. LEEMAN, Wyoming

\section{Nominations Committee}

(On motion of the committee chairman, the report of the Nominations Committee, voting key item 800 , was adopted in its entirety by the Conference. The results of the voting in the House of Representatives and the House of Delegates under the Conference voting system are totalized in the table that follows.)

Voting Results-Nominations Committee

\begin{tabular}{c|c|c|c|c}
\hline \hline \multirow{2}{*}{ Voting Key } & \multicolumn{2}{|c|}{$\begin{array}{c}\text { House of State } \\
\text { Representatives }\end{array}$} & \multicolumn{2}{c}{ House of Delegates } \\
\cline { 2 - 5 } & Yes & No & Yes & No \\
\hline \multirow{2}{*}{800} & 44 & 0 & 79 & 2 \\
\hline
\end{tabular}




\section{LIST OF FORMER NCWM CHAIRMEN}

National

Chairman

Conference

43rd (1958) J. P.McBride, Director of Standards, Massachusetts

44th (1959) C. M. Fuller, County Sealer of W \& M, Los Angeles, California

45th (1960) H. E. Crawford, Inspector of W \& M, Jacksonville, Florida

46th (1961) R. E. Meek, Director, Division of W \& M, Board of Health, Indiana

47th (1962) Robert Williams, County Sealer of W \& M, Nassau County, New York

48th (1963) C. H. Stender, Deputy Commissioner, Department of Agriculture, South Carolina

49th (1964) D. M. Turnbull, Director, Division of Licenses and Standards, Seattle, Washington

50th (1965) V. D. Campbell, Chief, Division of W \& M, Department of Agriculture, Ohio

51st (1966) J.F. True, State Sealer, Division of W \& M, State Board of Agriculture, Kansas

52nd (1967) J. E. Bowen, City Sealer of W \& M, Newton, Massachusetts

53rd (1968) C. C. Morgan, City Sealer of W \& M, Gary, Indiana

54th (1969) S. H. Christie, Deputy State Superintendent, Division of W \& W, Department of Law and Public Safety, New Jersey

55th (1970) R. W. Searles, Sealer of W \& M, Medina County, Ohio 56th (1971) M. Jennings, Director of Marketing, Department of Agriculture, Tennessee

57th (1972) E. H. Black, Director of W \& M, Ventura County, California

58th (1973) George L.Johnson, Director, Division of W \& M, Department of Agriculture, Kentucky

59th (1974) John H. Lewis, Chief, W \& M Section, Department of Agriculture, Washington

60th (1975) Sydney D. Andrews, Director, Division of Standards, Department of Agriculture and Consumer Services, Florida

61st (1976) Richard L. Thompson, Chief, W \& M Section, Division of Inspection and Regulation, Department of Agriculture, Maryland

62nd (1977) Earl Prideaux, Chief, W \& M Section, Division of Inspection and Consumer Services, Department of Agriculture, Colorado 
63rd (1978) James F. Lyles, Supervisor, W \& M Section, Division of Product and Industry Regulation, Department of Agriculture and Commerce, Virginia

64th (1979) Kendrick J. Simila, Administrator, W \& M Division, Department of Agriculture, Oregon 
Presented by George S. Franks, Superintendent, Weights and Measures and Consumer Protection, Cumberland County, New Jersey

(Thursday, July 26, 1979)

\section{VOTING KEY}

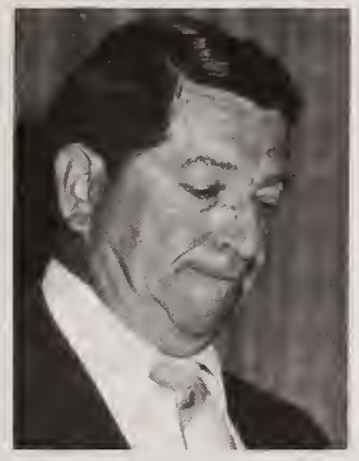

900

\section{INTRODUCTION}

The Auditing Committee met on Wednesday morning, July 25 , for the purpose of reviewing the financiai records of the Conference Treasurer, Mr. James H. Akey. The Committee finds these records to be in accordance with the Conference procedure and correct.

The Committee recommends that in the future the small transmittal checking account balance in the Union Trust Bank at NBS be included in the Treasurer's Annual Report. Also, we suggest that steps be taken for the Treasurer to be bonded both for his and the Conference's protection.

\section{GeORge S. Franks, Chairman, Cumberland County, New Jersey \\ Fred Gerk, New Mexico \\ Eugene KeELEY, Delaware}

\section{Auditing Committee}

(On motion of the committee chairman, the report of the Auditing Committee, voting key item 900 , was adopted by the Conference. The results of the voting in the House of Representatives and the House of Delegates under the new Conference voting system are totalized in the table that follows.)

Voting RESUlTs-Auditing Committee

\begin{tabular}{c|c|c|c|c}
\hline \multirow{2}{*}{ Voting Key } & \multicolumn{2}{|c|}{$\begin{array}{c}\text { House of State } \\
\text { Representatives }\end{array}$} & \multicolumn{2}{c}{ House of Delegates } \\
\cline { 2 - 5 } & Yes & No & Yes & No \\
\hline \multirow{2}{*}{900} & 35 & 0 & 41 & 0 \\
\hline
\end{tabular}




\section{REPORT OF THE CONFERENCE TREASURER}

Presented by James H. AKEY, Inspector, Weights and Measures, State of Wisconsin

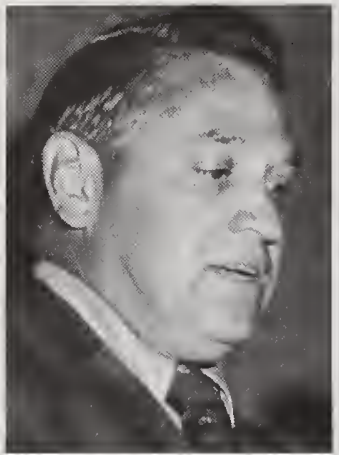

(Thursday, July 26, 1979)

VOTING KEY 1000

\section{INTRODUCTION}

It is my pleasure to report to you today on the financial status of the Conference treasury as follows:

Balance on hand, July 1, 1978

$\$ 9,467.45$

General Account Balance

$\$ 5,193.45$

Medallion Account Balance

306.90

Necktie Account Balance

(229.25)

(803.65)

Membership Plaque Account Balance

Certificate of Deposit

$5,000.00$

Total

$\$ 9,467.45$

General Account balance on hand, July 1, 1978

$\$ 5,193.45$

RECEIPTS

Registration, $360 @ \$ 50.00$........ \$18,000.00

Ladies Events tickets sold

270.00

Certificates of Deposit redeemed, January 22, 1979

$10,000.00$

Interest on Certificates of Deposit redeemed

140.56

Temperature Compensation

Symposium registration ..........

Metrologist's Dinner tickets sold ..

$2,254.25$

$300.00 \quad 30,964.81$

$\$ 36,158.26$

ACCOUNTS RECEIVABLE

U.S. Metric Board hearing expenses $2,070.00$

Total 
Hillwood Ladies Tour

$\$ \quad 450.00$

2 - 90 day Certificates of Deposit purchased

$10,000.00$

Registration desk \& operating expenses (cash)

$1,474.00$

Shoreham Americana Hotel,

Conference expenses

$4,318.16$

Howard Devron Orchestras,

Conference orchestra

800.00

Franklin Press, Consumer

Pamphlets \& stationery

331.55

Darrell Guensler, OIML meeting expenses

Ken Simila, Chairman, Travel expense, 3 meetings

James F. Lyles, OIML \& Interim

Meeting expenses

275.59

OWM, Interim Meeting expenses .-

Education, Administrative \&

Consumer Affairs Committee ...

Liaison Committee .................

S \& T Committee

580.10

$1,996.50$

377.50

$2,065.28$

$1,455.35$

$1,508.68$

L \& R Committee

$1,937.80$

Robert W. Probst, Temperature

Compensation Symposium

176.00

Treasurer's Conference

Transportation

822.10

U.S. Metric Board hearing expenses

$2,070.00$

Franklin Press, Conference

announcements \& receipts

501.85

Harold F. Wollin, Conference

planning trip

454.00

Temperature Compensation

Symposium expenses

General Account balance on hand \& receivable,

July 1, 1979

$\$ 4,347.04$

90 day renewable Certificate of Deposit No. 7467 $5,000.00$

Total $\$ 9,347.04$

\section{MEDALLION ACCOUNT}

Balance on hand, July 1, 1978 
RECEIPTS

Sale of Decals and Medallions ..... \$ $\quad$ \$ 117.23

DISBURSEMENTS

Anthony J. Ladd, Weights \&

Measures Week postage ........ \$ $\$ 30.00$

Medallion Account balance on hand, July 1, $1979 \quad \$ \quad 394.13$

\section{NECKTIE ACCOUNT}

Balance on hand, July 1, 1978

$\$(229.25)$

\section{RECEIPTS}

Sale of 114 Neckties @ \$6.50 ...... \$ $\$ 741.00$

Necktie Account balance on hand, July 1, 1979 _- $\quad \$ \quad 511.75$

\section{MEMBERSHIP PLAQUE ACCOUNT}

Balance on hand, July 1, 1978

$\$(803.65)$

\section{RECEIPTS}

Sale of 92 Plaques@ $\$ 5.00$........ \$ \$ 460.00

Membership Plaque Account balance on hand,

July 1, 1979

\section{RECAP}

Balances on hand, July 1, 1979

General Account $\$ 4,347.04$

Medallion Account 394.13

Necktie Account

Membership Plaque Account (343.65)

Net balance on hand, July 1, $1979 \ldots \ldots$............. $\$ 4,909.27$

Certificate of Deposit $5,000.00$

Total $\$ 9,909.27$

Depository: First Wisconsin National Bank of Wausau

(Signed) James H. AKey, Treasurer

(On the motion of the Treasurer, the report of the Conference Treasurer, voting key item 1000 , was adopted in its entirety by the Conference. The results of the voting in the House of State Representatives and the House of Delegates under the Conference voting system are totalized in the table that follows.) 
Voting RESULts-Conference Treasurer

\begin{tabular}{|c|c|c|c|c}
\hline \multirow{2}{*}{ Voting Key } & \multicolumn{2}{|c|}{$\begin{array}{c}\text { House of State } \\
\text { Representatives }\end{array}$} & \multicolumn{2}{c}{ House of Delegates } \\
\cline { 2 - 5 } & Yes & No & Yes & No \\
\hline 1000 & 33 & 0 & 43 & 0 \\
\hline
\end{tabular}




\section{REGISTRATION LIST}

\section{4th NATIONAL CONFERENCE ON WEIGHTS AND MEASURES}

July 22-27, 1979

Red Lion Motor Inn, Portland, Oregon

\section{ALABAMA}

STATE

JoHN B. RABB, Weights and Measures Laboratory Supervisor, State of Alabama, Department of Agriculture, P. O. Box 3336, 1445 Federal Drive, Montgomery, Alabama 36109 (Tel. (205) 832-3750)

\section{ALASKA}

STATE

Sharon L. Ferrara, Weights and Measures Inspector, State of Alaska, 2263 Spenard Road, Anchorage, Alaska 99503 (Tel. (907) 279-0508)

JAMES E. SNyder, Metrologist, Alaska Weights and Measures Section, 2263 Spenard Road, Anchorage, Alaska 99503 (Tel. (907) 279-0508)

Joseph L. Swanson, Chief, Weights and Measures Section, Alaska Section of Weights and Measures, 2263 Spenard Road, Anchorage, Alaska 99503 (Tel. (907) 279-0508)

\section{ARIZONA}

STATE

Patricia M. Fullinwider, Chief of Weights and Measures, State of Arizona, 3039 West Indian School, Phoenix, Arizona 85017 (Tel. (602) 2555211)

\section{ARKANSAS}

STATE

Sam F. Hindsman, Director, Arkansas Weights and Measures, 4608 West 61st Street, Little Rock, Arkansas 72209 (Tel. (501) 371-1759)

\section{CALIFORNIA}

STATE

Herbert L. Cohen, Department Counsel, California Department of Food and Agriculture, $1220 \mathrm{~N}$ Street, Sacramento, California 95831 (Tel. (916) 445-6429) 
Ezio F. Delfino, Chief, Division of Measurement Standards, State of California, 8500 Fruitridge Road, Sacramento, California 95826 (Tel. (916) 366-5119)

Darrell Guensler, Assistant Chief, Division of Measurement Standards, State of California, 8500 Fruitridge Road, Sacramento, California 95826 (Tel. (916) 366-5119)

JerRy SCRIBNer, Deputy Director, Department of Food and Agriculture, 1220 N Street, Room 100112, Sacramento, California 95814 (Tel. (916) 4458226)

\section{COUNTY}

Alameda

Patrick E. Nichols, Director of Weights and Measures, Alameda County, 333 - 5th Street, Oakland, California 94607 (Tel. (415) 874-6736)

Kings

M. Hugh Handley, County Sealer, President, California Association of Weights and Measures Officials, 280 Campus Drive, Hanford, California 93230 (Tel. (209) 582-3211 Ext. 2830)

Los Angeles

W. R. Mossberg, Director, Los Angeles County Department of Weights and Measures, 11012 Garfield Avenue, South Gate, California 90280 (Tel. (213) 922-8921)

Riverside

JoSEPH W. JoNES, Director of Weights and Measures, Riverside County, 2950 Washington, Riverside, California 92504 (Tel. (714) 787-2620)

San Bernardino

H. E. (Tiny) Sandell, Director, Department of Weights and Measures, County of San Bernardino, 777 East Rialto Avenue, San Bernardino, California 92415 (Tel. (714) 383-1411)

Santa Clara

DaniEl R. Smith, Director of Consumer Affairs, County of Santa Clara, 1555 Berger Drive, San Jose, California 95112 (Tel. (408) 299-2105)

Santa Cruz

JACK Simmen, Director of Weights and Measures, Santa Cruz County, 1430 Freedom Boulevard, Watsonville, California 94576 (Tel. (408) 7241149)

Yuba

JACK A. HuEY, Director of Weights and Measures, Yuba County, 921 W. 14th Street, Marysville, California 95901 (Tel. (916) 674-6376)

\section{COLORADO}


Leo Letey, Chief, Weights and Measures Section, Department of Agriculture, 3125 Wyandot, Denver, Colorado 80211 (Tel. (303) 839-2845)

\section{CONNECTICUT}

STATE

John T. BennetT, Chief, Weights and Measures, State of Connecticut, Department of Consumer Protection, State Office Building, Room G-17, Hartford, Connecticut 06115 (Tel. (203) 566-4778 or $566-5230$ )

Allan M. Nelson, Metrologist, Department of Consumer Protection, Weights and Measures Division, State Office Building, Room G-17, 165 Capitol Avenue, Hartford, Connecticut 06115 (Tel. (203) $566-4778$ or $566-5230$ )

CITY

GuY J. TommasI, City Sealer, President, Connecticut Weights and Measures Association, City Hall, Middletown, Connecticut 06457 (Tel. (203) 3474671 Ext. 215)

\section{DELAWARE}

STATE

Eugene KeEley, Supervisor, Delaware Weights and Measures, Drawer D, Dover, Delaware 19901 (Tel. (302) 678-4824)

\section{FLORIDA}

STATE

Sydney D. ANDREwS, Director, Division of Standards, Florida Department of Agriculture and Consumer Services, Mayo Building-Lab Complex, Tallahassee, Florida 32301 (Tel. (904) 488-0645)

Stan Darsey, Chief, Bureau of Weights and Measures, Florida Department of Agriculture and Consumer Services, Laboratory Complex, Tallahassee, Florida 32304 (Tel. (904) 488-9140)

\section{COUNTY}

Dade

John C. Mays, Director, Dade County Consumer Protection, 140 W. Flagler Street, Room 1604, Miami, Florida 33130 (Tel. (305) 579-4222)

\section{GEORGIA}

STATE

Thomas E. KIRBy, Director, Weights and Measures Laboratory, Georgia Department of Agriculture, Atlanta Farmers Market, Forest Park, Georgia 30050 (Tel. (404) 363-7611) 
Martin T. Colle, Assistant Director, Weights and Measures Laboratory, Georgia Department of Agriculture, Atlanta Farmer's Market, Forest Park, Georgia 30050 (Tel. (404) 363-7611)

John J. Peacock, Section Chief, Georgia Fuel and Measures, Department of Agriculture, Capitol Square, Atlanta, Georgia 30334 (Tel. (404) 6567057)

\section{HAWAII}

STATE

George E. Mattimoe, Deputy Director, Measurement Standards, State of Hawaii, 1428 South King Street, Honolulu, Hawaii 96814 (Tel. (808) 5487151-2-3)

Charles G. Bockus, Supervising Metrologist, State of Hawaii, P. O. Box 226, Captain Cook, Hawaii 96704 (Tel. (808) 323-2608)

\section{IDAHO}

STATE

Lyman D. Holloway, Chief, Department of Agriculture-Weights and Measures, 2216 Kellogg Lane, Boise, Idaho 83702 (Tel. (208) 384-2345)

\section{ILLINOIS}

STATE

Wayne W. Behrns, Bureau Chief, Illinois Department of Agriculture, Emmerson Building, State Fairgrounds, Springfield, Illinois 62706 (Tel. (217) 782-3817)

Sidney A. ColbrooK, Program Supervisor, Illinois Department of Agriculture, Emmerson Building, State Fairgrounds, Springfield, Illinois 62706 (Tel. (217) 782-3817)

STEve MCGuire, Lab Tech II, Illinois Department of Agriculture, 531 E. Sangamon Avenue, Springfield, Illinois 62702 (Tel. (217) 782-7655)

CITY

Chicago

Bradley R. Eidmann, JR., Consumer Service Officer, City of Chicago, 121 N. LaSalle, Room 808, Chicago, Illinois 60602 (Tel. (312) 744-4006)

Joyce M. Palmer, Consumer Service Supervisor, Consumer Service-Chicago, 121 N. LaSalle, Chicago, Illinois 60601 (Tel. (312) 744-4092)

Karen Petitte, Deputy Commissioner, Department of Consumer Services, City of Chicago, $121 \mathrm{~N}$. LaSalle Street, Room 808, Chicago, Illinois 60602 (Tel. (312) 744-4007) 


\section{INDIANA}

STATE

ROBERT W. WALKER, Director, Division of Weights and Measures, State of Indiana, 1330 West Michigan Street, Room A-120, Indianapolis, Indiana 46206 (Tel. (317) 533-0352)

\section{COUNTY}

Clark

HAROLD D. BRADSHAW, Inspector, Weights and Measures, Clark County, City-County Building, Room 314, Jeffersonville, Indiana 47130 (Tel. (812) 2834451 (Sta. 53)

Floyd

JAMES M. Moreillon, Inspector, Weights and Measures, Floyd County, 627 E. Fourth Street, New Albany, Indiana 47150 (Tel. (812) 944-1677)

Gibson

William R. SeIVER, Gibson County Inspector, Weights and Measures, Court House Annex, Princeton, Indiana 47683 (Tel. (812) 795-2532)

Greene

Edwin Goodman, Greene County Weights and Measures, 130 West Spring Street, Bloomfield, Indiana 47424 (Tel. (812) 384-4266)

Johnson

WAYNE E. HANDY, Inspector, Weights and Measures, Johnson County, Johnson County Courthouse, Franklin, Indiana 46131 (Tel. (317) 736-5774)

Lake

AlBerT M. Mysogland, Lake County Sealer, Department of Weights and Measures, $2293 \mathrm{~N}$. Main, Crown Point, Indiana 46307 (Tel. (219) 663-2896 or $738-2020$ Ext. 301 or 302 )

Laporth

Edwin Hanish, Inspector, 119 Tilden Avenue, Michigan City, Indiana 46360 (Tel. (219) 879-9480)

Porter

Richard H. Claussen, Sealer, Porter County, 1401 North Calumet (Room 105), Valparaiso, Indiana 46383 (Tel. (219) 766-2323)

St. Joseph

Chester S. Zmudzinski, Inspector, Weights and Measures, St. Joseph County, 227 W. Jefferson Boulevard, South Bend, Indiana 46619 (Tel. (219) 284-9751)

Tippecanoe

Webster McMurRy, Inspector, Tippecanoe County Weights and Measures, Court House Annex, P.O. Box 444, LaFayette, Indiana 47902 (Tel. (317) 4239229)

Vigo

ROBERT J. Silcock, Inspector, Vigo County Weights and Measures, Room 5, Courthouse, Terre Haute, Indiana 47802 (Tel. (812) 533-2955) 

Weights and Measures, 50 North 5th, Richmond, Indiana 47374 (Tel. (317) 935-4813)

\section{CITY}

Anderson

EARL GADBERRY, Anderson City Inspector, Anderson Department of Weights and Measures, City Building, P. O. Box 2100, Anderson, Indiana 46011 (Tel. (317) 646-5814)

Gary

John NaSTav, City Acting Sealer, 1100 Mass. Street, Gary, Indiana 46407 (Tel. (219) 944-6566)

Hammond

Dean Brahos, City Sealer, Room 104, 741 Michigan Street, Hammond, Indiana 46320 (Tel. (219) 8536377)

Indianapolis

Russell V. Brown, Deputy Inspector, City-County Building, Room G6, Indianapolis, Indiana 46204 (Tel. (317) 633-3733)

Frank L. BRUGH, Administrator, Division of Weights and Measures of Indianapolis, City-County Building, Room G6, Indianapolis, Indiana 46204 (Tel. (317) 633-3733)

Mishawaka

George Staffeldt, Inspector, City Hall, Mishawaka, Indiana 46544 (Tel. (219) 259-5265)

South Bend

BERT S. Cichowicz, Sealer of Weights and Measures, City of South Bend, Municipal Services Facility, Room 113, 701 West Sample Street, South Bend, Indiana 46621 (Tel. (219) 284-9273)

\section{IOWA}

STATE

JIM M. O'ConnoR, Supervisor, Iowa Department of Agriculture, Wallace Building, Des Moines, Iowa 50319 (Tel. (515) 281-5716)

KERMiT L. Toland, Metrologist, Iowa Department of Agriculture, Wallace Building, Des Moines, Iowa 50319 (Tel. (515) 281-5716)

\section{KANSAS}

STATE

JoHn L. O'NeILL, State Sealer and Director, State Board of Agriculture, P. O. Box 678, Topeka, Kansas 66601 (Tel. (913) 296-3846)

\section{KENTUCKY}

STATE

RonALD C. EgNEw, Laboratory Supervisor, State of Kentucky, Division of Weights and Measures, 106 W. 2nd Street, Frankfort, Kentucky 40601 (Tel. (502) 564-4870) 
George L. Johnson, Director, Department of Agriculture, Division of Weights and Measures, 106 West Second Street, Frankfort, Kentucky 40601 (Tel. (502) 564-4870)

\section{LOUISIANA}

STATE

William Hawk Daniels, Director, Department of Agriculture, Weights and Measures Division, P. O. Box 44456, Capitol Station, Baton Rouge, Louisiana 70804 (Tel. (504) 342-7011)

\section{MAINE}

STATE

Gaylon M. KEnNEDy, Deputy State Sealer of Weights and Measures, Maine Department of Agriculture, State House, Augusta, Maine 04333 (Tel. (207) 289-3841)

Marshall White, Metrologist, Maine Department of Agriculture, State House, Augusta, Maine 04330 (Tel. (207) 289-2751)

\section{MARYLAND}

STATE

LaCy H. Degrange, Assistant Chief, Maryland Department of Agriculture, Weights and Measures, Room 3205 Symons Hall, University of Maryland, College Park, Maryland 20742 (Tel. (301) 4543551)

\section{MASSACHUSETTS}

STATE

EdwaRd H. STadolnik, Assistant Director of Standards, Commonwealth of Massachusetts, Division of Standards, Room 1115, One Ashburton Place, Boston, Massachusetts 02108 (Tel. (617) 727-3480)

\section{CITY}

Barnstable

Thomas F. Geiler, Sealer, Town of Barnstable, 397 Main Street, Hyannis, Massachusetts 02601 (Tel. (617) 775-1120)

Pittsfield

RALPH J. MASSARO, Inspector of Weights and Measures, City of Pittsfield, City Hall-Room 149, Pittsfield, Massachusetts 01201 (Tel. (413) 442-7202)

Plymouth

David A. MontanaRI, Sealer of Weights and Measures, City of Plymouth, 35 Davis Street, Plymouth, Massachusetts 02360 (Tel. (617) 746-0556) 


\section{MICHIGAN}

LEO GAGNON, Supervisor, State of Michigan Weights and Measures, 1120 W. State Fair, Detroit, Michigan 48203 (Tel. (313) 368-0280)

Edward C. Hefrron, Chief, Food Inspection Division, Michigan Department of Agriculture, P. O. Box 30017, Lewis Cass Building, Lansing, Michigan 48909 (Tel. (517) 373-1060)

Frank C. Nagele, Weights and Measures Specialist, Michigan Department of Agriculture, P. O. Box 30017, Lewis Cass Building, Lansing, Michigan 48909 (Tel. (517) 373-1060)

\section{MINNESOTA}

STATE

EdWard P. SkluzaceK, Director, Minnesota Weights and Measures, 1015 Currie Avenue, Minneapolis, Minnesota 55403 (Tel. (612) 341-7205)

\section{MISSISSIPPI}

William P. Eldridge, Consumer Protection (Scales), Mississippi Department of Agriculture. P. O. Box 1609, Jackson, Mississippi 39205 (Tel. (601) 3546258)

Mark Freeman, Executive Assistant to the Commissioner, Mississippi Department of Agriculture and Commerce, P. O. Box 1609, Jackson, Mississippi 39205 (Tel. (601) 354-6569)

\section{MISSOURI}

STATE

BoB MERRICK, Director, Weights and Measures Division, Missouri Department of Agriculture, P. O. Box 630, Jefferson City, Missouri 65102 (Tel. (314) 751-4278)

JaCk Pierce, Program Supervisor, Weights and Measures Division, Missouri Department of Agriculture, P. O. Box 630, Jefferson City, Missouri 65102 (Tel. (314) 751-3440)

Louis Stephens, Program Supervisor, Weights and Measures Division, Missouri Department of Agriculture, P. O. Box 630, Jefferson City, Missouri 65102 (Tel. (314) 751-4992) 

Measures, City of St. Louis, 1220 Carr Lane Avenue-Room 145, St. Louis, Missouri 63104 (Tel. (314) 622-3252)

\section{MONTANA}

STATE

GaRy Delano, Administrator, Montana Division of Weights and Measures, 805 N. Main, Helena, Montana, (Tel. (406) 449-3163)

\section{NEBRASKA}

STATE

Steven A. Malone, Assistant Director, Department of Agriculture, Nebraska Division of Weights and Measures, Box 94757, State House Station, Lincoln, Nebraska 68509 (Tel. (402) 471-2875)

Norman M. Ross, Chief, Weights and Measures Division, Public Safety Department, Omaha Douglas Civic Center, 1819 Farnam, Omaha, Nebraska 68183 (Tel. (402) 444-5368)

RICHARD C. SuITER, Metrologist, Nebraska Standards Laboratory, Nebraska Department of Agriculture, Division of Weights and Measures, Box 94757, State House Station, Lincoln, Nebraska 68509 (Tel. (402) 471-2875)

\section{NEW JERSEY}

STATE

JAMES R. BIRD, Deputy State Superintendent, New Jersey Weights and Measures, 187 West Hanover Street, Trenton, New Jersey 08625 (Tel. (609) 2924615)

\section{COUNTY}

Camden

A. J. Francesconi, Superintendent, Camden County Weights and Measures, Room 416, Camden, New Jersey 08101 (Tel. (609) 757-8196)

Cumberland

George S. Franks, Superintendent, Weights and Measures and Consumer Protection, Cumberland County, 788 E. Commerce Street, Bridgeton, New Jersey 08302 (Tel. (609) 451-8000 Ext. 369 \& 370)

Gloucester

JosePh Silvestro, Deputy County Superintendent of Weights and Measures, County of Gloucester, 49 Wood Street, Woodbury, New Jersey 08096 (Tel. (609) 845-1600 (Ext. 252)) 

08901 (Tel. (201) 745-3298)

Salem

ROBERT B. Jones, Superintendent of Weights and Measures, Salem County Court House, Salem, New Jersey 08079 (Tel. (609) 935-7510 Ext. 368)

\section{NEW MEXICO}

Fred A. Gerk, Associate Chief, Weights and Measures, New Mexico Department of Agriculture, P. O. Box 3170, Las Cruces, New Mexico 88003 (Tel. (505) 646-1616)

Charles H. Greene, Chief, Division of Consumer \& Marketing Services, New Mexico Department of Agriculture, P. O. Box 3170, Las Cruces, New Mexico 88003 (Tel. (505) 646-1616)

\section{NEW YORK}

STATE

Ross ANDERSEN, Metrologist, New York State Bureau of Weights and Measures, Building 7-A, State Campus, Albany, New York 12235 (Tel. (518) 457-3449)

JoHn J. BARTFAI, Director, New York State Bureau of Weights and Measures, Building 7-A, State Campus, Albany, New York 12235 (Tel. (518) 457 3452)

Kenneth R. Gridley, Weights and Measures Specialist II, New York State Bureau of Weights and Measures, Building 7-A, State Campus, Albany, New York 12235 (Tel. (607) 962-0444)

COUNTY

Louis P. Romano, Director, Monroe County Weights and Measures, 1157 Scottsville Road, Rochester, New York 41624 (Tel. (716) 436-1330)

\section{NORTH CAROLINA}

James A. Graham, Commissioner, North Carolina Department of Agriculture, P. O. Box 27647, Raleigh, North Carolina 27611 (Tel. (919) 733-7125)

MaRION KInLAw, Director, Consumer Standards Division, North Carolina Department of Agriculture, P. O. Box 26056, Raleigh, North Carolina 27611 (Tel. (919) 733-3313) 
Tом Scoтt, Chief, Measurement Section, North Carolina Department of Agriculture, Consumer Standards Division, P. O. Box 26056, Raleigh, North Carolina 27611 (Tel. (919) 733-3313)

\section{NORTH DAKOTA}

STATE

Alvin M. SkaARvold, Inspector, North Dakota Weights and Measures, State Capitol, Bismarck, North Dakota 58505 (Tel. (701) 567-2179)

\section{OHIO}

STATE

Kenneth R. ADCock, Chief, Ohio Department of Agriculture, Division of Weights and Measures, 8995 E. Main Street, Reynoldsburg, Ohio 43068 (Tel. (614) 866-6361)

COUNTY

ROY K. РЕск, Deputy Inspector-Clark County, Clark Clark County Building, Springfield, Ohio 45502 (Tel. (513) 324-5871)

CITY

ANThony J. LADD, Superintendent, City of Akron

Akron Weights and Measures-Consumer Protection, 1420 Triplett Boulevard, Akron, Ohio 44306 (Tel. (216) 375-2878)

Cincinnati

Thomas Prager, Supervisor, City of Cincinnati Weights and Measures, 2147 Central, Cincinnati, Ohio 45211 (Tel. (513) 352-3135)

Dayton

LEON MilleR, City Sealer, Ohio Weights and Measures Association, 960 Ottawa Street, Dayton, Ohio 45402 (Tel. (513) 225-5304)

\section{OREGON}

Walter S. Arima, Heavy Capacity Weighing Specialist, Oregon Weights and Measures, Agriculture Building-635 Capitol Street, N.E., Salem, Oregon 97310 (Tel. (503) 378-3792)

DAVID G. CASNER, Weights and Measures Specialist, Oregon Department of Agriculture, Weights and Measures Division, Agriculture Building-635 Capitol Street, N.E., Salem Oregon 97310 (Tel. (503) 378-3792)

MAX L. ClaRK, Supervisor-Packaged Products Programs, Oregon Weights and Measures, Agriculture Building-635 Capitol Street, N.E., Salem, Oregon 97301 (Tel. (503) 378-3792) 
JAMES F. ClifFord, Standards Lab, Supervisor, Oregon Weights and Measures, Agriculture Building-635 Capitol Street, N.E., Salem, Oregon 97310 (Tel. (503) 378-3792)

RALPH CuRTIS, Weights and Measures Inspector, Oregon Weights and Measures, 606 S.E. 9th, Portland, Oregon 97214 (Tel. (503) 238-8364)

Elmer H. DeHaAs, Weights and Measures-LPG Inspector, Oregon Weights and Measures, Agriculture Building-635 Capitol Street, N.E., Salem, Oregon 97310 (Tel. (503) 378-3792)

RaY FleischmanN, Weights and Measures Division Supervisor, Oregon State Department of Agriculture, Agriculture Building-635 Capitol Street, N.E., Salem, Oregon 97310 (Tel. (503) 378-3792)

HARRY GaRABEDIAN, Weights and Measures Inspector I, Oregon Weights and Measures, Agriculture Building-635 Capitol Street, N.E., Salem, Oregon 97310 (Tel. (503) 378-3792)

CHuck Hilliker, Weights and Measures Inspector, Oregon Department of Weights and Measures, 606 S. E. 9th, Portland, Oregon 97214 (Tel. (503) 238 . 8364)

TONI HoDGE, Secretary, Oregon Weights and Measures, Agriculture Building-635 Capitol Street, N.E., Salem, Oregon 97310 (Tel. (503) 378-3792)

Donald W. Hylton, Packaged Products Specialist, Department of Agriculture-Weights and Measures Division, Agriculture Building-635 Capitol Street, N.E., Salem, Oregon 97310 (Tel. (503) 3783792)

Ron JoHnsen, Packaged Products Specialist, State of Oregon Weights and Measures Division, Agriculture Building-635 Capitol Street, N.E., Salem, Oregon 97310 (Tel. (503) 378-3792)

Gene KunKLe, Assistant Director, Oregon Department of Agriculture, Agriculture Building-635 Capitol Street, N.E., Salem, Oregon 97310 (Tel. (503) 378-4666)

Benson R. LAMONTE, Weights and Measures Inspector, Route 2, Box 69-A, Hillsboro, Oregon 97123 (Tel. (503) 238-8365)

HenRy G. LASHER, District Device Specialist, Weights and Measures Division, Department of Agricul- 
JoHN McCluRE, Weights and Measures Inspector I, Oregon State Department of Agriculture, Agriculture Building-635 Capitol Street, N.E., Salem, Oregon 97310 (Tel. (503) 378-3792)

William D. Nesbit, Weights and Measures Inspector I, Oregon Weights and Measures, 606 S.E. 9th Street, Portland, Oregon 97214 (Tel. (503) 2388364)

JoHN ReID, Packaged Products Specialist, Oregon Weights and Measures, Agriculture Building635 Capitol Street, N.E., Salem, Oregon 97310 (Tel. (503) 378-3792)

James Ross, Package Products Specialist, Oregon Weights and Measures, Agriculture Building635 Capitol Street, N.E., Salem, Oregon 97310 (Tel. (503) 378-3792)

George Shefcheck, Inspector I, State of Oregon Weights and Measures, 3990 Foots Creek Road, Gold Hill, Oregon 97525 (Tel. (503) 582-1430)

KendRICK J. Simila, Administrator, Oregon Weights and Measures Division, Agriculture Building635 Capitol Street, N.E., Salem, Oregon 97310 (Tel. (503) 378-3792)

WiLliam K. TodD, Weights and Measures Inspector, State of Oregon, Box 585, 169 W. Chestnut, Union, Oregon 97883 (Tel. (503) 562-5266)

Leo E. Weber, Weights and Measures Supervisor, Oregon Weights and Measures, 606 S.E. 9th Street, Portland, Oregon 79214 (Tel. (503) 2388364)

\section{PENNSYLVANIA}

STATE

Fred A. Thomas, Director, Bureau of Standard Weights and Measures, Pennsylvania Department of Agriculture, 2301 North Cameron Street, Harrisburg, Pennsylvania 17120 (Tel. (717) 787-6772)

CITY

Philadelphia
Sam F. Valtri, Chief, Weights and Measures, Room 636, 801 Arch Street, Philadelphia, Pennsylvania 19107 (Tel. (215) 686-3475)

\section{PUERTO RICO}

Maria A. Maldonado Garcia, Assistant Secretary, Department of Consumer Affairs, P. O. Box 41059, 
Minillas Station, Santurce, Puerto Rico 00940 (Tel. (809) 726-7585)

\section{RHODE ISLAND}

STATE

EDWARD R. FISHER, Administrator, State of Rhode Island, Mercantile Division Weights and Measures, 470 Allens Avenue, Providence, Rhode Island 02905 (Tel. (401) 277-2758)

\section{SOUTH CAROLINA}

STATE

John V. Pugh, Director, Metrology Division, South Carolina Department of Agriculture, P. O. Box 11280, Columbia, South Carolina 29211 (Tel. (803) 758-2130)

\section{SOUTH DAKOTA}

STATE

Allen L. Christie, Administrative Assistant, South Dakota Department of Commerce, Division of Commercial Inspection and Regulation, State Capitol Building, Pierre, South Dakota 57501 (Tel. (605) 773-3696)

BRUCE Farus, Director, South Dakota Department of Commerce, Division of Commercial Inspection and Regulation, State Capitol Building, Pierre, South Dakota 57501 (Tel. (605) 773-3696)

\section{TENNESSEE}

STATE

RoBerT M. REeves, Deputy Director, Tennessee Department of Agriculture, Weights and Measures, Box 40627, Nashville, Tennessee 37204 (Tel. (615) 741-1411)

BoB Williams, Technologist, Tennessee Department of Agriculture, Weights and Measures, Box 40627, Nashville, Tennessee 37204 (Tel. (615) 741-1530)

\section{TEXAS}

STATE

Charles E. Forester, Supervisor, Texas Weights and Measures, Texas Department of Agriculture, Box 12847, Austin, Texas 78711 (Tel. (512) 4756577)

CITY

Dallas

James C. Blackwood, Weights and Measures Administrator, City of Dallas, 1500 West Mockingbird, Room A-19, Dallas, Texas 75235 (Tel. (214) 670-6414) 
Charles H. Vincent, Director, City of Dallas Department of Consumer Affairs, Room 2B-North, City Hall, 1500 Marilla, Dallas, Texas 75201 (Tel. (214) 670-4433)

Fort Worth

David Watson, Consumer Affairs Director, City of Forth Worth, 1800 University Drive, Room 208, Fort Worth, Texas 76107 (Tel. (817) 870-7572)

\section{UTAH}

STATE

Edison J. Stephens, Supervisor, Weights and Measures, 5757 South-320 West, Murray, Utah 84107 (Tel. (801) 533-5459)

\section{VERMONT}

STATE

TRAFFORD F. BRINK, Director, Weights and Measures and Retail Inspection, Vermont Department of Agriculture, 116 State Street, Montpelier, Vermont 05602 (Tel. (802) 828-2436)

\section{VIRGINIA}

STATE

Marion W. CAIN, Metrologist, Virginia Weights and Measures Section, 1 North 14th Street, Room 032, Richmond, Virginia 23219 (Tel. (804) 786-2476)

JAMES F. LyLES, Supervisor, Weights and Measures Section, Virginia Department of Agriculture and Consumer Services, 1 North 14th Street, Room 032, Richmond, Virginia 23219 (Tel. (804) 7862476)

\section{WASHINGTON}

JOHN W. ALLEN, Weights and Measures Inspector, 406 General Administration Building, Olympia, Washington 98504 (Tel. (206) 753-5059)

LINDEN BAHNSEN, Weights and Measures, Inspector, Washington State Department of Agriculture, P. O. Box 186, Mt. Vernon, Washington 98273 (Tel. (206) 336-5542)

James H. CAMmEL, Inspector II, Washington State Weights and Measures, 406 General Administration Building, Olympia, Washington 98504 (Tel. (206) 753-5059)

GeORge J. Gerber, Weights and Measures Inspector II, 409 General Administration Building, Department of Agriculture, Weights and Measures Section, Olympia, Washington 98501 (Tel. (206) 7535059) 
M. RichaRd "SpUD" HARdin, Weights and Measures Inspector, $4704 \mathrm{~W}$. Prasch Avenue, Yakima, Washington 98908 (Tel. (509) 966-9124 or 5752754)

LARRY JOE KANOUSE, Weights and Measures Inspector I, Department of Agriculture, 2510 N.W. 299th Street, Ridgefield, Washington 98642 (Tel. (206) 887-4874)

G. N. Magnuson, Weights and Measures Supervisor, 406 General Administration Building, Olympia, Washington 98504 (Tel. (206) 753-5059)

JoHN R. MARTIN, Weights and Measures Inspector I, Department of Agriculture, 406 General Administration Building, Olympia, Washington 98504 (Tel. (206) 753-0277)

Robert L. Schlegel, Weights and Measures Inspector, 406 General Administration Building, Olympia, Washington 98504 (Tel. (206) 753-5059)

Milton N. SMith, Weights and Measures Inspector, N. 4213 Bessie Road, Spokane, Washington 99206 (Tel. (509) 924-3108)

JoHN H. LEWIS, Chief, Weights and Measures, Room 406, General Administration Building, Olympia, Washington 98504 (Tel. (206) 753-5059)

\section{CITY}

Everett

FRED K. LATCHAW, Inspector, City of Everett Weights and Measures, City Hall 3002 Wetmore, Everett, Washington 98201 (Tel. (206) 259-8845)

Seattle

William C. Sullivan, Supervisor, Weights and Measures, 805 South Dearborn Street, Seattle, Washington 98134 (Tel. (206) 625-2712)

Spokane

Gilbert R. Allen, City Sealer, North 221 Wall Street, Spokane, Washington 99201 (Tel. (509) 456-4306)

\section{WEST VIRGINIA}

STATE

David L. Griffith, Director, Consumer Protection Division, West Virginia Department of Labor, 1900 Washington Street, East, Charleston, West Virginia 25305 (Tel. (304) 348-7890)

\section{WISCONSIN}


WILliam BURKHARDT, Metrologist, 4702 University Avenue, Madison, Wisconsin 53705 (Tel. (608) 266-2761)

Gerald F. BurR, Weights and Measures Inspector, P. O. Box 14, Eau Claire, Wisconsin 54701 (Tel. (715) 874-6163)

Alden M. Lemke, President, Northwest Weights and Measures Association, Wisconsin Bureau of Weights and Measures, $801 \mathrm{~W}$. Badger Road, Box 8911, Madison, Wisconsin 53708 (Tel. (608) 2660608)

RoBert ProBST, Director, Bureau of Weights and Measures, Wisconsin Department of Agriculture, 801 West Badger Road, Box 8911, Madison, Wisconsin 53708 (Tel. (608) 266-7241)

\section{WYOMING}

Elvin R. LeEman, Standards/Measures Officer, Agriculture Products, State of Wyoming Department of Agriculture, 2219 Carey Avenue, Cheyenne, Wyoming 82001 (Tel. (307) 777-7321)

\section{MANUFACTURERS, INDUSTRY, AND BUSINESS}

\section{A-1 SCALES}

Ron R. Premo, Sales Manager, P. O. Box 256, Hillsboro, Oregon 97123 (Tel. (503) 640-3014)

ACME SCALE \& SUPPLY COMPANY

Ray Canfield, President, 5427 Butler Street, Pittsburgh, Pennsylvania 15201 (Tel. (412) 782-1808)

AMERICAN CAN COMPANY

William H. Marks, Senior Quality Associate, 1915 Marathon Avenue, Neenah, Wisconsin 54956 (Tel. (414) 729-8106)

AMERICAN FROZEN FOOD INSTITUTE

Howard H. WEATHERSPOON, Assistant Director Research and Technical Services, 1838 El Camino Real, Burlingame, California 94010 (Tel. (415) 697-6835)

AMERICAN NATIONAL METRIC COUNCIL (ANMC)

Michael F. Thompson, Program Manager, 1625 Massachusetts Avenue, N.W., Washington, D.C. 20036 (Tel. (202) 232-4545)

AMERICAN PETROLEUM INSTITUTE

Gary Hirschl, Marketing Assistant, 2101 L Street, N.W., Washington, D.C. 20037 (Tel. (202) 457-6370)

AMERICAN PETROLEUM INSTITUTE (API)

RICHARD SOUTHERS, Manager Operations and Engineering, 2101 L Street, N.W., Washington, D.C. 20037 (Tel. (202) 457-7014)

AMERICAN SOCIETY FOR TESTING AND MATERIALS

SAMUel F. ETrIS, Special Assistant to Managing Director, 1916 Race Street, Philadelphia, Pennsylvania 19103 (Tel. (215) 299-5524) 
William T. Cavanaugh, Managing Director, 1916 Race Street, Philadelphia, Pennsylvania 19103 (Tel. (215) 299-5524)

H. C. ZWEIFEL, Director, ASTM Western Activities, 8553 Verdosa Drive, Whittier, California 90605 (Tel. (213) 693-2212)

AMOCO OIL COMPANY

John A. StiTzel, Manager, Planning and Economics, 200 East Randolph Drive, Chicago, Illinois 60601 (Tel. (312) 856-5782)

AMSTAR CORPORATION

WALTER ZiELNICKI, Quality Control Coordinator, 1251 Avenue of the Americas, New York, New York 10020 (Tel. (212) 489-9000)

ANALOGIC CORPORATION

GuY WILSON, Product Marketing Manager, IDS, Audubon Road, Wakefield, Massachusetts 01880 (Tel. (617) 246-0300)

APT-PHILLIPS PETROLEUM COMPANY

J. L. Stevenson, Operations Coordinator, 390 AB, Bartlesville, Oklahoma 74004 (Tel. (918) 661-7012)

ASSOCIATION OF AMERICAN RAILROADS

JoHN J. ROBINSON, Executive Director-O-T Division, 1920 L Street, N.W., Washington, D.C. 20036 (Tel. (202) 293-4144)

ATLANTIC RICHFIELD COMPANY

Nicholas D. BaBIC, Metric Coordinator, AP-40103, 515 S. Flower Street, Los Angeles, California 90071 (Tel. (213) 486-1564)

T. J. MacWilliams, Maintenance Engineer, 515 S. Flower Street, Los Angeles, California 90071 (Tel. (213) 486-1247)

BASIC RESOURCE SERVICES, INC.

D. J. Hine, Manager-Systems Calibration, P. O. Box 40594, Washington, D.C. 20016 (Tel. (202) 389-8346)

BENNETT PUMP COMPANY

John P. HaUet, Manager, Field Service, P. O. Box 597, Muskegon, Michigan 49443 (Tel. (616) 733-1302)

BERKEL, INCORPORATED

John J. McLellan, Region Manager, 428 North Buchanan Circle, Pacheco, California 94553 (Tel. (415) 676-2688)

B.L.H. ELECTRONICS

Martin C. SPOOR, Manager of Engineering, 42 Fourth Avenue, Waltham, Massachusetts 02154 (Tel. (617) 890-6700)

BRINKMANN INSTRUMENTS

D. F. Schluter, Vice President, Sartorius Balance Division, Cantiague Road, Westbury, New York 11590 (Tel. (516) 334-7500)

BROOKS INSTRUMENT DIVISION-EMERSON ELECTRIC

BARRIE Bloser, Chief Engineer, P. O. Box 450, Statesboro, Georgia 30458 (Tel. (912) 764-5471)

BURDITT AND CALKINS

George M. BurditT, Attorney, 135 South LaSalle Street, Chicago, Illinois 60603 (Tel. (312) 641-2121)

CARGILL, INCORPORATED

John A. Johnston, 3444 Dight Avenue South, Minneapolis, Minnesota 55406 (Tel. (612) 371-4897)

Luke RenZI, Senior Project Leader, Grain Research Lab, 3444 Dight Avenue, South, Minneapolis, Minnesota 55406 (Tel. (612) 371-4897)

CARDINAL SCALE MANUFACTURING COMPANY

W. TerRy JAMES, Vice President, Engineering, Box 151, Webb City, Missouri 64870 (Tel. (417) 673-4631) 
CHADWELL, KAYSER, RUGGLES, McGEE AND HASTING, LTD.

Merrill S. Thompson, Attorney and Vice President, 8500 Sears Tower, 233 South Wacker Drive, Chicago, Illinois 60606 (Tel. (312) 876-2163)

CHEVRON U.S.A., INC.

R. B. Feldman, Engineer, Maintenance, 575 Market Street, Room 2614, San Francisco, California 94105 (Tel. (415) 894-4703)

CITIES SERVICE COMPANY

W. M. KiTtLE, Engineering and Construction Manager, P. O. Box 300, Tulsa, Oklahoma 74102 (Tel. (918) 586-3747)

COCA-COLA COMPANY

R. A. Lester, Attorney, P. O. Drawer 1734, Atlanta, Georgia 30301 (Tel. (404) 898-2530)

A. Lee Turner, Public Affairs Department, P. O. Drawer 1734, Atlanta, Georgia 30301 (Tel. (404) 898-2623)

COLGATE-PALMOLIVE

EDWARD E. WoLSKI, Manager-Quality Control, 300 Park Avenue, New York, New York 10022 (Tel. (212) 751-1200)

CORDEMEX

Victor M. Barredo, President, 3555 Sunset Office Drive, St. Louis, Missouri 63127 (Tel. (314) 821-7373)

CORDEMEX S.A. DE C.V.

Jorge CARlos LoPEz, Counselor, Merida, Yucatan, Mexico, c/o 3555 Sunset Office Drive, St. Louis, Missouri 63127 (Tel. (314) 821-7373)

Jose Palomeque, Regional Sales Manager, Merida, Yucatan, Mexico, c/o 3555

Sunset Office Drive, St. Louis, Missouri 63127 (Tel. (314) 821-7373)

CORN REFINERS ASSOCIATION, INC.

Lucien D. Agniel, JR., Director, Scientific Activities, 1001 Connecticut Avenue, N.W., Washington, DC 20036 (Tel. (202) 331-1634)

CPC NORTH AMERICA

AlFREd E. JoHANSON, Senior Counsel-Regulatory Affairs, International Plaza,

Englewood Cliffs, New Jersey 07632 (Tel. (201) 894-2383)

J. B. DEE \& COMPANY, INC.

Miles D. Fishman, Vice President, 1722 W 16th Street, Indianapolis, Indiana 46202 (Tel. (317) 635-5548)

DETECTO SCALES, INC.

Michael V. Visconte, Sales Manager, Industrial Scale Division, 103-00 Foster Avenue, Brooklyn, New York 11236 (Tel. (212) 272-4500)

DICKEY-JOHN CORPORATION

David B. FunK, Senior Design Engineer, Box 10, Auburn, Illinois 62615 (Tel. (217) 438-6181)

\section{DIMEAWEIGH}

Dennis S. Phares, P. O. Box 243, Ogden, Utah 84402 (Tel. (801) 392-0994)

DRESSERWAYNE

Warren J. DubSky, Chief Engineer, Fuel Dispensing Products, 124 W. College Avenue, Salisbury, Maryland 21801 (Tel. (301) 546-6688)

DUNBAR MANUFACTURING, INC.

HaRvey M. Lodge, Vice President, 307 Broadway, Swanson, Ohio 43558 (Tel. (419) 244-3021)

David G. DunBar, Sales Representative, 307 Broadway, Swanton, Ohio 43558 (Tel. (419) 244-3021)

DUNNINGTON, BARTHOLOW \& MILLER

Michael B. Weir, Attorney, 161 E. 42nd Street, New York, New York 10017

(Tel. (212) 682-8811) 
ELECTROSCALE CORPORATION

JoSEPH F. GeISSER, N.E. Sales Manager, 3 Genoa Street, North Providence, Rhode Island 02904 (Tel. (401) 728-0044)

ELDEC CORPORATION

DoNALD E. KELSo, Staff Engineer, 20215 Cedar Valley Road, Lynnwood, Washington 98036 (Tel. (206) 775-6471)

EMPIRE SCALE COMPANY

AL Stoler, President, 301 South Los Angeles Street, Los Angeles, California 90013 (Tel. (213) 629-3311)

EXXON COMPANY U.S.A.

HaRold E. HaRRIS, Technical Advisor, P. O. Box 2180, Houston, Texas 77001 (Tel. (713) 656-6170)

EXXON CORPORATION

Raymond A. Hartmann, Advisor, 1251 Avenue of Americas, New York, New York 10020 (Tel. (212) 398-3764)

EXXON CHEMICAL

JoHn B. O'NeIL, Manager, Twine Technology, Highway 78 West, Summerville, South Carolina 29483 ('Tel. (803) 873-5800)

FAIRBANKS WEIGHING DIVISION OF COLT INDUSTRIES

KenNeth F. Hammer, President, 711 East St. Johnsbury Road, St. Johnsbury, Vermont 05819 (Tel. (802) 748-5111)

Robert E. CAlLihan, Vice President, Engineering, 711 East St. Johnsbury Road, St. Johnsbury, Vermont 95819 (Tel. (802) 748-5111)

Dick HURLEy, Manager, Engineering Services, 711 East St. Johnsbury Road, St. Johnsbury, Vermont 05819 (Tel. (802) 748-5111)

FAIRBANKS SCALES

Ellis FitzGerald, Service.Manager, 2934 Fleetbrook Drive, Memphis, Tennessee 38116 (Tel. (901) 332-8002)

FLEXIBLE PACKAGING ASSOCIATION

ThомаS J. Dunn, Technical Director, 12025 Shaker Boulevard, Cleveland, Ohio 44120 (Tel. (216) 229-6373)

FOOD MARKETING INSTITUTE

ToDd S. MANN, Research Manager, 1750 K Street, N.W., Washington, DC 20006 ('Tel. (202) 452-8444)

FRANKLIN ELECTRIC COMPANY

JoHN Young, Product Distribution Manager Exact Weight, Box 666, Levittown, Pennsylvania 19058 (Tel. (215) 949-2400)

Bert M. MEsSerschitT, Western Regional Manager, 6677 E. 26th Street, Los Angeles, California 90040 ( $T e l . ~(213)$ 722-7787)

GENERAL MILLS, INCORPORATED

DONALD B. CoLPITTS, Technical Manager, Weights and Measures, 9000 Plymouth Avenue North, Minneapolis, Minnesota 55427 (Tel. (612) 540-2729)

Neal Peterson, Attorney at Law, 1730 M Street, N.W., \#907, Washington, DC 20036 (Tel. (202) 296-0360)

WILLIAM C. MAILHOT, Director, Quality Control, Sperry Division, 9200 Wayzata Boulevard, Minneapolis, Minnesota 55426 (Tel. (612) 540-2354)

GERBER PRODUCTS COMPANY

LyLE LITTLEFIELD, Director, Government Relations, 445 State Street, Fremont, Michigan 49412 (Tel. (616) 928-2264)

GETTY REFINING AND MARKETING COMPANY

W. C. GrosshauSER, Coordinator Construction and Engineering, 1437 South Boulder, Tulsa, Oklahoma 74102 (Tel. (918) 560-6753) 
JoHN S. Grose, Chief Experimental Engineer, 7300 Friendly Road, Greensboro, North Carolina 27420 (Tel. (919) 292-3011)

Claude R. Parent, Director, National Accounts, 1020 Aileen Street, Lafayette, California 94549 (Tel. (415) 284-1810)

THE GILLETTE COMPANY

RALPH Levine, Corporate Quality Assurance Manager, Prudential Tower Building, Boston, Massachusetts 02199 (Tel. (617) 421-7371)

GROCERY MANUFACTURERS OF AMERICA, INC.

Mahlon A. BuRnETTE, III, Director, Scientific Affairs, 1010 Wisconsin Avenue, N.W., Suite 800, Washington, DC 20007 (Tel. (202) 337-9400)

GUILD OF PROFESSIONAL PAPERHANGERS

Sid Benjamin, Co-Chairman, Wallcovering Standard Commission, Box 25, Carle Place, New York 11514 (Tel. (516) 249-3358)

ISADORE GeCKeR, Co-Chairman, Wallcovering Standard Commission, Box 25, Carle Place, New York 11514 (Tel. (516) 249-3358)

HARDY SCALE

Emil Micono, Product Manager, 1001 E. Touhy-Suite 95, Des Plaines, Illinois 60018 (Tel. (312) 299-8070)

HOBART CORPORATION

EDwin Boshinski, Director, Research, Hobart Corporation, Troy, Ohio 45374 (Tel. (513) 223-0452)

Fred H. KatTERHEINRICH, Manager, Weights and Measures, Hobart Corporation, Troy, Ohio 45374 (Tel. (513) 278-9496)

John H. Nielsen, Weights and Measures Representative, 325 Phelan Avenue, San Jose, California 95112 (Tel. (408) 297-4209)

HOWE-RICHARDSON SCALE COMPANY

JoHN W. AQUADRo, Vice President Engineering, 668 Van Houten Avenue, Clifton, New Jersey 07470 (Tel. (201) 471-3400)

Gerald J. Devine, Consultant, 680 Van Houten Avenue, Clifton, New Jersey 07015 (Tel. (201) 471-3400)

HUNT WESSON FOODS, INC.

CHIP KLoos, Section Head-R \& D, 1645 W. Valencia, Fullerton, California 92634 (Tel. (714) 871-2100 Ext. 1098)

INTERFACE, INC.

JAMES BuTcher, Sales Manager, 7401 E. Butherus Drive, Scottsdale, Arizona 85260 (Tel. (602) 948-5555)

INTERNATIONAL WEIGHING SYSTEMS

Billy Joe Click, President, 313 N. Dexford, Colton, California 92324 (Tel. (714) 824-0880)

JEWEL COMPANIES, INC.

RalPh W. Miller, JR., Vice President, Regulatory Research and Planning and General Counsel, Jewel Food Stores Division, 1955 W. North Avenue, Melrose Park, Illinois 60160 (Tel. (312) 531-6104)

THE KROGER COMPANY

David P. LEAHY, Technical Consultant, 1240 State Avenue, Cincinnati, Ohio 45204 (Tel. (513) 244-3829)

LIQUIDS CONTROLS CORPORATION

Howard Siebold, Vice President-Technical Services, P. O. Box 784, Fort Bragg, California 95437 (Tel. (707) 964-4171) 
LOCKHEED ELECTRONICS COMPANY

JosePh F. DEviTT, Service Manager, U.S. Highway 22, Plainfield, New Jersey 07061 (Tel. (201) 757-1600)

LUFKIN RULE COMPANY

Don Oltz, Vice President Marketing, "The Cooper Group", P. O. Box 728, Apex,

North Carolina 27502 (Tel. (919) 362-7511)

MARATHON OIL COMPANY

LEM MCMANNESS, Manager, Marketing Engineering Department, 539 South Main Street, Findlay, Ohio 45840 (Tel. (419) 422-2121)

MARTIN-DECKER COMPANY

Fred Conley, Manager of Scale Design, 1928 South Grand Avenue, Santa Ana, California 92705 (Tel. (714) 540-9220)

E. I. "JIM" SHELLEY, Industrial Sales Manager, 1928 South Grand Avenue, Santa Ana, California 92705 (Tel. (714) 540-9220)

THE MEASUREGRAPH COMPANY

ERIC Allen, Chairman, Associate Membership Committee, 4245 Forest Park

Boulevard, St. Louis, Missouri 63108 (Tel. (314) 533-7800)

MEASUREMENT SYSTEMS INTERNATIONAL

JoHn B. Gannon, Director of Marketing, 580 South Lucile Street, Seattle, Washington 98108 (Tel. (206) 767-7433)

METRON CORPORATION

Fred GRESOVIC, National Sales Manager, 928 West 9th Street, Upland, California 91786 (Tel. (714) 981-4981)

METTLER INSTRUMENT CORPORATION

DON MILlER, Marketing Manager, Box 71, Hightstown, New Jersey 08520 (Tel. (609) 448-3000)

METTLER INSTRUMENTE AG

Hans EigenmanN, CH-8606 Greifensee, Switzerland, c/o Mettler Instrument Corporation, Box 71, Hightstown, New Jersey 08520 (Tel. (609) 448-3000)

MILK INDUSTRY FOUNDATION/INTERNATIONAL ASSOCIATION OF ICE CREAM MANUFACTURERS

AUSTIN RHOADS, Administrative Assistant, 910 17th Street, N.W., Washington, DC 20006 (Tel. (202) 296-4250)

MILLERS' NATIONAL FEDERATION

JoHn J. SHERLOCK, Vice President, 1776 F Street, N.W., Washington, DC 20006 (Tel. (202) 452-0900)

MINNESOTA MINING AND MANUFACTURING

Kenneth S. Jensen, Manager, Reliability Assurance and Technical Service, Box 33331, Building 42-3E \#52, St. Paul, Minnesota 55133 (Tel. (612) 778-5282) MISSOURI FARMERS ASSOCIATION, INC.

WILliam M. BAKER, Supervisor, Weights and Measures, 3501 Berrywood, Columbia, Missouri 65201 (Tel. (314) 874-5440)

MOBAY CHEMICAL CORPORATION

Frank L. STRIBLING, Quality Control Coordinator, 8400 Hawthorn Road, Kansas City, Missouri 64120 (Tel. (816) 242-2461)

MOBIL CHEMICAL_PLASTICS DIVISION

Boв Wiseman, Quality Control Manager, Technical Center, Macedon, New York 14502 (Tel. (315) 986-6419)

MOBIL OIL CORPORATION

J. A. Petrelli, Manager, Marketing Operations-Engineering, 150 E. 42nd Street, New York, New York 10017 (Tel. (212) 883-5204)

JOHN MORRELL \& COMPANY

V. J. Del Giudice, Quality Control Director, 208 South LaSalle Street, Chicago, Illinois 60604 (Tel. (312) 443-3075) 
MORRIS SCALE COMPANY

Clifford V. Morris, President, 1537 S.E. Morrison Street, P. O. Box 14306, Portland, Oregon 97214 (Tel. (503) 232-5339)

NATIONAL CATTLEMEN'S ASSOCIATION

Eldon White, Director of Marketing Programs, P. O. Box 569, Denver, Colorado 80201 (Tel. (303) 861-1904)

NATIONAL CONFECTIONERS ASSOCIATION

LESTER L. BETTES, Senior Consultant-Societe Candy Co., 11959 Northrup Way, Bellevue, Washington 98005 (Tel. (206) 544-8400)

NATIONAL CONFERENCE OF STANDARDS LABORATORIES

RonAlD E. KIDD, Manager, Microwave Associates, South Avenue, Burlington, Massachusetts 01803 (Tel. (207) 272-3000)

NATIONAL CONTROLS, INC.

Boв E. PRINCE, 3220 Airport Boulevard, Santa Rosa, California 94504 (Tel. (707) 527-5555)

Frank C. Rock, Vice President R \& D, 2300 Airport Way, Santa Rosa, California 95404 (Tel. (707) 527-5555)

NATIONAL SCALE MEN'S ASSOCIATION

William V. GoodPaSTER, President, 1610 North C Street, Sacramento, California 95814 (Tel. (916) 441-0178)

Sylvia T. WAGNER, Executive Director, 214 $\frac{12}{2}$ South Washington Street, Naperville, Illinois 60540 (Tel. (312) 355-4788)

NATIONAL SEMICONDUCTOR CORPORATION

John E. MARTIN, National Marketing Support Manager, 1130 Kifer Road, Sunnyvale, California 94086 (Tel. (408) 737-6258)

JoHN PAGE, Manager of Training, 3605 Kifer Road, Mail Stop 11-1000, Santa Clara, California 95051 (Tel. (408) 737-6254)

NRC CORPORATION, WORLD HEADQUARTERS

A. R. DANIELS, Director, Industry Standards and Relations, Dayton, Ohio 45479 (Tel. (513) 449-6655)

NEPTUNE HARDY SCALES

James A. BEAton, Sales Manager, 3565 Corporate Court, San Diego, California 92123 (Tel. (714) 565-7701)

NEPTUNE MEASUREMENT COMPANY

EmmetT F. Wehmann, Assistant Chief Engineer, P.O. Box 792-Emerald Road, Greenwood, South Carolina 29646 (Tel. (803) 223-1212)

NEW BRUNSWICK INTERNATIONAL, INC.

Louls P. BonaPaCe, President, 5 Greek Lane, Edison, New Jersey 08817 (Tel. (201) 287-2288)

NORTHEAST PETROLEUM INDUSTRIES, INC.

JoHN G. BUCKLEY, Vice President-Director, 100 Federal Street, Boston, Massachusetts 02110 (Tel. (617) 884-7570)

PEABODY COAL COMPANY, ARIZONA DIVISION

RAY HelmiCK, Manager, Weighing Systems, 1638 E. Cinnabar Avenue, Phoenix, Arizona 85020 (Tel. (602) 943-3837)

PEABODY COAL COMPANY

STANLEY L. CisIEWSKI, Director-Weights and Measures, 301 N. Memorial Drive, St. Louis, Missouri 63102 (Tel. (314) 342-3469)

J. C. PENNEY COMPANY, INC.

JoSEPH R. KraJCl, Attorney, 1301 Avenue of Americas, New York, New York 10019 (Tel. (212) 957-0242) 
PENNSYLVANIA SCALE COMPANY

WilliaM J. KAUTTER, JR., Manager-Electronic Engineering, 21 Graybill Road, Leola, Pennsylvania 17540 (Tel. (717) 656-2653)

PHILLIPS PETROLEUM COMPANY

H. M. Faulconer, Technical Representative, Seneca Building, Bartlesville,

Oklahoma 74004 (Tel. (918) 661-6334)

PHILLIPS SCALE COMPANY

O. BRICK PHILlIPS, 3130 Elliott Avenue, Seattle, Washington 98121 (Tel. (206) 284-6090)

THE PILLSBURY COMPANY

Carl A. Taubert, 608 2nd Avenue South, Minneapolis, Minnesota 55404 (Tel. (612) 330-8009)

PITNEY-BOWES

RUTHERFoRd H. FENN, Director Corporate Standards, Walnut and Pacific Streets, Stamford, Connecticut 06904 (Tel. (203) 853-2031)

POWERINE OIL COMPANY

Paul Samsing, Retail Sales Manager, 12354 Lakeland Road, Santa Fe Springs, California 90670 (Tel. (213) 944-6111)

PRESTO PRODUCTS, INC.

MARvin A. LAMBERT, Quality Control Director, P.O. Box 2399, Appleton, Wisconsin 54953 (Tel. (414) 739-9471)

Tony ZELler, Director of Packaging, Box 2399, Appleton, Wisconsin 54913 (Tel. (414) 739-9471)

PROCTER AND GAMBLE

William H. Braun, Packaging Section Head, 6100 Center Hill Road, Cincinnati, Ohio 45224 (Tel. (513) 977-5233)

J. D. Wallace, Packaging Section Head, ITC Building, Cincinnati, Ohio 45217 (Tel. (513) 763-5172)

John P. SiEgfried, Counsel, 301 East Sixth Street, Cincinnati, Ohio 45202 (Tel. (513) 562-4400)

ARTHUR L. Smith, Technical Services Manager, P.O Box 13220, Sacramento, California 95813 (Tel. (916) 383-3800)

PETROLEUM METER AND PUMP COMPANY

Rich Allen, Sales Manager, P.O. Box 422, Avon, Connecticut 06001 (Tel. (203) 677-9656)

THE QUAKER OATS COMPANY

Fred A. Dobbins, Director, Quality Assurance-Compliance, 617 West Main, Barrington, Illinois 60010 (Tel. (312) 381-1980 Ext. 2256)

RAMSEY ENGINEERING COMPANY

Max C. Casanova, Manager, Field Service, 1853 W. Country Road South, St. Paul, Minnesota 55113 (Tel. (612) 633-5150)

S. H. RASKIN CORPORATION

S. H. RAskin, President, P.O. Box 402426, Dallas, Texas 75240 (Tel. (214) 742 2727)

RATH PACKING COMPANY

MERLIN J. ANDERA, Director of Quality Assurance, Waterloo, Iowa 50704 (Tel. (319) 235-8703)

REVERE CORPORATION OF AMERICA

JohN J. ELEngo, JR., Vice President-Engineering, North Colony Road, Wallingford, Connecticut 06492 (Tel. (203) 269-7701)

ROCKWELL INTERNATIONAL/AUTONETICS

Rolf B. F. SchumACHER, Department 120 HC02, 3370 Miraoma Avenue, Anaheim, California 92803 (Tel. (714) 632-5981) 
SAFEWAY STORES, INC.

Robert L. WINSLOW, Manager Food Technology Division, Oakland, California 94660 (Tel. (415) 891-3250)

SCALE MANUFACTURERS ASSOCIATION

RoBert M. ZweIG, President, (President-John Chatillon and Sons, Inc.), 83-30

Kew Gardens Road, Kew Gardens, New York 11365 (Tel. (212) 847-5000)

RAYMOND J. LlOYd, Executive Director, 1000 Vermont Avenue, N.W., Washington, D.C. 20005 (Tel. (202) 628-4634)

DARYL ToninI, Technical Director, 1000 Vermont Avenue, N.W., Washington, D.C. 20005 (Tel. (202) 628-4634)

SCHWAN'S SALES ENTERPRISE, INC.

Don WichmanN, National Retail Marketing Manager, 115 West College Drive, Marshall, Minnesota 56258 (Tel. (507) 532-3274)

SERAPHIN TEST MEASURE COMPANY

Raymond R. Wells, Vice President Sales, 30 Indel Avenue, Rancocas, New Jersey 08068 (Tel. (609) 267-0922)

SHELL OIL COMPANY

Matthew B. HaRrington, Marketing Engineering Manager, \#1 Shell Plaza, Houston, Texas 77077 (Tel. (713) 241-2701)

R. D. Mueller, Retail Commercial Engineering Manager, Box 3105-Milam Building, Room 739, Houston, Texas 77001 (Tel. (713) 241-2901)

Charles L. Van Inwagen, Staff Engineer, P.O. Box 3105, Houston, Texas 77001 (Tel. (713) 241-6973)

SINGLE SERVICE INSTITUTE

JoSEPH W. Bow, Director of General Services, 1025 Connecticut Avenue, N.W., Washington, D.C. 20036 (Tel. (202) 347-0020)

Robert W. Foster, Executive Vice President, 1025 Connecticut Avenue, N.W., Washington, D.C. 20036 (Tel. (202) 347-0020)

SMITH METER OPERATIONS, GEOSOURCE INC.

Philip E. Swanson, Senior Engineer, 1602 Wagner Avenue, Erie, Pennsylvania 16512 (Tel. (814) 899-0661)

SOUTHERN WEIGHING AND INSPECTION BUREAU

M. R. Gruber, JR., Supervisor of Weights, 151 Ellis Street, N.E., Room 306, Atlanta, Georgia 30303 (Tel. (404) 659-6266 Ext. 266)

SWEDA INTERNATIONAL

H. Warren Gross, Product Line Management, 34 Maple Avenue, Pine Brook New Jersey 07058 (Tel. (201) 575-8100)

TEXAS A \& M UNIVERSITY

W. B. JonEs, Professor and Head Electrical Engineering Department, College Station Texas 77843 (Tel. (713) 845-3429)

THATCHER GLASS MANUFACTURING COMPANY

William N. ARdUSER, Design Assurance Manager, P.O. Box 265, Elmira, New York 14845 (Tel. (607) 737-3194)

THRUMAN SCALE COMPANY

JoSEPH R. SchaEfFER, Vice President, 1939 Refuge Road, Columbus, Ohio 43216 (Tel. (614) 443-9741)

TOKHEIM CORPORATION

BoB ANDERSON, Western Sales Representative-Meters, 35 S. Bayshore (P.O Box 5046), San Mateo, California 94401 (Tel. (415) 342-9795)

Walter F. Gerdom, Manager-Technical Services, 1602 Wabash Avenue, Fort Wayne, Indiana 46801 (Tel. (219) 423-2552)

William D. KEY, Chief Engineer, 1602 Wabash Avenue, Fort Wayne, Indiana 46801 (Tel. (219) 423-2552) 
T.M. StaBler, Manager-Weights and Measures, P. O. Box 1705, Columbus, Ohio 43216 (Tel. (614) 438-4548)

Mike G. Lewis, Arga Manager, 8208 Capwell Drive, Oakland, California 94621 (Tel. (415) 569-5980)

TRANSAMERICA COMPUTER COMPANY

Richard STAFF, Regional Director, 2446 Estand Way, Pleasant Hill, California 94523 (Tel. (415) 798-3680)

Jim CoRZINE, Director of Weighing Systems, 2446 Estand Way, Pleasant Hill, California 94523 (Tel. (415) 798-3860)

TRANSDUCERS, INC.

Bob NoRdSTROM, Regional Manager, 14030 Bolsa Lane, Cerritos, California 90701 (Tel. (714) 739-1991)

Peter R. Perino, President, 14030 Bolsa Lane, Cerritos, California 90701 (Tel. (714) 739-1991)

JAMEs R. STORY, Director of Marketing, 14030 Bolsa Lane, Cerritos, California 90701 (Tel. (714) 739-1991)

TRINER SCALE AND MANUFACTURING COMPANY

JAMES R.F. Woods, Director of Government Sales, 3857 Chain Bridge Road, Fairfax City, Virginia 22030 (Tel. (703) 691-0076)

UNION CARBIDE CORPORATION

W. L. (LEW) JoHNSON, Manager, Quality and Specifications, Home and Automotive Products Division, 55 Haul Road, Wayne, New Jersey 07470 (Tel. (201) 694-8800)

UNION OIL COMPANY

KENNETH L. McGINNIS, Operations Engineer, Union Oil Center, Los Angeles, California 90017 (Tel. (213) 486-6108)

W. J. MyERS, Manager of Marketing Equipment, 1650 East Golf Road, Schaum. berg, Illinois 60196 (Tel. (312)885-5144)

\section{VEEDER ROOT COMPANY}

Tom McLaughlin, Western Regional Manager, 1049 Grand Central Avenue, Glendale, California 91201 (Tel. (213) 245-0161)

ROBERT E. NIX, Manager, Customer Services, 70 Sargeant Street, Hartford, Connecticut 06102 (Tel. (203) 527-7201)

Ron C. Pugh, Petroleum Sales Engineer, 70 Sargeant Street, Hartford, Connecticut 06102 (Tel. (203) 527-7201)

WALLCOVERING MANUFACTURERS ASSOCIATION

Robert E. Hebda, 1730 Pennsylvania Avenue, N.W., Washington, D.C. 20006 (Tel. (202) 783-0800)

WEIGHING AND CONTROL SYSTEMS, INC.

Daniel J. Cockrell, President, P.O. Box 1483, Brandon, Florida 33511 (Tel. (813) 689-8791)

\section{UNITED STATES GOVERNMENT}

\section{U.S. DEPARTMENT OF AGRICULTURE}

BENJAMIN BANKs, Scale Testing and Weighing Specialist, Federal Grain Inspection Service (FGIS), Weighing Division, Auditors Building, 3117, 201 14th Street, S.W., Washington, D.C. 20250 (Tel. (202) 447-8529) 
Sydney J. Butler, Deputy Assistant Secretary for Food and Consumer Services, 14th and Jefferson Streets, S.W., Washington, D.C. 20250 (Tel. (202) 4474691)

Edward L. Jones, Scale Specialist, Federal Grain Inspection Service (FGIS), P. O. Box 3837, 606 9th Street, Portland, Oregon 97209 (Tel. (503) 221-2807)

Chuck Merkhofer, Scales and Weighing Specialist, Packers and Stockyards, 9370 S.W. Greenburg Road, Suite E, Portland, Oregon 97223 (Tel. (503) 2463395)

Charles H. OAKley, Chief of Scales and Weighing Branch, Packers \& Stockyards-AMS, 14th and Independence Avenue, S.W., Washington, D.C. 22050 (Tel. (202) 447-3140)

RICHARd R. Pforr, Chief, Scale Testing and Weighing Branch, Weighing Division, Federal Grain Inspection Service (FGIS), 201 14th Street, S.W., Room 3117 Auditors Building, Washington, D.C. 20250 (Tel. (202) 447-8529)

Roger SANDMAN, Deputy Director-Intergovernmental Affairs, Office of Governmental and Public Affairs, Washington, D.C. 20250 (Tel. (202) 447-6643

Clifford A. Watson, Branch Chief, Richards-Gebaur Air Force Base, Bldg. 221, Grandview, Missouri 64454 (Tel. (816) 926-6680)

DEPARTMENT OF HEALTH, EDUCATION, AND WELFARE

TAYLOR M. QUINN, Associate Director for Compliance-Bureau of Foods, Public Health Service, Food and Drug Administration Washington, D.C. 20204 (Tel. (202) 245-1243)

Charles H. Pogue, Food and Drug Officer, U.S. Food and Drug Administration, HEW-FDA-Division of Federal/State Relations, State Services Branch (HFO310), Parklawn Building Room 15-A-19, 5600 Fishers Lane, Rockville, Maryland 20857 (Tel. (301) 443-6200)

Roger L. Lowell, Supervisor, Portland Resident Post, Food and Drug Administration, Room 694, Federal Building, 511 N.W. Broadway, Portland, Oregon 97209 (Tel. (503) 221-2031)

Allan SCHURR, Federal State Liaison Officer, Region X, Food and Drug Administration, 5003 Federal Office Building, 909 First Avenue, Seattle, Washington 98174 (Tel. (206) 442-5304)

FEDERAL TRADE COMMISSION

JAMES G. MiLls, Attorney, Division of Energy-Product Information, Federal Trade Commission, Washington, D.C. 20580 (Tel. (202) 724-1967)

U.S. METRIC BOARD

L. J. ChISHOLM, Director, State Programs, 1815 N. Lynn Street, Arlington, Virginia 22209 (Tel. (703) 235-2583)

NATIONAL BUREAU OF STANDARDS

CARRoll S. BRICKENKAMP, Manager, Research and Development, Office of Weights and Measures, Room A211, Building 220, Washington, D.C. 20234 (Tel. (301) 921-2403)

DAvid E. Edgerly, Chief, Office of Domestic and International Measurement Standards, Room A353, Building 221, Washington, D.C. 20234 (Tel. (301) 9213307) 
AlLEN J. FARRAR, Legal Adviser, Administration Building, Room A1128, Washington, D.C. 20234 (Tel. (301) 921-2425)

JoAnNe HaLl, Packaging and Labeling Coordinator, Room B364, Building 220, Washington, D.C. 20234 (Tel. (301) 921-3751)

STEPHEN HASKo, Engineer, Office of Weights and Measures, Room A211, Building 220, Washington, D.C. 20234 (Tel. (301) 921-2402)

AnN P. Heffernan, Conference Coordinator, Office of Weights and Measures, Room A211, Building 220, Washington, D.C. 20234 (Tel. (301) 921-2403)

Donald R. Johnson, Deputy Director for Programs, Washington, D.C.20234 (Tel. (301) 921-2822)

BLAYNE C. KeYSAR, Engineering Technician, Office of Weights and Measures, Room A211, Building 220, Washington, D.C. 20234 (Tel. (301) 921-2401)

JoE KIM, Electronic Engineer, Office of Weights and Measures, Room A211, Building 220, Washington, D.C. 20234 (Tel. (301) 921-2401)

ARTHUR O. McCoubrey, Associate Director for Measurement Services, National Measurement Laboratory, Room A363, Building 221, Washington, D.C. 20234 (Tel. (301) 921-3301)

Henry V. Oppermann, General Physical Scientist, Office of Weights and Measures, Room A211, Building 220, Washington, D.C. 20234 (Tel. (301) 921-2401)

H. STEFfen Peiser, Chief, Office of International Relations, Room A511, Administration Building, Washington, D.C. 20234 (Tel. (301) 921-2463)

Charles C. Raley, Public Information Specialist, Office of International Relations, Room A511, Administration Building, Washington, D.C. 20234 (Tel. (301) 921-2779)

RICHARD N. SMITH, Technical Coordinator, Office of Weights and Measures, Room A211, Building 220, Washington, D.C. 20234 (Tel. (301) 931-2401)

Evelyn TALlerico, Secretary, Office of Weights and Measures, Room A211, Building 220, Washington, D.C. 20234 (Tel. (301) 921-3677)

AlBerT D. Tholen, Chief, Office of Weights and Measures, Room A211, Building 220, Washington, D.C. 20234 (Tel. (301) 921-3677)

Eric A. VADELund, Program Manager, Fair Packaging and Labeling Act, Center for Consumer Product Technology, Room B364, Building 220, Washington, D.C. 20234 (Tel. (301) 921-3751)

OтTо K. Warnlof, Manager, Technical Services, Office of Weights and Measures, Room A211, Building 220, Washington, D.C. 20234 (Tel. (301) 921-2401)

Harold F. Wollin, Assistant Chief, Office of Weights and Measures, Room A211, Building 220, Washington, D.C. 20234 (Tel. (3g01) 921-3677)

U.S. OFFICE OF CONSUMER AFFAIRS

RodNey E. LeONARD, Deputy Director, U.S. Office of Consumer Affairs, Room 
435, Old Executive Office Building, Washington, D.C. 20503 (Tel. (202) 4566226)

U.S. POSTAL SERVICE

W. Clent Crocker, Acting Manager Systems and Procedures Branch, U.S. Postal Service, Office of Mail Classification, Washington, D.C. 20260 (Tel. (202) 245-4353)

\section{U.S. METRIC ASSOCIATION}

VALERIE Antoine, Vice President, 10245 Andasol Avenue, Northridge, California 91325 (Tel. (213) 363-5606)

Louis F. SoKol, President, Sugarloaf Star Route, Boulder, Colorado 80302 (Tel. (303) 442-3342)

\section{OREGON JOURNAL}

PhILIP AdAMSAK, Reporter, 1320 S.W. Broadway, Portland, Oregon 97201 (Tel. (503) 221-8391)

\section{RETIRED REGISTRANTS}

Everett Black, 2282 Foster Avenue, Ventura, California 93003 (Tel. (805) 6483434)

William A. KerLin, Chief, California Bureau of Weights and Measures (Retired), 5509 Valerie Way, Sacramento, California 95841 (Tel. (916) 332-4882)

\section{FOREIGN REGISTRANTS}

CANADA

John D. Buchanan, Departmental Metric Coordinator, Department of Consumer and Corporate Affairs, Place DuPortage, Ottawa Hull KIAOC9, Canada

Eugene Gosh, Executive Director, B.C. Metric Conversion Office, 300-777 EGYPT

Broughton Street, Victoria, B.C. V8W 1E3, Canada (Tel. (604) 387-3601)

M. Ammar Mohammed, Director, National Institute for Standards, P.O. Box 2343, Dokki, Cairo, Egypt

HONDURAS

Guillermo Rivera, Engineer, Department of Engineering and Standardization, INDIA

General Direction of Industry, Ministry of Economy, Tegucigalpa, Honduras

DeBabrat.4 SEn, Scientist-in-Charge, Length Standards, Dimensional Metrology and Mass Metrology Sections, National Physical Laboratory, Hillside Road, New Delhi 110012, India 
LIBERIA

J. Kiemue Kollie, Assistant Director, Bureau of Standards, Ministry of Commerce, Industry and Transportation, P.O. Box 9041, Monrovia, Liberia

MEXICO

Julian Basurto, General Direction of Standards (DGN), Tuxpan No. 2, 8 Piso, Mexico 7 D.G., Mexico

\section{NIGERIA}

Y.A. BAlogun, Deputy Superintendent of Weights and Measures, Policy and Management Division, Federal Ministry of Trade. P.M.R Nn 12514, Lagos, Nigeria

\section{SAUDI ARABIA}

Jewell H. EASTMan, Scales and Weighing Specialist, Kingdom of Saudi Arabia, U.S. Rep/JECOR, APO New York (Saudi Arabia) 09038

\section{SRI LANKA}

A.P.H.G. De WaAs Gunawardena, Assistant Superintendent of Weights and SUDAN

Measures, Weights and Measures Division, Park Road, Colombo 5, Sri Lanka

Babiker ABu El Hassan, Assistant Director, Weights and Measures Administration, Ministry of Cooperation, Commerce and Supply, P.O. Box 194, Khartoum, Sudan

THAILAND

Wichian Pratoommas, Commercial Counselor, Royal Thai Embassy (Thailand), TUNISIA

5 World Trade Center, Suite 3443, New York, New York 10048

Mohieddine Ben LaRBI, Chief, Laboratury of Food Processing, Weights and Measures Control Division, Laboratoire Central, Montfleury, Rue Dr. Braquehaye, Tunis, Tunisia

\section{WEIGHTS AND MEASURES PUBLICATIONS}

The following publications may be obtained from the Superintendent of Documents, U. S. Government Printing Office, Washington, D.C. 20402. Remittance must accompany order.

NBS Handbook 44, 1979 Edition-Specifications, Tolerances, and Other Technical Requirements for Commercial Weighing and Measuring Devices SN003-003-02143-1

NBS Handbook 112-Examination Procedure Outlines for Commercial

Weighing and Measuring Devices

SN0303-01162

NBS Handbook 117-Examination of Vapor-Measuring Devices for Liquefied

Petroleum Gas

SN003-003-01563-6

NBS Special Publication 304-Metric Chart

SN003-003-01072-3

NBS Special Publication 304A-Brief History of Measurement Systems SN003-003-1713-2

NBS Special Publication 330-The International System of Units (SI) (1977 Edition)

SN003-003-01784-1

NBS Special Publication 345-A Metric America-A Decision Whose Time Has Come

SN003-003-00884-2 
NBS Special Publication 447-Weights and Measures Standards of the United States, A Brief History

SN003-003-01654-3

NBS Handbook 105-3-Specifications and Tolerances for Graduated Neck

Type Volumetric Field Standards

SN003-003-02044-3

\section{Reports of the National Conference on Weights and Measures:}

NBS Special Publication 377-Index to the Reports of the National Conference on Weights and Measures (1905-1971)

SN003-003-01107-0

NBS Special Publication 391-Report of 58th Conference (1973)

SN003-003-01260-2

NBS Special Publication 407-Report of 59th Conference (1974)

SN003-003-01379-0

NBS Special Publication 442-Report of 60th Conference (1975)

SN003-003-01614-4

NBS Special Publication 471-Report of 61st Conference (1976)

SN003-003-01806-6

NBS Special Publication 517-Report of 62nd Conference (1977)

SN003-003-01966-1

NBS Special Publication 532-Report of 63rd Conference (1978)

SN003-003-02045-1

The following publications may be obtained from the National Technical Information Service, 5285 Port Royal Road, Springfield, Virginia 22161. Remittance must accompany order. The prices listed are for paper copies.

NBS Handbook 94-The Examination of Weighing Equipment

(COM No. 73-10635) $\$ 9.25$

NBS Handbook 98-The Examination of Farm Milk Tanks

(COM No. 72-10619)

NBS Circular 593-The Federal Basis for Weights and Measures

(COM) No. 75-10234)

NBS Handbook 99-The Examination of Liquefied Petroleum Gas Liquid-

Measuring Devices

NBS Handbook 105-1-Specifications and Tolerances for Field Standard Weights

(COM No. 72-50707)

NBS Handbook 105-2-Specifications and Tolerances for Field Measuring Flasks

(COM) No. 71-50065)

The following publications may be obtained from the Office of Weights and Measures,

National Bureau of Standards, Washington, D.C. 20234, at no charge:

Mission of the Office of Weights and Measures

National Conference on Weights and Measures-Its Organization and Procedure Model Weights and Measures Ordinance (for cities or counties)

List of State, Commonwealth, District, and Local Weights and Measures Offices of the United States

NBS Special Publication 430-Household Weights and Measures Card

NBS Circular 1035-Units and Systems of Weights and Measures-Their Origin, Development, and Present Status 
NBS Circular 1056-Guidelines for Use of the Metric System

NBS Circular 1070-References on Metric Information

NBS Circular 1071-Factors for High Precision Conversion

NBS Circular 1078-The Metric System of Measurement (Si)-Federal Register Notice of October 26, 1977

NBS Circular 1098-Preferred Metric Units for General Use by the Federal Government 
NBS-114A (REV. O-T6)

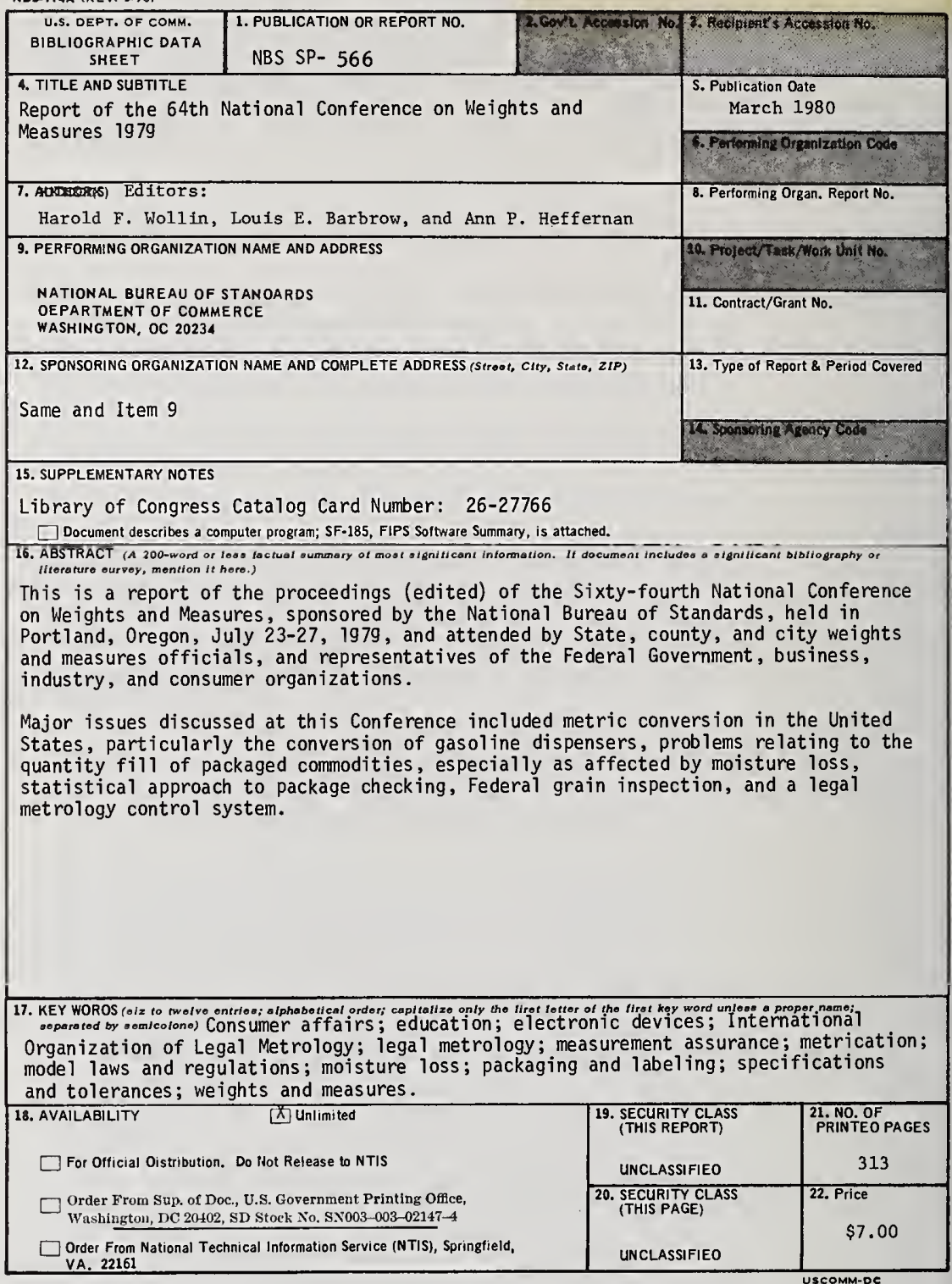




\section{PERIODICALS}

JOURNAL OF RESEARCH-The Journal of Research of the National Bureau of Standards reports NBS research and development in those disciplines of the physical and engineering sciences in which the Bureau is active. Thesc include physics. chemistry, engincering. mathematics, and computer sciences. Papers cover a broad range of subjects, with major emphasis on measurement methodology and the basic technology underlying standardization. Also included from time to time are survey articles on topics closely related to the Bureau's technical and scientific programs. As a special service to subscribers each issue contains complete citations to all recent Bureau publications in both NBS and nonNBS media. Issued six times a year. Annual suhscription: domestic $\$ 17$; foreign \$21.25. Single copy, \$3 domestic: $\$ 3.75$ foreign.

NOTE: The Journal was formerly published in two sections: Section A "Physics and Chemistry" and Section B "Mathematical Sciences."

DIMENSIONS/NBS - This monthly magazine is published to inform scientists, engineers, business and industry leaders, teachers, students, and consumers of the latest advances in science and technology, with primary emphasis on work at NBS. The magazine highligh ts and reviews such issues as energy research. fire protection, building technology, metric conversion, pollution abatement, health and safety, and consumer product performance. In addition, it reports the results of Bureau programs in measurement standards and iechniques, properties of matter and materials, engineering standards and services, instrumentation, and automatic data processing. Annual subscription: domestic \$11; foreign $\$ 13.75$.

\section{NONPERIODICALS}

Monographs-Major contributions to the technical literature on various subjects related to the Bureau's scientific and technical activities.

Handbooks - Recommended codes of engineering and industrial practice (including safety codes) developed in cooperation with interested industries, professional organizations, and regulatory bodies.

Special Publications-Include proceedings of conferences sponsored by NBS. NBS annual reports, and other special publications appropriate to this grouping such as wall charts, pocket cards, and bibliographies.

Applied Mathematics Series_Mathematical tables, manuals, and studies of special interest to physicists, engineers, chemists, biologists, mathematicians, computer programmers, and others engaged in scientific and technical work.

National Standard Reference Data Series-Provides quantitative data on the physical and chemical properties of materials, compiled from the world's literature and critically evaluated. Developed under a worldwide program coordinated by NBS under the authority of the National Standard Data Act (Public Law the auth
NOTE: The principal publication outlet for the foregoing data is the Journal of Physical and Chemical Reference Data (JPCRD) published quartcrly for NBS by the American Chemical Society (ACS) and the American Institute of Physics (AIP). Subscriptions, reprints, and supplements available from ACS. I155 Sixteen th St., NW, Washington, DC 20056.

Building Science Series-Disseminates technical information developed at the Bureau on building materials, components, systems, and whole structures. The series presents research results, test methods, and performance criteria related to the structural and environmental functions and the durability and safety characteristics of building elements and systems.

Technical Notes-Studies or reports which are complete in themselves but restrictive in their treatment of a subject. Analogous to monographs but not so comprehensive in scope or definitive in treatment of the subject area. Often serve as a vehicle for final reports of work performed at NBS under tbe sponsorship of other government agencies.

Voluntary Product Standards-Developed under procedures published by the Department of Commerce in Part 10. Title 15, of the Code of Federal Regulations. The standards establish nationally recognized requirements for products, and provide all concerned interests with a basis for common understanding of the characteristics of the products. NBS administers this program as a supplement to the activities of the private sector standardizing organizations.

Consumer Information Series-Practical information, based on NBS research and experience, covering areas of interest to the consumer. Easily understandable language and illustrations provide useful background knowledge for shopping in today's technological marketplace.

Order the above NBS publicatians fram: Superintendent of Documents, Gavernmtent Printing Office, Washingtan, DC 20402.

Order the following NBS publications-FIPS and NBSIR's-from the Natianal Technical Informatian Services, Springfield, VA 22161.

Federal Information Processing Standards Publications (FIPS PUB)-Publications in this series collectively constitute the Federal Information Processing Standards Register. The Register scrves as the official source of information in the Federal Government regarding standards issued by NBS pursuant to the Federal Property and Administrative Services Act of 1949 as amended, Puhlic Law 89-306 (79 Stat. 1127), and as implemented by Executive Order 11717 (38 FR 12315, dated May 11, 1973) and Part 6 of Title 15 CFR (Code of Federal Regulations)

NBS Interagency Reports (NBSIR)-A special series of interim or final reports on work performed by NBS for outside sponsors (hoth government and non-government). In general, initial distribution is handled by the sponsor, public distribution is by the National Technical Information Services, Springfield. VA 22161, in paper copy or microfiche form.

\section{BIBLIOGRAPHIC SUBSCRIPTION SERVICES}

The following current-aw areness and literature-survey bibliographies are issued periodically by the Bureau:

Cryogenic Data Center Current Awareness Service. A literature survey issued biweekly. Annua] subscription: domestic \$25; foreign $\$ 30$.

Liquefied Natural Gas. A literature survey issued quarterly. Annual subscription: $\$ 20$.
Superconducting Devices and Materials. A Jiterature survey issued quarterly. Annual subscription: $\$ 30$. Please send subscription orders and remittances for the preceding bibliographic services to the National Bureau of Standards, Cryogenic Data Center (736) Boulder, CO 80303. 
